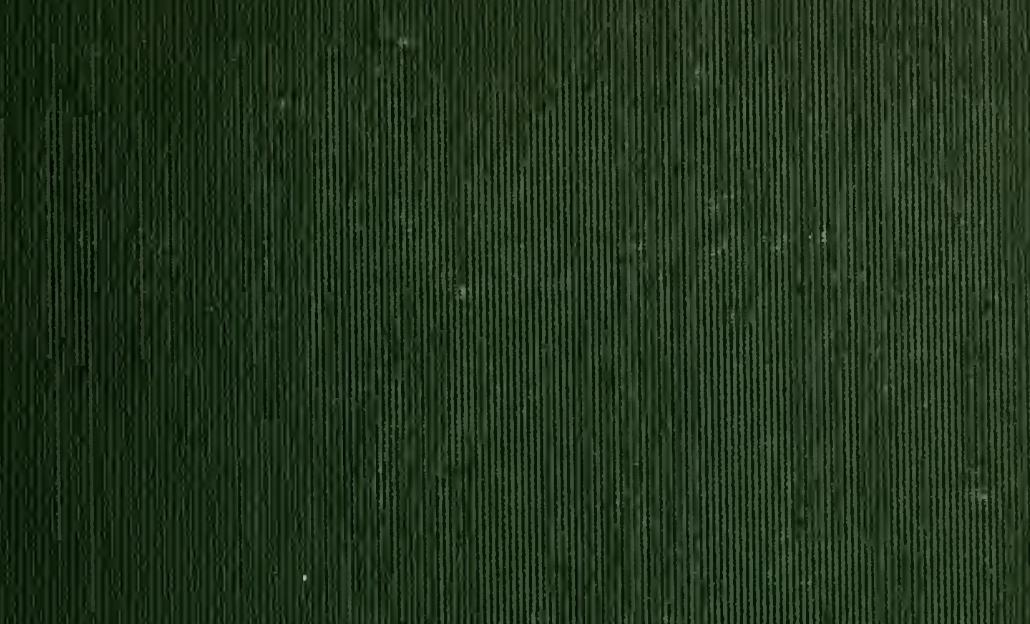





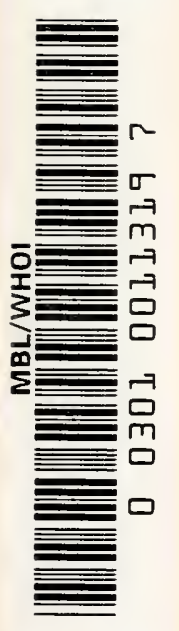





\section{AN OUTLINE OF THE}

THEORY OF ORGANIC EVOLUTION 
Thes 


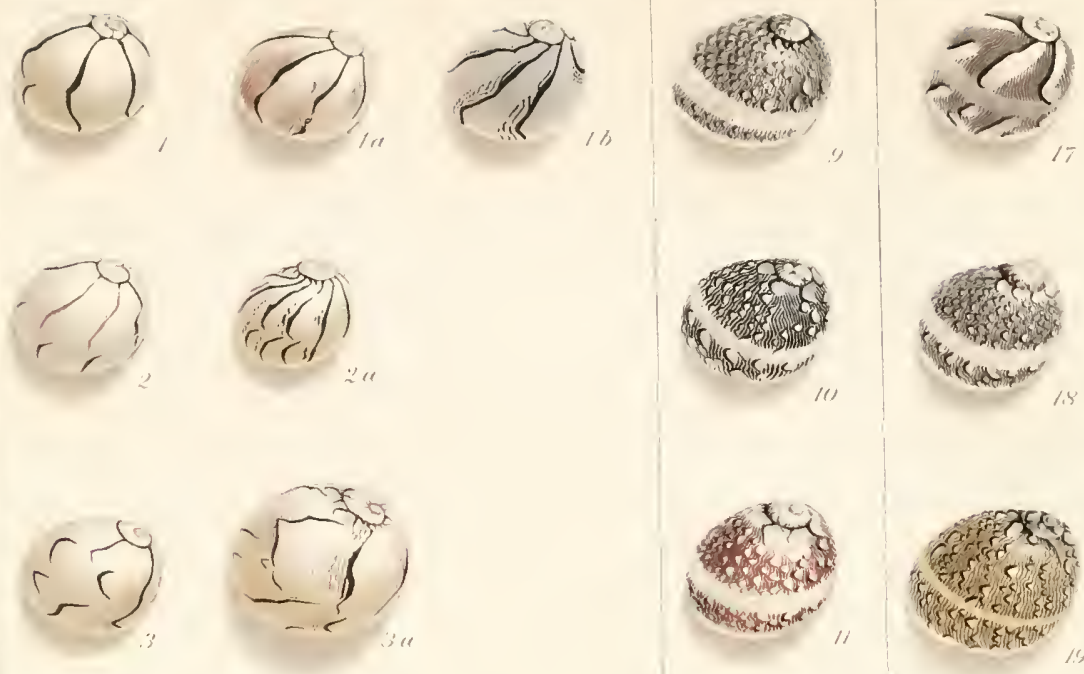

तर्या
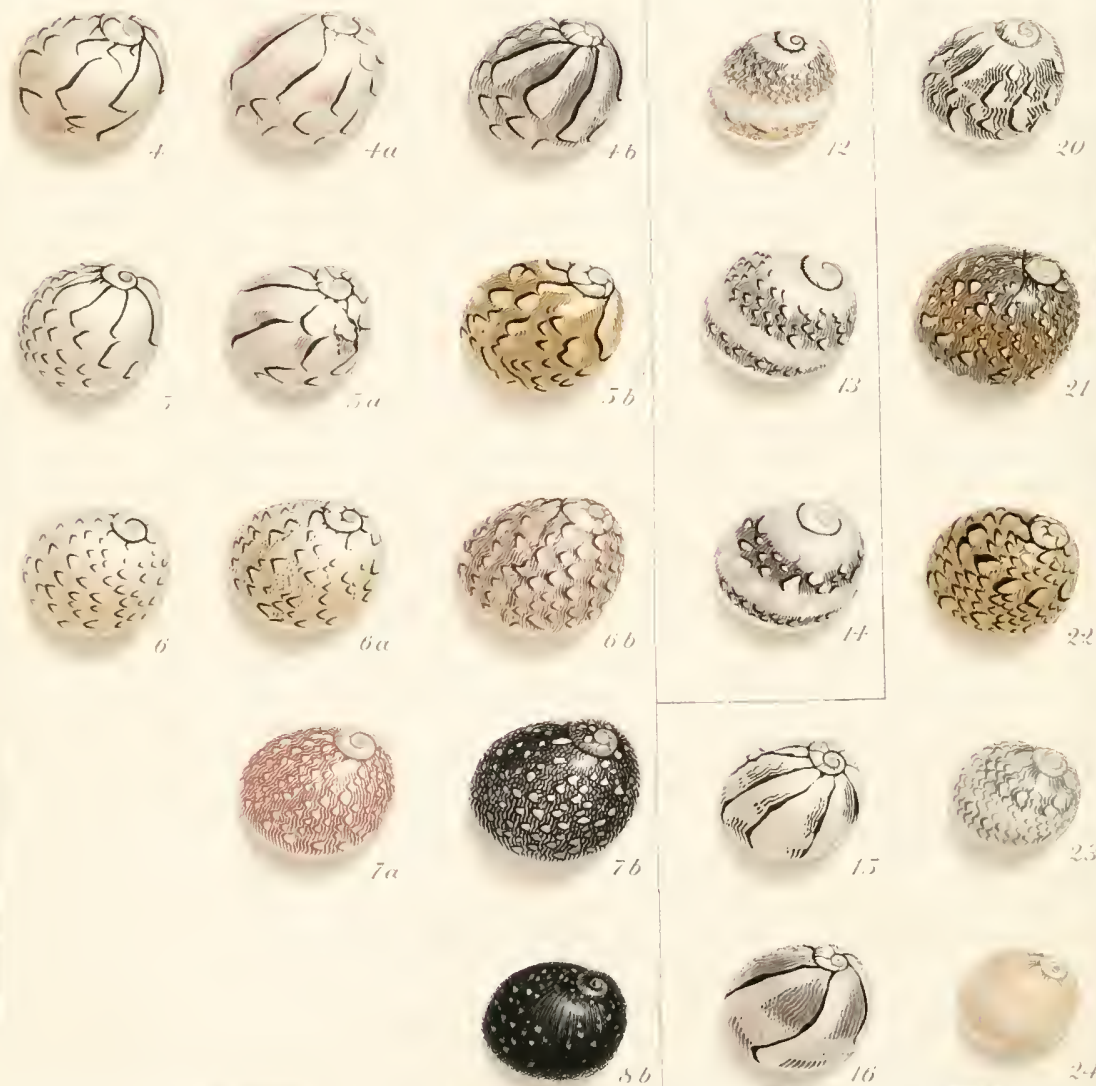


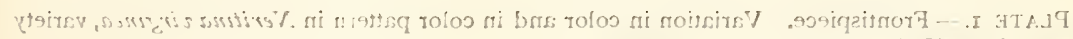

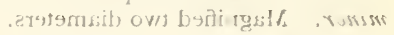
: sivitist 1050.$)$

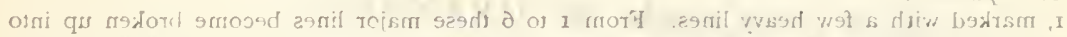

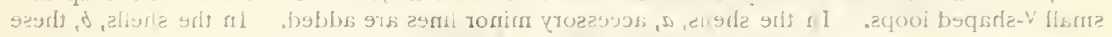
vingle . vithde

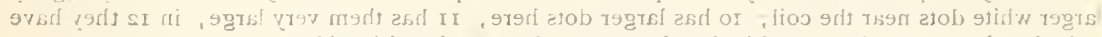

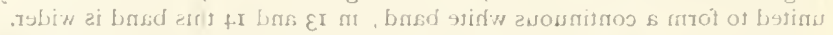

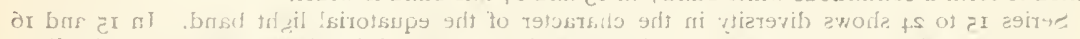

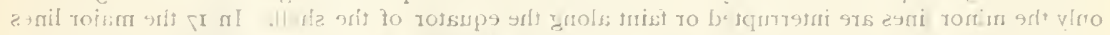

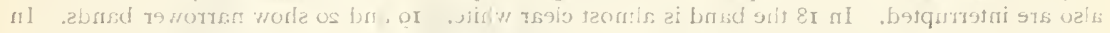

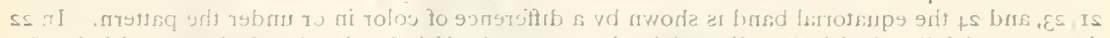

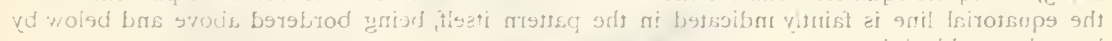

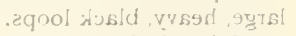
: sbusistz roto?

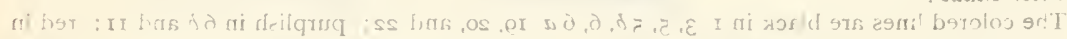

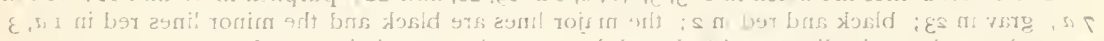

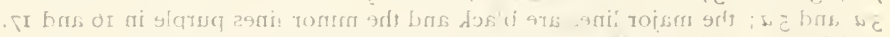

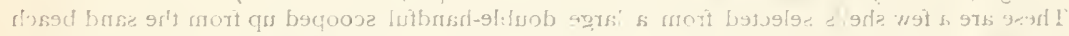

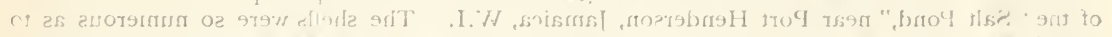

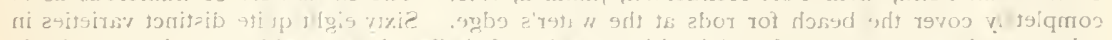

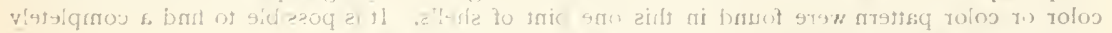

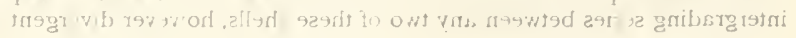



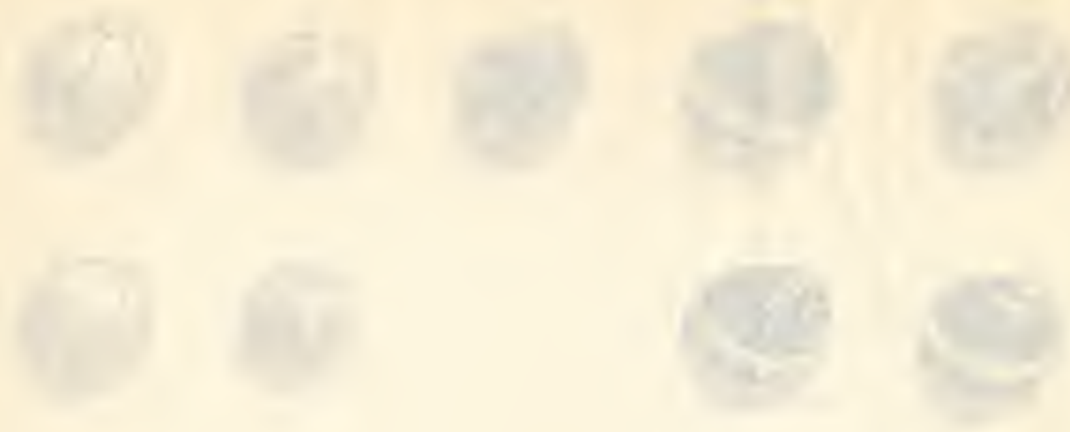

PLATE 1. - Frontispiece. Variation in color and in color pattern in Nerifina virginea, variety minor. Magnified two diametess.

\section{Color pattern:}

I, marked with a few heavy lines. From I to 6 these major lines become broken up into small $\mathrm{V}$-shaped loops. In the shells, $a$, accessory minor lines are added. In the shells, $b$, these are more numerous.

Series 9 to $\mathbf{I}+$ shows diversity in the pattern ncar the apex of the coil : 9 has a few very slightly larger white dots near the coil; Io has larger dots here; II has them very large; in I2 they have united to form a continuous white band; in $I_{3}$ and $I_{4}$ this band is wider.

Series 15 to 24 shows diversity in the character of the equatorial light band. In 15 and 16 only the minor lines are interrupted or faint along the equator of the shell. In $I_{7}$ the major lines also are interrupted. In 18 the band is almost clear white. I9 and 20 show narrower bands. In $2 \mathrm{I}, 23$, and 24 the equatorial band is shown by a difference of color in or under the pattern. In 22 the equatorial line is faintly indicated in the pattern itself, being bordered above and below by large, heavy, black loops.

\section{Color shade:}

The colored lines are black in $\mathbf{I}, 3,5,5 b, 6,6 a, \mathbf{1 9}, 20$, and 22 ; purplish in $6 b$ and $\mathbf{I I}$; red in $7 a$; gray in 23; black and red in 2; the major lines are black and the minor lines red in $\mathrm{I} a, 3$, $3 a$, and $5 a$; the major lines are black and the minor lines purple in $\mathbf{1 6}$ and $\mathbf{1 7}$.

These are a few shells selected from a large double-handful scooped up from the sand beach of the "Salt Pond," near Port Henderson, Jamaica, W.I. The shells were so numerous as to completely cover the beach for rods at the water's edge. Sixty-eight quite distinct varieties in color or color pattern were found in this one pint of shells. It is possible to find a completely intergrading series between any two of these shells, however divergent. 


\section{AN OUTLINE OF THE THEORY $\mathrm{OF}$ \\ ORGANIC EVOLUTION}

WITH A DESCRIPTION OF SOME OF THE PHENOMENA WHICH IT EXPLAINS

BY

MAYNARD M. METCALF, Ph.D.

PROFESSOR OF BIOLOGY IN THE WOMAY'S COLLEGE OF BALTIMORE

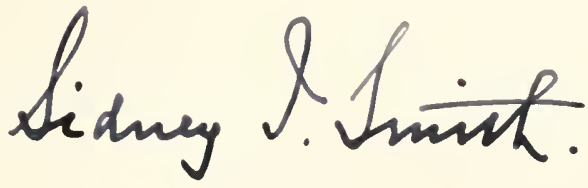

NEW TORK

THE MACMILLAN COMPANY

LONDON: ADAM \& CHARLES BLACK

I 904 
COPYRIGHT, I90.4,

BY THE MACMILLAN COMPANY.

Set up and electrotyped. Published October, I904.

Norrvood Press

7. S. Cusbing G Co. - Berzuick \& Smith Co.

Norwood, Mass., U.S.A. 


\section{To ftlu fiatlor}

WHO LOVED AND IIELD FRIENDLY INTERCOLRSE

WITH NATURE 
Tom to Mother Carey" "I heard, ma'am, that you were always making new beasts out of old."

Mother Carey: "So people fancy. But I am not going to trouble myself to make things, my little dear. I sit here and make them make themselves."

- Charles Kingsley's “The Water Babies." 


\section{PREFACE}

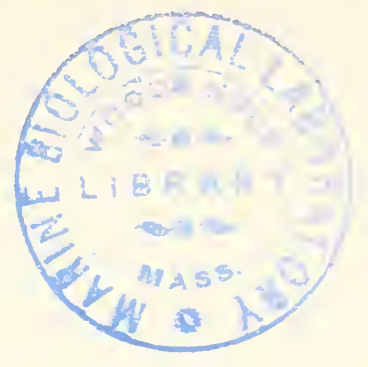

THE lectures out of which this book has grown were written for the author's students at the Woman's College of Baltimore, and for others in the college not familiar with biology who had expressed a desire to attend such a course of lectures. The book is, therefore, not intended for biologists, but rather for those who would like a brief introductory outline of this important phase of biological theory.

It has been the author's endeavor to avoid technicality so far as possible, and present the subject in a way that will be intelligible to those unfamiliar with biological phenomena. The subject, however, is somewhat intricate, and cannot be presented in so simple a manner as to require no thought on the reader's part; but it is hoped that the interest of the subject will make the few hours spent in the perusal of this book a pleasure rather than a burden.

In many instances matter that might have been elaborated in the text has been treated in the pictures, which, with their appended explanations, form an essential part of the presentation of the subject. This method of treatment has been chosen both for the sake of the greater vividness thus secured and because it enables the book to be reduced to the limits desired. Nany of the illustrations have been obtained from books with which the reader may wish later to become familiar.

In his lectures upon evolution the author made no attempt to avoid following the manner of presentation or even the phraseology of prominent writers upon the subject, 
and for this book little claim to originality can be made. 'The author has attempted to present the subject in the way that seemed simplest and most natural to him, realizing that in so doing he would almost necessarily follow in large meas. ure the authors who have influenced his thinking upon the subject. He is especially indebted to his former instructor, Professor $\mathrm{W}$. K. Brooks.

There are a number of very valuable books which treat of the evolution theory. Most prominent among these are the writings of Darwin and IVallace, and Romanes' Darwin and After Darwin. The author does not intend that this volume shall be accepted by any reader as a substitute for those more important books, but rather that it shall serve as an introduction to the subject, giving a comprehensive outline of the theory, with just sufficient illustration to invite the reader to seek fuller knowledge of the great number of most interesting phenomena which are related to the theory. At the end of this book will be found a list of a few of the more important volumes treating of the theory of evolution and the phenomena which it explains.

In the preparation of this book, especially in securing or preparing the pictures, the author has received much assistance and many courtesies. It is a pleasure to him to acknowledge his indebtedness:

For the gift or loan of photographs or material for illustration, to the authorities of the United States National Museum, the American Museum of Natural History, the United States Department of Agriculture, the United States Fish Commission, to A. Radcliffe Dugmore, Rev. Dr. John T. Gulick, Mr. C. L. Allen, and especially to his friend, Horace $\mathrm{IV}$. Britcher, whose untimely death has removed one of our keenest students of living spiders;

For assistance in the identification or in the preparation of material for illustrations, to Dr. Harrison G. Dyar, Dr. I. O. Howard, Dr. F. H. Chittenden, Dr. Charles IV. 
Richmond, Miss Mary J. Rathbun, Mr. Nathan Banks, and Professor L. H. Merrill;

For generously giving permission to copy certain figures, to the Open Court Publishing Company, Macmillan \& Company, D. Appleton \& Company, Edward Arnold, Bradlee Whidden, Swan Sonnenschein \& Company, Smith, Elder \& Company, Charles Scribner's Sons, E. P. Iutton Company, to P'rofessor August Weismann, Professor E. B. Poulton, Dr: and Mrs. G. W. Peckham, Rev. Dr. H. C. McCook, Mr. A. R. I ugmore, Dr. F. M. Chapman, President I). S. Jordan, Professor Vernon L. Kellogg, and Hon. Addison Brown;

For kindly selling the right to use certain figures, to Doubleday, Page \& Company, A. \& C. Black, the Autotype Company, and A. G. Wallihan;

For assistance in revising certain paragraphs, to Dr. C. Hart Merriam and Professor WV. B. Clark;

For assistance in revising proof of all of the illustrations, to Mr. Max Broedel. 



\section{TABLE OF CONTENTS}

PAGES

INTRODUCTION

xix-xixii

\section{PART I}

The Theory of Organic Evolution . . . . . . . . $3-3_{3}$

Natural Selection . . . . . . . . . . . $3-47$

Heredity . . . . . . . . . . . $3^{-10}$

Variation . . . . . . . . . . . . $7-10$

The Struggle for Existence . . . . . . .

Mutation . . . . . . . . . . I $8-20$

General Principles in the Operation of Natural Selection . . 20-2S

Artificial Selection . . . . . . . 2S-3I

Objections to Natural Selection as a Factor in Erolution . . 3 $3 \mathrm{I}-47$

Sexual Selection . . . . . . . . . . . $47-60$

Objections to the Theory of Sexual Selection . . . . . 56-60

Segregation . . . . . . . . . . . 60-67

The Inheritance of Parental Modifications . . • . . 67-82

Summary of Part I . . . . . . . . . . $\$_{2}-\$_{3}$

\section{PART II}

The Phexomena explaned by the Theory • • • . . 87-i63

Comparative Anatomy . . . . . . . . . . . . . 88-96

Classification . . . . . . . . . . . $88-92$

Homology . . . . . . . . . . . . 9 $92-93$

Vestigial Structures . . . . . . . . . 93-96

Embryology . . . . . . . . . . . . 96-103

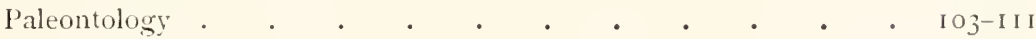

Geographical Distribution . . . . . . . . III-II6

Color in Animals . . . . . . . . . II6-I5I

Protective Coloration and Resemblances . . . . . II7-125

Aggressive Coloration and Resemblances . . . . . 125-127 
Alluring Coloration and Resemblances . • . . . 127-129

Warning Colors

Convergence in Warning Coloration . . . . . . . 134

Mimicry

Protective Mimicry . . . . . . . . I35-I45

Aggressive Mimicry . . . . . . . . I . . . . . . . 46

Signals and Recognition Marks . . . . . . I I6-147

Confusing Coloration . . . . . . . . $1+7-149$

Sexual Coloration . . . . . . . . $149-15 \mathrm{I}$

Summary of the Treatment of Color in Animals . . . . I 5 r

Color in Plants . . . . . . . . $15 \mathrm{I}-\mathrm{I} 63$

Max in Relation to Evolution . . . . . . I63-183

Gexieral Consmerations . . . . . . . . . . I83-188

Ar'PEDix. - A few books which treat of organic evolution and phenomena of special adlaptation . . . . . I89-19I 


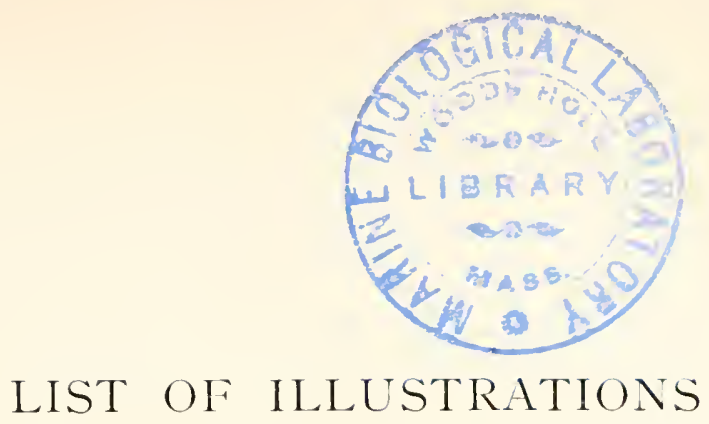

(IN THE ORDER OF THEIR INSERTION)

PAGE.

Plate I. Variation in color and in color pattern in Veritina sirginea. variety miner. (In color) . . . . . Frontispiece

FIG. I. Goose-barnacle . . . . . . . . . . + t

Fig. 2. Gerarde"s figure of "Barnacles producing geise" . . . . 5

PLATE 2. Tariation in Trillium grandiflorum . . . . Folloz'ing 6

PLate 3. Varieties of Paludestrina froted . . . . . . . . S S

FIG. 3. "Bag-worm," Thyroidopteryx ephemeriformis . . . . . 2I

Fig. 4. Honey-bees . . . . . . . . . . 22

Plate 4. Tarieties of horses . . . . . . Following 28

PLATES 5-7. Varieties of cabbage: Saroy cabbage, kale. broccoli. Brussels sprouts, cauliflower, Swedish turnip, and kohlrabi. Following $2 S$

Plate 8. Varieties of cabbage. etc.. as figured in Gerarde's Herball. sixteenth century . . . . . . . . Following

Plate 9. Varieties of turnips . . . . . . . . . . . . . . . . 28

PLAte io. Varieties of dahlias . . . . . . . . . . . . . . . . . . 28

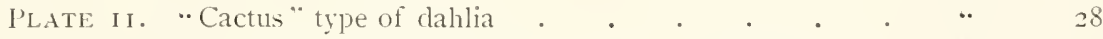

Plates 12-15. Tarieties of domestic chickens. (1n color) . . * 30

P'LATE i6. A. Jungle fowl (Gallus bankiza). B. The evolution of the game cock . . . . . . . Following 30

PLATE I7. Japanese long-tailed cocks . . . . . . . . . . 30

PLATE is. A. "Frizzled fowls." l'. Head of Breda cock. C. Head of salmon farerolle . . . . . . . . Following

PLATE I9. A. Feather from a ". silky fowl." $b$. Leg of Cochin cock. C. .. Cochin" bantams. . . . . Following

PLATE 20. Tarieties of domestic pigeons . . . . . . . . . . 30

FIG. 5. Skull of Polish fowl . . . . . . . . . . 30

Fig. 6. Rock pigeon (Columba lizia) . . . . . . . 3I

PLATE 2r. Skeletons of various unicellular animals and plants. Following 32

PLATE 22. Male and female bobolink (Dolichony oryzitorus) . . . $\quad 48$

Plate 23. Ruffed grouse (Fonasa umbellus). male. female. and young " $\quad$ tS

PLATE 24. A. Male and female argus pheasant. B. Male and female lyre bird . . . . . . . . . Following

PLATE 25. A. Male and female Vesocentor milo. B. Nale and female pigeon (Phloganas jobiensis) . . . . . . . Following

PLATE 26. Male and female humming-birds . . . . . . . . . 48

PLATE 27. Turkey cock "strutting" . . . . . . . . . 4

PLATE 28. Courting attitudes in hunting spiders . . . . . . . 50 
Plate 29. A. Male and female seventeen-year cicada. B. Staghorn beetle. males and female.

- Following 50

PLATE 30. Male and female Hercules beetle . . . . . . . 50

Fic. 7. Heads of male and female beetles . . . . . . 52

P'A

P'LATE 32. Male and female fish: A. Callionymus lyra. B. Xiphophorus hellerii. . . . . . Following

PLATE 33. A. Male and female dragon-fly (Calopteryx maculata). B. Male, female, and larva of crested newt (Triton cristatus) Following 52

l'LATE 34. Males and females of different species of lizards . . " . 52

Fis. 8. Secondary sexual characters in copepods . . . . . 57

FI(i. 9. Locusts from the Galapagos Islands . . . . . . . . 62

Fic. Iо. Map of Oahu, Hawaiian Islands . . . . . . . . 64

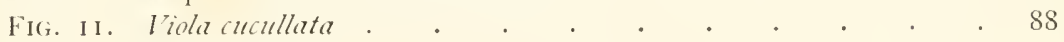

FIG. 12. Viola rostrata . . . . . . . . . . . . . . . . . . . 89

FIG. I3. Solea concolor . . . . . . . . . . . . . . . 90

Fic. I4. Skeletons of the fore limbs of various vertebrates . . . . 92

Fic. 15. Vestigial bones of the hind limbs in a boa constrictor . . 94

Fig. I6. Skeleton of Greenland whale . . . . . . . . 94

PLATE 35. Apteryxalstralis . . . . . . Following 94

PLATE 36. Eyes of various vertebrates, showing the nictitating membrane

PLATE 37. Hair tracts on the arms and hands of a man and a male chimpanzee . . . . . . . . . Following

FIG. I7. Muscles of the human ear . . . . . . . . . 95

FIG. 18. Three fishes, showing stages in the loss of eyes and color . . 95

FIr. I9. Stages in the development of the pond snail (Lymnaus) • . 97

P'LATE 38 . Embryos of various vertebrates . . . . . Following 98

FIG. 20. Tadpole of salamander . . . . . . . . . . 98

PLATE 39. American lobster . . . . . . . . Following 98

PlATE 40. A. Central nerrous system of crawfish. B. "Blue crabs" $\quad$. $\quad 98$

P'LATE 4I. A. "My'sis stage" in the development of the American lobster.

13. Mysis stenolepis. C. Leg of Mysis stenolepis. Following 98

Fir. 21. Three stages in the development of a crab . . . . . 100

Fig. 22. Hydra. A diagrammatic longitudinal section . . . . 101

Fif. 23. Gastrula of a coral polyp (Montrenia darainii) . . . . I02

PLATE 42. Longitudinal sections of gastrule of: A. frog, young. $B$. frog. older. C. chick. . . . . . Following

FIg. 24. Longitudinal sections of gastrule of various animals . . . 103

PLATE 43. Antlers of a stag. showing the addition of new branches in successive rears . . . . . . . Following

Fig. 25. Fossil deer antlers . . . . . . . . . . . 107

Fig. 26. Successive forms of Paludina from the tertiary deposits of Slavonia 108

I'LATE 44. Archaopteryx lithographica . . . . . Following ros

I'LATE 45. Fossil skeletons of: A. Hesperornis regalis. B. Ichthyornis rictor. C. Phrodactylus spectabilis . . . Following $\mathrm{o8}$

Fic. 27. Skeleton of a crow . . . . . . . . . . 1 Io 
Plate 46. Fossil skeleton of I'henacodus primar'us

PLATE 47. Changes in foot-structure and teeth in fossil and recent species of the horse family

- Folloring

FIG. 28. Map of southeastern Asia. the East Indies, and Australia . .

Plate 48. A. Bluefish. B'. Sand flounder . . . . . Following

PLATE 49. A. Field sparrows. B. Quail . . . . . . . 118

PLATE 50. Woodcock on nest . . . . . . . . . . . . .

Plate 51. A. Nighthawk. B. Humming-bird's nest . . . . 118

PLATE 52. Tree lizards on oak bark . . . . . . . . 120

PLATE 53. Protectively colored mammals. A. *Cotton-tail " rabbit.

b. Thirteen-striped spermophile . . . . Following 120

Plate 5-. . Cony (Otochona) among rocks. B. Moth on bark * 120

PLATE 55. Protectively colored woods-moths. (In color) . . . . 120

PLATE 56. Protectively colored caterpillars. (In color) . . . . . 120

FIG. 29. A straw-colored spider (Tetragnatha grallator) in its accustomed position on a blade of dead grass . . . . . .

PLATE 57. Snow grouse in winter, spring, summer. and fall plumage 120 Following 120

Plate 58. Grass porgy, showing changes in color occurring in a few moments . . . . . . . Following 120

Piate 59. Color adaptation in pupe of Pieris rape and I'anessa urtica. (In color)

- Following 120

F1G. 30. Twig-like caterpillar of the moth Selenia tetralunaria . . . 122

PLATE 6o. Caterpillar of the moth Catocala amatrix. on a poplar twig.

Following 122

PLATE 61. A. "Walking sticks " on a twig. B. "Moss insect " . . 122

Plate 62. Leaf insects. A. Locust (Cycloptera). B. Mantis (Plyllium)

C. Longicorn beetle (1/ormolyce) . . . . Folloa'ing

122

PLATE 63. Logoc opercularis and L. crispata. adults, larvæ. and cocoons

Following 122

Plate 64. Spiders whose color and shape render them difficult to see $\quad$ * $\quad 124$

FiG. 31. A crab (Cryptolithodes sitchensis) which resembles a pebble . 124

PLATE 65. Sargassum fish (I'terophryne histrio) in a tuft of Hoating seaweed (In color) . . . . . . . . . Following

124

FIG. 32. A *sea-horse" (Hippocampus) . . . . . . . . 124

FIG. 33. Tree-frogs whose backs resemble oak leaves in color and color pattern . . . . . . . . . . 125

Plate 66. A. Tree-frog on bark. B. Common toads . . Following 126

PLATE 67. Weasels in winter and in summer pelage . . . . . 126

PLAte 68. A. Tiger. D. Jaguar . . . . . . . . 126

Fig. 34. Polar bear . . . . . . . . . . . 126

Fig. 35. Arctic fox, in winter and in summer pelage . . . . . 127

Fig. 36. A mantis (Hymenopus) which resembles an orchid blossom - 128

PLATE 69. Warning form and coloration in: A. Two bugs (Prionotus and Euchistus). B. Lady-beetles. C. Colorado potato beetle . Following 130

PLATE 70. Warning coloration and mimicry in moths. (In color) " $\quad$ I32 
I'LATE 71. Inedible caterpillars, showing warning coloration. (In color) .

Following

PLATE 72. 4. (Gila monster (Iteloderma). 13. Skunk (Mephitis mephitica)

132

Hollowing 132

Firi. 37. Salamander (Salamandra maculosa).

I 33

PLATE: 73. Inedible eurculios and lady-beetles imitated by edible longicorn beetles and grasshoppers . . . . . Following

PLAT: 74. Several species of tlies and the bees and wasps which they imitate .

PLATE 75. A. Agresessive coloration in a spider (Hisumena satia). I; and $c$ : ". Tree-hoppers" which imitate leaf-cutting ants with their bits of leaves. (In color) . . . Following

Fir. 38. A spicler which imitates an ant . . . . . . . I37

Fis. 39. Spiclers which mimic ants . . . . . . . . . I 38

I'LATl: 76. Edible buttertles which mimic inedible Danaida and Acracida. ( In color) . . . . . . . . . Following

PI.1TL: 77. Convergence in warning coloration, and mimicry among butterflies. ( ln color) . . . . . . . . . Following

PL.iTl: 78. Caterpillars which assume "terrifying attitudes" when startled. ( $\ln$ color)

FIs. to. Caterpillar of the large elephant hawk-moth . . . . 1 fo

Fir. fI. A moth (Smerinthus ocellata) in "*terrifing attitude. . . I +2

Pl.1Tl: 79. Mimicry in snakes . . . . . . . Following

Fis. 42. Amoth from India (. Htatus atlas) at the tips of whose wings are markings resembling those upon the head of a cobra.

P1.ATE 80. A "honey-sucker " or " friar-bird "which is imitated by an oriole $1+3$ Following 1 th

Fir. 43. "Cottontail" rabbit, showing white patch under tail . . . If6

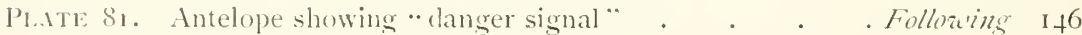

PLATE 82. " Recognition marks" in: A. Killdeer or ring-necked plover. l. Nighthawk . . . . . . . . Folloa'mg

P'l.1TE $\delta_{3}$. Confusing coloration in buttertlies, moths, and grasshoppers. (In color)

Following

P'late 8f. Sexual coloration and mimicry in butterfies and moths. (In color) . . . . . . . . . Following

I'1.1Tl: 85. Sexual coloration and protective coloration in spiders. (In color) Following 150

Pr.nTE 86. Diagrams of various flowers to show the arrangement of their pirts . . . . . . . . Following

Fis;. H. Fertilization in the rock-rose (Helianthemum marifolium). .

PLATl: 87. Plants whose pollen is carried by wind. A. New Jersey scrub pine. li. Fescue-grass . . . . . Following I 46 $14^{6}$

Fir. 45. A bee. showing hairs on the head, body, and legs to which pollen grains are clinging 
Plate 91. A. Skeletons of man and various apes. B. Pelvis of man and various apes . . . . . . . . . Following

PLATE 92. A. Teeth of man and gorilla. B. Cerebral hemispheres of man and chimpanzee . . . . . . . . Following 164

Plate 93. Hair tracts on the arms and hands of a man and a male chimpanzee. . . . . . . . Following I6t

Plate 94. Ears of various Primates . . . . . . . . . . 164

Plate 95. A. Head of fotus of orang. showing pointed ear. I'. Ear of a man. showing a point on the recurved edge. C. Vestigial tail muscles in man, abnormal . . . . Following 164

Plate 96. A. Vestigial muscles of the human ear. B. Vermiform appendices in orang. man. and human foetus . . . Following 164

Plate 97. Eyes of various vertebrates. showing the nictitating membrane .

Following I 66

Plite 95. Embryos of various vertebrates . . . . . . . . . . $\quad$ i 66

PLATE 99. Foot position and curvature of spinal column in gorilla, adult man. and human infant . . . . Following I66

Plate 100. Foot position and strength of grip in human infants . . . I66

Plate 10I. Derelopment of Sacculina carcini . . . . . . . Ist

FIG. 46. Early development of Saculina carcini . . . . I $\$ 5$ 



\section{INTRODUCTION}

IT is not my purpose to argue in favor of the theory of evolution as opposed to the theory of special creation. The time is past when such discussion would be profitable. It is rather my wish to set forth in brief outline the evolution theory and describe some of the phenomena which it explains, and then to discuss the relation of mankind to evolution.

The biological sciences have been the last to come to a position of dignity as orderly, self-consistent explanations of phenomena. Supernaturalism and anthropomorphic interpretations once prevailed in the whole domain now claimed by natural science. Gradually the so-called physical sciences were emancipated from the superstitions that oppressed them. Galileo, Kepler, Newton, and the more modern physicists and chemists have shown that the phenomena of nature are orderly and self-dependent, that the explanation of natural phenomena is to be sought in other natural phenomena. The stellar systems of the universe are held in their proper places by that mutual influence they exert upon one another which we call gravitation. Our own sun moves along its appointed daily course not because of the guiding reins of the charioteer Apollo, but under the control of this same omnipresent force, gravitation. The mysteries of chemistry were not so much in the thought of men as were the more patent physical phenomena, so we find less of supersti- 
tion and unnatural interpretation in this field, yet the false hopes of the alchemist and his unscientific methods show that even chemistry has had to grow away from a mass of ignorant belief that prevented its being worthy the name of science.

But the biological sciences were still slower to come to their true position as dignified science. Here was the last stronghold of the supernaturalist. Thrust out from the field of "physical science" it was in the phenomena of life that the last stand was made by those who claim that supernatural agency intervenes in nature in such a way as to modify the natural order of events. "When Darwin came to dislodge them from this, their last intrenchment, there was a fight, intense and bitter, but, like all attempts to stay the progress of human knowledge, this final struggle of the supernaturalists was foredoomed to failure. The theory of evolution has taken its place beside the other great conceptions of natural relations, and largely through its establishment biology has become truly a science with a large group of phenomena consistently arranged and properly classified. The discussion which followed the publication of Darwin's "Origin of Species" lasted for nearly a generation, but it is now practically closed, so far as any attempt to discredit evolution as a true scientific generalization is concerned. Scientists are no

I The author believes that all nature is controlled by an intelligent Providence. and that every phenomenon of nature is either natural or superuatural, according to one's point of view. A book upon the philosophical bearing of the theory of evolution might treat of the supernatural aspects of nature. It is my purpose, however, to discuss only the natural aspects. But it is important to insist that all our scientific knowledge of natural phenomena points to the conclusion that these phenomena are orderly and self-consistent, and that the supernatural and natural are never in conflict: in other words, that natural phenomena are capable of being studied and classified. 
longer questioning the fact of evolution; they are busied rather with the attempt to further explore and more perfectly understand the operation of the factors that are at work to produce that development of animals and plants which we call organic evolution.

But though the fact of organic evolution seems satisfactorily established, we are still far from a satisfactory knowedge of the factors which are at work to produce it, and especially are we ignorant of the manner of their operation. For many generations to come there will be in this field abundant opportunity for profitable study. It is not my purpose to enter into much discussion of the more doubtful questions, but rather to give, as briefly as is consistent with clearness, an outline of the apparently well established facts as to the theory and some of its important corollaries.

By thus avoiding critical discussion as far as possible, I would not create the impression that biologists are entirely agreed upon all points of the theory. There is endless discussion of many phases of the subject. In three cases where there is general difference of opinion upon a fundamental point I have tried to state the divergent opinions and to show what seems to me to be the safest conclusion, with the reasons for my opinion. Two of these much mooted points are the degree of efficiency of natural selection, and the inheritance of the effects of use and disuse. Another much discussed factor in evolution is sexual selection. This I have treated largely by pictures, showing some of the phenomena about the explanation of which there is so much difference of opinion. But however much difference of opinion there may be among biologists in regard to many subsidiary points of the theory, there is substantial agreement upon the 
fact of evolution. Biologists do not doubt that evolution has occurred and is continuing.

It has seemed best to develop some one subdivision of the subject a little more fully than the rest. The author has chosen the phenomena of color in animals for this fuller treatment, being led to this choice chiefly by the fact that these phenomena may readily be observed by any reader in any locality.

We will speak first of the theory, then of some of the phenomena which find their explanation in the theory; we will consider the relation of man to evolution, and finally will refer to a few of the corollaries of the theory which are of general interest. 


\section{PART FIRST}





\title{
ORGANIC EVOLUTION
}

\section{THE THEORY}

Heredity.

\author{
NA'TURAL SELECTION
}

Every one knows that among both animals and plants the offspring tend to resemble their parents. The young of a horse is always a horse and never a zebra. Nolves do not give birth to foxes. Sunflowers will not grow from thistle seed. Each kind of animal and plant breeds true, as we say. This was not always recognized, as is illustrated by the ancient Greek conceptions of the origin of animals from plants, not only supposed to have taken place in the original creation of animals, but also thought to be of continued occasional occurrence. Similarly, the belief, prevalent during the Middle Ages, that the goose-barnacle (a kind of crustacean, Fig. I) transforms into the barnaclegoose (Fig. 2) is an indication that at that time the inclependence of different species was not so clearly recognized as now. Sylvester Giraldus, in his Relations concerning Ireland. written in II $S_{7}$, quaintly describes this remarkable reputed process as follows:-

"Chap. II, Of Barnacles which grew from fir timber and their nature.

"There are likewise here [in Ireland] many birds called 
barnacles, which nature produces in a wonderful manner, out of her ordinary course. 'They resemble the marsh geese, but are smaller. Being at first gummy excrescences from pine-beams floating on the water, and then enclosed in shells to secure their free growth, they hang by their

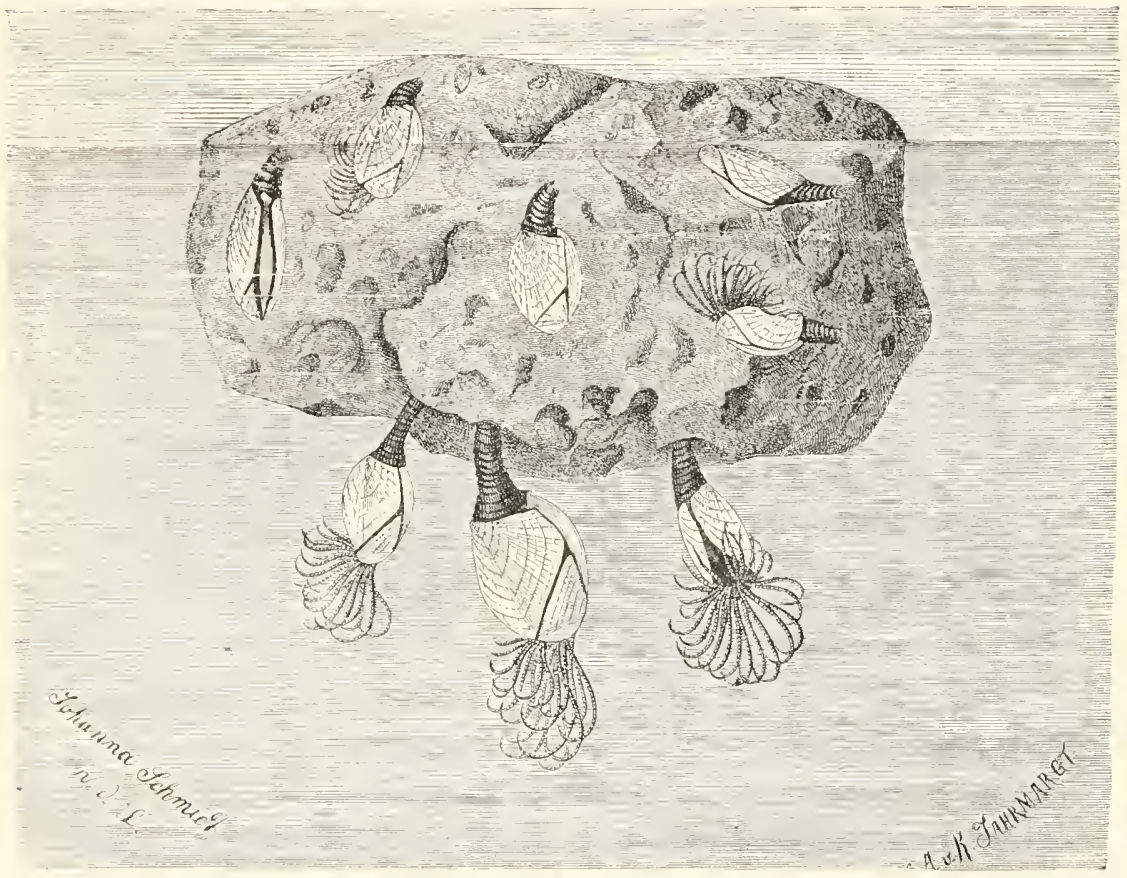

FIG. I. - Goose-barnacles (Lepas anatifera) attached to a floating piece of wood. Naturat size. - From Brehm's Thierleben.

beaks, like seaweeds attached to the timber. Being in process of time well covered with feathers, they either fall into the water or take their flight into the free air, their nourishment and growth being supplied, while they are bred in this very unaccountable and curious manner, from the juices of the wood in the water. I have often seen with my own eyes more than a thousand minute embryos of 
birds of this species on the sea-shore, hanging from one piece of timber, covered with shells, and already formed. No eggs are laid by these birds ...; the hen never sits on eggs in order to hatch them; in no comer of the world are they seen either to pair, or build nests. Hence, in some parts of Ireland, bishops and men of religion make no scruple of eating these birds on fasting days, as not being flesh, because they are not born of flesh, but these men are curiously drawn into error. For, if any one had eaten part of the thigh of our first parent, which was really flesh, although not born of flesh, I should think him not guiltless of having eaten flesh. Repent, O unhappy Jew."

Again, Sir Robert Murray, in 1676 , reports his observations of these phenomena to the Royal Society of England:-

"In many shells I opened, I found a perfect Sea-Fowl; the little Bill like that of a Goose:

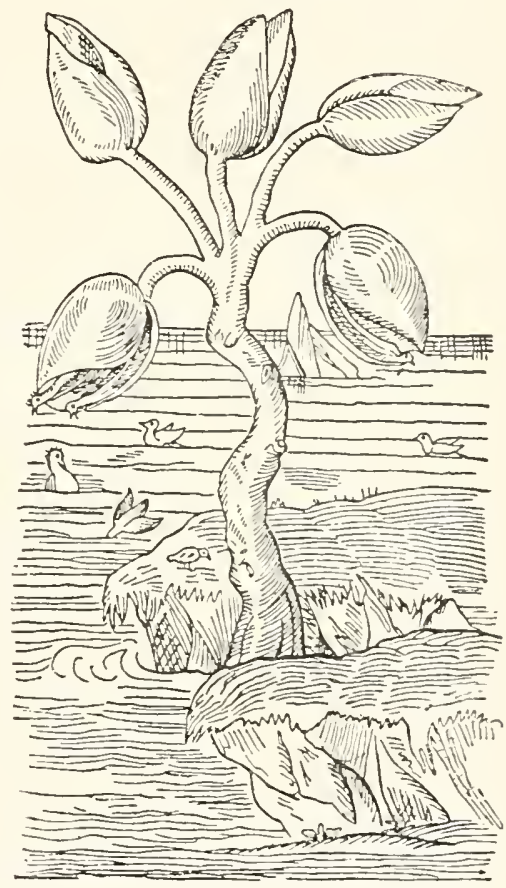

FIG. 2. - Gerarde's figure of " Barnacles producing geise." - From Gerarde's Herball. the Eyes marked; the Head, Neck, Breast, Wings, Tail, and Feet, formed; the Feathers everywhere perfectly Shaped, and Blackish colored; and the Feet like those of other WaterFowl, to my best Rememberance. The biggest I found upon the Tree, was but about the size of the Figure [an inch long]; nor did I ever see any of the little Birds alive, nor meet with any Body that did; only some credible Per- 
sons have assured me that they have seen some as big as their Fist."

This conception of the transformation of barnacles into geese, remarkable as it was recognized to be, was still accepted among scientific men for a long time. And why should not we gather figs from thistles? why should not plants give rise to animals as the Greek philosophers believed? That they do not do so is really a remarkable fact which no one without experience of nature could safely have predicted.

We, however, have had sufficient experience of nature to affirm with confidence that animals and plants do breed true. The statement needs no proof to our minds.

We can go farther and say that not only do plants and animals, when they reproduce, give rise to young which belong to the same species as their parents; the young resemble usually the particular individuals from which they have sprung. This is a fact perfectly familiar to breeders. Among domestic cattle, for example, the offspring resemble their parents in such qualities as size, form, color, amount and quality of milk, in disposition, in fact in all features which we can observe. The same is true of all our domestic animais, and no less true of cultivated plants, and of both plants and animals in their natural habitat.

We can accept, then, without further discussion, the statement that plants and animals (all living things) breed true; that offspring tend to resemble their parents in both specific characters and individual peculiarities. This relation between parent and offspring we have named hordity. 

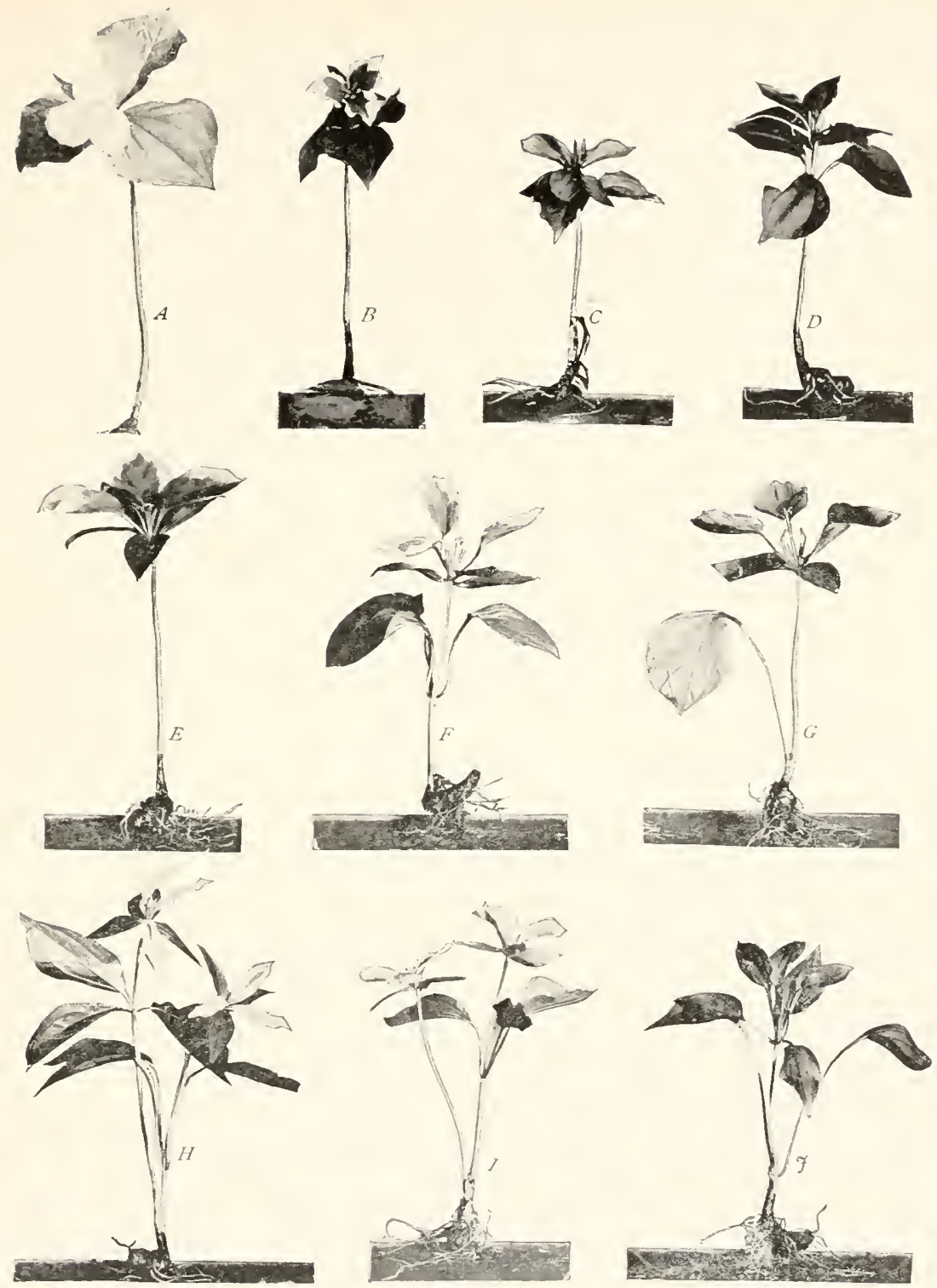

PLATE 2. - Variation in Trillum grandifomm. [After BRITCHIF.]

Mr. Britcher collected all these varieties at one time in a single very restricted area. Observe that the plants differ in size of blossoms, color of petais (all white, $A ;$ ail green, $C ; D, \mathcal{F}$; or of green and white in varying proportions, $I, E, F, G, H, I$ ); shape of petals (sessile, $I, B, C, H, I$; or stalked with stalks of varying lengths, $I, E, F, G, \mathcal{F}$; broad, $A$; or slender, $H$ ); form of flower bracts (sessile, $A, B, C, D, E, G, H, I$; or with long, $\mathcal{F}$, or short, $F$, stalks; broad, $E, F, G, \mathcal{F}$; or siender, $f, B, C, H)$; position of stem leaves (arising from the base of the stem, ( $\vec{F}$; or situated at different levels upon the stem, $\mathcal{F}, F, H, D, B, C$; often occurring just below the flower bracts, $A ;$ in one case absent altogether, $E$ ); form of stem leaves (sessile, $A, B, C, E$; or with petioles of varving lengths, $D, F, I, H, \mathcal{F}, G$; slender, $H$, or broad, $A$ ); number of stem leares (one, $G$; or three, $A, B, C, D, F, I, \mathcal{F}$; or none, $E)$; number of stalks from a single bultb (one, $A, B, C, D, E, F, G, \mathcal{F} ;$ two $H, I$; or in some cases, not shown, three may be found). The stamens and pistils also vary in form and in size, $B, D, F, G, F$. P'robably no finer example of variation in any plant has been described. 



\section{Variation.}

Yet however clearly we see that offspring tend to resemble their parents, it is no less evident that this resemblance is not an exact one. Among human kind we find excellent illustrations of this principle. However strong may be the family resemblance between the different menbers of a family, still each has his or her own individual peculiarities. No two are exactly alike. The children do not exactly resemble each other or their parents. These facts of individual differences we group under the one term, variation. We say that while, under the influence of heredity, the young tend to resemble their parents, because of variation this resemblance is more or less imperfect.

No one doubts the existence of variation. All about us we constantly see illustrations of the principle. Yet few but trained biologists realize how universal and how extensive is variation. All species of organisms are always varying in every characteristic and in almost all directions, and the extent of the variation is very considerable in most species. The individual plants of any species vary in size, in size of the several parts, in shape of stem and roots and leaves, in number of leaves and of blossoms, in color of petals, in number of seeds, and in hardiness, that is, in ability to resist adverse conditions of heat or cold, of drouth or flood, and of unfavorable soil. In all features, both structural and physiological, we find the individuals of any species of plant will differ from one another. Absolute uniformity is not found in organic nature (Plate 2).

Study a thousand individuals of any species with regard to any single character, and you will see how true this is. Take the common trailing arbutus as an example. You will 
find the greatest difference in the number of blossoms in a single head; the number of clusters of blossoms on a single plant will vary greatly; the number of seeds is very variable, ${ }^{1}$ so, also, is the proportion of these that will mature; the size, shape, and weight of the seeds vary; within the seeds is a variable amount of inutriment, and careful chemical analysis would show that this nutriment is not absolutely constant in character; the relative proportions of the parts within the seeds are by no means constant, for in some seeds the embryo will be relatively larger and the nutrient materials fill a smaller space, while in other seeds these relations will be reversed; in the minute embryo which each seed contains the relative proportions between the several parts, the miniature stem and leaf and bud, are subject to much variation; examine still more closely, and you will find that in the cells of which any portion of this minute embryo is composed there is no uniformity in shape, size, or structure. The analysis can be carried to any extent, and still it will be found that every part of the organism is variable, and that this variation is not confined to a particular direction. The flowers of the arbutus, for example, vary, not in a single regard. They vary in number, size, shape, number of petals, length of petals, breadth of petals, thickness of petals, color of petals. in the size of the nectaries upon the petals, in the abundance of the nectar secreted, in its strength of fragrance, in its quality of fragrance, etc. I have developed this point to the extent perhaps of wearying the reader, for it has not usually been sufficiently prominent in the minds of those who are thinking of the processes of evolution, and much confusion and false thinking can be avoided if we remember

1 In many localities the trailing arbutus rarely matures seed. 


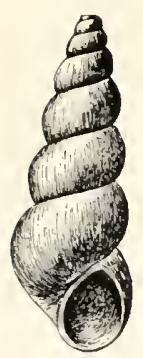

1

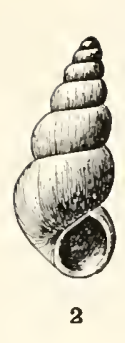

(

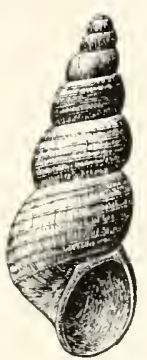

3
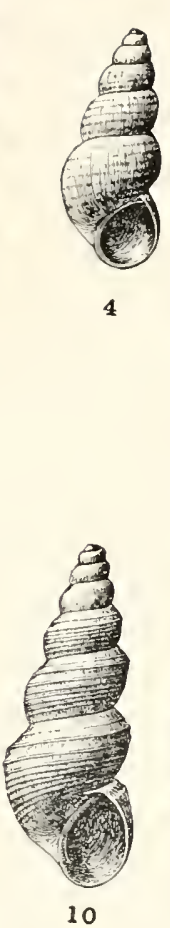

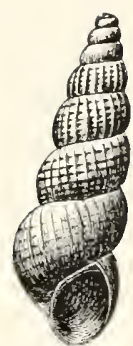

5

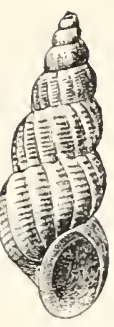

6

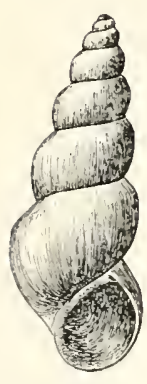

7
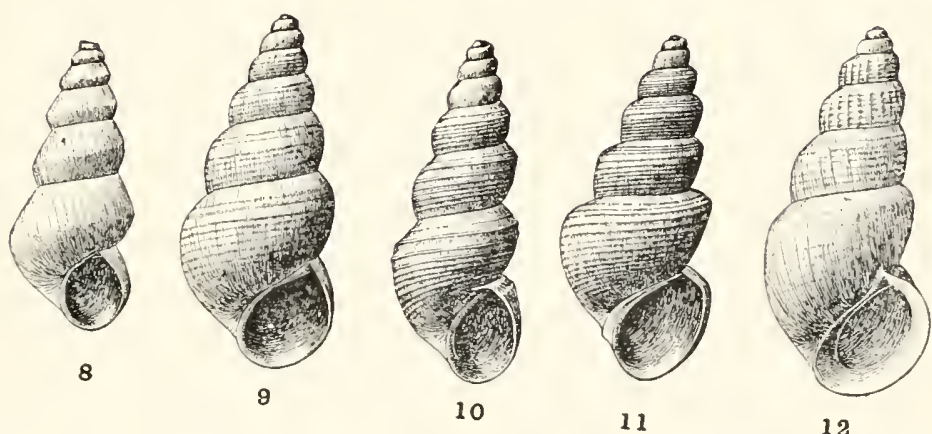

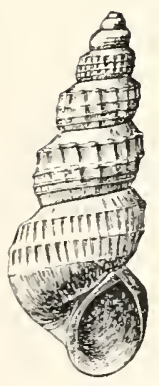

13

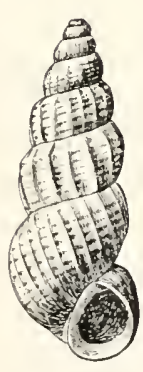

14

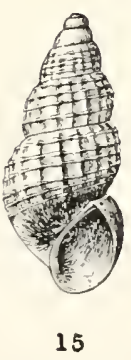

15

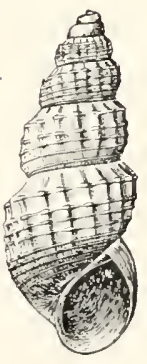

16

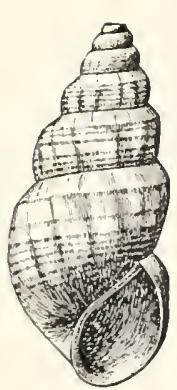

17

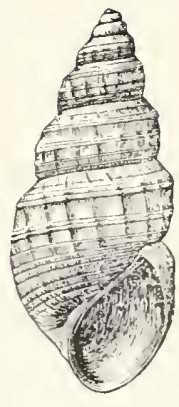

18

PLATE 3. - Varieties of Paludestrina protea. [After STEARNS.] 

that almost all sorts of variations are always present among the individuals of every species. We have taken illustrations from the plants; of course the same phenomena are found among animals (Plate 3 ).

Not only is variation universal, affecting all organisms and all parts of every organism; we find also that the degree of divergence is really very great. In some of our common bircls, for example, the length of wing varies to the extent of one quarter of the average for the species. So also with the length of tail, the proportion between length of wing and length of tail, the size of beak, the proportions of the legs, feet, toes, and claws, and many other characters. Mr. J. A. Allen, in his memoir On the Mammals and IIinter Birds of East Florida, says, "The facts of the case show that a variation of from fifteen to twenty per cent in general size. and an equal degree of variation in the relative size of different parts, may be ordinarily expected among specimens of the same species and sex, taken at the same locality, while in some cases the variation is even greater than this."

Animals and plants do not all show an equal amount of variation. Among animals the domestic goose is a good example of a species in which variation is comparatively slight. Partly as a result of this stability, clomestication has resulted in the establishment of but few breeds of geese. But eren in those species of animals and plants in which there is the least variation the differences between individuals are still readily noticed upon careful observation.

As an example of variation in color and color pattern notice the frontispiece, which shows thirty-five shells of Neretina virgined variety minor selected from a thousand, most of which were gathered by the author in the Salt Pond 
near Port Henderson, Jamaica. Among the shells there collected were sixty-eight distinct varieties, as indicated by the color and the pattern of their markings. I know of no finer example of variation in color and color pattern than is shown in these little shells.

Remembering now these facts of heredity and variation, let us observe the conditions under which organisms live, and see how these operate to cause and guide their evolution.

\section{The struggle for cristence.}

As we go about unobservant through the woods and fields, glancing carelessly at the bright flowers and the birds busily seeking their food or singing in apparent contentment, or as we look over the ocean and think of the fish darting swiftly through the clear water, it all seems to us an idyl of perfect happiness, full of ease and play. We rarely think of the constant struggle for food and life in which all these trees and flowers, all the fish and birds and other animals, are engaged. Ire fail to see that for them life is one continual struggle; that the gathering of food, that resistance to the unfavorable conditions of climate, cold, drouth, flood, and stom, that rivalry in marriage and the effort to rear their young when born, absorb the energy of animals and plants alike; and that, despite the strenuous efforts put forth, the result, in the great majority of cases, is failure and death. Yet this is by far the truer picture of organic nature. Everywhere is starvation and death, failure to reach success in their own lives or in rearing their young. To some this aspect of nature may not secm so pleasant to contemplate, yet a moment's consideration will show its truth. 
The never ending, ever stressful struggle for life is a direct and necessary result of two facts: first, that the amount of food and the space to be occupied on the earth by animals and plants are limited; and, second, that the processes of reproduction, if unhindered by any adverse circumstances, would give a geometrical ratio of increase of plants and animals. Let us look a moment at the second of these two propositions. The first, that the earth is capable of supporting only a limited number of living things, is, of course, understood without illustration, but the facts of geometrical ratio of increase in animals and plants, unless opposed by unfarorable conditions, are worth illustrating. Our common American animals and plants give us as good examples as we could wish.

The common robin raises annually one to three broods, of three to six young in each brood. Say that the yearly offspring of each pair of birds is four on the average, which is surely a low estimate, then a single pair of robins would have in the first generation four young. The second year they would have four more young, and their young of the first year, mating, would have eight young, four for each of the two pairs. If for ten years the original pair and all of their offspring were to live and reproduce at the assumed rate, four young a year for each pair of adults, then at the end of the tenth year there would be over one hundred thousand robins, all descendants of the first pair. (See Table.)

One pair of adult robins

Aduits

Young

First year, their young .

2

Second year.

$\begin{array}{rr}6 & 4 \\ 18 & \text { 1 } 2 \\ & 36\end{array}$

Third year. 


\begin{tabular}{|c|c|c|c|c|c|c|c|}
\hline & & & & & & Adults & Young \\
\hline Fourth year & . & . & . & . & - & 54 & 108 \\
\hline Fifth year & . & - & . & . & . & I 62 & 324 \\
\hline Sixth year & . & - & . & - & - & 486 & 972 \\
\hline Seventh year & . & . & . & . & - & $\mathrm{I}, 45^{8}$ & 2,9 I 6 \\
\hline Eighth year & . & • & . & - & . & 4,374 & 8,748 \\
\hline Ninth year & - & & - & - & & $I_{3}, I_{22}$ & 26,244 \\
\hline Tenth year & . & & • & & & 39,366 & 78,732 \\
\hline End of tenth & & & & & & I I $8,0_{9} S$ & \\
\hline End of twent & year & . & . & • & • & $94^{8,8} 4^{6}$ & \\
\hline
\end{tabular}

IVe see at once that the earth could not support the animals of even a single species that would arise were not the natural increase of the species held in check.

As a matter of fact, the number of animals or plants of any given species remains about constant. There are usually no great fluctuations from year to year. To return, then, to our illustration of the robin, we can say that more birds (including eggs and young) die every year than live. If the whole number remains constant from year to year and if each pair of robins have four young yearly, of course four robins die every year for each two that survive. That is, the death-rate is twice as great as the total permanent population.

This death-rate is greatly surpassed by that of many species both of animals and plants, which have a much larger yearly birth-rate. Among mammals the average birth-rate would perhaps be no greater than it is among the robins, but among birds are many which have twice or three times or even four times as many young each year as do the robins; $c . g$. the whole grouse tribe, including the pheasants, the partridges, and the quail, also the wild jungle-fowl from which our domestic chickens have been derived. Snakes, turtles, lizards, and most reptiles 
have a yearly birth-rate at least as great as that of the more prolific birds. Frogs and other Amphibia have an immensely larger number of young each season, often several hundred for each pair. Many of the fishes lay half a million eggs for each mature female, so that here we have an example of a yearly death-rate two hundred and fifty thousand times as great as the permanent population, since on the average only one male and one female out of this half-million of young survive to take the place of their parents and keep the number of individuals in the species up to its usual mark. A starfish may lay a million eggs each season, and, as the number of adult starfish remains about constant from year to year, we see that for every starfish living nearly half a million die each year. The birth-rate among the Mollusca, worms, jellyfish, sponges, and the Protozoa, like that of the starfish, is enormous. Taking animals as a whole, it would be safe to say that hundreds of thousands die every year for each one that lives.

Among plants the figures are no less startling. The higher flowering plants reproduce much more slowly than most of the lower plants, yet among them the death-rate is very large. The common marguerite daisy, which grows so abundantly in eastern America, is a fair example. It is a moderate estimate to say that one of these daisies of ordinary size, blooming as it does for about two months, would have one hundred and twentyfive heads of bloom each year. Each head of blossoms would have about five hundred seeds, making a total of sixty-two thousand five hundred seeds for each plant each year. Of this number sixty-two thousand four hundred 
and ninety-nine, all but one, are destined, on the average, to die, even assuming that the parent plant dies, which is by no means always the case. Very many of our flowering plants form more seeds than this annually, yet their numbers do not materially increase under ordinary conditions.

Fern spores are much more numerous than the seeds of flowering plants, and the lower cryptogams, the Fungi, especially the Bacteria, breed with a rapidity which is far beyond our comprehension. Under favorable conditions a single bacterium might produce a million bacteria in a day. If this rate of increase should continue, we would have at the end of a week a million million million million million million million bacteria, all derived from the single individual with which we started.

If all living things tend to reproduce with such astonishing rapidity, and yet we find that their numbers do not materially increase, but remain about constant, what is it that holds them in check? What kills the excess? Many things, unfavorable conditions of all sorts. Starvation claims probably the largest share of victims; heat and cold kill many; floods, drouth, and storms destroy others; multitudes perish to feed their enemies; disease takes its share. Nature is fertile in expedients for killing. Life is not easy. Success is not the rule but the rare exception. For every one which lives and succeeds in rearing offspring, thousands and thousands perish. Competition is so keen that no unhealthy or imperfect individual can endure it. The weak fall first, leaving the field to their stronger brethren, who in turn fight it out among themselves, till finally only the strongest and finest survive. In a struggle 
so severe any advantage, however slight, of greater vigor, or better structure, may be decisive and turn the scale.

In these three sets of phenomena, heredity, variation, and the strenuous struggle for existence, we have the basis for progress, for evolution, by the survival of the most perfect individuals. Let us illustrate.

Among the existing individuals of any species of animal or plant there will be found, at any time, a great variety of more or less divergent forms. Take as an example the common rabbit of eastern America. Some when full grown are larger, some smaller; some are swifter, some run less swiftly; some are darker colored, some lighter colored; some are grayish, some more brownish; some are more shy than the average, some more bold than their fellows; some are more observant, some less so; some have greater endurance, some diverge to the other extreme. So we might go on. Whatever character we choose to observe, we will find it more strongly developed in some individuals than in the rest, and conversely in some it will be developed to less than the average degree. The larger number of individuals in the species will usually pretty closely agree in the extent to which any particular character is dereloped, but a considerable number will be found who diverge toward either extreme.

Suppose now there be introduced into the region where these rabbits live some predatory enemy swifter and more sly than those to which the rabbits are now exposed. The first result would be the extermination of those rabbits which are less swift and less cautious and observant. Most of those of average swiftness and alertness also might be caught and killed. There would soon be 
left, then, only the individuals in which these valuable qualities are most highly developed. They would persist, and, escaping their enemies, would succeed in rearing young, to which, according to the principles of heredity, they would hand down their good qualities, so that the young, like the parents, would be swift and keen. 'Thus, by the elimination of the less perfect individuals of the species, there will have been developed a race of rabbits in which the qualities which aid in escape from a swift, keen enemy are more highly marked than in the former race. This is evolution by the elimination of the unfit, or by the survival of the fittest, the process which is called natural selection, meaning the selection or retention of the individuals most perfectly adapted to the environment in which they live.

The new race referred to in the illustration chosen might be especially characterized not only by the two qualities mentioned, swiftness and keenness, but also very likely by other qualities that would aid in escaping the new enemy, such, for example, as more perfect conformity in color to the environment, provided its conditions of life had been so easy that perfect color resemblance to the enviromment had not been previously a necessity. Several of the desired qualities could probably be perfected at the same time, since the variations from which to select would not appear separately in different individuals, but would often be present in the same individual at one time. Thus there would be found among our Eastern rabbits some which were at once more swift, more keen-sighted, more observant, more shy, more perfectly like the environment in color, and perhaps marked by special development 
of other desirable qualities. Variation is much more extensive than we usually think, and such divergence in many qualities at once might readily be found.

Illustrations of this principle of natural selection might be indefinitely multiplied. The environment presses upon the animal or plant at all points, and the whole organism is capable of adaptive response, since the whole organism varies, giving favorable peculiarities for selection. Any feature, of structure or of function, may be perfected whenever it becomes desirable to have it emphasized. The only things necessary are that the useful character shall be present year after year as a variation in some individuals, and that it shall be of sufficient importance to aid its possessors to win in the struggle for life in which they are constantly engaged. This struggle is so severe that only the most perfectly endowed can hope to win; so that an advantage, though very slight, may determine survival, or, as Romanes puts it, be "of selection value."

There are two quite different methods used by both plants and animals to enable the several species to persist and not be destroyed in the battle of life. The first is the one already illustrated, namely, the gradual establishment, by selection of the most perfect individuals, of a condition of more perfect adaptation of the individuals of the species to the environment in which it lives. The second is to so greatly increase the number of the offspring by great development of the reproductive functions, that from very numbers they will have more chance of survival. We can hardly say that a million starfish eggs have a million times more chance of survival than would one, but surely a starfish that lays a million eggs has much more 
likelihood of leaving descendants than would one which laid but few eggs, other things of course being equal. Most animals and plants adopt both methods, being very prolific and being well adapted to their environment.

Now, evolution is brought about by the occurrence, among the individuals of a species, of certain ones which are better fitted for the life they are to live than are the others of the species; by the survival of these favored ones; and by the transmission of their valuable qualities from parent to offspring generation after generation. The appearance of the desirable quality is an example of variation: the survival of those individuals which possess these qualities is secured by natural selection: and the perpetuation of the useful qualities is secured by heredity. It would seem necessary that, given these three factors, variation, natural seiection, and heredity, evolution should be the result. Later we will take up some of the most frequently urged objections and see if there is any flaw in this argument.

\section{Mutation.}

Recently De Vries has shown by a very careful and very extensive series of observations of wild and cultivated plants, chiefly of the species Enothera lamarckiana, that there may be two somewhat different types of variation(I) "fluctuating variation," by which a species varies in greater or less degree and in almost all directions, and (2) "mutation," by which the whole character of the species is changed and a new species established at one leap. The new species thus established by mutation will show, as did the former species, a series of fluctuating variations. Every species of animal and plant with its numerous fluctuating 
variations still shows a certain rather definite "species mean," to which most of the variants rather closely conform, but from which some considerably diverge. Mutation, according to De Vries, establishes a new species with a new species mean and a new series of fluctuating variations gathered about the new mean.

Similar phenomena have long been known to florists and breeders of animals, the divergent individuals of the new type having been called sports. To De Vries, however, belongs the credit of having studied these phenomena in many thousands of individuals through many generations. Yet, careful and extensive as has been De Vries' work, we cannot yet be assured that the appearance of discontinuity in variation, by which new types are suddenly established, is not due to insufficient observation, and that the study of a still larger series of individuals would not show forms completely bridging over the gap between the old and new types. At present we can say only that De Iries' work has shown the likelihood of there being a real distinction between fluctuating variations and mutations. Other features of De Iries' observations will be referred to later.

The individuals of new character, arising by mutation, must be subject to natural selection, and therefore those which are not well adapted to their environment will be destroyed, as in the case of divergent individuals arising by fluctuating variation.

Referring again to the illustration given above, observe that all the rabbits in the given region are subject to natural selection and the more perfectly adapted individuals will be preserved. It makes no difference 
whether they obtained their useful character through fluctuating variation or through mutation. This does not affect the fact of their survival being determined by natural selection.

Before referring to the objections to the theory of natural selection, let us notice a few general principles in the operation of this factor in evolution.

Observe that in the process of evolution by natural selection the welfare of the individual is conserved only so far as it contributes to the welfare of the race. It is necessary that the more perfect individuals should survive long enough to breed and hand down to their young their useful qualities, but, having done this, their further life is a matter of indifference, so far as the processes of evolution are concerned. In case an animal or plant has several breeding seasons during its normal life period, of course its preservation until the completion of all these reproductive processes may be an important advantage to the species, and, if so, will tend to be secured; but in the case of a species whose members have but a single reproductive period in a lifetime, as is the case with many insects for example, their persistence after the completion of the processes of reproduction would be even disadvantageous to the species, since they would consume food and occupy space needed for the younger individuals which are to continue the species by reproduction. It is natural to find, then, as we do among the insects, the adults usually dying after the breeding season is over. The same thing is true, of course, of all annual plants. Among some kinds of animals the parents care for the young after birth, and 
in these cases it is easily seen that the life of the parent will naturally be continued until the completion of the period of parental care over the offspring. In the case of animals which form communities, it may be advantageous to these communities to have their members continue to live even after their reproductive activity ceases, since they may aid the community in other ways than by reproduction.

Let us see a few concrete illustrations of this principle that in the processes of natural selection the welfare of the race and not of the individual is sought. Very commonly seen on our trees are the egg-cases of the bag-worm (Fig. 3), a moth,

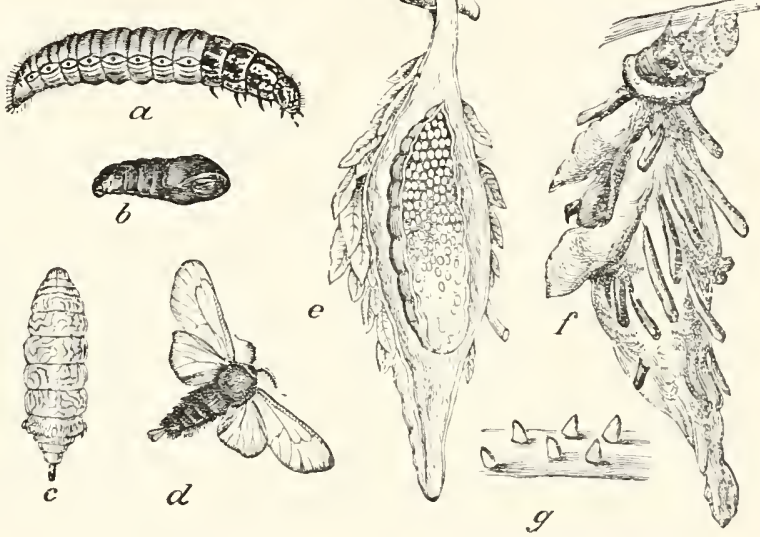

FIG. 3.- The "bag-worm," Thyroidoptery.r ephemeriformis.

a. Larva. b. Pupa, c. Adult female (wingless). d. Aduit male. c. Longitudinal section of a cocoon showing the degenerate female full of eggs. $f$. One of the larve, showing the covering of silk and twigs in which the posterior part of the bodv is enclosed. $g$. Young larve, natural size.-By the courtesy of the United States Department of Agriculture.

the female of which never comes to complete development, in fact, never leaves the cocoon, but is fertilized by the male and lays her eggs without ever emerging into a free life as an active, flying adult. Nore than this, not only is the active life of the adult female suppressed: her body disintegrates in the process of laying the eggs, so that orulation and the death of the female are simultaneous. Here we see the continued existence of the adult female after the eggs are laid is of no value to the species, and she is 
allowed to die. The male in this same species is an active, flying moth, flight being necessary in order that he may seek the female and fertilize the ova.

Another example of a similar sort is found among the bees. Here the males die in the process of fertilizing the eggs. The males in the beehive take no active share in the work of the community, except to fertilize the eggs, so
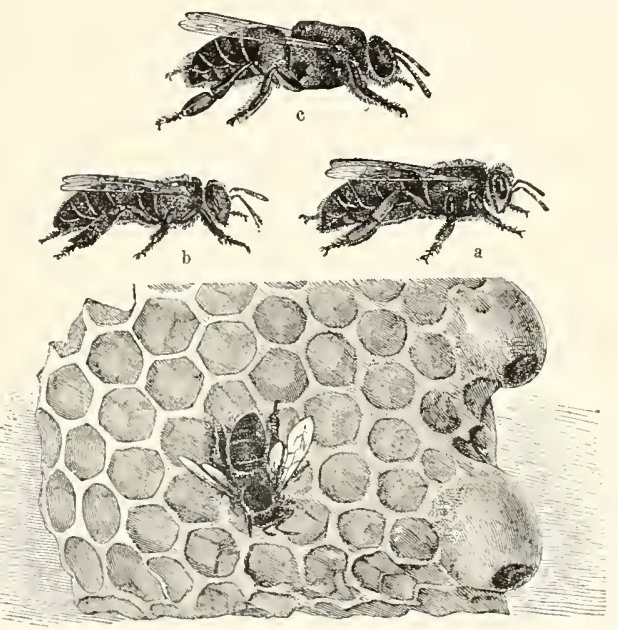

FIG. 4. - Honey-bees and a piece of honeycomi.

$a$. Nale bee, or drone. $b$. Worker-bee, a sterile female, $c$. Queen bee, a fertile female. - From Brehm's Thierleben. that when this function is performed their continued life would be of no profit to the community, in fact would be a positive disadvantage, since they would use food and space which could better be given to those individuals who were of present value to the community.

Still another example from the bees. The beehive contains three sorts of individuals (Fig. 4): the males, or drones, whose only function, as just stated, is to fertilize the eggs; the perfect female, or queen, which lays all the eggs, usually only one adult queen at a time being present in a normal hive; and the workers, sterile females, who perform all the labor of the hive and show the remarkable instincts so well known among the bees. The workers generally keep on hand a number of queen larva, so that if anything should destroy the old 
queen they can rear another queen; but they do not allow these larva to hatch so long as the old queen is still in the hive and in good condition, unless swarming is about to occur. The queens have the bitterest antipathy for one another, and should a new queen be allowed to hatch there would at once be a mortal duel between her and her mother, the old queen. As this would not be conducive to the welfare of the hive, the workers allow the old queen to approach the cells of the young queens, just as these are ready to hatch, and permit her to sting them to death before they hatch. Now these young queens are partially encased in an outer envelope which is not easily pierced by the sting of their would-be destroyer; but as it is advantageous for the hive that these unhatched queens should be put to death, we find that in forming this envelope around themselves they have left the posterior part of their bodies naked, so that the sting of the adult queen can readily penetrate and kill them, death being certain when once they are stung. In this case we see that the queen larva provide in their own structure for their own destruction, since this is for the advantage of the communities in which they live. The welfare of the race, not of the individual, is secured.

As an example of communal forms in which the continued life of the individual members of the community is advantageous to the community, even though these individuals be not active in reproduction, we can again instance the bees. The worker-bees are not usually able to reproduce; they are sterile females, generally incapable of laying eggs. Yet these workers are the most valuable members of the community, carrying on all the wonderful activities 
of the hive, making the honeycomb, gathering and storing the honey, rearing the young, guiding the queen in the performance of her duties, expelling the males when the breeding season is over, in fact running the whole hive. In this case it is not the individual worker which is the unit, but the community in which it lives, the hive. It is the whole hive, with all its mutually helpful members, that enters the struggle for existence, and natural selection determines which hives, just as much as which individual bees, shall survive. There is selection here of communities as well as individuals for survival, and an individual useful to the community for some other reason than breeding will be preserved because of this other value.

Among human beings we have excellent illustration of the fact that their helpfulness to the young or to the community as a whole may make the continued life of the parents of value, though they bear no more children. The human child is very imperfectly developed at birth; it is dependent on the parent's care; should the parent die the child would suffer. The life of the parent cannot be allowed, then, to cease with the birth of the child. More than this, the family is in a very real way a unit in the struggle for existence, and the continued life of its members helps the family to succeed, so that when the children of the family shall begin to rear families of their own, they shall have an advantageous start in their new, semi-independent life. Again there is a rivalry between communities of a larger sort. Different industrial centres enter into competition with one another, and nation contends with nation and race with race. As the continued life of the individual beyond the close of the reproductive period is 
of advantage to these larger communal units, we find the length of life is not determined by the close of the time of functional reproduction among men, as it is among so many of the lower forms. Still, among men, as among other animals, it is the advantage of the race and not the welfare of the individual which determines the length of life.

This fact, that among men the welfare of the race is the thing secured even at the sacrifice of the good of the individual, is clearly seen when the two come into conflict. It is not well for the individual that he die in battle, yet, when the national welfare demands it, thousands so perish, and there has even been developed among men a passion for such death for the good of their country. When a man has so indulged his evil impulses that he has become a menace to the communal welfare, he is restrained by a fine, or is deprived of his liberty, or may even be killed, and no conditions of his personal welfare are allowed to interfere. Even those who oppose capital punishment do so chiefly because they believe it hurtful to the community as a whole. Altruistic self-sacrifice is in line with the great principle in accordance with which nature seeks the welfare of each species as a whole, with no hesitation because of any hardship to individuals which may be involved.

Let us give attention to one other corollary of the theory of natural selection. The struggle for existence is most severe between those animals or plants which seek to occupy the same place in nature. Plants which live in moist valleys may come into very severe competition with one another, but they do not come into rivalry with the plants which like the dry hills or the barren rocks. The 
individuals of a single species, fitted as they are for life under the same conditions, enter into the most constant and the most severe rivalry. We may state this fact in another form by saying that the struggle for existence is most severe between near relatives. Now see what is the effect of this. IVe have a group of individuals belonging to the same species. Between them the competition is more severe than is the rivalry between themselves and any other forms. If now there arise among them individuals that diverge, so as to fit them to occupy a place slightly different from that occupied by the parent stock, this will allow the divergent forms to withdraw a little from the place where competition is most severe, and so will give them a better chance for survival. IVe see the tendency is constantly toward divergence, since divergence lessens the severity of the competition for life. Variations which arise, if they enable their possessors slightly to change their habit of life, will tend to be preserved, even though the place to which the divergent individuals migrate is, in itself, no better than the one they leave. This, we see, may materially affect the result of the process of evolution, causing forms to survive which otherwise would not be chosen.

Evolution, so far as it is dependent upon natural selection, is more rapid while the environment is changing than it is under stable envirommental conditions. By the continued action of natural selection animals and plants become so well adjusted to their environment that while this remains unchanged they undergo comparatively little modification; but when the environment is changing the plants and animals must change with it, if they are to be well adapted to 
their surroundings. Under changing environmental conditions, especially if the changes be rapid and considerable, the more plastic species, and those in which the largest degree of variation is present, will have a decided advantage over their less readily modified neighbors, and those species which do not so greatly vary. Many of the less plastic and less variable species may be destroyed because of their inability to keep pace with the changes in their surroundings. The plasticity of the organism and its variation are, therefore, important elements, and the degree to which they are dereloped in any given species may have an important bearing upon the fate of that species. Lloyd Morgan and J. Mark Baldwin have emphasized the importance of plasticity, showing very clearly that the ability of the individuals of a species each to so change its habit or structure as to adapt itself to new disadvantageous conditions may preserve its life and so prevent the rapid extermination of the species when environmental conditions change for the worse. In this way a plastic species may be tided over a period of hurtful environmental changes until natural selection shall have time to secure the fundamental adaptation of the species to its new conditions of life, after which the individuals will be born in a condition so suitable to their surroundings that they will not need to change their structure or natural habits in order to survive. In a species which withstands unfavorable environmental conditions through the plasticity of its individual members, each individual will need to be educated into harmony with the environment. Such individuals of the species as vary toward greater natural adaptation will need less education. Of course innate adaptation is more advantageous than adaptation 
through education, since it is immediate, no period of disadvantage appearing in the early life of the individual. The death-rate of the individuals which become adapted through education will be greater than that among the individuals with more perfect innate adaptation. Thus in time innate adaptation will be established for the species as a whole.

Mankind are in all intellectual features more plastic than animals of any other species. By education, to which they readily respond, they learn to so adapt themselves to unfavorable conditions as to escape from much of the stress of the struggle for existence. 'They have learned to protect themselves from cold and inclement weather, from hunger and from disease, and from many other dangerous elements in their environment. Man's great individual adaptability has secured his survival, but at the same time, has greatly hindered his evolution. This will be discussed later. It is desirable here merely to observe that plasticity (educability) in any species of organism hinders its evolution by lessening the destruction which lack of conformity to the environment would cause. If the plasticity is very marked, as among human kind, it may almost prevent evolution through natural selection.

\section{Artificial sclection.}

Before leaving the subject of natural selection it would be well to refer to the similar phenomena of artificial selection. Florists and breeders of animals use methods that very closely parallel natural selection. WTe are familiar with the remarkable results which have been obtained in the rearing of domestic animals and plants. The many kinds of horses in use (Plate 4 ) are widely different from the origi- 


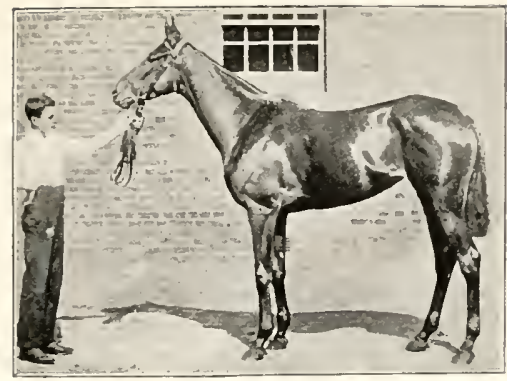

A

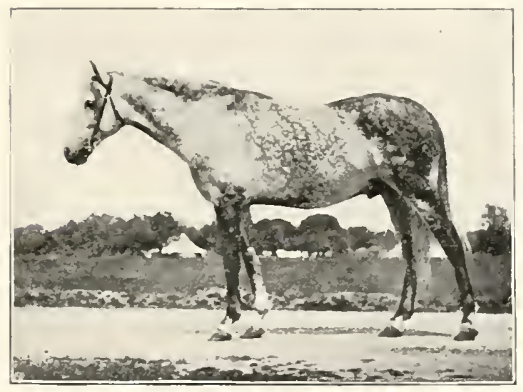

C

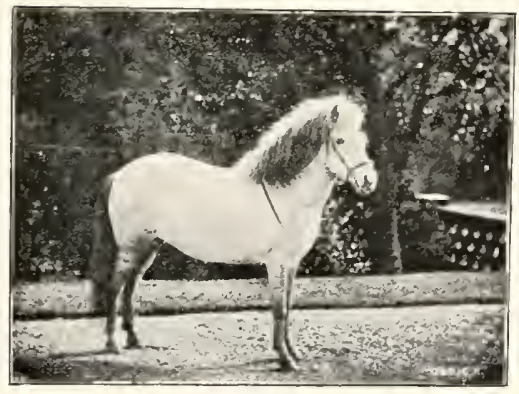

E

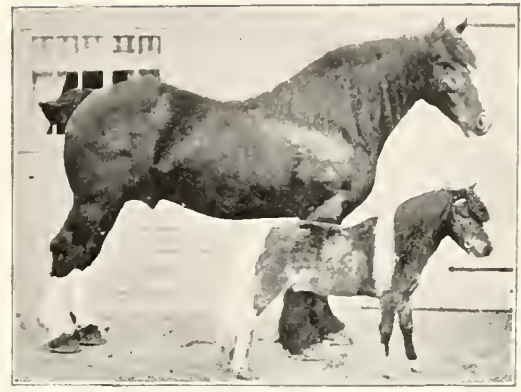

B

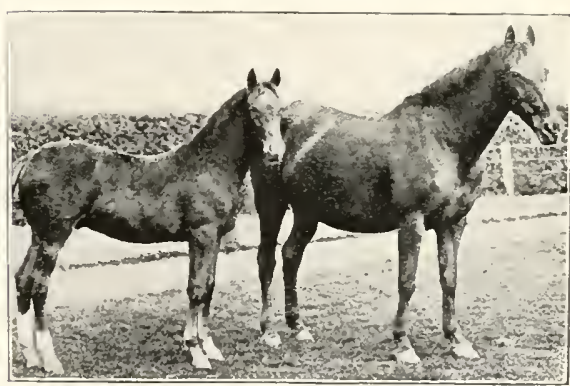

$D$

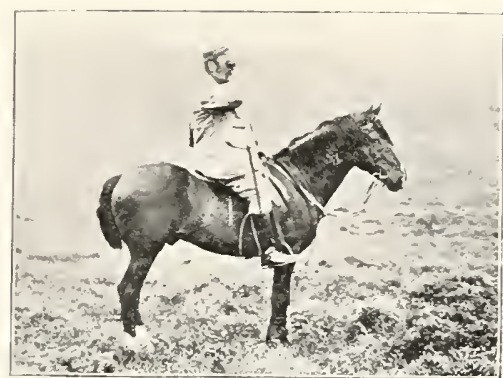

F

PLATE 4.- TARIETIES OF HORSES.

$A$. Thoroughbred mare. $B$. Shire horse and Shetland pony. C. Arab horse. D. Hackney mare and foal. E. Iceland pony. F. New Forest pony stallion.-From Hayes' Points of the Horse. 



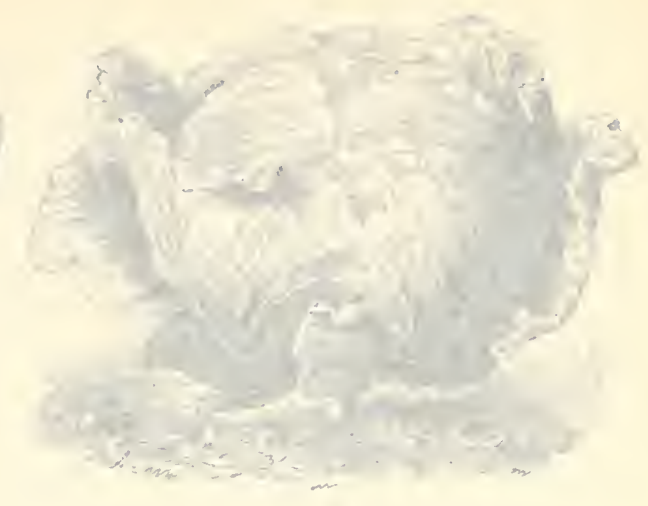

PLATES 5, 6, 7.- Different varieties of cabbage, Savoy cabbage, kale (borecole), broccoli, Brussels sprouts, cauliflower, Swedish turnip, and kohlrabi; all of which have been derived by cultivation from the wild species Brassica oleracea, which is a member of the Mustard Family or Cruciferce.

Plate 5.- I. Cabbage, dark red, early, pointed head, 2. Cabbage, "Schweinfurt," spherical head, large. 3. Cabbage, "green-glazed American," no head. 4. Cabbage, "sugar loaf," long, oval head. 5. Cabbage, "Rennes early," small. 6. Savoy cabbage, "Frankfurt," long, oval head.

Plate 6. - 7. Savoy cabbage, "extra early midsummer." 8. Savoy cabbage, "Tours." (6, 7,8 , differ in size, shape of head, and degree of curling or crinkling of leaves.) 9. Kale, curled, dwarf, sometimes called "German green." Io. Kale, tall, curled. II. Kale, "marrow-stemmed." I2. Kale, very tall, "cow or tree-kale." (In kale the leaves are highly developed, but are not compacted into heads.)

Plate 7.-I3. Brussels sprouts, dwarf; many small heads along the stalk. I4. Broccoli, purple sprouting; leaves and blossoms both used. I5. Cauliflower, Sicilian, "purple Cape broccoli," 16. Cauliflower, dwarf, early "Chalon." (In the cauliflower the blossoms are greatly developed, forming a compact head.) I7. Swedish turnip. In this type, which is said to have been derived from the same wild species as the cabbage, the underground portion of the stalk has been enlarged. I8. Kolnlrabi; the staik above ground has been enlarged.
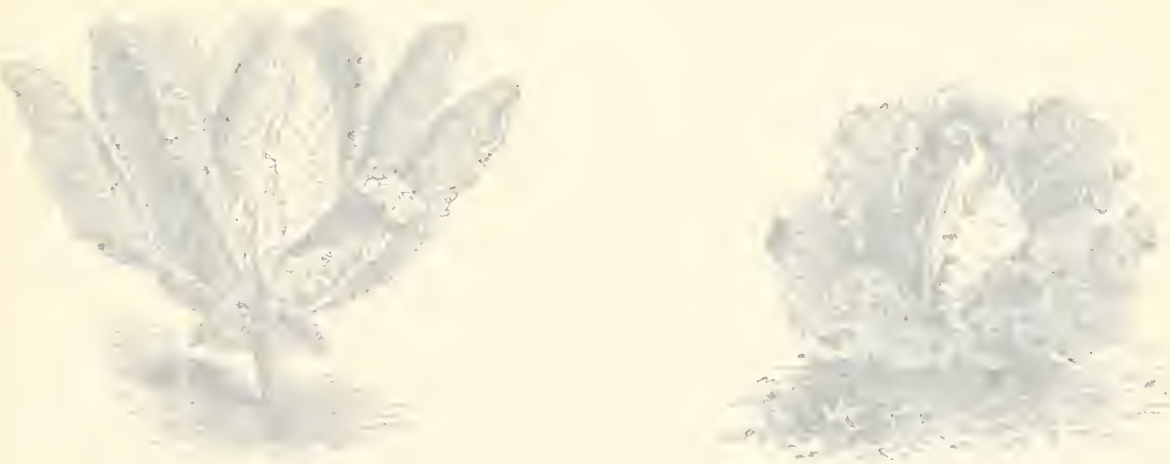


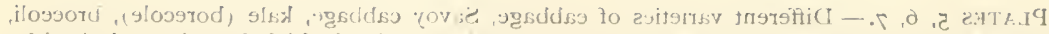

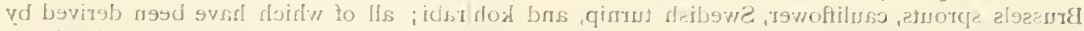

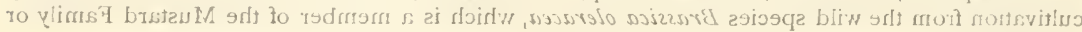
.2019 is 1350

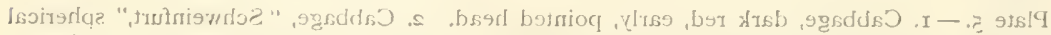

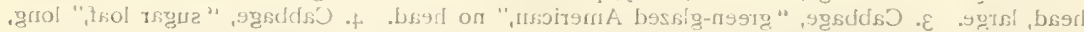

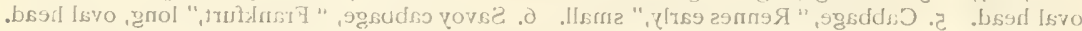

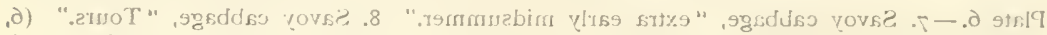

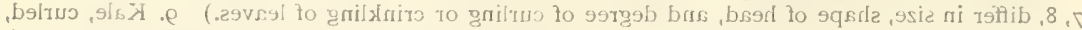

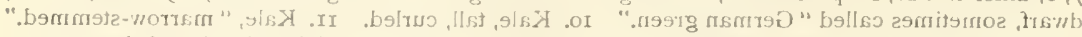

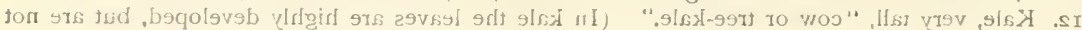
(.ebserl ofri batosqmoo

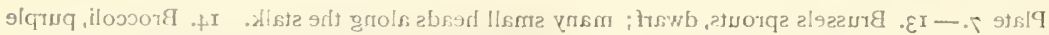

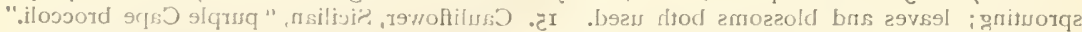

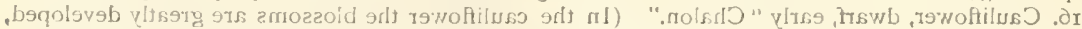

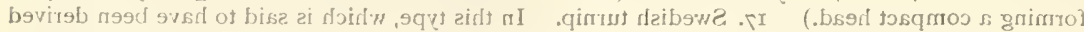

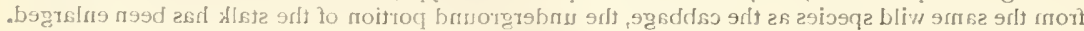

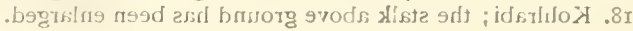




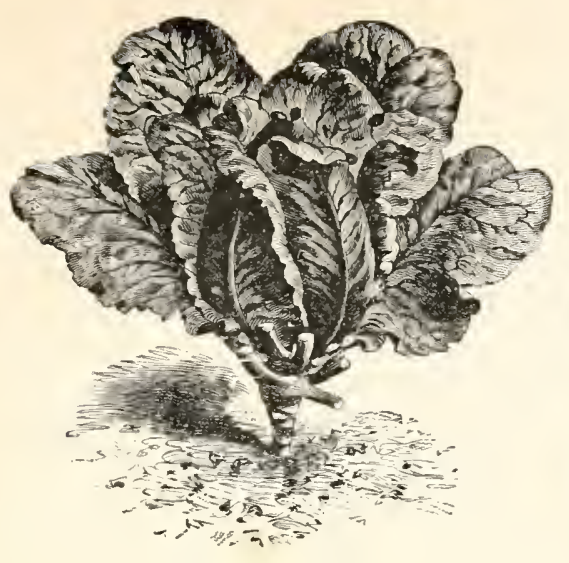

I

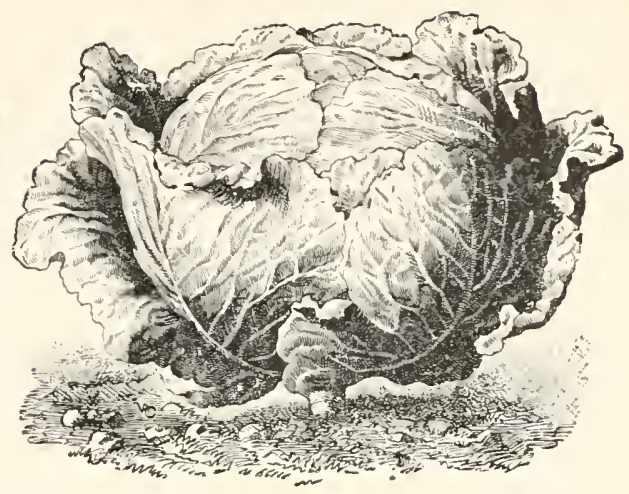

\section{Nivente}

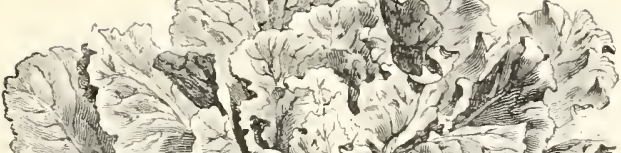

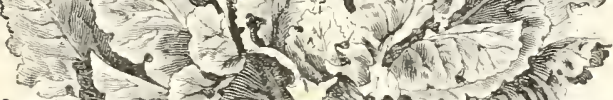

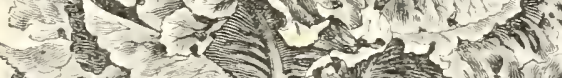
E.

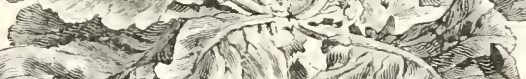

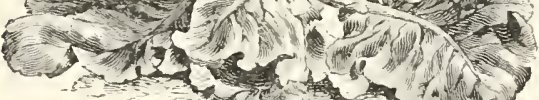

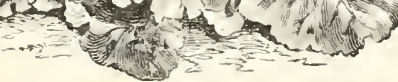

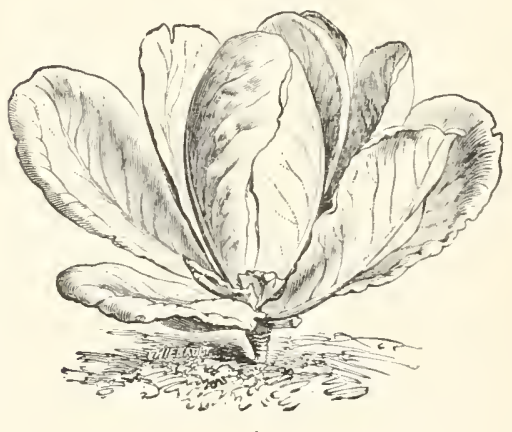

4

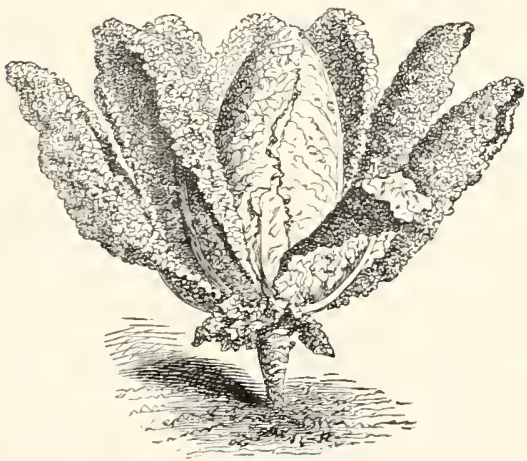

PLATE 5.

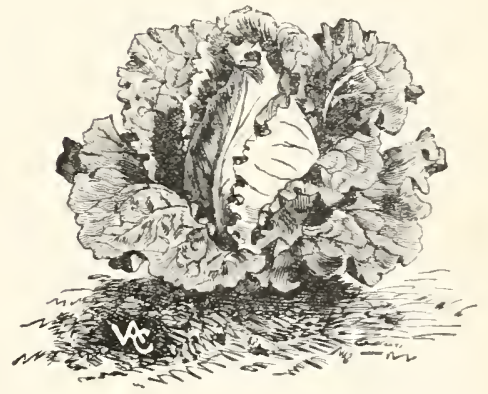



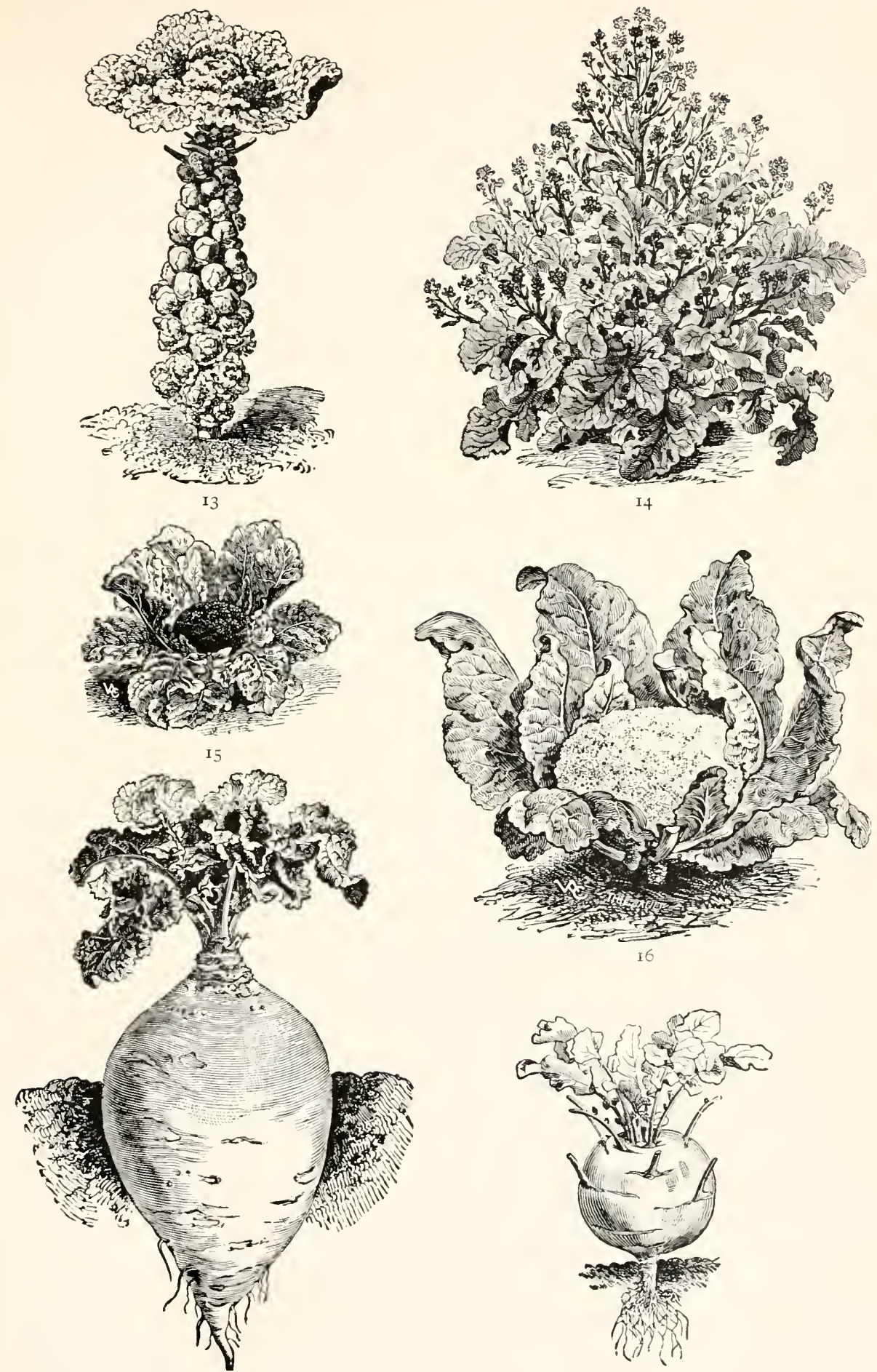

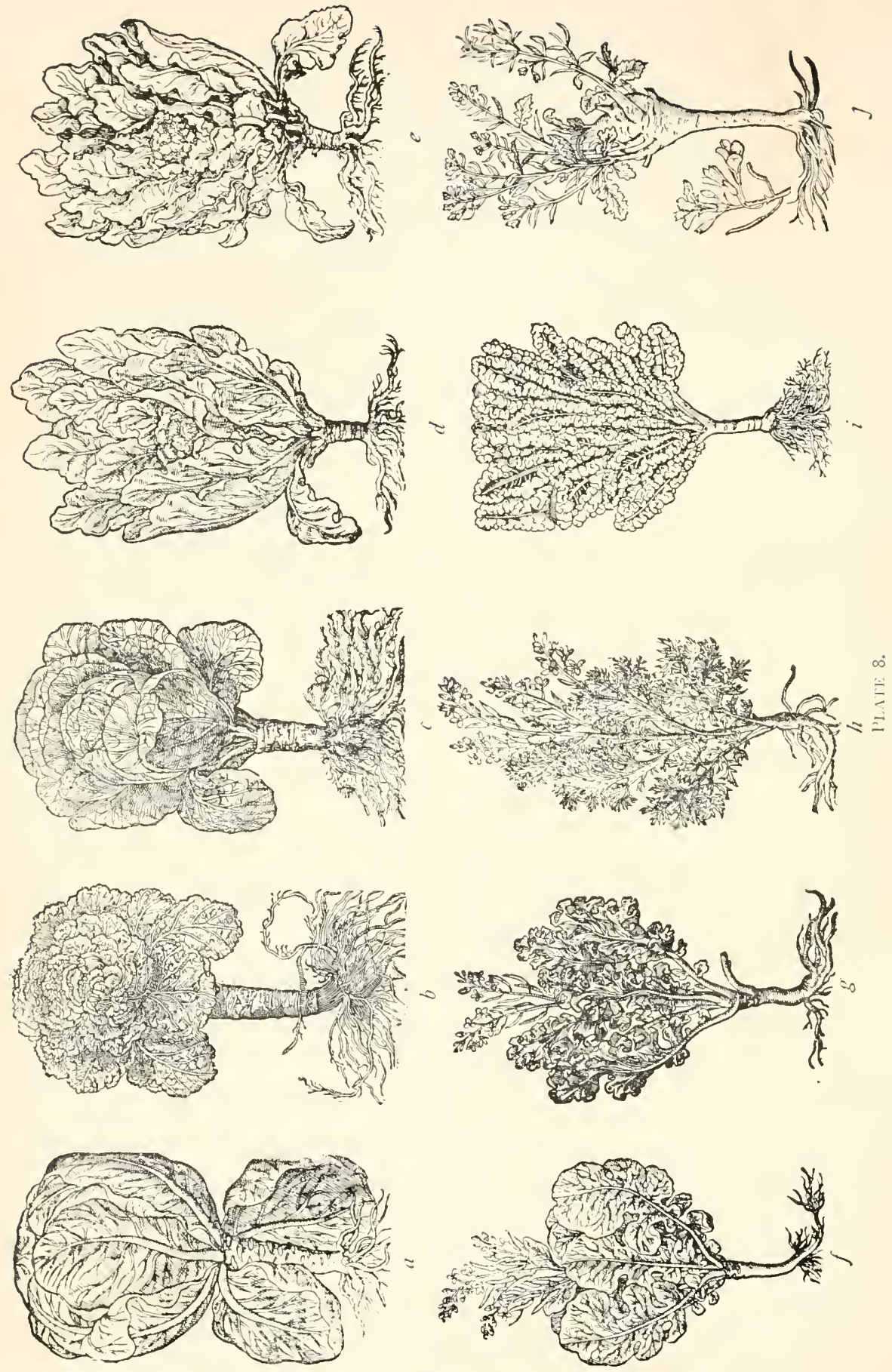
PLATE 8. - Varieties of cabbage, or "colewort," in the latter part of the sixteenth century. $a$. "White cabbage cole" (red cabbage also was known at that time). b. "Open cabbage cole" (head less compact). c. "Savoy cole." $d$. "Curled Savoy cole" (leaves and flowers both developed; head of flowers almost like cauliflower). e. "Cole-florie." ff "Garden colewort" (kale). g. "Curled garden cole." h. "Parsley colewort." i. "Swollen colewort." j. "Round rape cole" (kohlrabi). - From Gerarde's Herball. Comparison with Plates 5, 6, and 7 shows something of the extent of modification in the last three hundred years. 


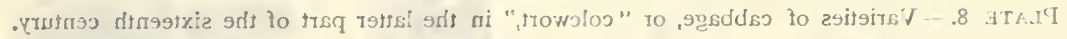

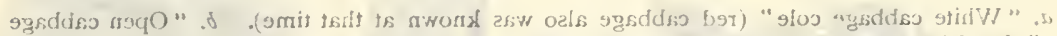

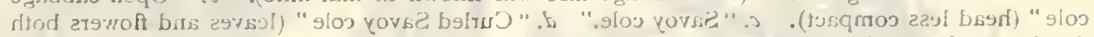

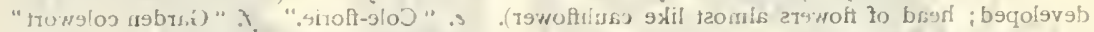

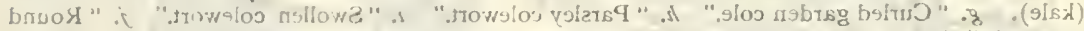

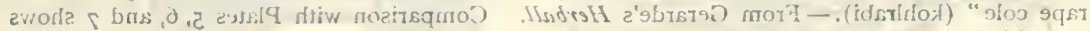

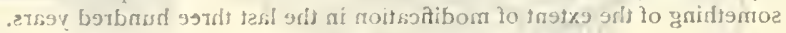



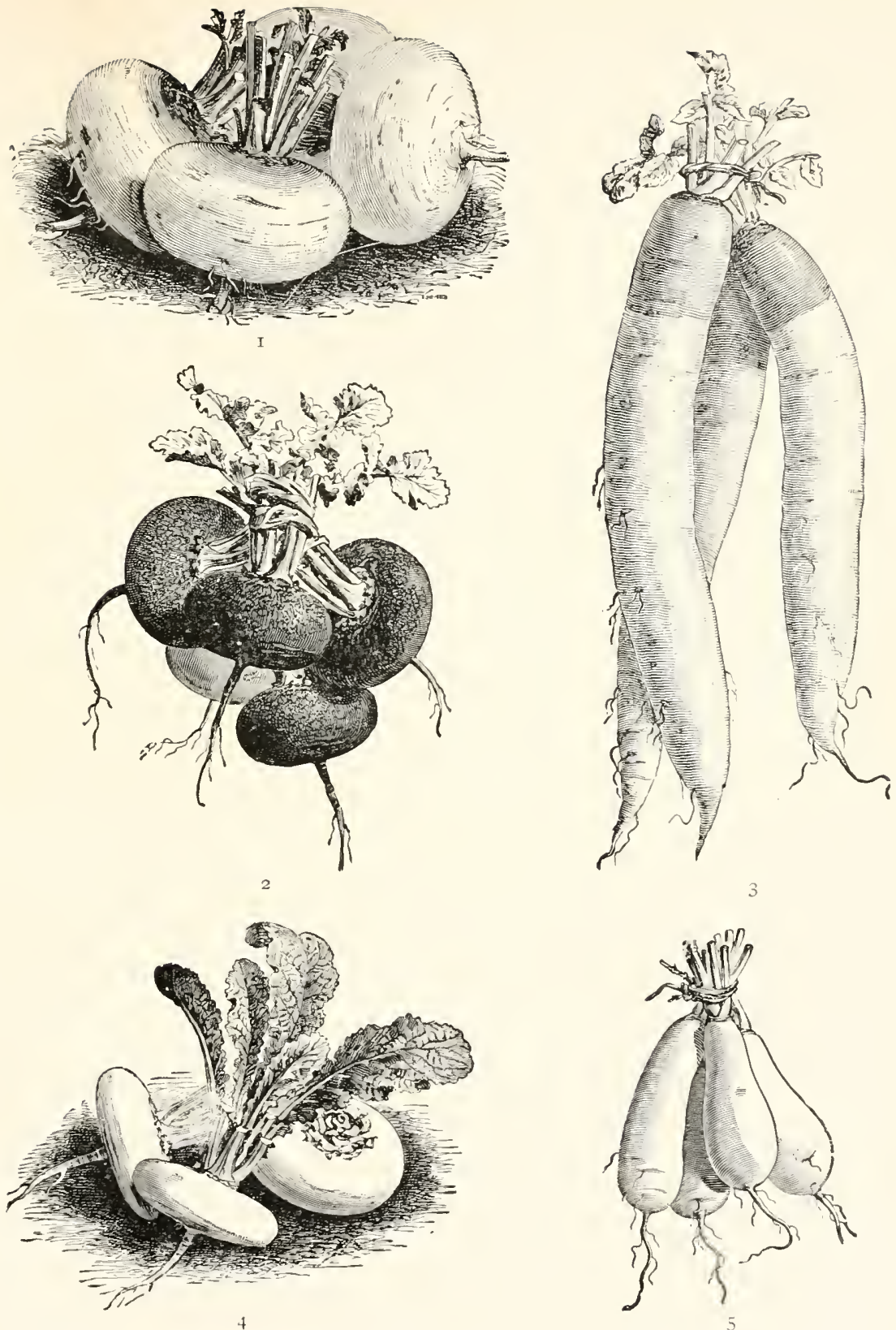

PLATE 9. - Varieties of turnips, all of which have been derived by cultivation from the wild species, Brassica rapus, L., a member of the Mustard Family.

I. "Early stone or stubble," green top. 2. "Chirk Castle black stone," dark purple. 3. "Long, white Meaux or cowhorn," pale green top. 4. "Early, white, strap-leaved American," all white. 5. "Early Vertus or Jersey." Observe how these varieties differ in form. 



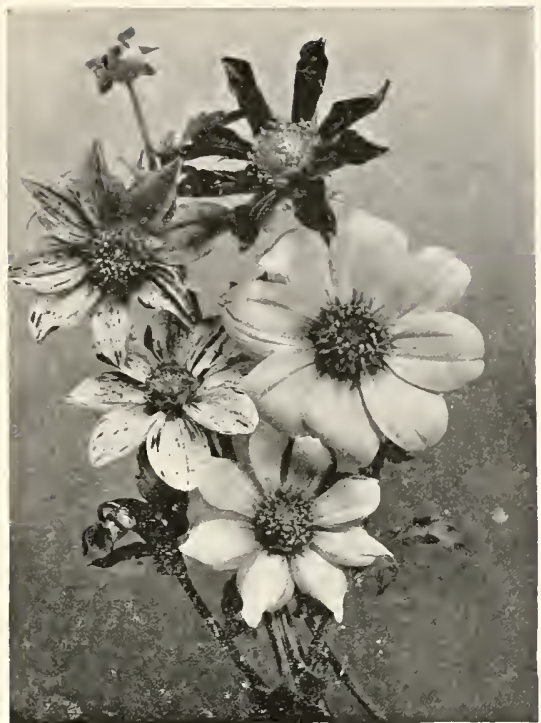

$a$

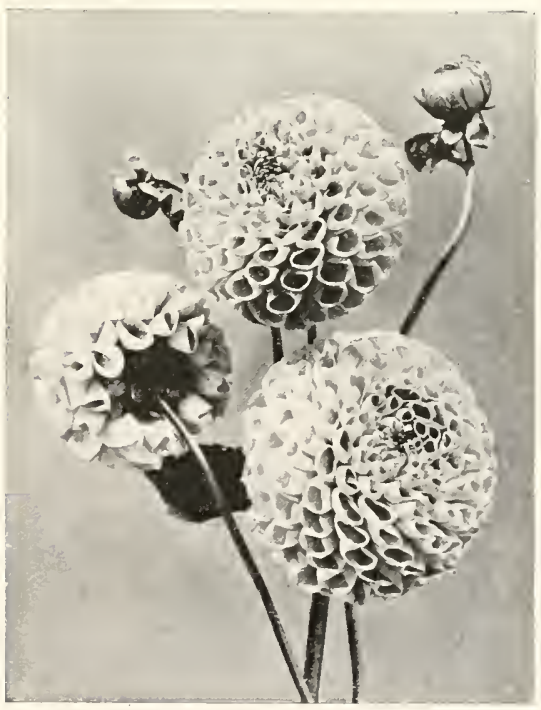

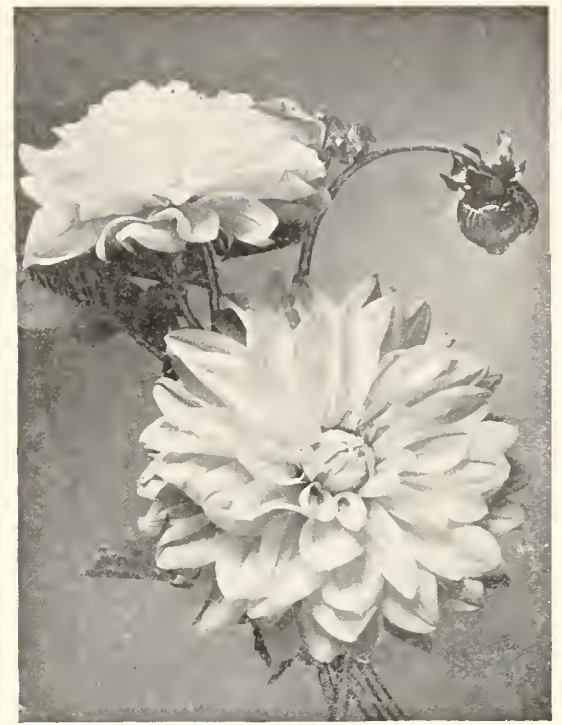

$b$

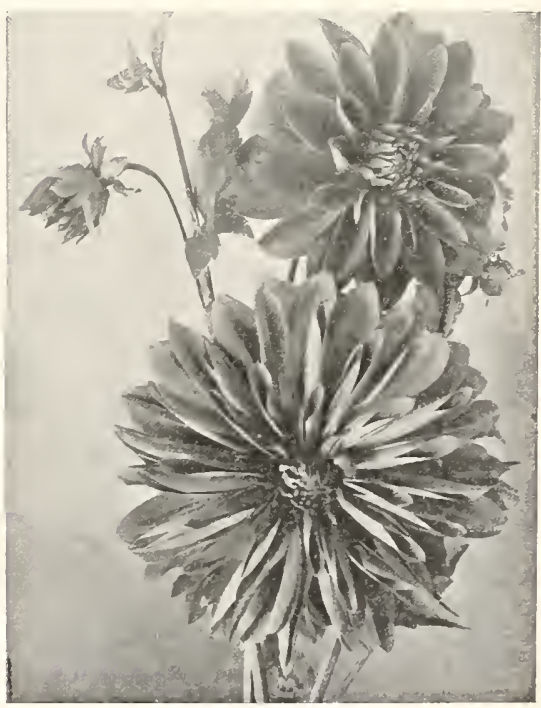

$d$

Plate io. - Varieties of Dahlias.

a. Types of single dahlias. b. "Clifford W. Bruton," a large, yellow dahlia. c. "A. D. Livoni," pink, pompon type. d. A modern form, red. - From Country Life in America, by permission of Doubleday, Page and Co. 



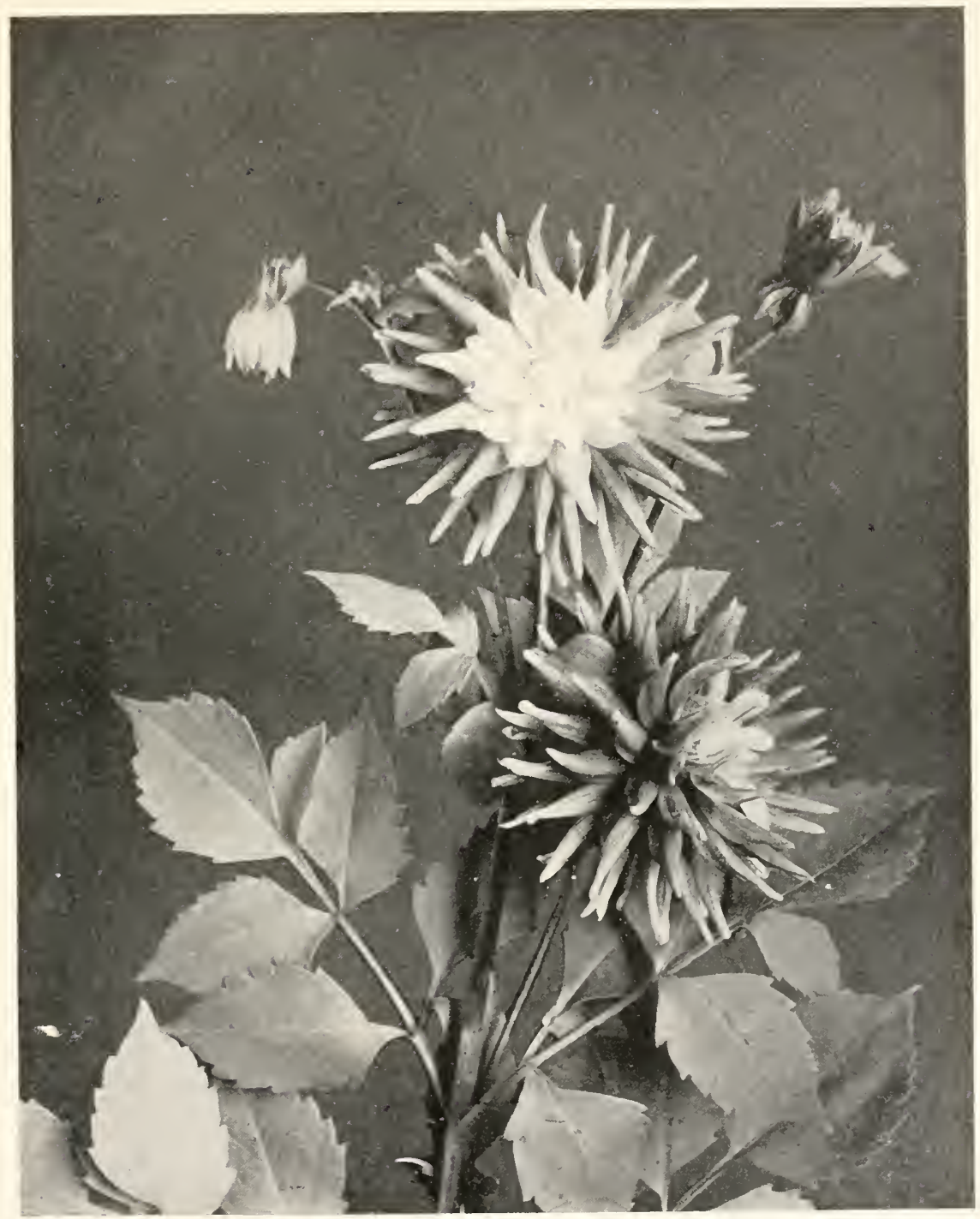

PLATE 11. - A new "cactus" type of dablia. This particular variety is called "Kriemhilde." - From Country Life in America, by permission of Doubleday, Page and Co. 

nal stocks from which they were derived. ${ }^{1}$ Our domestic chickens have been much modified from the jungle fowl, their ancestor: Sheep, cattle, hogs, canary birds, pigeons, and other kinds of domesticated animals show similar modifications of the original stock. Among plants we have more numerous instances; for example, most of our garden vegetables, the many varieties of the cabbage (Plates 5-S), the several sorts of potatoes, peas, lettuce, etc. (Plate 9). Other instances are furnished by the numerous kinds of roses, chrysanthemums, pansies, tulips, sweetpeas, asters, hollyhocks, dahlias (Plates io and I I), and a host of others of our common flowers which show many varieties. Now, as just stated, the methods used by breeders to produce these varieties of the different species of domestic animals and plants are closely similar to the chief method adopted by nature in the evolution of natural species. The breeder, whether of plants or animals, finding in his stock an individual or several individuals which show some desirable quality, chooses these individuals to breed from, and when, among their offspring, he finds some in which the useful quality is especially pronounced, these again are chosen for breeding. The desired character can be intensified by choosing, generation after generation, those individuals in which it is most strongly dereloped, and rejecting the others. The breeder rejects the individuals in which the important quality is weakly dereloped. So also does nature in the process of natural selection. The resemblance between the two processes is very close, and the results are similar. In the case of natural selection we get modification of the original stock

${ }^{1}$ It is probable that domestic horses have been derived from several wild species. 
in such a way as to give more perfect conformity to the environmental conditions; while in artificial selection the modification is such as to make the altered form more perfectly suit the uses to which man wishes to put it. The results of artificial selection are usually more quickly seen; for the selection for breeding purposes of individuals with the desirable qualities is generally more rigid than in nature, where the more and the less adapted forms will for a time breed side by side, the more perfect gradually predominat-

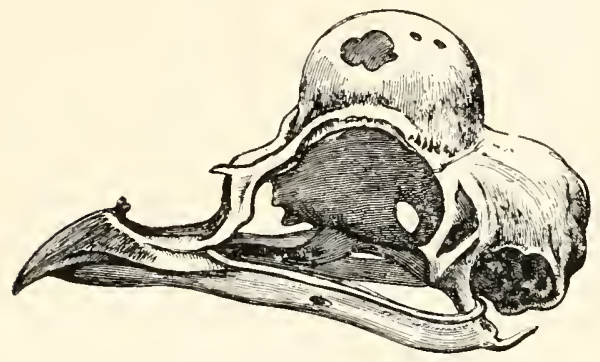

FIG. 5.-Skull of Polish fowl, showing the peculiar knob that has been developed in front of the brain case. - From Wright's Nezo Book of Poultry, by the courtesy of Cassell \& Company. ing more and more.

The extent of the modification produced by artificial selection is very great in many cases. Notice the common domestic chickens, in which the different breeds differ from one another to such a degree that if they occurred in nature the several kinds would be referred not only to different species, but to different genera (Plates I 2-I 9 and Fig. 5). Compare the slender "game" (Plate 12, $A$; 16. $B$ ), which most closely of all resembles the ancestral "jungle fowl" (Plate I6, A), with the heary "Brahma "(Plate I 5, $A, B$ ) or "Cochin-china" (Plate I 5, C, D; I 9, B), or with the long-tailed "Japanese" cocks (Plate I 7 ), or with the little "bantam" (Plate I 4, D; I 9, C). Or notice the varieties of pigeons, as shown in another illustration (Fig. 6; Plate 20).

These races differ from one another anatomically and in disposition as much as do natural species, yet in one important particular they fail to resemble natural species. 


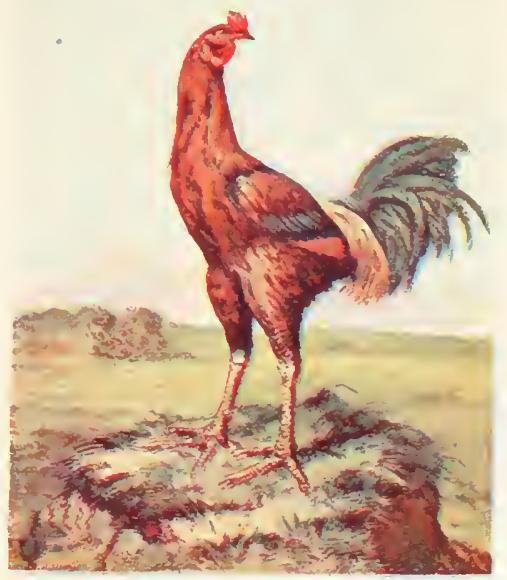

A. Malay cock.

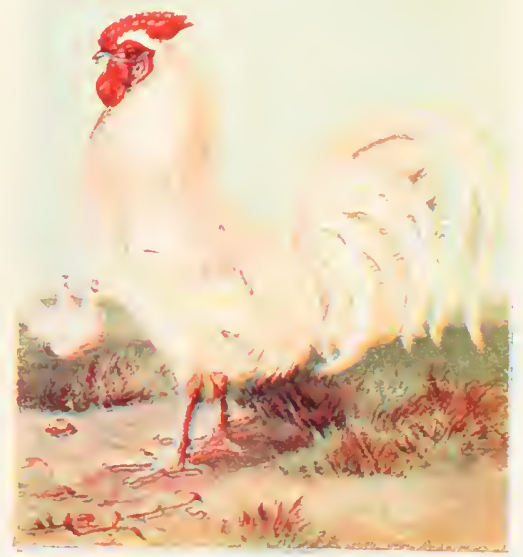

C. White Dorking.

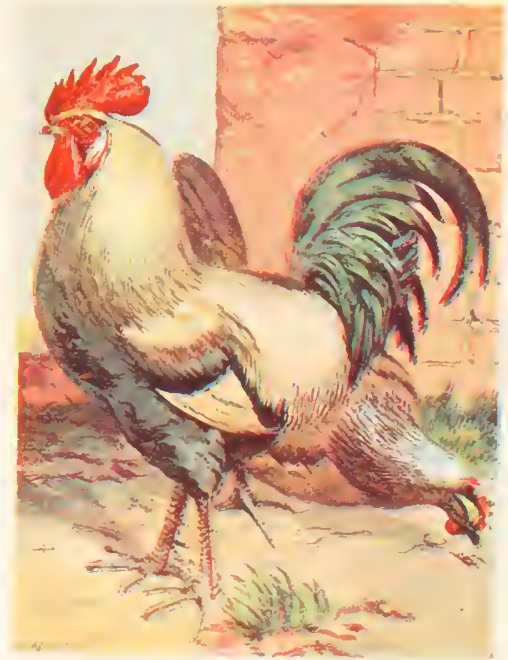

$B$. Colored Dorkings.

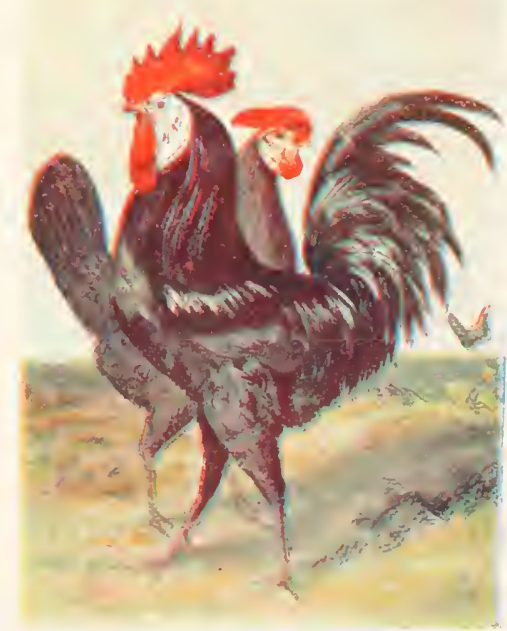

D. Spanish.

Plate i2. - Varieties of Domestic Cinckens. [After Tegetmeier.] 



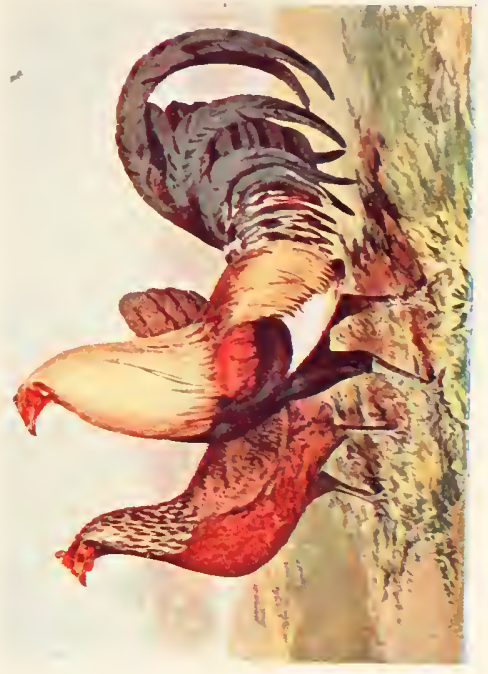

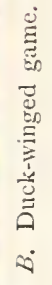

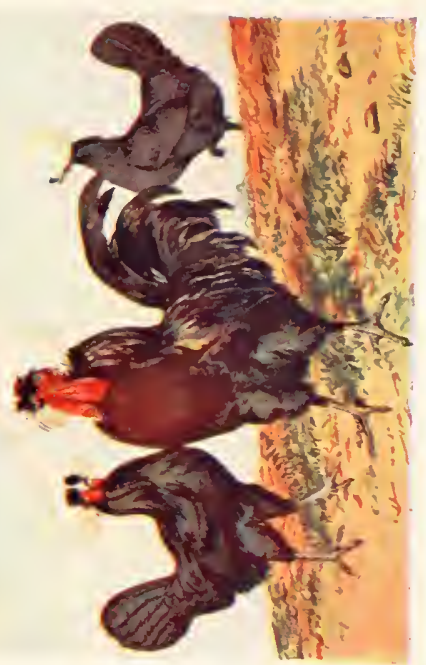

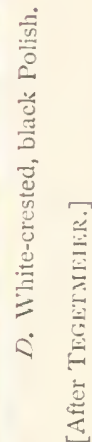
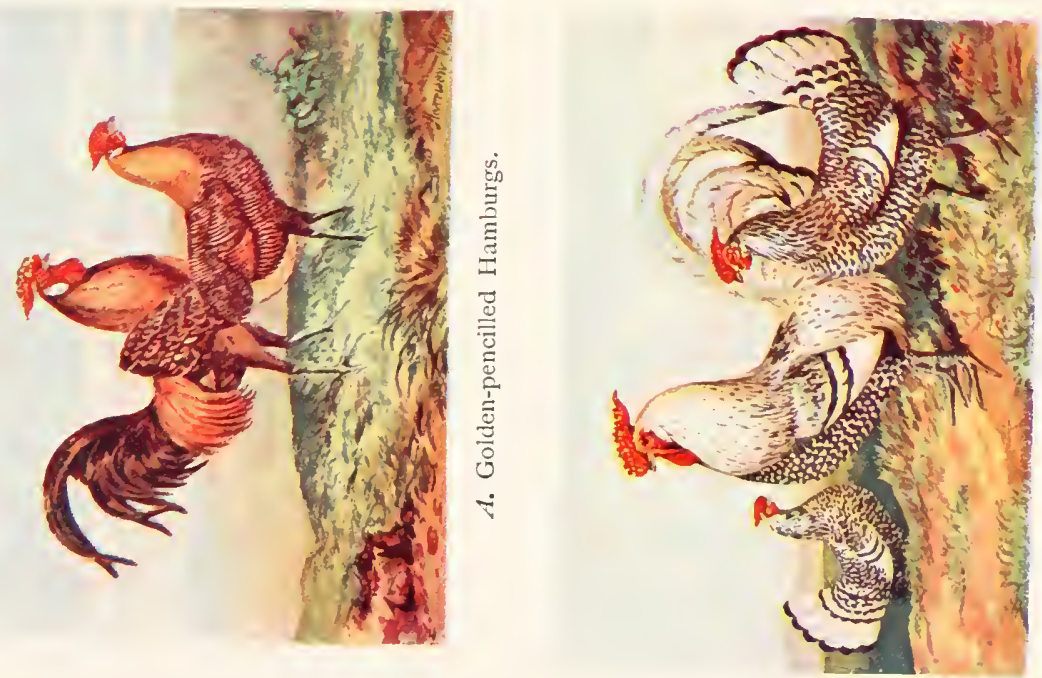



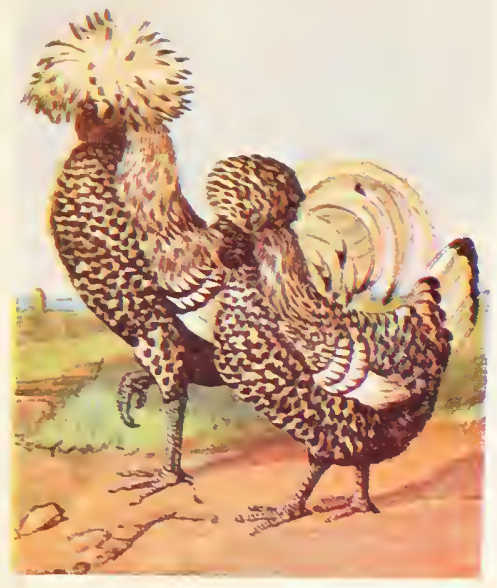

A. Silver Polish.

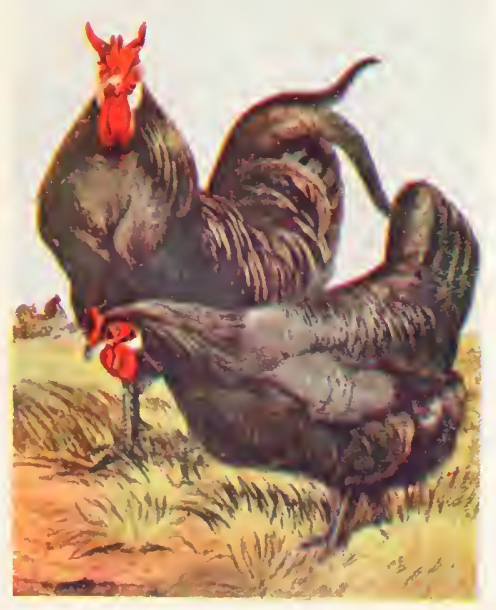

C. La Flèche.

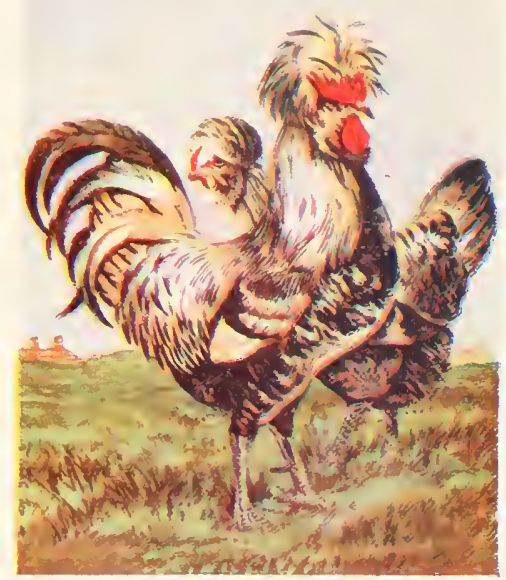

$B$. Houdans.

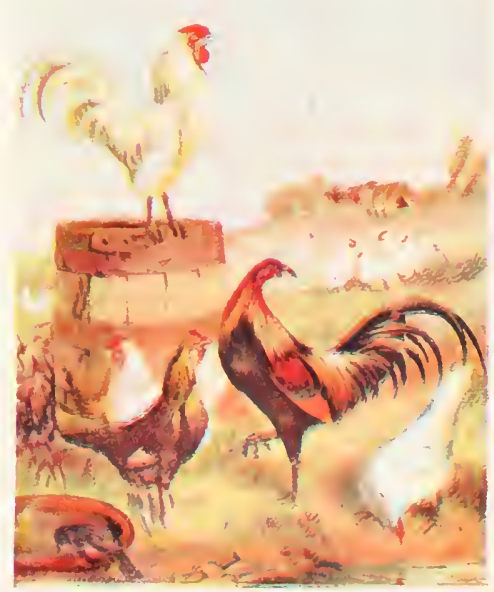

D. White and game bantams.

Plate i. - - Varieties of Domesilic Chickens. [After Tegetmeite.] 



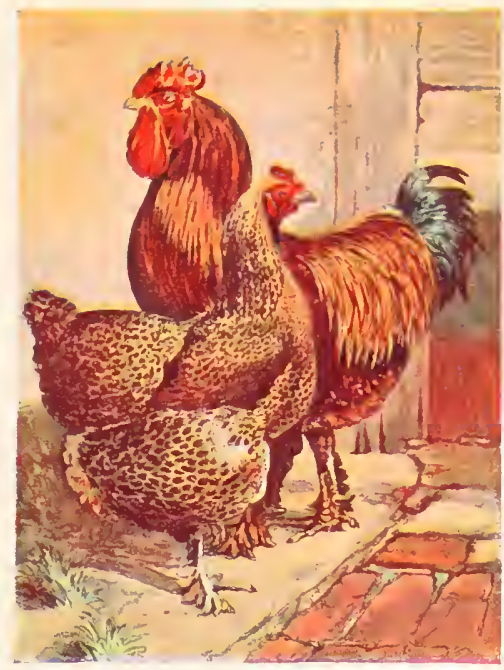

A. Partridge Cochins.

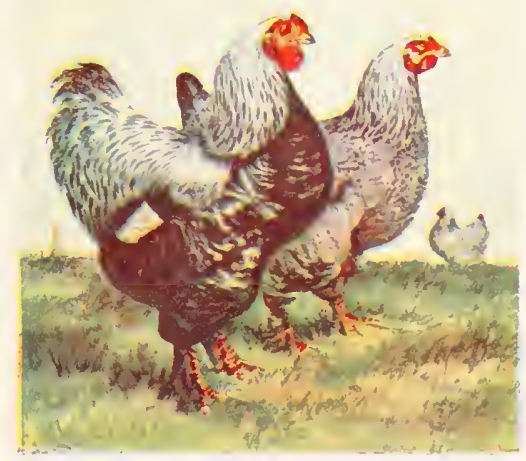

C. Dark Brahmas.

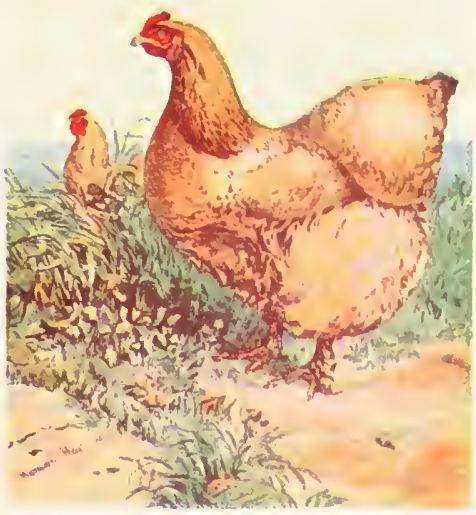

$B$. Buff Cochin hen.

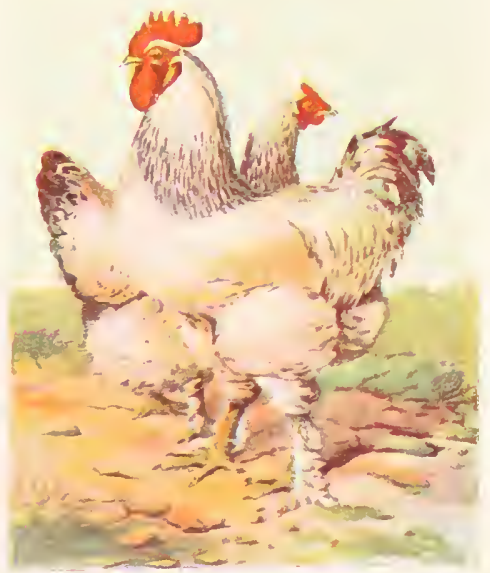

D. Light Brahmas.

Plate i5. - VARiftifs or Domimile Chickexs. [After Tegetmeier.] 


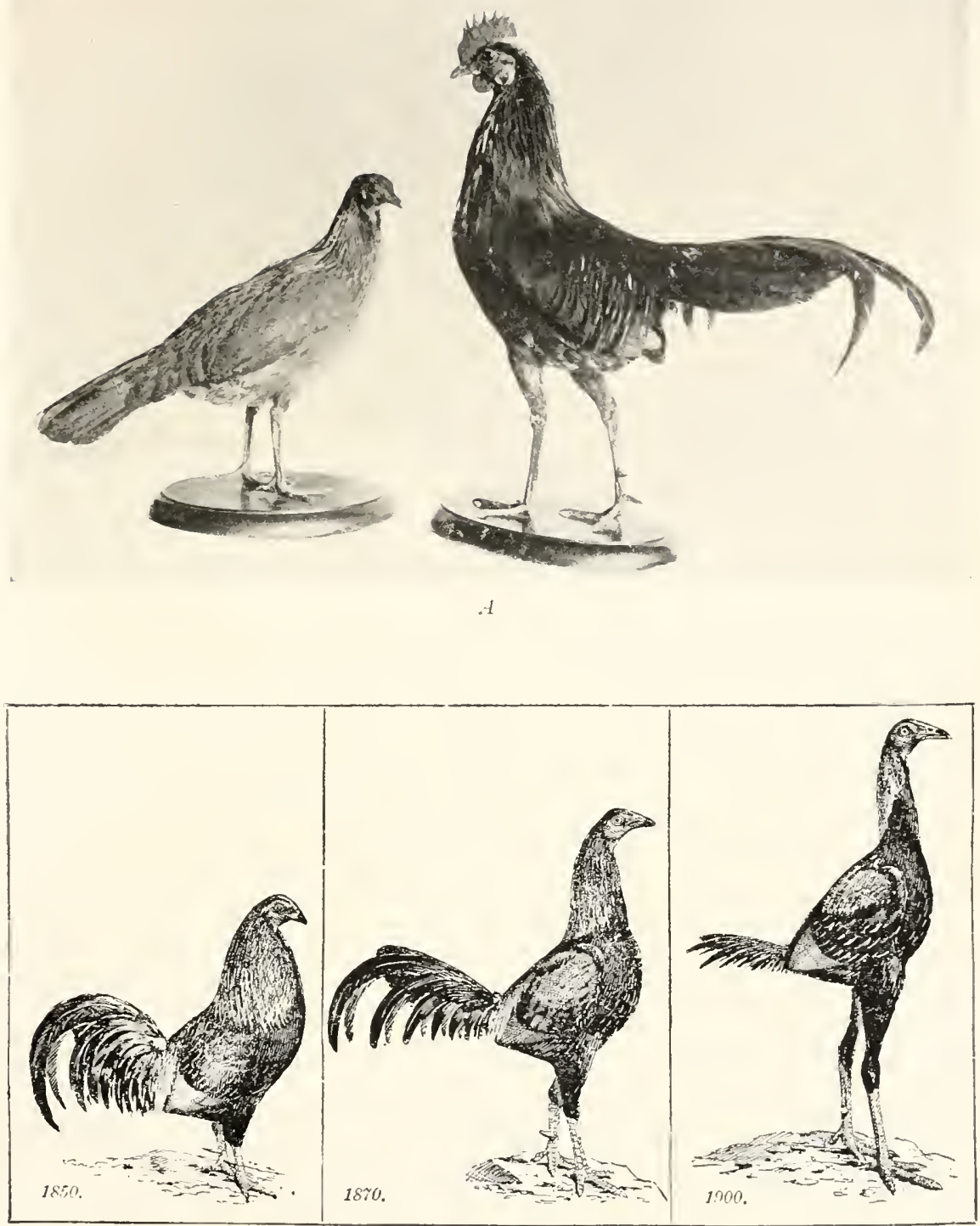

$B$

PLATE, 16. - A. Jungle fowl, cock and hen (Gallus bankiva), a wild species found in southern Asia, from which our domestic chickens have been derived. - From mounted specimens in the United States National Museum, B. The evolution of the game cock, - From WVright's New Book of Poultry, by the courtesy of Cassell and Company. 


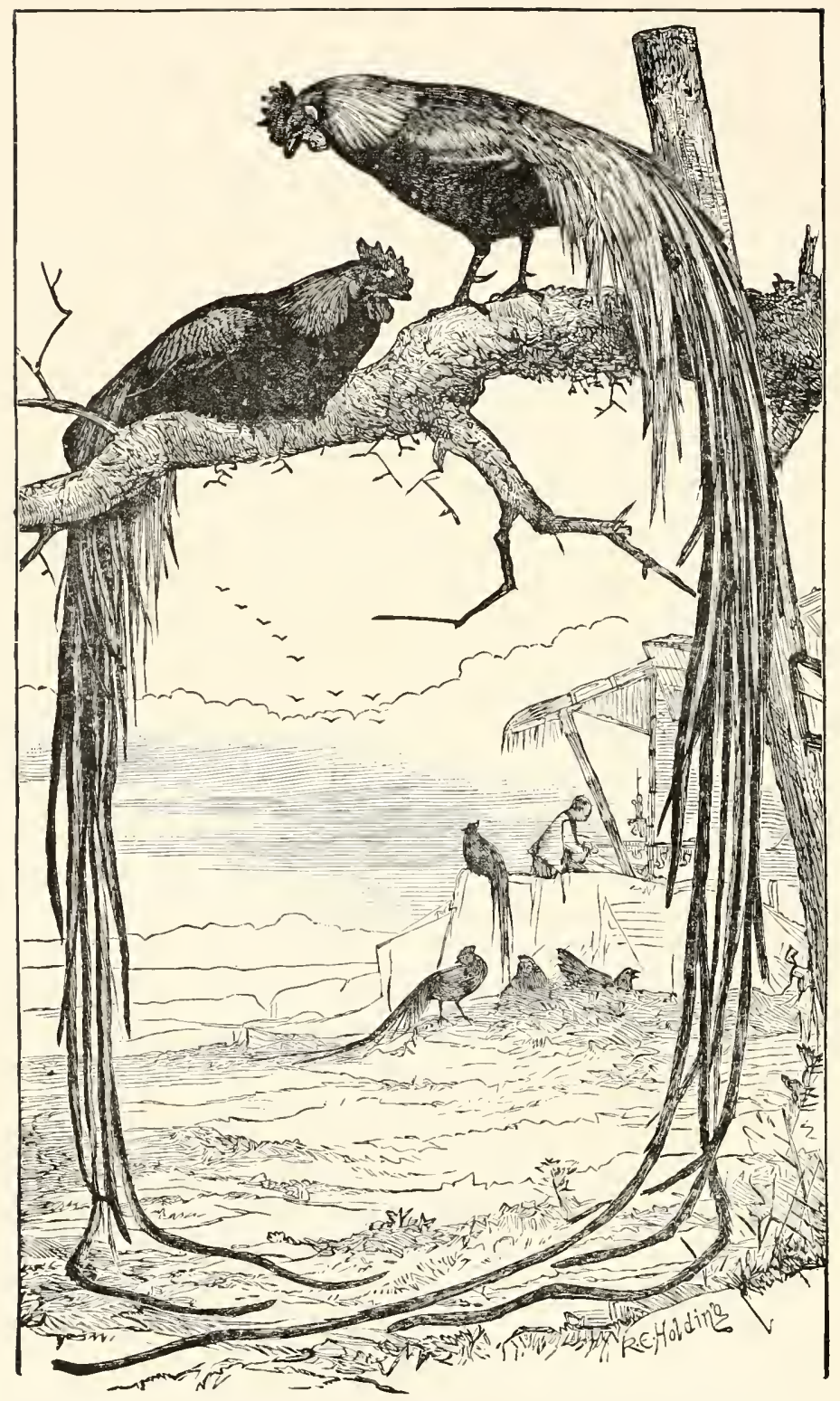

Plate 17. - Japanese long-tailed cocks. - From Romanes' Darwin and After Darwin, by the courtesy of The Open Court Publishing Company. 


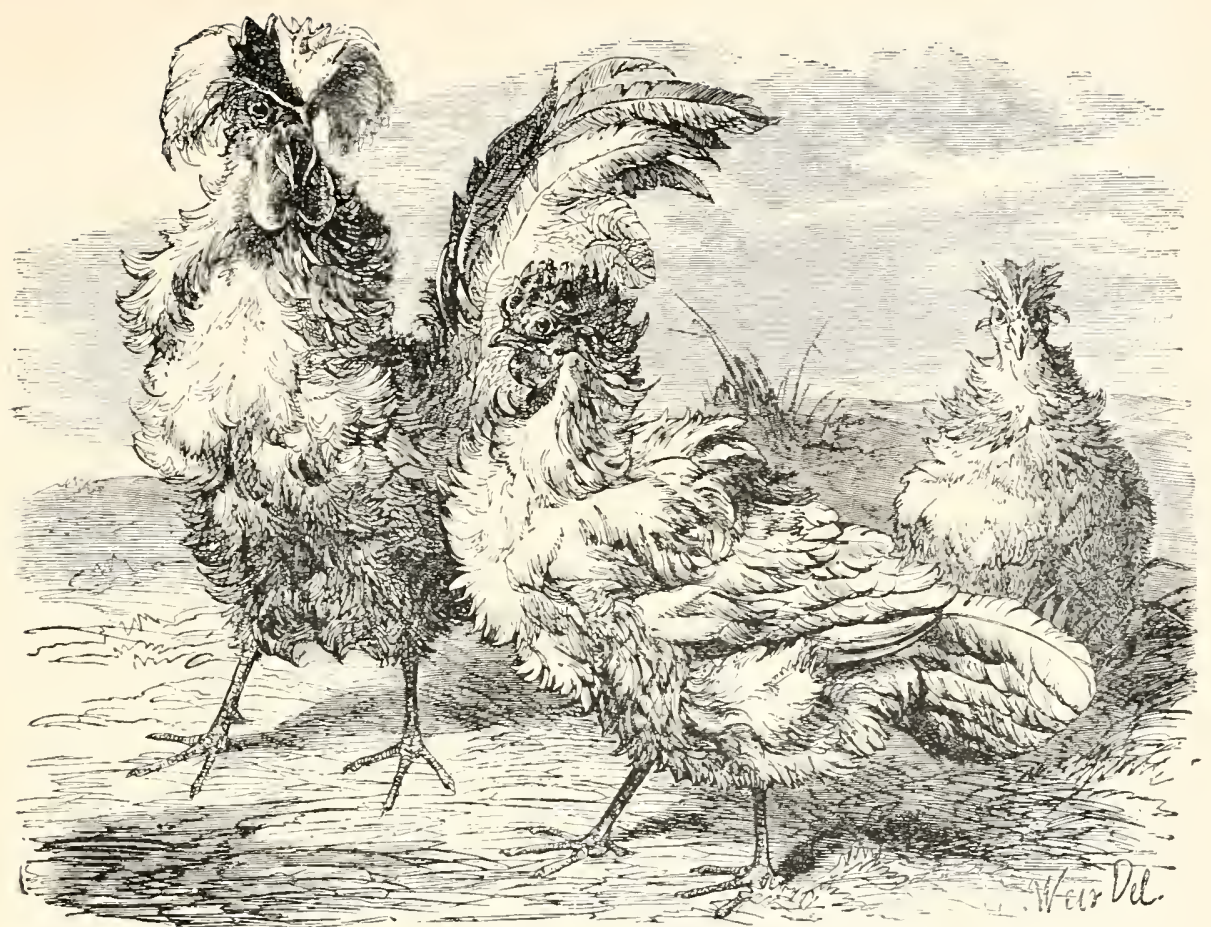

$A$
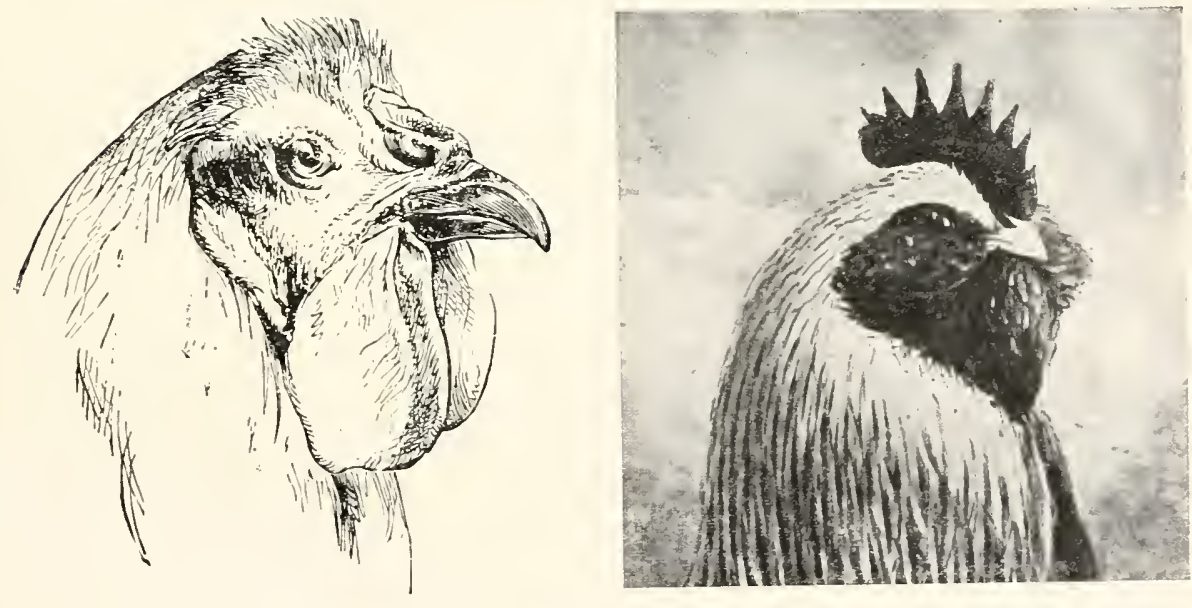

$B$

PLATE I8. - A. "Frizzled fowls." Many different kinds of the ragged-feathered chickens, both bantam and larger varieties, have been bred. [Atter TEMil.MEIER.] B. Head of Breda cock. - From Wright's New Book of Poultry, by the courtesy of Cassell and Company. C. Head of salmon foverolle, showing the peculiar development of the feathers beneath the eyes and the bill. - From Wright's New Book of Poultry, by the courtesy of Cassell and Company. 


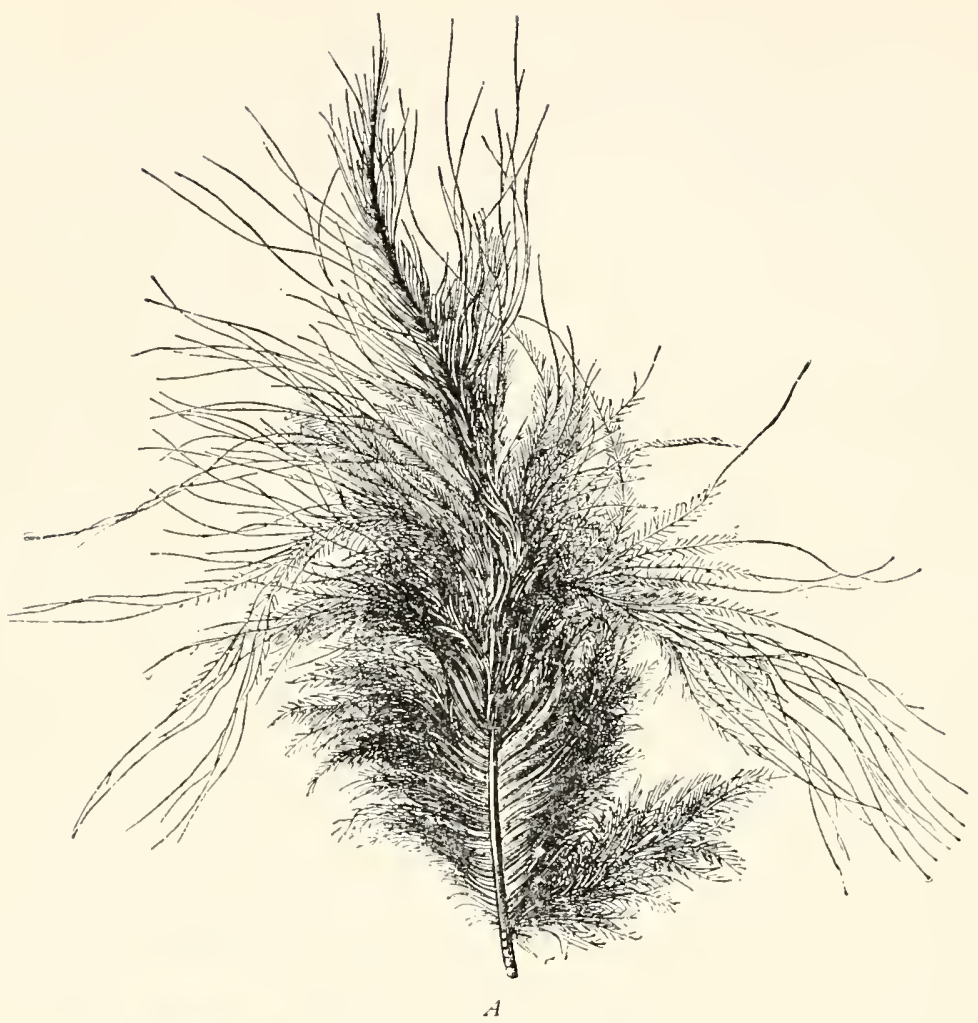

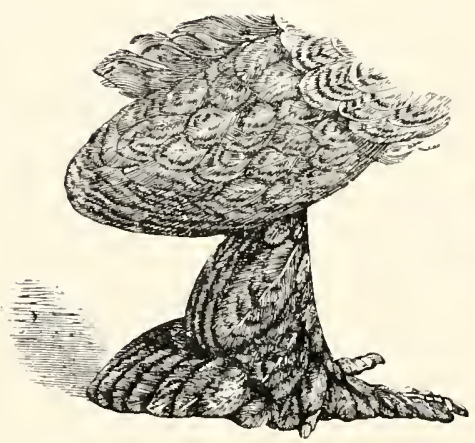

$B$

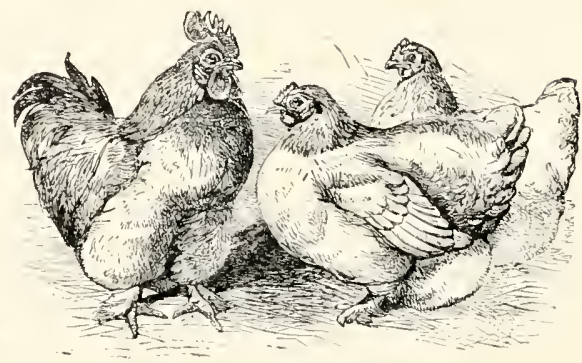

C

Plate I9. - A. A single feather from a "silky fowl." Almost any breed can be obtained with this type of feathers. [After Trgetmeifr.] B. Leg of Cochin cock. All the feathers shown are upon the leg. - From Wright's Neze heok of Poultry, by the courtesy of Cassell and Company. C. "Cochin" bantams. [After Tegetieier.] 


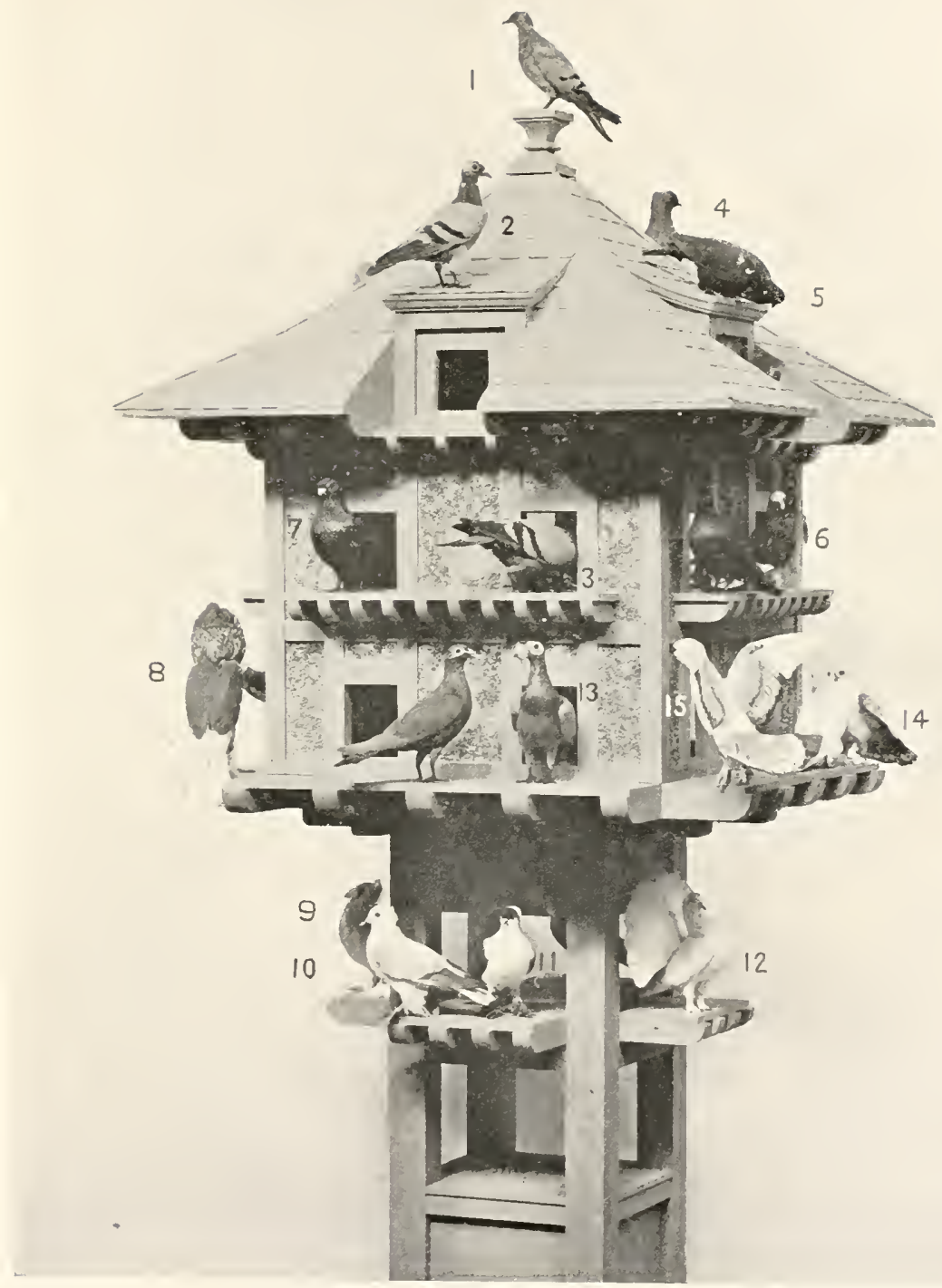

PLATE 20. - VARIETIES OF DOMESTIC PIGeONS.

I. Wild blue-rock pigeon (Columba livia). 2. Homing pigeon. 3. Common mongrel pigeon. 4. Archangel. 5. Tumbler. 6. Bald-headed tumbler. 7. Barb. 8. Pouter. 9. Russian trumpeter. I0. Fairy swallow. II. Black-winged swallow. I2, Fantail. I3. Carrier. It and I5. Bluetts. The bird between $I_{4}$ and $I_{5}$ is a tailed turbit. - From a photograph of an exhibit in the United States National Museum. 

They will often freely intercross in breeding, while, as a usual thing, natural species will not do so. This brings us

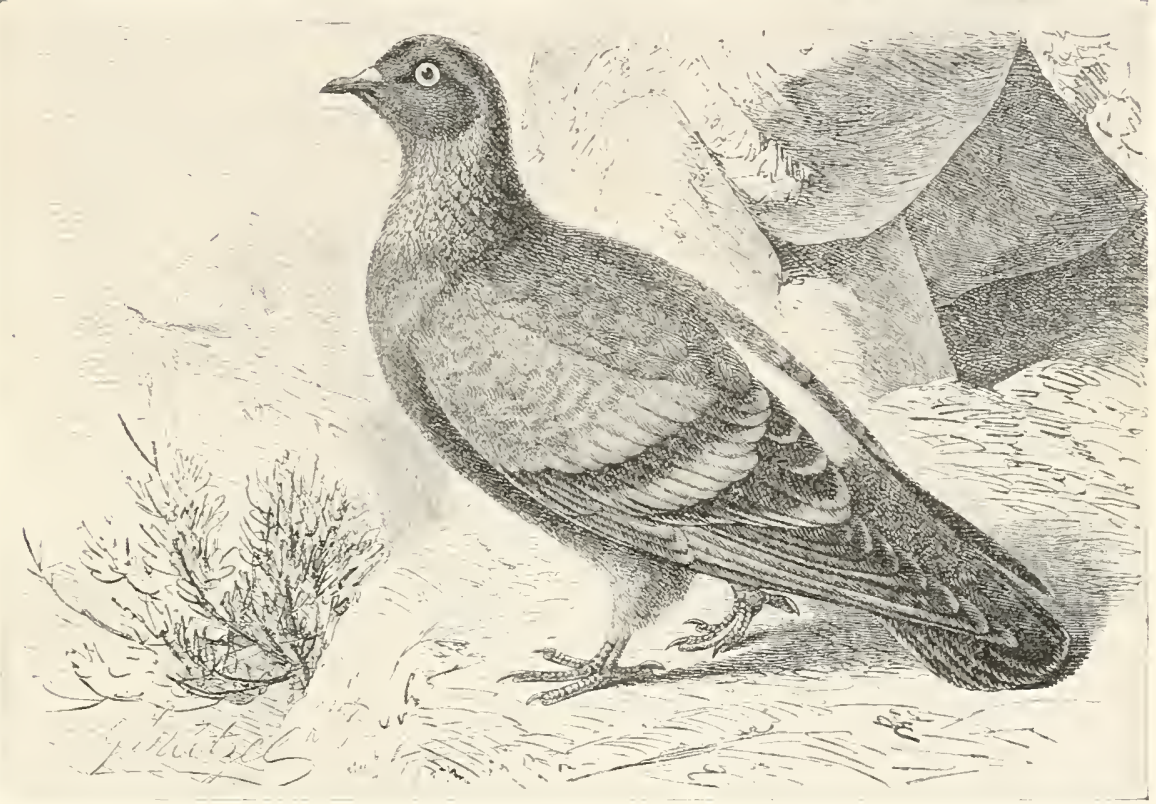

FIG. 6. - The rock pigeon (Columba liaria) of northern Africa, from which the different varieties of domestic pigeons have been derived by artificial selection. - From Brehm's Thierleben.

to a discussion of some of the objections urged against natural selection as a widely effective factor in evolution.

Objections to natural selection as a factor in coolution.

To Huxley the inability of natural selection to produce races which are sterile when crossed, seemed the strongest objection to the certainty of effectiveness in natural selection to produce true species, which in nature are so generally characterized by inability to breed together, or at least by infertility in their hybrid offspring, in cases in which hybrids can be obtained. Doubtless mutually infertile races could be produced by artificial selection if breeders should care- 
fully observe relative degrees of fertility and select as progenitors for the several races individuals which would not readily breed with others than those of their own race. As a matter of fact breeders have not cared to produce infertile races and have not done so. There seems little doubt that they could have done so.

Mutual infertility between certain individuals may often in nature have been the starting-point in the divergence which has resulted in the establishment of new species. This point will be discussed farther on.

Another objection which has been urged against the efficiency of natural selection as a factor in evolution is the fact of the apparent uselessness of some of the characteristics of different species, both animals and plants. If a character is useless how can it have been developed by natural selection, which operates only to perpetuate characters which aid their possessors in the struggle for existence? First let us ask, are useless characters really found? Apparently they do occur, but much less frequently than we would at first thought suppose. Careful study often shows that structures or habits apparently useless are of real value to their possessors. One would find it difficult to give an instance of an organ or characteristic which he is sure is of no value to the plant or animal in which it is found. Yet we could probably find such instances. Many are familiar with the beautiful markings on the shells of diatoms, a group of microscopic Alga, or with the beautifully regular skeletons of many other microscopic animals and plants. These shells and their markings are often of elaborate pattern (Plate 2I); they are regular in their 

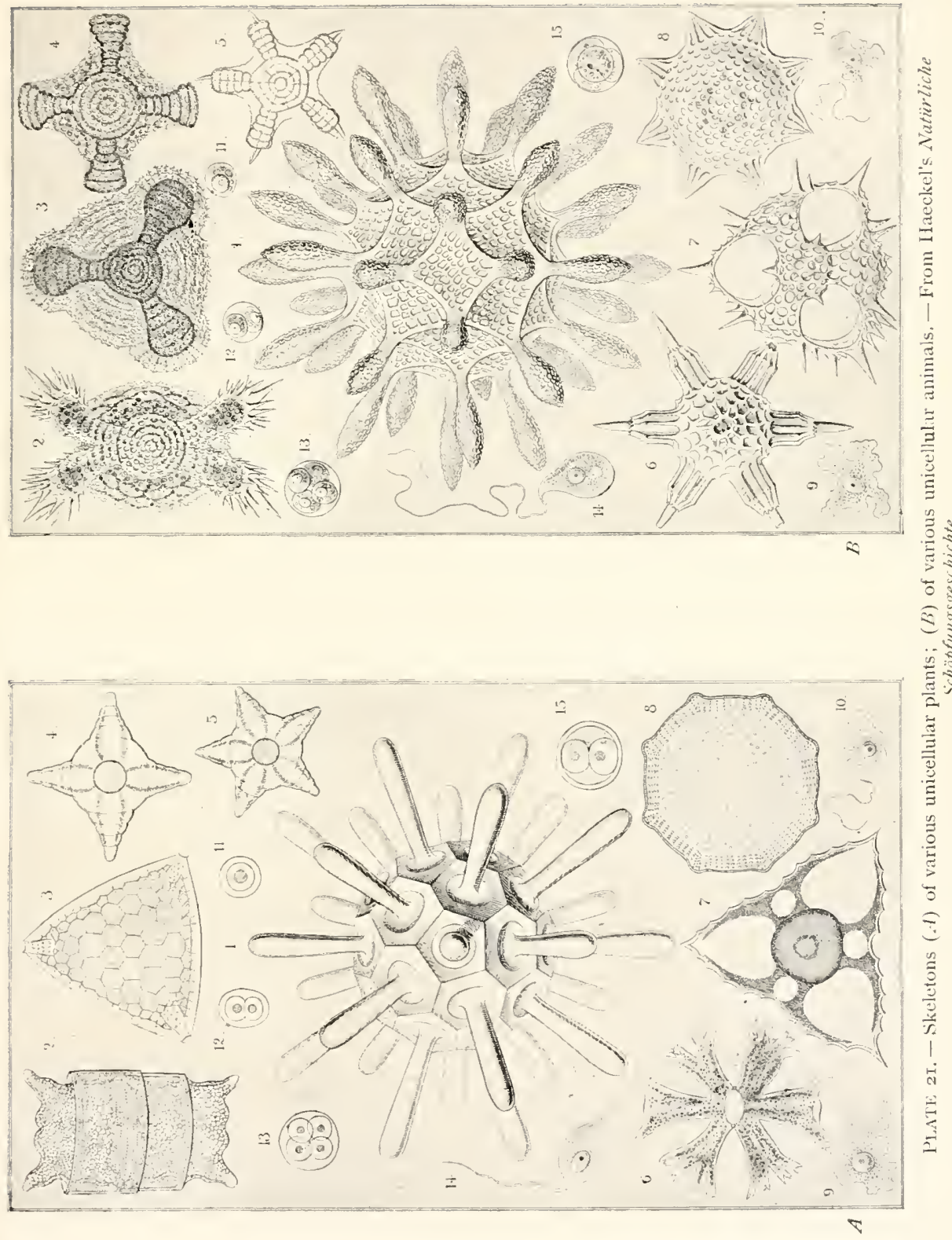

arrangement, and this arrangement is constant for the species. They are, then, true specific characters. Of what possible use can these minute ridges and furrows upon the shell, or the particular arrangement of skeletal spicules, be to these little plants and animals; or why are they more useful if regularly arranged according to a particular pattern; or why is it important that each species should have a pattern peculiarly its own? We cannot satisfactorily answer these questions. We know comparatively little about the details of the life of these species. If we knew more it is possible the explanation of these skeletal characters might appear and we see that they are useful. Much of our inability to show the utility of the apparently useless characters of animals and plants is probably due to our ignorance of the life habit of these organisms.

Yet we may, for the present, grant that certain structures and habits are useless. We must, however, remember that natural selection is not the only factor of evolution, and that, while it develops directly none but useful characters, the other factors give rise to characters that are not necessarily useful. This point will come out more clearly after we have described the action of these other factors.

But, setting this point aside, natural selection may indirectly give rise to features of organization or disposition that are not useful to their possessors. An organism is a very complex thing, with its parts most intimately related to each other. No single structure in the body is independent of the rest. One part acts upon another in ways most remarkable. The intimacy of this interrelation of parts and the complex way in which they react upon and influence 
one another we have lately been able to appreciate more than ever before. There seems to be some reason to believe, though it is not yet proven, that every organ and cell in the body so acts upon every other as to affect its behavior.

This is well illustrated by the effects of extirpation of organs. We do not know what effect the thyroid glands have on the other organs of the human body, but if they be removed or become badly diseased, we find there results a profound disturbance of the functions of other parts of the body, showing that the thyroid glands when present and normal probably exert some influence the absence of which from the body is disastrous. There are many other organs whose functions we do not understand, whose extirpation is seriously injurious. Their influence upon other organs of the body must be very important. The changes which follow the destruction of the organs of reproduction are of especial interest in this connection. In the common domestic chickens the destruction of the testes in a young male prevents the comb and wattles and spurs reaching their normal size, the habit of crowing is given $u p$, the characteristic combative disposition of the male is lost. Likewise the destruction of the ovaries in a young hen makes the comb and wattles enlarge, the habit of crowing may be acquired, and the disposition becomes more pugnacious. Here we have a clear indication that the presence or absence of the reproductive organs influences organs which seemed to casual observation to be unrelated to them, namely the brain (change of disposition), the comb and wattles upon the head, and the spurs on the feet. Probably many other organs of the body are equally influenced in ways not so readily observed. 
Now if the organs of the body are so intimately connected with one another that what affects one may affect also the others, we see at once that changes produced by natural selection in any organ of the body because of the usefulness of such change, might very likely bring about correlated changes in other organs, though these latter changes be not in themselves useful. The secondary modifications would not be directly due to natural selection and so would not necessarily have to be useful. Their connection with a useful modification would be enough to account for their presence. This principle of correlation is undoubtedly of great importance, but it is often difficult to understand the details of its operation in particular cases, since the nexus between the different organs, postulated by this principle, may be so intimate and subtle as to be exceedingly difficult to study.

As a very evident example of correlation think for a moment of the great weight of the antlers of an elk and the great strength required in the ligamentum mucha, the ligament which stretches from the top of the skull along the back of the neck to the vertebra between the shoulders. The strength of this ligament must have increased as the weight of the antlers which it supported increased, the two being correlated. In this instance it is easy to see the nature of the connection between the two structures, and that natural selection has probably produced the correlation. In many cases, however, it is very difficult to understand the relation between correlated structures, as in the case of the reproductive organs and the organs affected by their extirpation in the domestic fowl. Wallace, in his delightful book, Darwinism, says: "In Paraguay, 
horses with eurled hair occur, and these always have hoofs exactly like those of a mule, while the hair of the mane and tail is much shorter than usual. Now, if any of these characters were useful, the others correlated with it might be themselves useless, but would still be tolerably constant because dependent on a useful organ. So the tusks and bristles of the boar are correlated and vary in development together, and the former only may be useful, or both may be useful in equal degrees." If, in case of the boar, the conditions of life became such that increase in the size of the tusks would be useful, there might be developed a race of boars with larger tusks, and at the same time the length and coarseness of the bristles would probably increase, not because better developed bristles are needful in themselves, but because of the correlation between large tusks and coarse, long bristles, a correlation the reason for which we are unable to understand.

In the case of the regular patterns in the skeletons of many unicellular animals and plants, to which we have referred, it is possible, I will not say probable, that the regularity of their arrangement may be due to the constitution of the protoplasm of the cells which form them, to some regular arrangement of the constituent particles of this protoplasm, especially as regards its chemical activity, so that the skeletons will be regular, not because of any utility in their regularity, but because they are each formed by a bit of protoplasm so constituted that, if it is to form a skeleton at all, it must form a regular skeleton. Thus the regularity of the diatom shell may be due to correlation with a kind of protoplasmic structure which is itself useful.

But, though natural selection is a factor in evolution, 
and even if it were, as it is not, the only factor, why should all characters of animals and plants be useful to their possessors? Would not many chance variations be preserved whether they were useful or not? Hurtful characters, of course, would be eliminated, but why should not certain neutral characters persist without reference to natural selection? It is truly a remarkable fact, and one hardly to have been anticipated, that so large a proportion of the habits and structures of organisms are useful to their possessors. On page $66 \mathrm{ct}$ seq. is shown one way in which useless characters may be preserved. [Physiological segregation.]

A third objection urged against the importance of the agency of natural selection in evolution is that certain organs which are useful in their present condition could hardly have been so when beginning to form in the past, or, at least while as yet very slightly differentiated, could hardly have been sufficiently useful to be of "selection value," i.c. to secure the survival of the animals or plants possessing them. This is really a modification of the objection last mentioned. In reply we may say, as we did in the last case, that it is difficult to say what might be the usefulness of the lowly developed organs from which the at present clearly useful organs have come by modification. If it is difficult to determine the usefulness of an organ in a living animal which we can study, how much more difficult it must be to decide as to the usefulness of an organ in an extinct animal, and the early stages in the evolution of organs at present useful were generally passed through in animals or plants of a kind no longer found 
on the earth. Also the principle of correlation between organs is important here. Organs not useful in themselves may be correlated with other organs of great value and be developed and perfected along with these until they reach a degree of development that renders them themselves useful.

There is another important principle that helps us understand the beginnings in the evolution of useful structures and habits. If some organ is to be developed to meet some new need, it is rarely, if ever, formed from a previously undifferentiated part of the organism, but is rather formed by modification of some organ already present, the change in this organ fitting it for a different use, fitting it to meet the new need. Similarly if a new habit needs to be acquired, it is likely to arise as a modification of some previous habit. The different stages in the evolution of an organ may each be useful for a different purpose. In fact it is probable that the organ in its several conditions will serve somewhat different purposes. One can hardly mention an organ in the human body, for example, which has not in this way been changed in its function. The heart was once a simple blood vessel, serving for the carriage of blood, not for its propulsion; the lungs were, in the fishes, the swim-bladder, which became changed into an air-breathing organ as the terrestrial habit was acquired; the limbs in the early aquatic vertebrates probably were used as guides and balancers in swimming and as swimming paddles; later, as the terrestrial habit was acquired, they assumed a form adapted for locomotion on land. Change of function and change of structure go hand in hand, so that the different stages in the evolution of an organ do not all serve the same purpose. Hair was 
derived from delicate cuticular sense organs. The internal ears were probably once represented by minute bristle-like organs in the skin, which probably were organs of touch or for the perception of pressure. Remembering this most important principle of change of function, we find that many apparent difficulties in the way of understanding the origin of structures in the body disappear.

But the chief apparent force of the objection that in their beginnings organs could not have been of use lies in the misconception that variation is very slight and that therefore any organ would first appear as a very slight modification and would progress by minute stages toward a condition in which it could be of use. In reality variation is very considerable, so that a structure at its first appearance may be sufficiently dereloped to be of real importance to its possessor. What has been said of organs would apply as well to instincts and other mental characters.

Individuals which diverge to a very considerable degree from the species average are often called sports. De Vries and some others are inclined to believe that most species have arisen as sports which breed true, handing down to their offspring their own peculiar characters. If this be true, natural selection will still be operative to determine which of these new species shall survive, only those persisting which advantageously conform to the environmental conditions. The derivation of new species from sports has been called by De Vries, "mutation."

A fourth objection, which is related to the latter two, is that in our study of the fossil remains of extinct animals we sometimes find that as we pass from the older to the more 
recent species there is a progressive series of modifications of one or more organs, showing that there has been a gradual, steady change in a particular direction, the several steps in this change being very slight. In the fossil remains which give us the history of the evolution of the horse (Plates 46 and 47 ) we see the gradual loss of the outer toes, and a corresponding increase in size of the middle toe, a gradual increase in length of the molar teeth, and a gradually increasing complexity of the ridges on their grinding surfaces. It has been claimed that the several steps in these modifications are not of enough importance to have given their possessors decided advantage in the struggle for existence, and that their progressive development in these particular directions must indicate an inherent tendency to become modified in these directions. If this progressive modification in the ancestors of the horse be due to some inherent tendency rather than to natural selection acting on a great number of all sorts of variations, selecting only the useful ones, then this casts doubt on the importance of the rôle of natural selection in other cases. May not much of the evolution of which we have evidence be due to similar, not understood, inherent tendencies?

The last and by far the most important objection, which we will mention, to the idea of evolution by means of natural selection is this: It is well known, of course, that, in general, the offspring of any pair of parents tend to be somewhat intermediate in character between the two parents. ${ }^{1}$ Now if

1 This statement needs slight modification, as will appear later when we come to the mention of Mendel's laws in their relation to the persistence of variations (page 4 ). 
a certain favorable variation arise in but a few individuals of a species, it seems improbable that these divergent individuals will breed with one another rather than with the much more numerous non-divergent members of the species. If, however, a divergent individual crosses with a non-divergent individual, the useful character which has appeared in the divergent individual will be less marked in the offspring. In the following generations it would be still more diminished by the same process, until finally it will be entirely lost. This swamping of variations by interbreeding has seemed to some to make the development of new characters by natural selection improbable.

The force of this objection is great. Doubtless many divergent characters are swamped by their possessors interbreeding with those individuals of the species in which these characters do not appear. If it were not for this fact erolution might be much more rapicl. Evolution is slow, and the swamping effect of interbreeding may largely account for the slowness of the process. But while evolution may be retarded by intercrossing, we have no indication that it is prevented.

Two individuals of different species ordinarily will not breed together in a state of nature, though occasionally they will do so; and in those rare cases in which species do cross, the offspring only very rarely are fertile. Nature, by this infertility, has provided against promiscuous interbreeding between species, and has thus prevented the species already developed from being lost by confusion with one another. Does she in some similar way prevent promiscnous intercrossing between the individuals of a single species, and thus secure the perpetuation of favorable varia- 
tions that may arise? There are ways in which she might do so. In what ways may free intercrossing between the individuals of the same species be prevented?

In the first place, self-fertilization is a most effective bar to promiscuous intercrossing and must serve to perpetuate many variations that otherwise might be swamped. This would be more common among plants than among the higher animals, but it could occur among the lower animals, many of which are bisexual. As a rule, however, at least occasional cross-fertilization is advantageous and is often secured either by a reluctance on the part of the sperm to fertilize the ova of the same individual, as is the case, for example, in most flowering plants, or by the sperm ripening either before or after the eggs of the same individual, so that self-fertilization cannot occur. Yet self-fertilization does frequently occur among both animals and plants, and when it does occur it may allow certain variants to persist which would be likely to be swamped by cross-fertilization.

Interbreeding between near relatives is another thing that serves to perpetuate and intensify new characters which may appear. This is the same thing which among domestic animals and plants is called "breeding in and in" and is a most effective method in artificial selection. Similar interbreeding between near relatives among undomesticated forms will often be helped by the fact that the individuals of any species in a limited locality are likely to be closely related. An insect, for example, lays its eggs on a certain food plant. When these hatch it is very probable that the males and females in the brood will mate together and so hand down unimpaired to the offspring of the second generation the characteristics they received from their parents. Among sedentary ani- 
mals and plants, and among those that are restricted to a limited locality, breeding in and in, or breeding between near relatives, must be frequent or even usual. An occasional cross with some individual less closely related will be sufficient to aroid deleterious effects from the close inbreeding.

The influence of locality will sometimes serve to hinder swamping of variations by free intercrossing. The environmental conditions are frequently not uniform throughout the whole range of a species. Take as an example a species of plant which spreads over a wide area, part of which is moist bottom-land, and part drier upland. If the individuals of the species vary in their adaptability to conditions of moisture and drouth, as they almost surely would do, some being better fitted for life where moisture is abundant, others for life in drier soil, then natural selection would, in each generation, eliminate from the bottom-lands a large proportion of the plants best fitted for dry soil, and, conversely, would destroy on the dry hills a large proportion of the individuals adapted to wet soil. Thus in each locality, in each generation, the chances would be greater of like breeding with like than with unlike. Natural selection, acting on each generation separately, would in this way raise a bar to free intercrossing of all variants in the species and would create a probability of like breeding with like that would materially increase the cumulative effect of natural selection from generation to generation.

Variations in the time of breeding act as a direct bar to free intercrossing between the members of a species, those which mature their reproductive products at different times being, of course, by this fact, prevented from interbreeding. In this way differences in breeding season 
might soon become definitely established in two groups of the species, making a constant distinction which might become a specific character. Now, as no part of an organism varies independently of the rest, there would doubtless, in establishing the two groups which differ in time of breeding, also be established as constant certain other characters associated with the difference in breeding time.

Among some of the higher animals sexual selection, that is, the exercise of choice in mating, prevents promiscuous intercrossing and so may serve to preserve from swamping certain divergent characters which may be associated with such choice. To this point we will refer again.

Anything which divides a species into groups will be likely to prevent free intercrossing, and so tend to preserve characters associated with the different groups. ITe will come back to this point soon.

The recently rediscovered work of Mendel has a bearing upon the question of the persistence of variations. Mendel showed a half-century ago, and recent workers have more fully established, certain facts of heredity in the case of hybrids between distinct species, and crosses between widely divergent varieties of the same species. Castle's work in breeding mice, which closely agrees with Mendel's observations, shows the point clearly. Castle bred white mice and common gray mice together and got the following results. The offspring developed from the first cross were all apparently normal gray mice. When, however, a male and female from this first lot of young were bred together very interesting results were obtained. Three-fourths of the young of this second lot appeared to be normal gray mice, but one-fourth were found to be 
pure white mice. If two of these white mice were bred together they had white offspring, and the same was true in breeding again from their young, generation after generation, showing that they were of pure strain without admixture from the gray variety, though the original parents in the first cross were one gray and one white. It is of great interest to note that, in spite of the crossing of the two varieties, there appeared in the later generations certain individuals which were of pure blood, showing no trace of the admixture which we would expect to find resulting from the cross. Extensive experiments in breeding showed that the results were to be interpreted as follows: a gray mouse, $G$, bred with a white mouse, $I^{\prime}$, gave offspring which seemed to be all gray, but were really a mixture of gray and white, the gray character being dominant and the white character obscured, or "recessive," as Mendel called it. That is $G \times W$ gave $G(I V), G(I V), G(I V)$, etc., the parenthesis indicating that the white character was recessive. This hidden complex nature of the second generation (the young from the first cross) was clearly indicated when they were bred together. It was found that their offspring were of three sorts, and that these three kinds were in definite and constant numerical proportions. $G(W) \times G(W)$ gave offspring I $G+2 G(W)+$ I $W$, one-fourth being pure gray, onefourth pure white, and one-half apparently gray, but really, as further breeding showed, gray and white, the white character being recessive and obscured. These numerical proportions held true for an extensive series of experiments in the case of white mice, as they had done in the experiments of Mendel upon certain plants. 
We do not care here to discuss in detail the Mendelian laws, their cytological explanation, and the exceptions to them, though these subjects are most interesting and important. We are chiefly interested, in the present connection, in the fact that if the individuals crossed be sufficiently divergent the result is not a mere admixture of the qualities of the two parents in the young, but that individuals of pure strain, showing no admixture, appear in the third generation and in succeeding generations. Very divergent individuals which arise by variation are commonly called "sports." It is easy to see that if a single brood of sports arose which were especially well adapted to their environment, although they might breed with non-divergent individuals of the species, yet among the offspring of the third generation there would be individuals like the original sports. It might, therefore, be possible for natural selection to change the character of the species from the old type to that of the sport, by preserving the sports and allowing them by competition to destroy the individuals of the old type. Should the sports prove to be more fertile when crossed with one another than when crossed with individuals of the old type this would increase the probability of the new type becoming predominant.

It may be that less divergent characters also may be preserved from immediate swamping by intercrossing, but it is too early in our study of the Mendelian phenomena for us to be able to say. We do not know whether the Mendelian laws apply at all to ordinary varieties or only to sports. If they apply to ordinary varieties of course the possible effect upon evolution would be greater.

We should also note that in the experiments of Mendel, 
and of others who have followed him, the results stated above were not without exception. For example, Castle found that a certain proportion of the mice resulting from the first cross of a gray with a white mouse were not gray, as we would have expected according to Mendel's laws, nor yet white, but were a dappled gray and white. In such a case there was a true mingling of the characters of both parents in the young, neither set of characters predominating.

Enough has been said to show that interbreeding between the different individuals of a species is not promiscuous and wholly indeterminate, and therefore the favorable varieties preserved by natural selection from among the individuals of any generation will not necessarily be swamped when these divergent forms come to breed. We will return to this subject again. The phenomena of organic nature seem to indicate very clearly that erolution has taken place, and the evidence points strongly to natural selection as a real factor and apparently the chief factor in this evolution.

But natural selection is not the only factor in evolution. Reference has already been made to sexual selection and segregation, and besides these there is still another important factor, the inheritance of parental modifications. Let us consider these.

\section{SEXUAI, SELECTION}

By sexual selection, as we will use the term, is meant the exercise of choice in mating. ${ }^{1} \quad$ Among plants and lower animals, if cross-fertilization occur at all, propinquity at the

1 Those familiar with Darwin's writings will recognize that I use the phrase sexual selection in a more limited sense than does Darwin, following rather the usage of Wallace. Lloyd Morgan, and others. For example. Darwin includes under 
time of reproduction is usually the thing that determines which individuals shall mate with one another. Of preference or choice, of course, there is nothing. But among some of the higher animals there is evidence that individual choice is exercised in the selection of mates. Breeders of domestic animals find that the females sometimes prefer certain mates rather than others. To quote Lloyd Morgan: "Professor Low, one of the greatest authorities on our domestic animals, says, "The female of the $\log$, when not under restraint, makes selection of her mate,' and again, 'The merino sheep and the heath sheep of Scotland, if two flocks are mixed together, each will breed with its own variety.' Mr. Darwin has collected many facts illustrating this point. One of the chief pigeon fanciers in England informed him that, if free to choose, each breed would prefer mating with its own kind. Darwin was informed by the Rev. W. D. Fox that his flocks of white and Chinese geese kept distinct." Many other instances of preferential mating could be mentioned among domestic animals. To some further illustrations we will refer in connection with the description of segregation. Among wild animals, also, choice of mates can be observed. Phenomena which are often explained by sexual selection are found in some kinds of insects, among spiders, and among fishes, Amphibia, reptiles, birds, and mammals. Among humankind sexual selection is, of course, an important factor in evolution.

The birds give us some of the best examples of sexual

sexual selection the fighting between the males for the possession of the female, though this may have no connection with any exercise of choice on the part of the female. I would include this rather under natural selection, restricting the term sexual selection to the voluntary choice of mates by either the female or the male. 


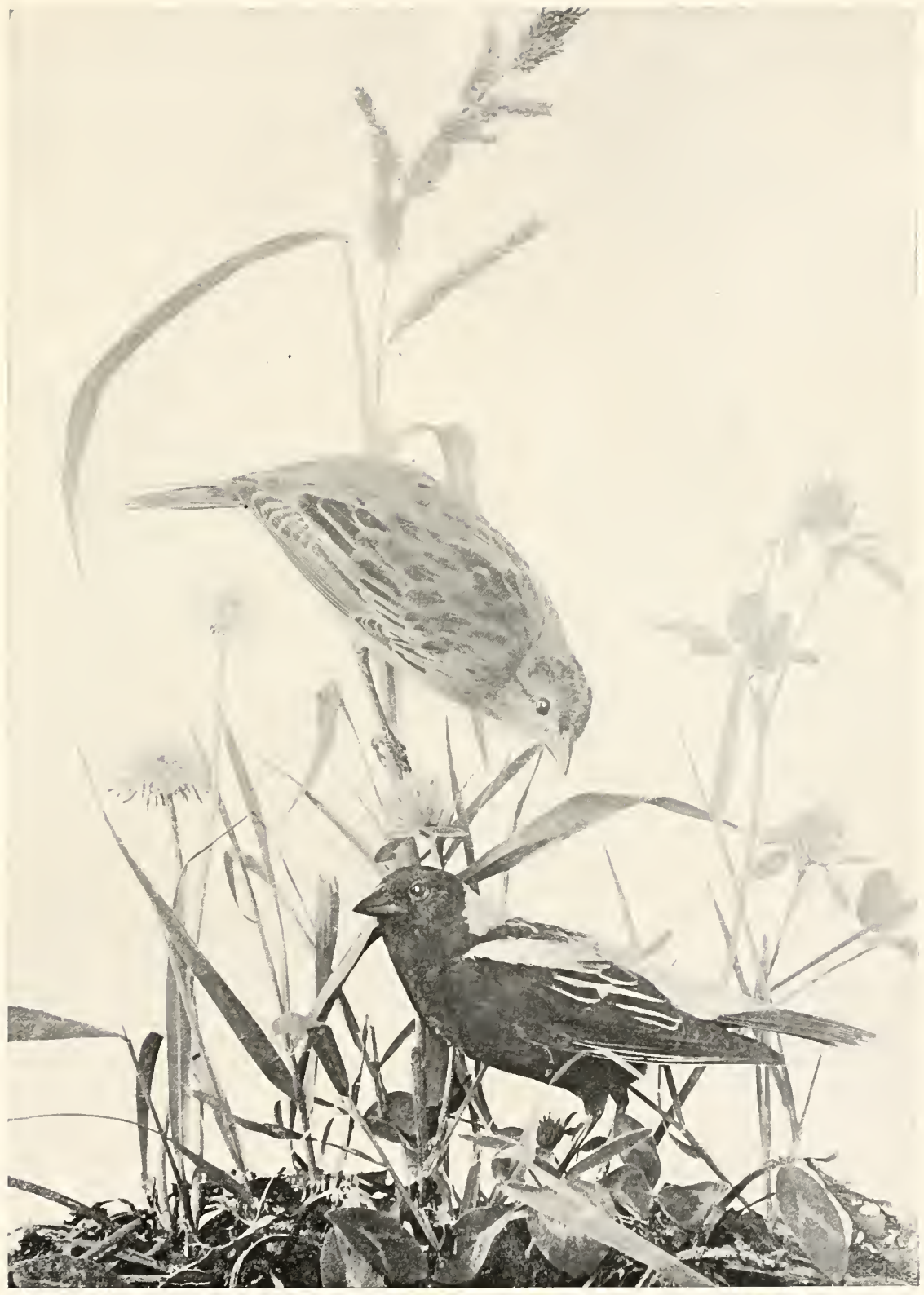

PLATE 22. - Male and female bobolink (Dolichonyx oryizivorus). - From a photograph provided by the American Museum of Natural History. 



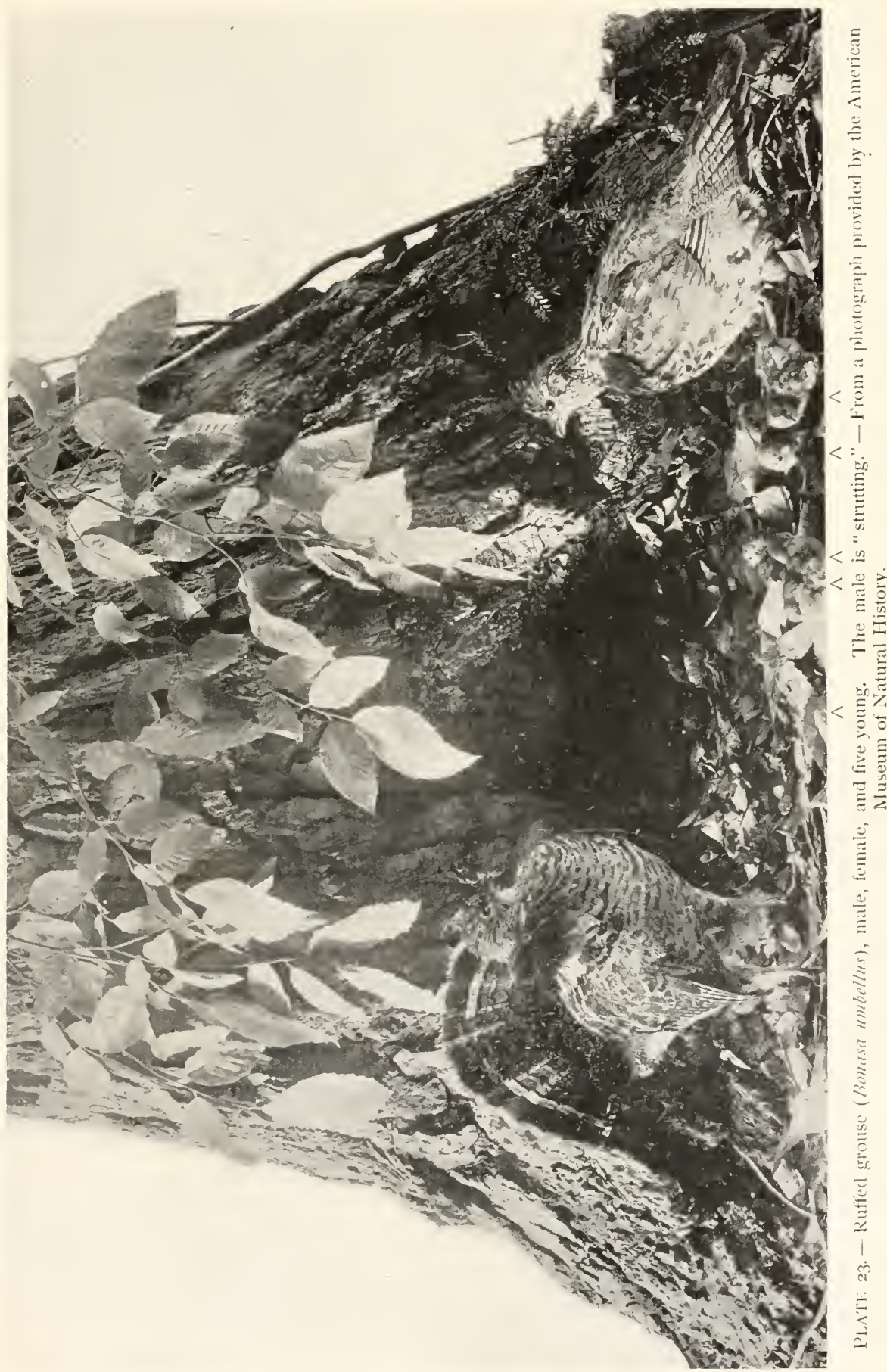





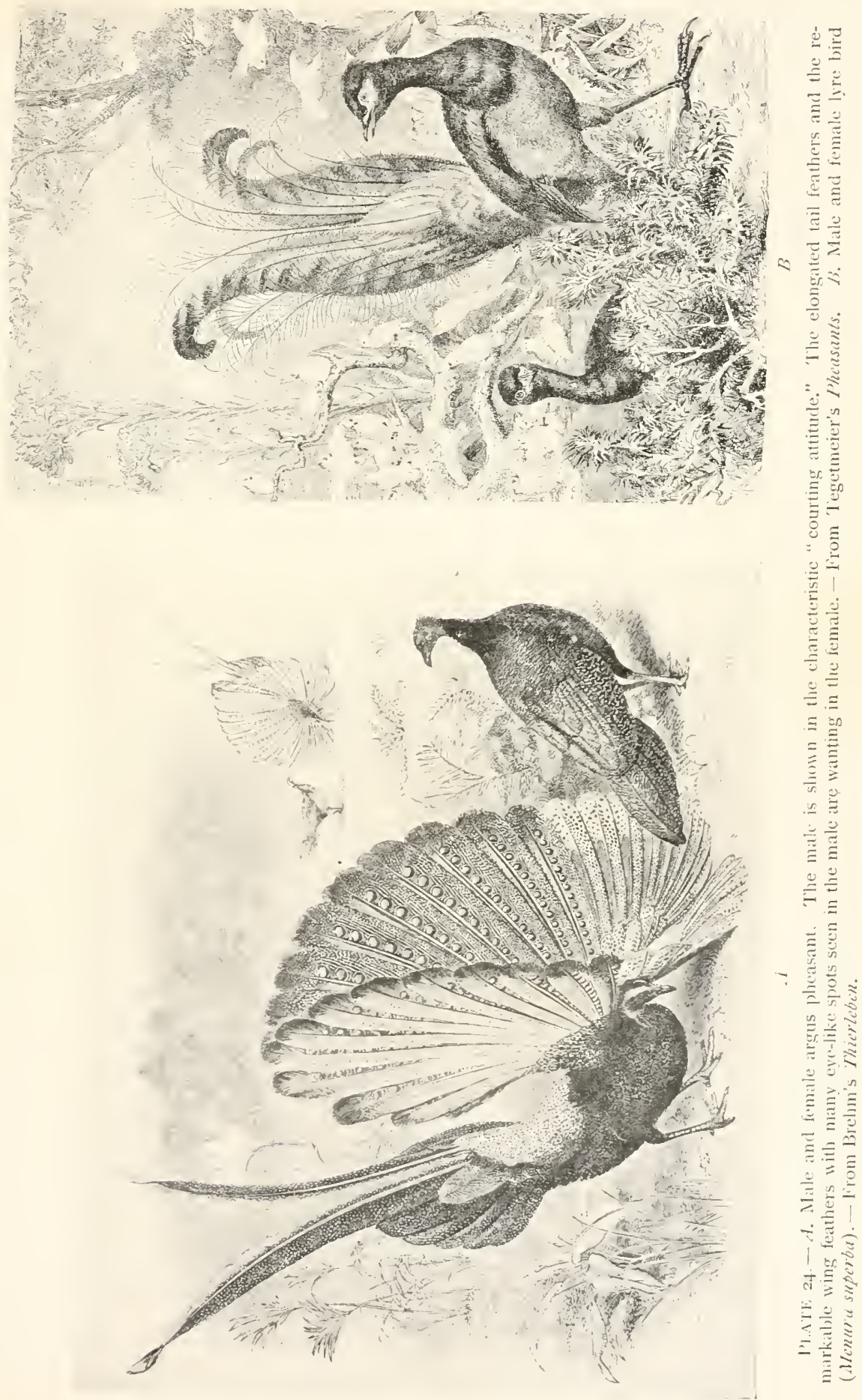




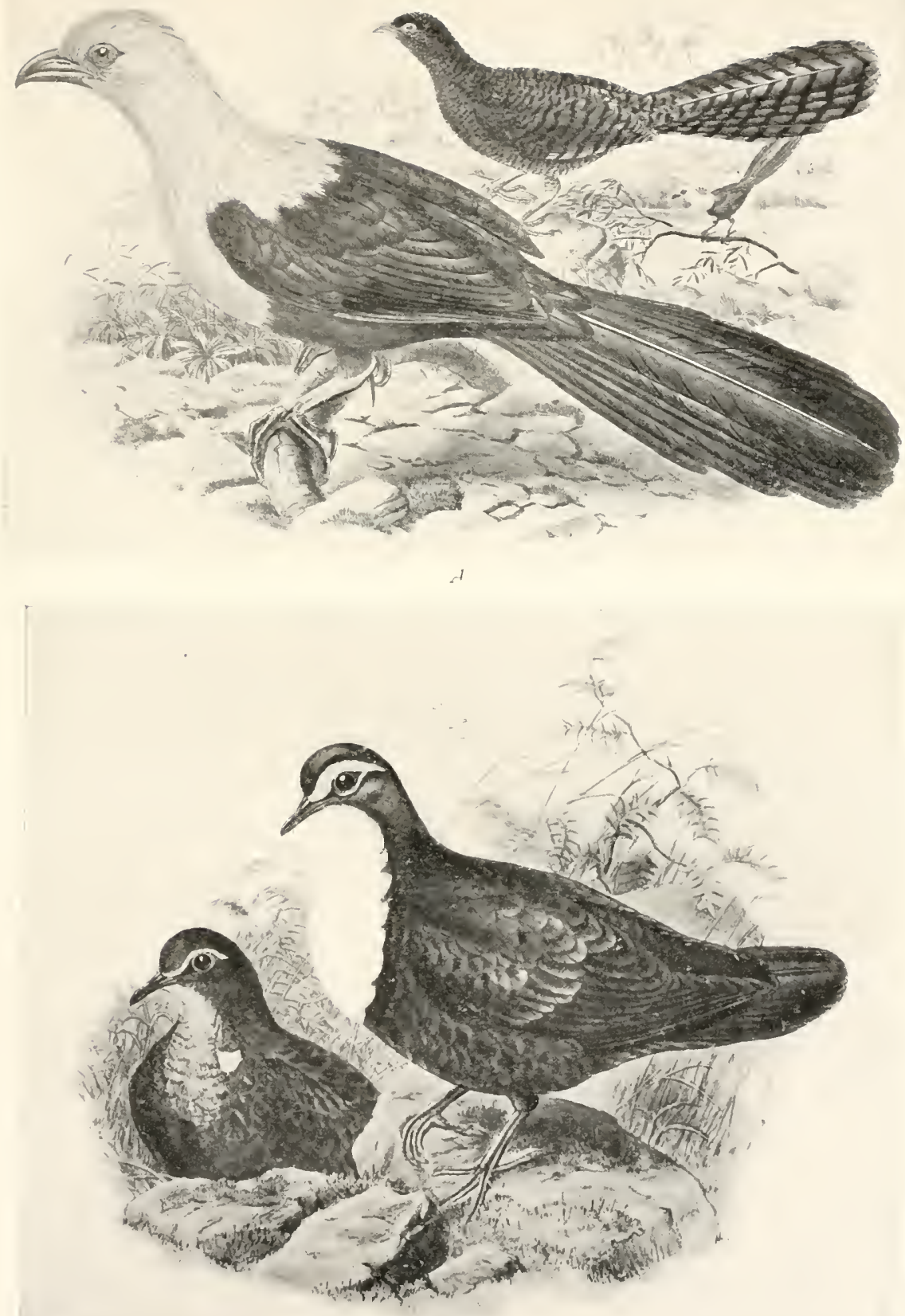

PLATE 25. - A. Male and female Vesocentor milo. B. Nale and female pigeon (Phlogenas jobiensis). - From Gould's Birds of New Gunea. 


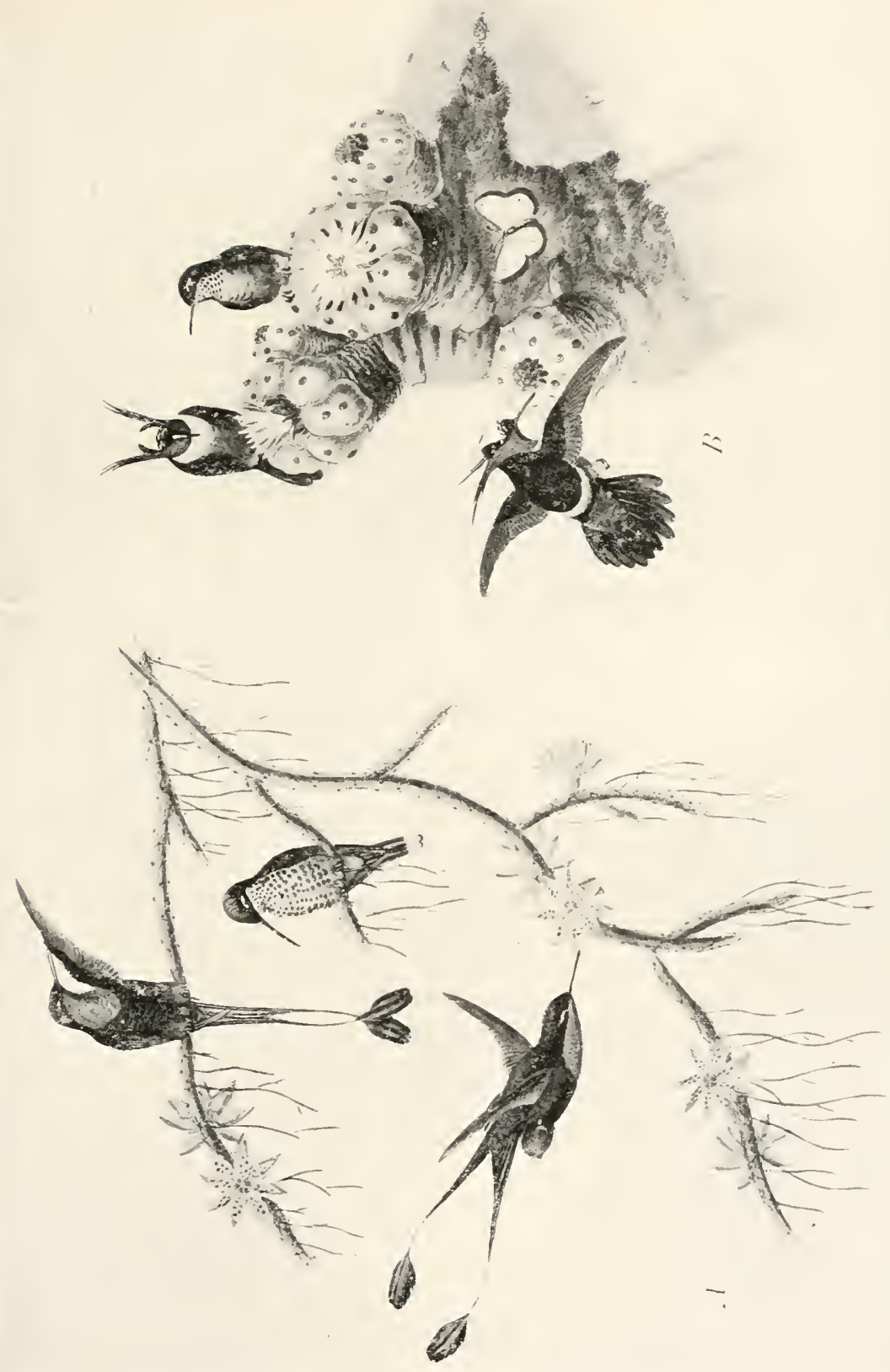



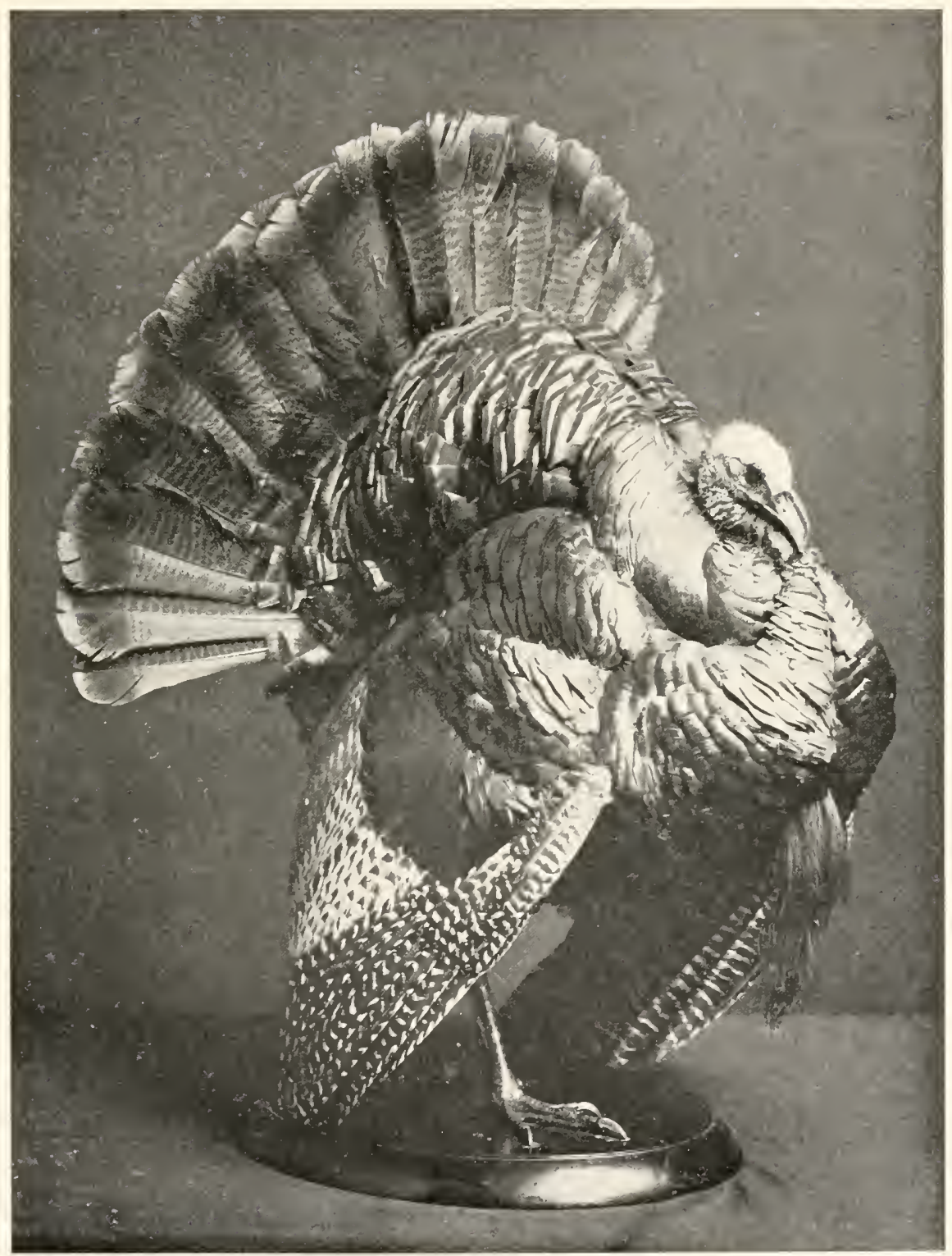

PLATE 27. - Turkey cock "strutting." - From a mounted specimen in the United States National MIuseum. 

selection. The males are usually more brilliant in plumage and have more highly dereloped roices than the females (Plates 22-27). At the mating season they parade their fine plumage before the females and use all their charms of voice to render themselves attractive to their desired mates. They often go through the most remarkable courting antics, and there seems to be sufficient evidence from observation that these antics and the brilliant voice and fine plumage influence the female in her choice, that they act as a sexual excitant. The strutting of the rooster or the turkey cock (Plate 27) is a good example of courting habits among birds that is familiar to all ( $c f$. also Plates 23 and 24). Under the influence of the courting instinct the behavior of many of our birds changes its whole character. The American woodcock is one of the most retiring birds we have. Few but sportsmen have ever seen it in its native woods. (See Plate 50.) By day it stays close in the thickets, feeding. It rarely flies except at night. It has no calls or song. But at the beginning of the breeding season even this shy bird loses his sedate character and lightly turns his fancy to thoughts of love. During the morning and evening twilight a male and female may come day after day to the same spot at the edge of the woods, where the male will go through a series of performances wholly foreign to his usual quiet habit. Chapman, in his Handbook of Birds of Eastem North America, thus describes the courting of the woodcock: "How many evenings have I tempted the malaria germs of the New Jersey lowlands to watch the woodcock perform his strange sky dance! He begins on the ground, with a formal, periodic peent, pecnt, an incongruous preparation for the wild rush that follows. It is repeated several times before he 
springs from the ground and on whistling wings sweeps out on the first loop of a spiral which may take him three hundred feet away from the ground. Faster and faster he goes, louder and shriller sounds his wing song; then, after a moment's pause, with darting, headlong flight he pitches in zigzags to the earth, uttering as he falls a clear, twittering whistle. He generally returns to near the place from which he arose, and the pout is at once resumed as a preparation to another round in the sky."

In most birds the males are colored more conspicuously than the females, and in many species the males show special development of certain feathers, or of spurs, or comb and wattles, which are less marked or wholly absent in the females.

Wallace has called attention to the fact that natural selection could hardly allow the females of the birds, which are chiefly occupied in brooding the eggs and caring for the young, to be conspicuously colored because of the danger to the nest and young that would thus result. It has also been suggested that brilliant coloration in the male may aid him to serve as a decoy to distract attention from the female and the nest. Unfortunately for both of these suggestions, some brilliantly colored males help the female in brooding the eggs and caring for the young.

Among the spiders also are seen good examples of certain courting colors and habits (Plate 2S). ${ }^{1}$ Here the males of many species have brilliantly colored legs or have other portions of the body brightly colored. The eyes also are like splendid little jewels of different shades of red and green and blue. As the diminutive male approaches the often much larger female, he advances with a swaying, 

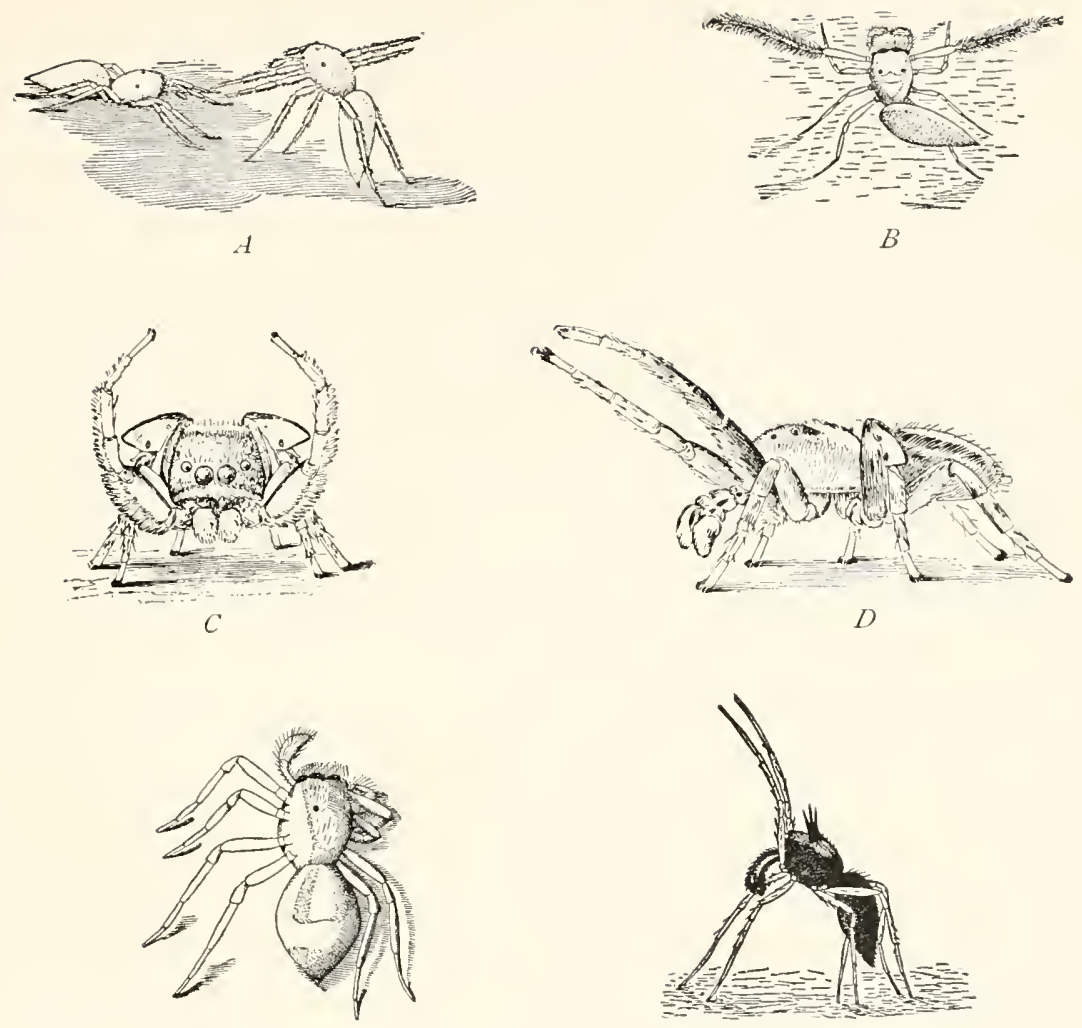

E
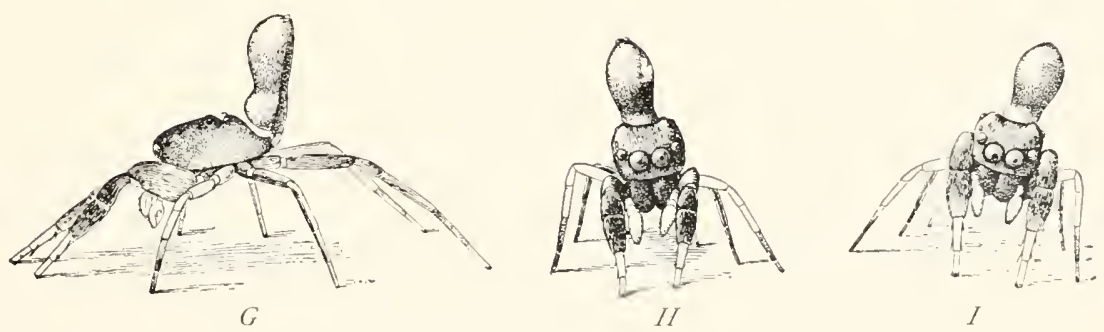

PLiTE, 28, - Courting attitudes in hunting spiders. [After G. Wr. and E. G. PEckirim.]

A. Marptusa fimiliaris. Left-hand figure, female; right-hand figure, male. B. Icurs mitnatus, male dancing before female. $C, D$. Habrocestum hozidrdii, front view and side view of male in courting attitude. The first legs in the male are "a delicate, light-green color, with a fringe of white hains along the outer side." The patella (second joint) of the third leg is enlarged, and its anterior face is white, with a black spot. The eyes are brilliant. Observe that the male assumes a position which shows all of these features to best advantage. E. Sattis pulex, male in his conrting dance. He bends the legs, first of one side, then of the other, scurrying back and forth before the female, moving always toward the side on which the legs are bent. F. Astia vittati, varicty mgra, position of male approaching female. $G, H$, I. Symageles picata, male dancing before the female. His first pair of legs are "of a brilliantly iridescent steel-blue color." 

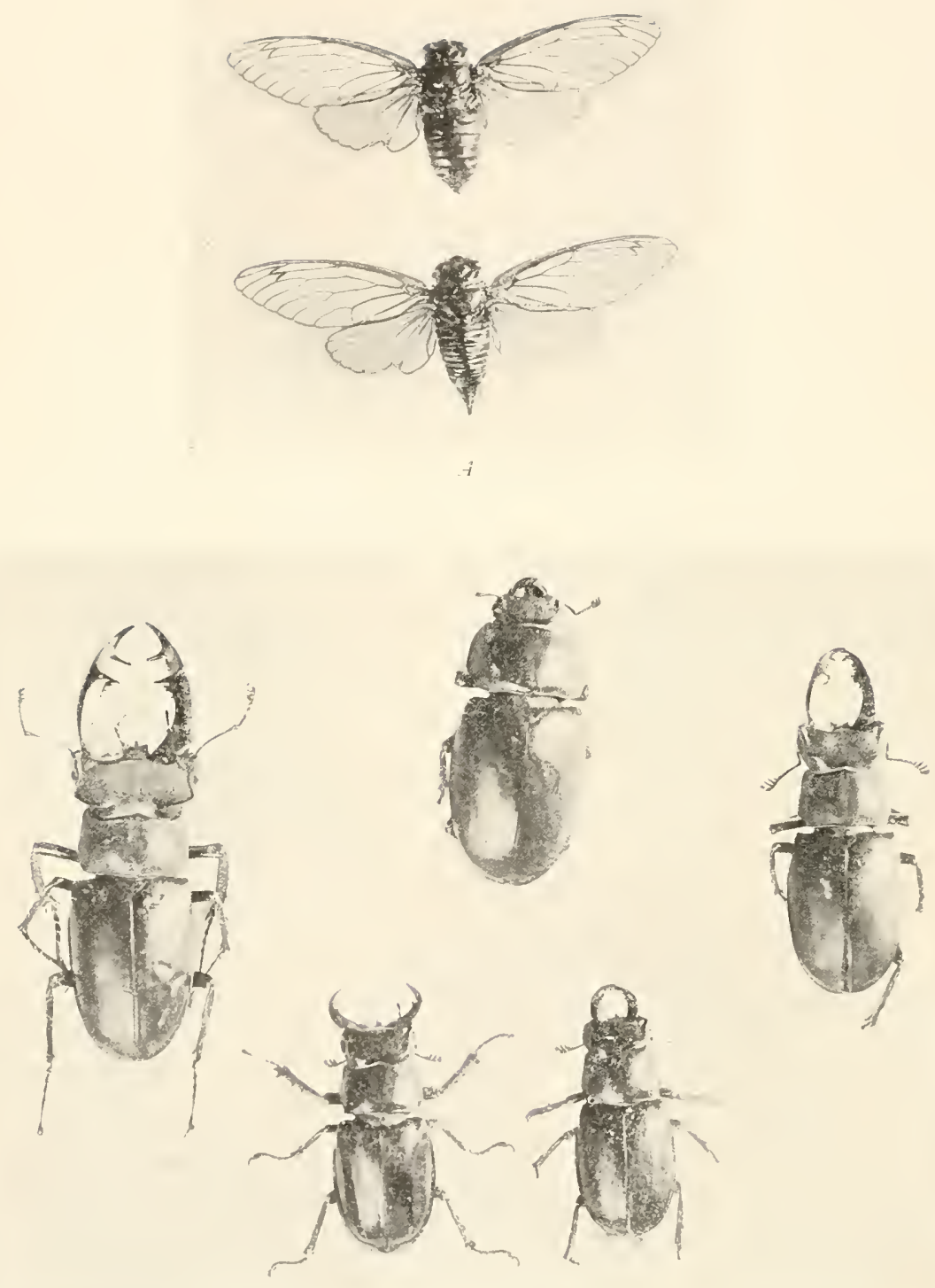

b

PL.111: 29. - 1. Male (upper figure) and female (lower figure) of seventeen-year cicada (cicadi septendecim), often inaccurately called "seventeen-year locust." $x$. Stridulating organ of the male. It is absent in the female. B. Males and female (middle figure above) of staghorn beetle (Lucunus dama). These figures illustrate not only the difference between the sexes, but also the variation in size among the males. 


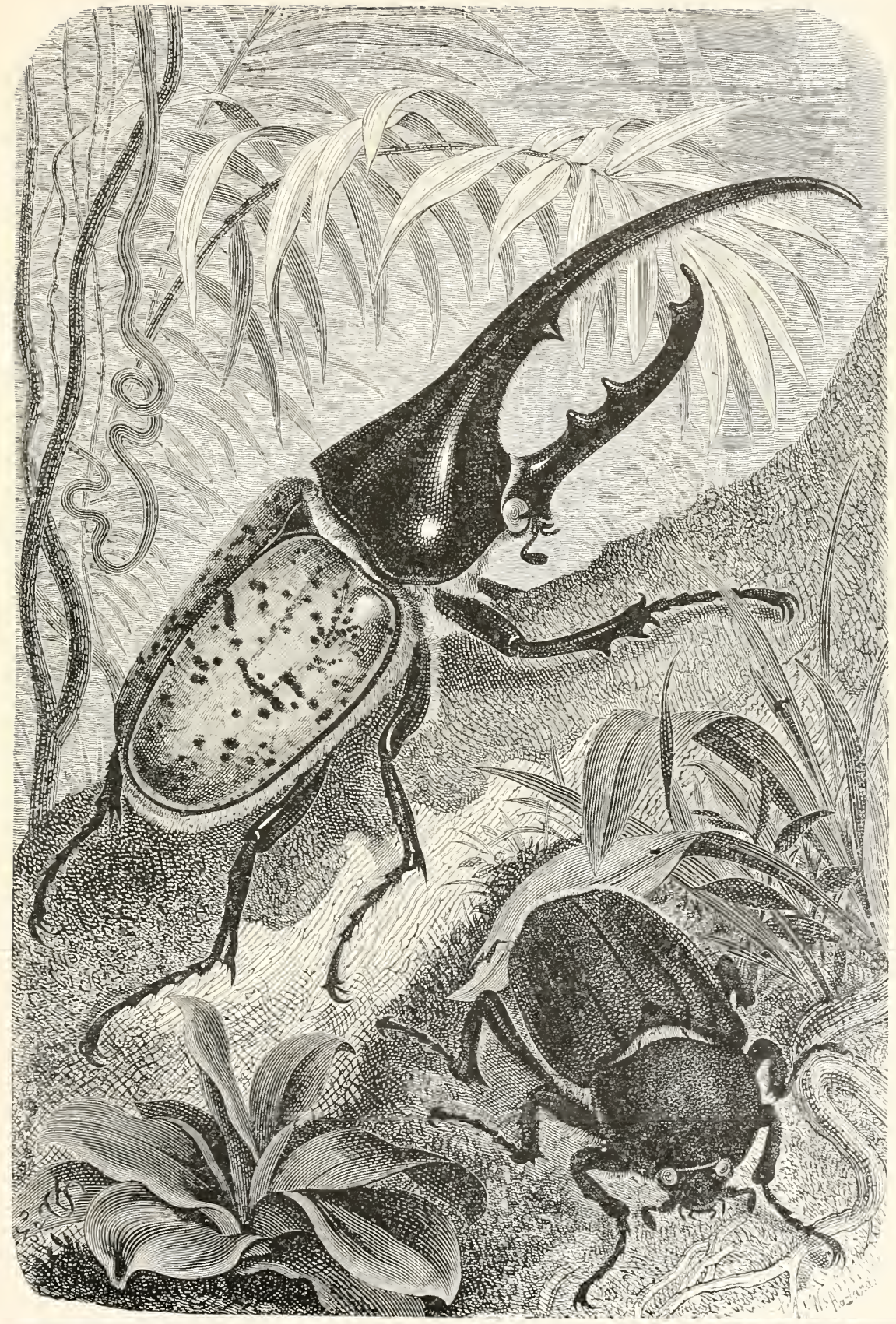

PLAIE 30. - Male (upper figure) and female of the "Hercuies beetle" (Dynastes hircules). 

teetering gait, the bright-colored portions of the body being displayed to the most advantage. It behooves him to be discreet in his courtship, for, if he fails to charm the female, he is likely to be seized and devoured by her. Dr. and Mrs. Peckham, of Milwaukee, who have been the most careful observers of the hunting spiders, the group of spiders in which courting colors and courting habits are perhaps most developed, are fully convinced that the female is influenced by the display of his charms made by the male, and that his success is often determined by this stimulus.

Among insects are found many instances of structures present in the males and wanting in the females of the same species. Stridulating organs for the production of sounds are common among the grasshoppers, crickets, and cicadas (Plate 29, A). The males of many beetles have enlarged jaws of a form not useful for fighting (Plate 29, B), or hornlike appendages on the head or thorax, which are not seen in the females (Plate 30 ; Fig. 7). In many species of butterflies the males are decidedly more brilliant than the females (Plate $8_{4}$ ). Bates, speaking of the butterflies on the upper Amazon, says: "They were of almost all colors, sizes, and shapes. I noticed here altogether eighty species, belonging to twenty-two different genera. It is a singular fact that, with a few exceptions, all the individuals of the various species thus sporting in sunny places were of the male sex; their partners, which are much more soberly dressed and immensely less numerous than the males, being confined to the shades of the woods." ${ }^{1}$ (Italics mine.) Again, speaking of the butterflies of the whole ${ }^{1}$ The Naturalist on the Riser Amazon. 
Amazon region, Bates says: "It is almost always the males only which are beautiful in colors." (See also Plates 31 and $33, A$.)

The males of many kinds of fishes are more brilliantly colored than the females, and in some species the males

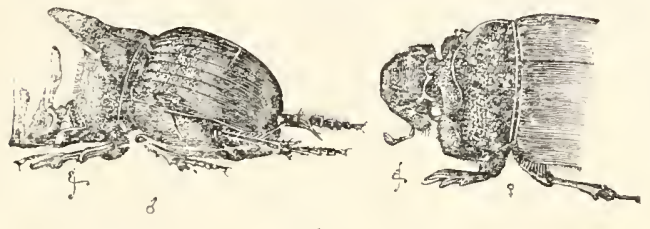

have ornamental appendages which are not found, or are less developed, in the females (Plate 32). Apparently
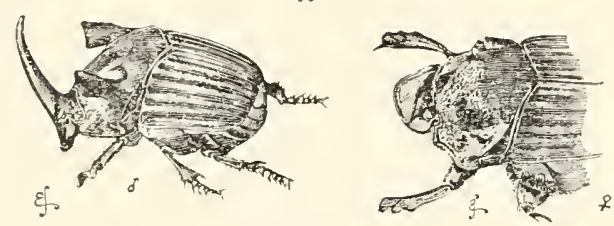
these characters are to be referred to sexual selection, for the colors are generally more brilliant at the breeding
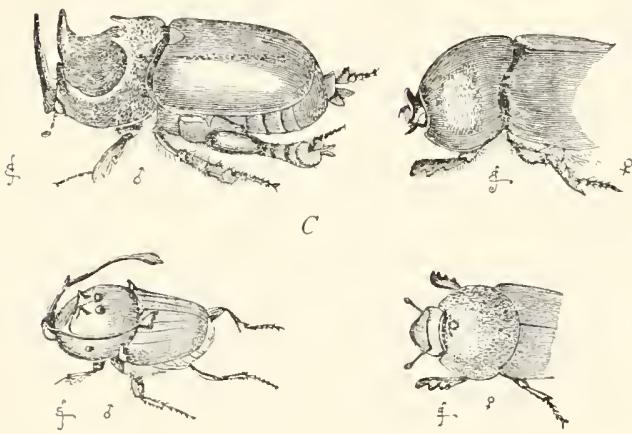

D season, and the behavior of the male in the presence of the female is such as to show off to the best adrantage the brightly colored parts of his body, or the ornamental appendages.

In some of the $A m$ -

Fif. 7.- Heads of male and female beetles. The left-hand figures show the maie. [After D.irwiN.]

A. Copris isidis. R. Phanceus fuunus. C. Dipelicus cantori. D. Onthophugus rangifer.

phibia the males are more conspicuous than the females during the breeding season. Darwin says, in his Descent of Man: "With our common newts (Triton punctatus and cristatus) a deep, much indented crest is dereloped along the back and tail of the male during the breeding season, which disappears during the winter (Plate 

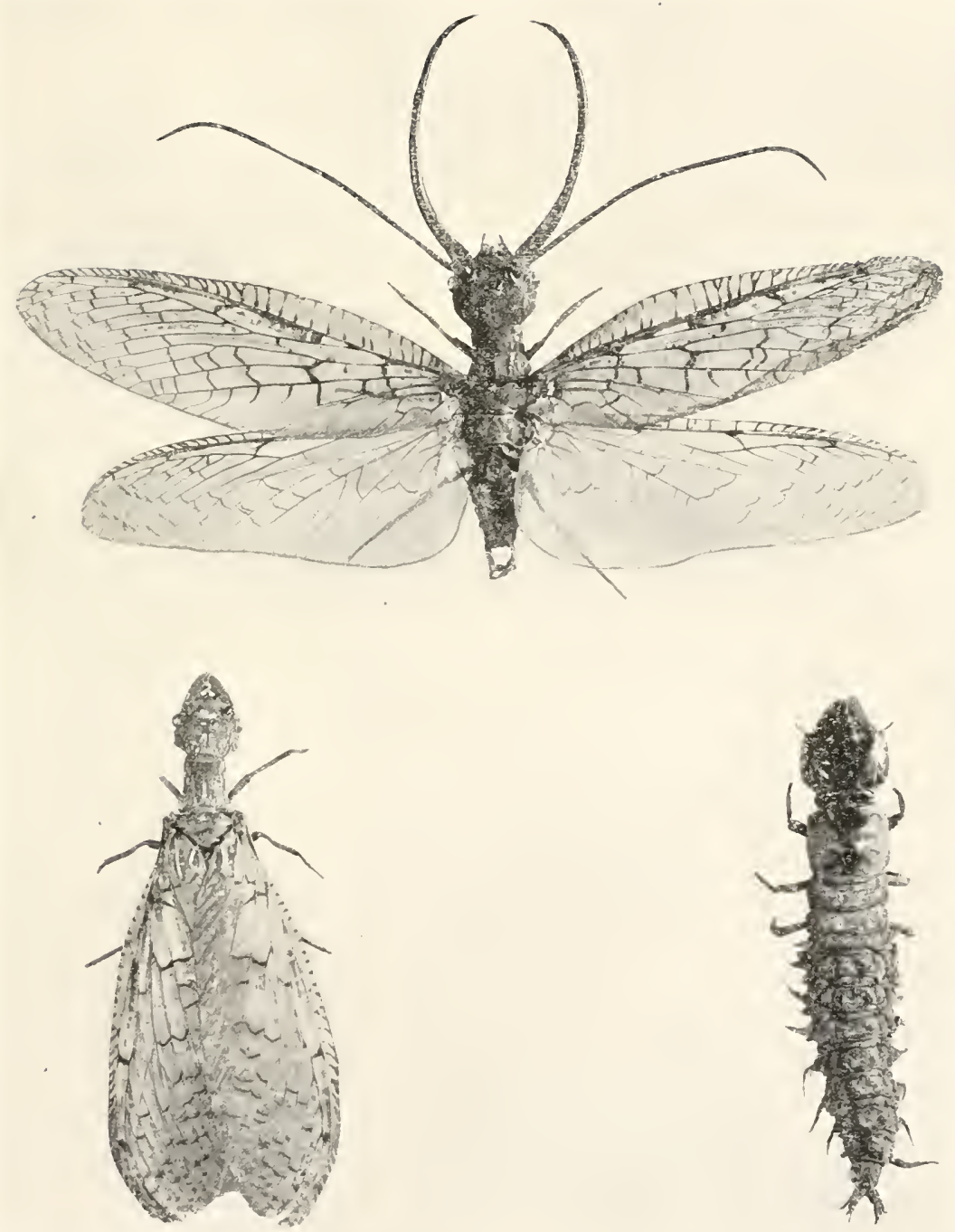

PLATE, 3I. - Male, female, and larva of chauliodes cormutus, a relative of the dragon-Hics The upper figure shows the male. 


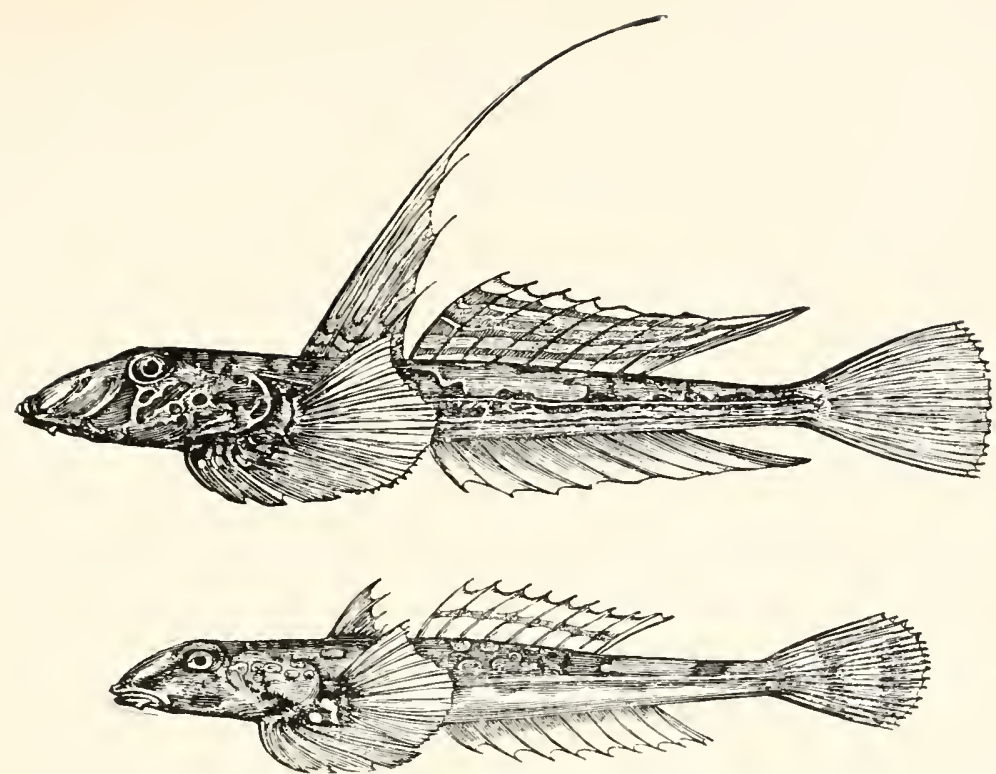

A
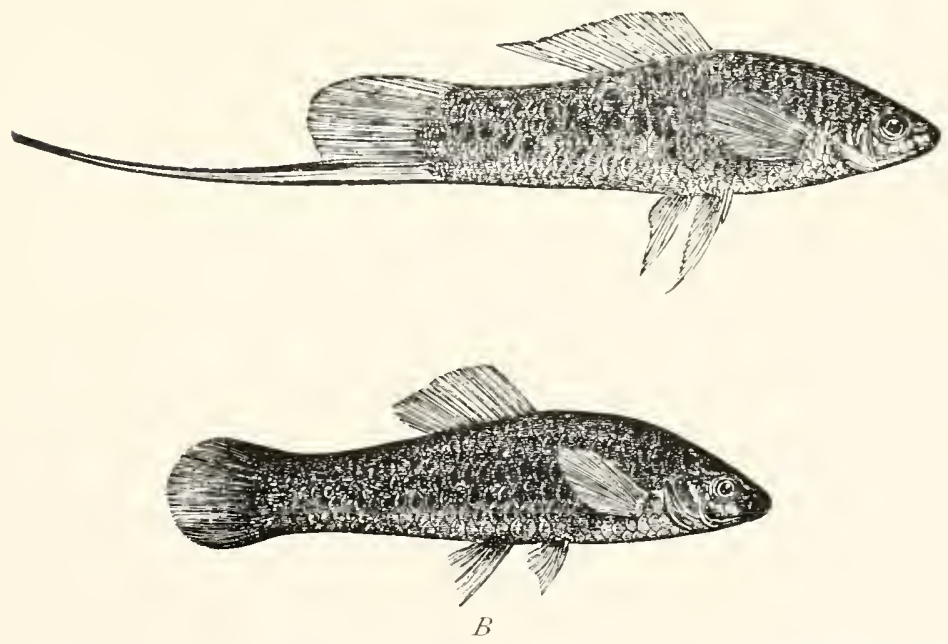

Plate 32.-A. Callionymus ly'ra, male and female. [After DARWIN.] The upper figure shows the male. The lower figure is more reduced than the upper. B. Xiphophorus hellerii, male and female. [After DARW'N.] The upper figure is the male. 


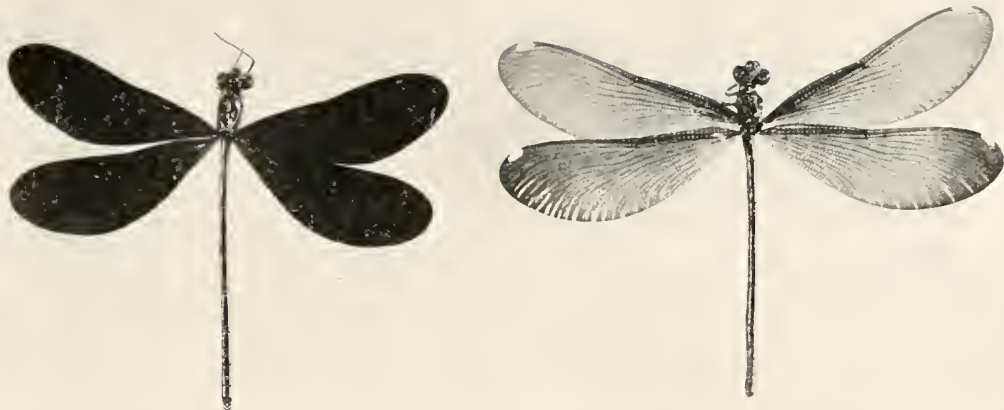

d

b

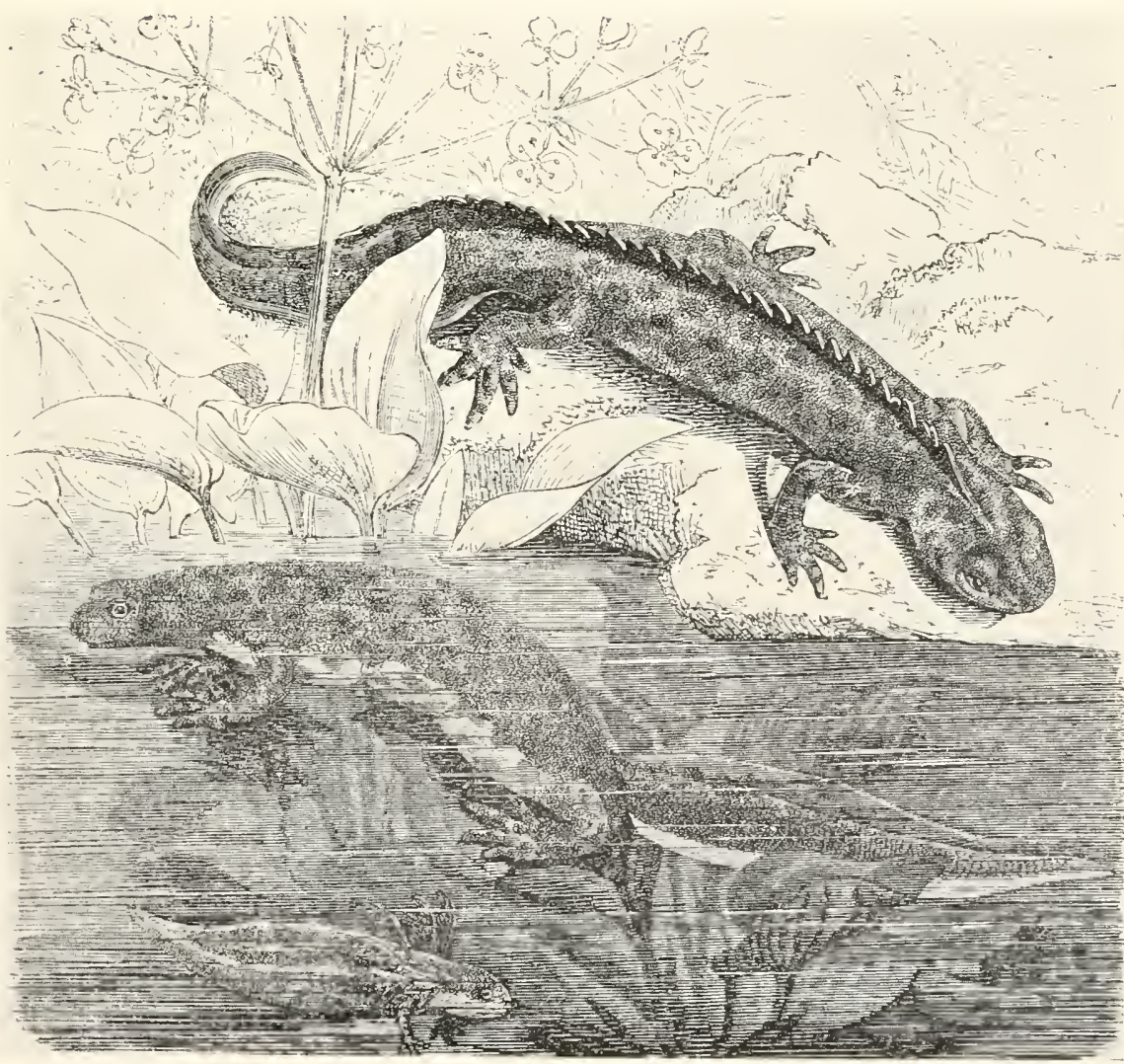

B

PLATE 33.- 1. Male $(a)$ and female $(b)$ dragon-fly (Caloptery maculata). The wings of the male are a rich lustrous green, almost black. The wings of the female are very pale green, almost colorless. 'The male is much more conspicuous. F. Triton cristatus, male, female, and larva. The upper figure is the male. - From Brehm's /hierliten. 



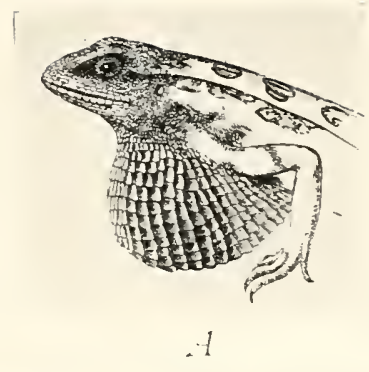

xontis
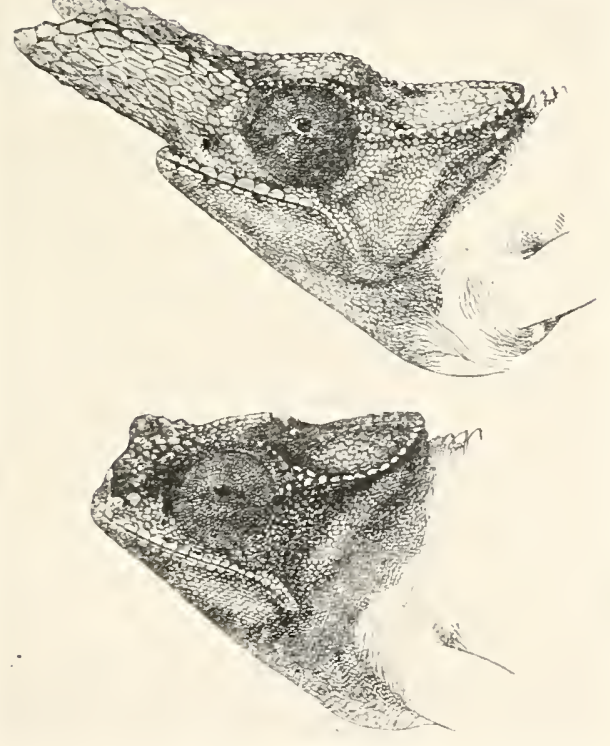

C
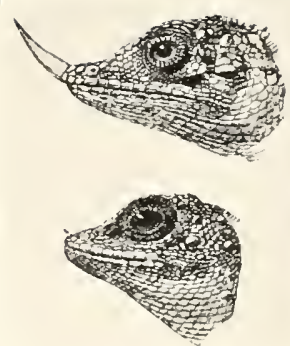

I3
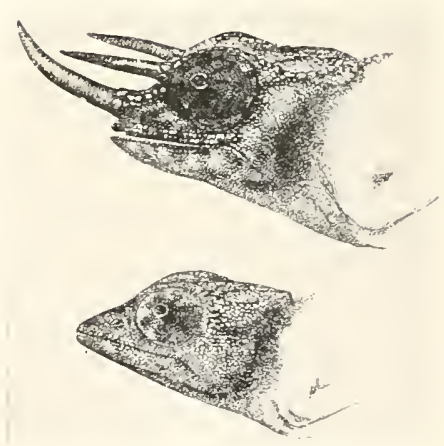

I)

F'ATF, 34. - Males and females of various species of lizards.

A. Sitana minor, male. B. Ceratophora stoddartii, male and female. C. Chameleo bifurcus, male and female. D. Chameleo owenii, male and female. 

33, B). Mr. St. George Mivart informs me that it is not furnished with muscles, and therefore cannot be used for locomotion. As during the season of courtship it becomes edged with bright colors, there can hardly be a doubt that it is a masculine ornament. In many species the body presents strongly contrasted, though lurid tints, and these become more vivid during the breeding season. The male, for instance of our common little newt (Triton punctatus), is brownish gray above, passing into yellow beneath, which in the spring becomes a rich bright orange, marked everywhere with round dark spots.' The edge of the crest is then tipped with bright red or violet. The female is usually of a yellowish brown color with scattered brown dots, and the lower surface is often quite plain."

The males of some kincls of lizards have certain portions of the body, especially about the head and neck, brightly colored, and sometimes there are in these regions brilliantly iridescent folds of skin which may be distended and in this way made more showy (Plate 34 ). It is possible that these are used in attracting the female.

The mane of the lion, the antlers of the male deer, the proud carriage of the male in many species of mammals, may be instances of structures and habits used in courtship and cieveloped, in part, through sexual selection, though the former two may be due partly to natural selection also. since they are of use in fighting, the lion's mane as a protection, the deer's antlers as weapons.

Referring once more to the birds, observe how the use of these special characters and habits in the male is indicated by the following facts (I quote from Romanes): "(a) Male secondary sexual characters of an embellishing 
kind are, as a rule, developed only at maturity, and most frequently during only a part of the year, which is invariably the breeding season; (b) they are always more or less seriously affected by emasculation; (c) they are always, and only, displayed in perfection during the act of courtship; $(d)$ then, however, they are displayed with the most elaborate pains; yet always, and only, before the females; $(c)$ they appear, at all events in many cases, to have the effect of charming the females into" accepting the male. These statements are perhaps a little too emphatic, yet they indicate clearly the reasons for believing in sexual selection. Remembering the facts of individual preference in choice of mates observed among domestic animals by their breeders, the reality of sexual selection seems well established.

Groos ${ }^{1}$ has pointed out that the coyness of the females, in those groups of animals in which sexual selection occurs, may be developed through natural selection. He says: "As the sexual impulse must have tremendous power, it is for the interest of the preservation of the species that its discharge should be rendered difficult. This result is partly accomplished in the animal world by the necessity for great and often long-continued excitement as a prelude to the act of pairing. This thought at once throws light on the peculiar hereditary arts of courtship, especially on the indulgence in flying, dancing, or singing by a whole flock at once. But the hindrance to the sexual function that is most efficacious, though hitherto unappreciated, is the instinctive coyness of the female. This it is that necessitates all the arts of courtship, and the probability is that seldom or never does the female exert any choice. She is 
not an awarder of a prize, but rather a hunted creature. So, just as the beast of prey has special instincts for finding his prey, the ardent male must have special instincts for subduing feminine reluctance, and just as in the beast of prey the instinct of ravenous pursuit is refined into the various arts of the chase, so, from such crude efforts at wooing, that courtship has finally developed in which sexual passion is psychologically sublimated into love." Groos is very likely correct in his belief that the importance of the act of pairing has led, through natural selection, to the development of coyness in the female, in order that more ardor may be necessitated in the male and the act of pairing effectually performed. This belief, however, does not diminish at all the reasons for recognizing that the females do exercise choice. This choice is probably not so much a conscious choice between rival males as a choice between accepting a certain mate and refusing to pair at all with him. But, under this conception, it will be those males which most successfully stimulate the sexual instincts of the females which will secure mates. It has been observed by Dr. and Mrs. Peckham that often a male hunting spider may fail to win the female. In observing the courtship of butterflies I have found the male unsuccessful after more than an hour of pursuit, until finally he has abandoned his quest. There seems no doubt that the females of many groups of animals do exercise choice, accepting or rejecting certain mates.

Now observe what is the effect of sexual selection on evolution. Natural selection secures the preservation of characters which help their possessors to survive in the struggle for existence. ${ }^{1}$ Sexual selection, on the other hand,

1 This statement is not quite accurate, as we will see later (page 82 ), but it will serve for the present use. 
secures the perpetuation of those characters in the male which make him attractive to the female, irrespective of any advantage or disadvantage in the struggle for existence. Those males which are attractive will, because of their attractiveness. gret mates and have offspring, while many of the less attractive males will fail to find mates. In time, then, through the action of this preference on the part of the females, there will be developed a race whose males show the characters which are attractive to the females. The results of sexual selection are different from those produced by natural selection, and may often be opposed to the latter. For example, it is of advantage to most birds to be inconspicuously colored, so that they may more readily escape their enemies. Natural selection, therefore, will tend to produce protectively colored forms. Sexual selection, on the other hand, in the case of many species, tends to produce brilliantly colored males. The two tendencies are thus often opposed to one another, sometimes one, sometimes the other, predominating.

Important objections have been urged against the theory of sexual selection. Many species of animals which show bright colors or ornaments in the male that are not found in the female are forms in which we have observed no court. ing habits by which these adomments are displayed before the female; and many of these are forms in which we would not expect to find the females exercising choice on the basis of the ornamentation of the male. Note, for example, the beetles (Plates 29 and 30 , and Fig. 7 ) and certain lowly Cmstacea (Fig. S, A). If the peculiar adormment of the mates in these species is due to something other than sexual selec- 
tion, it is distinctly possible that sexual selection may not be the cause, or at least the sole cause, of the adormment of the males among butterflies, spiders, fishes, Amphibia, lizards. and birds, in all of which courting has been observed.

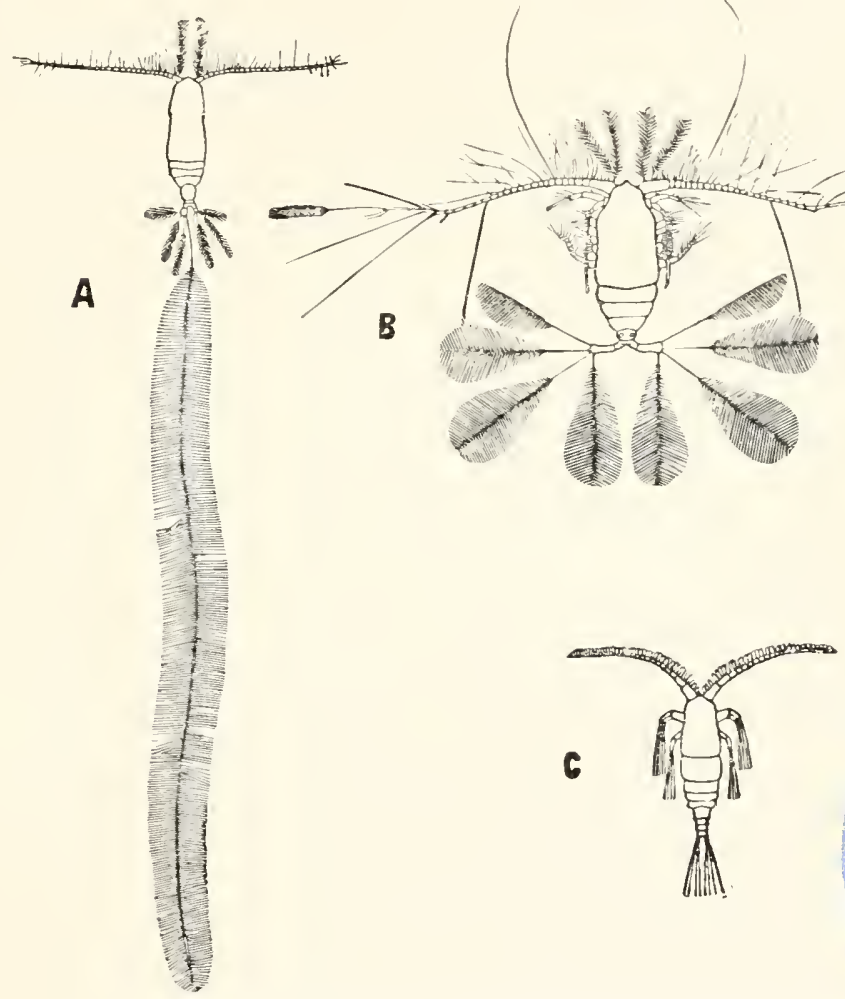

FIG. 8. - Secondary sexual characters in copepods.

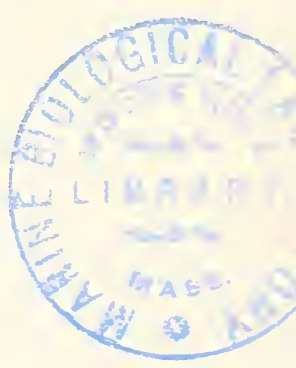

A. Male of Calocalanus plumulosus. D. Female of Calocalanus paro. C. Male of the same species. [From MORG.1X, after GIEsbRECHT.]

IVallace believes that the greater brilliancy of the male or his possession of finer roice or special ornamental appendages is due to his greater vigor and vitality, which is associated with his greater ardor.

Groos has suggested that the coyness of the female necessitates greater ardor in the male and that this secures 
greater effectiveness in the act of pairing, and that this difference in mental character in the two sexes has been brought about by natural selection because of its usefulness, and has not been developed through the females choosing the more ardent males. (Compare page 54.)

Sometimes it is the female and not the male which shows the greater development of secondary sexual characters (Fig. $S, B$ and $C$ ). In these forms we have no evidence of the exercise of choice by the male or of ardent courtship by the female. These cases, however, are rare, and we do not know what may be the use of the special appendages.

Wallace urges that for sexual selection to produce the results claimed the less ornamented males must fail to find mates, and, he says, we have no evidence that the less adorned males do fail to obtain mates, but that, on the contrary, the less adorned as well as the highly ornamented have offspring.

This statement of Wallace's is not surely true. If there is a correlation between vigor and high development of the ornamental sexual characters, as there is between vigor and high development of other structures, then, though the less ornamented males may obtain mates, they are less vigorous and will have less vigorous offspring. If it be also true that the more vigorous females are more sought after by the males than are their less vigorous sisters, then they will have first choice of the males, choosing the most highly ornamented, which are at the same time the more vigorous. Thus the vigorous, highly ornamented males will mate with the vigorous females, having vigorous offspring, while the less ornamented and less vigorous males will mate with the less vigorous females and have less vigorous offspring. Nat- 
ural selection will then preserve the vigorous offspring of the vigorous parents, and the males among these will be highly ornamented like their fathers. This is but conjecture. The relations suggested have not been established by observation. It is clear, however, that Wallace's statement is not self-evident.

Morgan keenly suggests an interesting objection. He says, "If in order to bring about, or even maintain, the results of sexual selection, such a tremendous elimination ${ }^{1}$ of individuals must take place, it is surprising that natural selection would not counteract this by destroying those species in which a process, so useless for the welfare of the species, is going on." ... "If, in nature, competition between species takes place on the scale that the Darwinian theory of natural selection postulates, such forms, if they are much exposed, would be needlessly reduced in numbers in the process of acquiring these [ornamental] structures" in the male. This objection of Morgan's is based upon the same assumption as that of Wallace which is criticised in the preceding paragraph.

Prolonged and careful observation, on a large scale, of the courting and mating of animals is needed to give us a sound basis for judging of the reality and degree of importance of sexual selection. We do not even know from observation whether the highly ornamented males are more successful in finding mates than are their less adorned fellows. Such observation is very difficult, for it involves keeping large numbers of individuals under as nearly natural conditions as possible, and observing them continuously, as well as keeping complete records of the mating and offspring.

${ }^{1}$ Elimination from the breeding process. 
It is not surprising, in view of these difficulties, that the statistical records are very scant.

There is no doubt of the reality and great importance of sexual selection among mankind, and to the author its operation seems probable at least among birds, fishes, and spiders.

\section{SEGREGATION}

Natural selection and sexual selection, and also the inheritance of parental modifications which we will discuss later, are primary factors in evolution. Segregation, to which we have already made some reference, is not a primary factor in the development of species, but, acting in connection with the primary factors, it greatly modifies the results produced by these. Anything which divides a species into groups which do not freely interbreed is said to segregate the members of the species into these subdivisions. In connection with one of the objections urged against the effectiveness of natural selection we spoke of some of the things that may cause segregation within a species. It is well to treat the subject a little more fully.

Segregation may be due to any of a number of causes. If only anything operates to prevent free interbreeding between any of the individuals of a species, it is a true cause of segregation.

The cause of segregation may be geographical. A species of wide distribution is likely to be divided into groups, which do not habitually interbreed, by the intervention of rivers, or mountain ranges, or deserts, or oceans between the different groups. The foxes of Europe differ from those of America, and probably this divergence from 
their common ancestral condition was somewhat influenced by the fact that the foxes east of the Atlantic Ocean were unable to breed with their relatives on this continent. The Rocky Mountains have been a most effective cause of segregation in this country, and to their presence is due probably a considerable part of the difference between eastern and western forms with common ancestry. The fauna and flora of some of the islands off the west coast of South America give us fine examples of the effects of isolation. We find the species distinct from those on the continent, but closely related to the latter. It is hardly possible that the island forms are not different from what they would have been if they had not been so separated from the continental members of the species that interbreeding with the latter was impossible. Even the species of the several islands within the Galapagos group are different, as is well illustrated by the locusts (Fig. 9). The divergence of these allied species has not been due to segregation alone. The environmental conditions in the different areas being different, natural selection must have been constantly at work to produce differences between the individuals residing in the two regions. But, though natural selection may have been the cause of divergence, we can readily see that its results nust have been materially affected by segregation. Segregation operates in conjunction with the other factors of evolution.

Another cause of segregation is climate. Conditions of drouth or of excessive humidity, of heat or cold, often raise effective barriers to the migrations of both animals and plants, and so segregate widely distributed species into groups which are separate from one another so far as 
reproduction is concerned. The faunas and floras of eastern Asia and of our west coast give us possibly the best example of the segregating effect of climate. At one time the climate of Siberia and that of Alaska was semi-tropical, being considerably more mild than the present climate of Baltimore. Of this we have abundant evidence in the fossil remains of semi-tropical plants and animals over

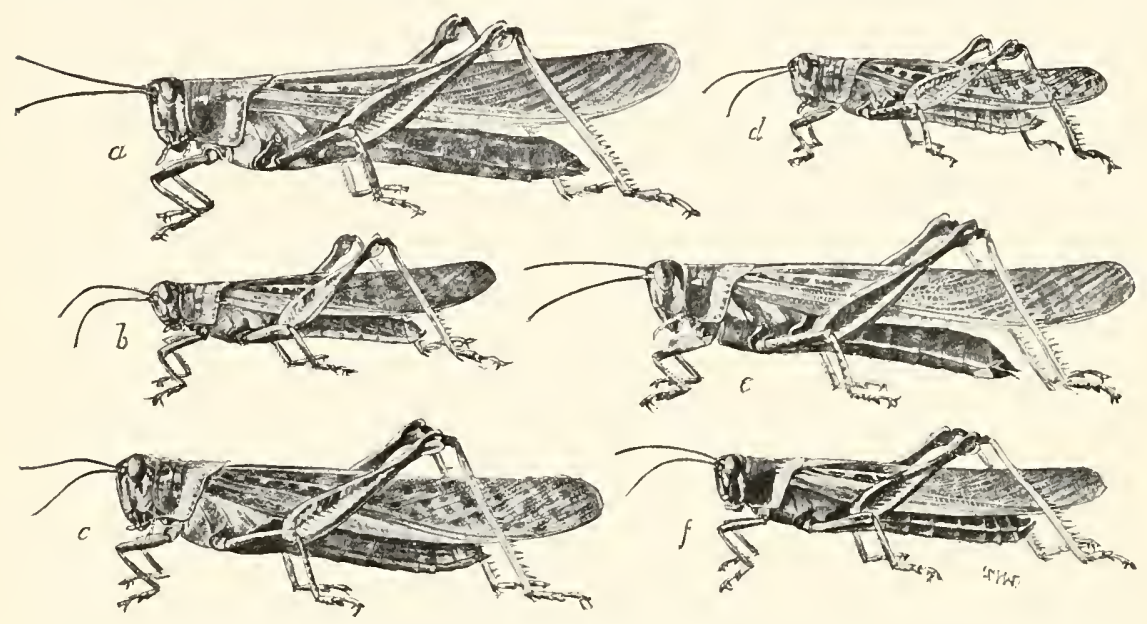

FIG. 9. - Locusts taken on the Galapagos Islands, Pacific Ocean. All descended from a common ancestor, but now scattered over the various islands and differing in size and markings.

a. Schistocerca melamora (Charles 1sland). b. S. intermedia borealis (Abingdon and Bindloe lslands). c. s. intermedia (Duncan 1sland). d. S. literosa (Chatham Island). e. S. melanora lineata (Albemarle lsland). f. S. melamora immaculati (Indefatigable Island.) The species mtermedia is probably a hybrid between the other two species. - From Jordan and Kellogg's Animal life, by the courtesy of the authors and of D. Applcton \& Co.

this whole area. During the continuance of the warm climate many species crossed from Asia to America and vice versa across Behring straits. As the cold increased, culminating in the extreme cold of the glacial period, there was formed a most effective barrier to further migration from one continent to the other, resulting in the complete segregation into two groups of each species which had representatives in both regions. We now find, as we 
would expect from these conditions, that the Siberian and western American faunas and floras, while having many forms which are closely similar, because of common descent, are still distinct, having very few species in common. (Of common genera, of course, there are many.) Natural selection, aided by segregation, has had time to produce great changes.

Diversity in soil conditions produces segregation among plants, and local differences in food conditions thus arising must cause segregation among animals, different groups of a single species being found in the separate localities where the suitable conditions of soil or food exist.

One of the finest examples of extreme segregation within a limited area is furnished by the land shells of Oahu, one of the Hawaiian Islands. Along the northeastern shore of the island is a high mountain range whose sides have by erosion been cut into deep valleys (Fig. Io) with high and steep ridges between. The soil in the lower ground of each valley is rich and bears a profusion of tropical trees, shrubs, ferns, and other plants. The tops of the main ridge, however, and also the tops of the lateral ridges, are barren, being denuded of their soil by the heavy rains. Several genera of land snails, which feed upon the foliage of the trees, shrubs, and herbs, are very abundant along this whole series of valleys, and it is interesting to observe that each of the several species (or varieties?) of snails is confined to a single valley or to two or three adjacent valleys. Their proper food and the necessary shade being absent on the tops of the ridges, the snails do not cross from one valley to the next. Such spreading as has occurred has probably been due to the 
snails being transported by birds or by some different means other than their own powers of locomotion. Gulick, who first called attention to the importance of segregation as a

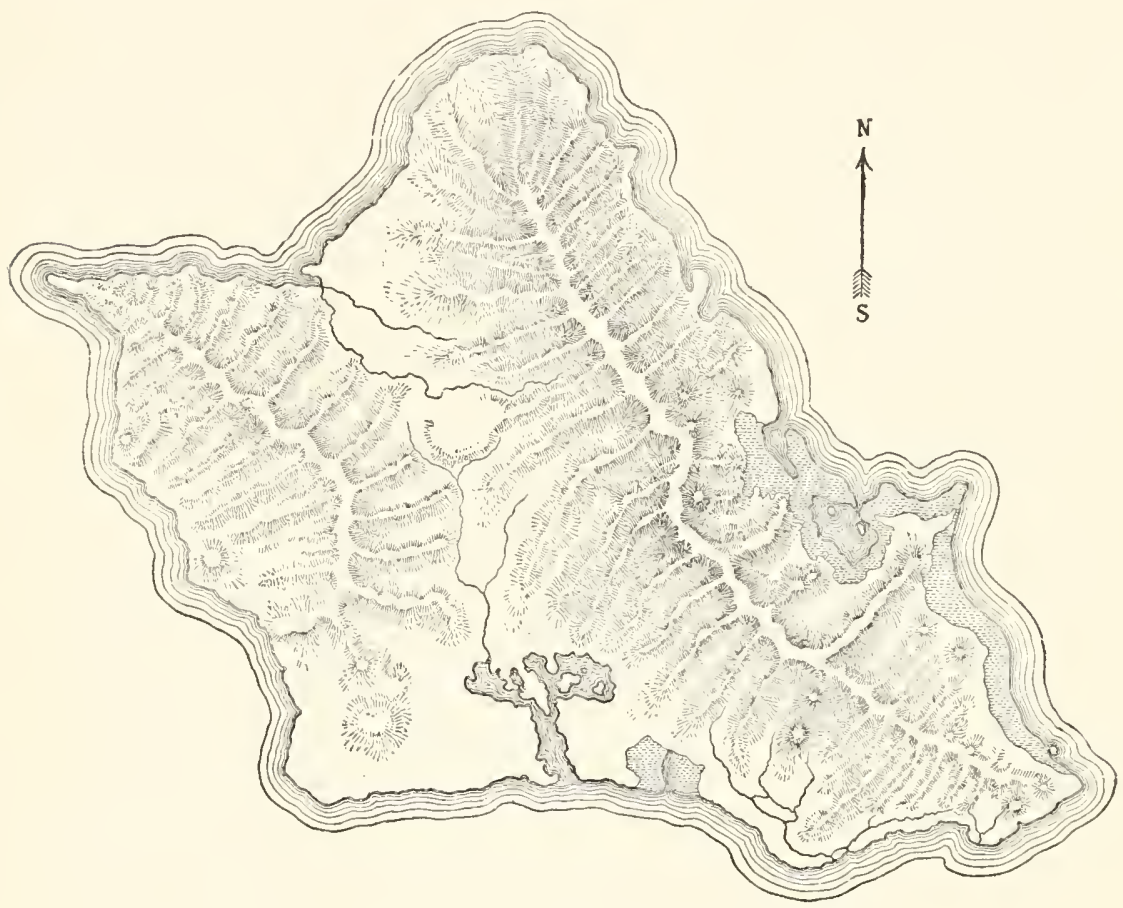

FIG. Io. - Map of Oahu, one of the Hawaiian Islands.

factor in evolution, was led to his conclusions by his study of the remarkably restricted range of each of the many species of land snails in these Oahu mountain gorges.

The difficulties in the way of migration over great distances must tend toward segregation among both plants and animals. The individuals at the extremes of the area occupied by any species cannot intercross directly unless the area be very limited in extent or their powers of migration very considerable. And even the birds, whose powers of migra- 
tion are so well known, usually breed year after year in the same localities, the same individuals returning each spring to the same spot and often occupying the same nest that was left the year before. Of course, as those individuals of the species which occupy the intermediate area will breed freely with those nearer the two extremes, the segregation of the latter is but partial, yet it must be sufficient to affect evolution.

Natural selection, sexual selection, and segregation all mutually interact, as we can readily see. Sexual selection, the exercise of choice in mating, causes reproductive segregation, and this, in turn, may affect natural selection. Let me again quote Lloyd Morgan: "Among the wild horses in Paraguay those of the same colour and size associate together; while in Circassia there are three races of horses which have received special names, and which, when living a free life, almost always refuse to mingle and cross, and will even attack one another. In one of the Faroe Islands, not more than half a mile in diameter, the half-wild native black sheep do not readily mix with imported white sheep. In the Forest of Dean and in the New Forest the dark and pale-coloured herds of fallow deer have never been known to mingle; and even the curious ancon sheep, of quite modern origin, have been observed to keep together, separating themselves from the rest of the flock when put into enclosures with other sheep. ... This preference of animals for their like, even in the case of slightly different varieties of the same species, is evidently a fact of great importance in considering the origin of species by natural selection, since it shows us that, so soon as a slight differentiation of form or colour has been effected, isolation will at once arise by the selective action 
of the animals themselves." This is a good statement of the case except that Lloyd Morgan should have said isolation may at once arise, not "will" at once arise.

Romanes ${ }^{1}$ has called attention to a factor in segregation which has as yet been insufficiently studied, but which may prove of the greatest importance. He has called it physiological selection. It has been observed that certain individual animals of the same species, when crossed with each other, are infertile, whereas either one, if crossed with a different mate, might have been normally fertile. There exists some insufficiently understood bar to fertility between those two individuals. This is a restraint upon the perfect freedom of intercrossing, a sort of negative segregation, and must have a real effect on evolution. It seems quite possible that further observation and experiment may show this factor in segregation to be more common and important than, in our present ignorance of the actual facts, we can assert. The reproductive function is very delicate and liable to disturbance from apparently slight causes. Many wild animals, however well kept, are barren in captivity or are less fertile than when unrestrained. Transportation to a strange locality sometimes interferes with reproduction. Again, there are some observations which suggest that variation in structure in any of the different organs of the body may be correlated with such disturbance of the reproductive functions as to decrease the fertility of crosses between the individuals which diverge from the species type and those which do not so diverge. This point, however, needs much more study before we can determine the importance of its influence in producing physiological segre-

${ }^{1}$ Darwin and After Darwin, Volume III, "Isolation and Physiological Selection." 
gation. If it be true that closely related individuals, when bred together, are more fertile than are distant relatives, as seems under some circumstances to be true, this fact also is of great importance. The whole subject of physiological selection needs much more study. It is surely of some importance as a cause of segregation; it may be of great importance.

Segregation might cause the perpetuation of divergent characters, though these were of no use and so not subject to the preserving action of natural selection. This, however, would not produce adaptation to the environment, which is the striking character of animals and plants. Segregation, therefore, unaided by natural selection, cannot have been an important factor in that evolution of animals and plants which we find has taken place, bringing them into harmony with their environment. Segregation becomes important when it acts in connection with the other factors of evolution, natural selection, sexual selection, and, possibly also, among lowly forms, in connection with the inheritance of parental modifications.

\section{THE INHERITANCE OF PARENTAL MODIFICATIONS}

One more factor in evolution needs careful discussion, namely, the inheritance of parental modifications, that which Weismann has called the "inheritance of acquired characters." For this factor the largest claims are made by some biologists. It probably exerts a powerful influence on the evolution of some of the lower forms of plants and animals. Its influence upon higher forms is much more doubtful. 
It is well known that both animals and plants change constantly during their whole lives as a result of the effects on them of the environment, and through the reaction upon themselves of their own activity. Use strengthens a muscle and disuse allows it to waste away. Some claim that, as a matter of course, any such effect produced in one individual will be handed down to his descendants, and that here we have a most potent cause of evolution in the transmission to the offspring of the modifications produced in the parent. Favorable or poor conditions of nutrition produce great effects on individual plants and animals; so also do climatic conditions. Are these effects upon the individuals of one generation transmitted to their offspring of the next generation? If so, this inheritance of parental modifications must have the greatest influence upon evolution. The matter needs careful scrutiny.

Among the lower forms of living things, the unicellular forms, many of which are so lowly that we cannot determine whether they be animals or plants, among these lower forms the inheritance of parental modifications is undoubtedly a fact, as a single illustration will suffice to show. An Amaba is a lowly animal of microscopic size, consisting of a bit of protoplasm with a single nucleus. It has no highly differentiated organs, but the whole body takes part in the performance of each function. When this animal reproduces, it merely divides into two (or more) little Amoba, each of which eats and grows again to the characteristic adult size, when the process of division is repeated. The offspring are merely parts of the original parent, and of course show in themselves the features of organization characteristic of this parent. We can readily see that modifications of the parent 
nuy affect the offspring, which are but detached portions of the parent. Even the effects of injuries to the parent may be inherited by the offspring. Parental modifications among the unicellular animals and plants must, then, often be inherited. This is probably an important factor in their erolution, perhaps as important as any other, though this is doubtful, natural selection seeming eren here to be the chief factor. Among these lowly forms the whole body shares in the process of reproduction. There are no special parts of the body set aside for this function, while the rest of the body functions as bone and muscle and gland and nerve. The whole body divides, learing no residue, so that any modification in the parent may pass directly to the offspring.

But how is it with more highly organized animals in which the body is differentiated into different portions, each with its special function, - bone, muscle, nerve, digestive organs, renal organs, and a great number more of special organs and tissues? In these higher animals, and in the higher plants as well, the function of reproduction is not performed by the body as a whole, but is given over to special groups of cells, the germ cells, constituting the oraries and testes. It is these cells, and these only, which under ordinary conditions give rise to new individuals. Under such circumstances the problem of the inheritance of parental modifications is not so simple. How can the enlargement of a muscle, due to exercise, so affect the germ cells, which lie perhaps at a distance from the muscle in question, as to cause the new individual, which shall arise from these germ cells, to have the corresponding muscle in its body enlarged? The question, we see, is not a simple one.

The germ cells in the body are the only ones which 
under ordinary conditions have any descendants in the following generation. The whole body of the offspring comes from two united germ cells, - an egg from one parent and a spermatozoon from the other parent. No bone cell, or muscle cell, or any other body cell, in either parent, gives rise to any part of the offspring. Weismann has used the term soma to include all the cells of the body which are not germ cells, that is, the muscle cells, bone cells, nerve cells, etc.... This distinction between the germ cells, from which the young are derived, and the soma cells, which ordinarily have no offspring in the next generation but are destined to die, is a very important one, and upon it must be based the discussion of the inheritance of parental modifications.

As a fertilized egg is developing into an adult organism it divides into a number of portions called blastomeres, certain of which will form the germ cells of the new organ. ism, while the remainder will become its soma. The germ cells of one generation are thus derived almost directly from the germ cells of the preceding generation.

The accompanying diagram may make the matter clearer.
Generation A,
Germ cells
Soma.
Generation B,
Germ cells
Soma.
Generation C,
Germ cells
Soma.
Generation D,
Germ cells
Soma.

In the diagram the lines indicate lines of descent. Both the germ cells and soma cells of any generation are derived from the germ cells alone of the preceding generation. The 
soma cells have no descendants. ${ }^{1}$ They die without offspring. Moreover, apparently no germ cell has ever been anything but a nascent germ cell. It has never been a muscle cell or a nerve cell. Nuscle cells, or any other highly differentiated soma cells, do not change into germ cells.

We can leave out of account the processes of asexual reproduction (fission, budding, reproduction by asexual spores), for, while modifications of the soma of the parent could pass from parent to offspring by these processes of asexual reproduction, the modifications, if unable to be inherited through sexual reproduction, would be lost whenever, perhaps after several asexually produced generations, sexual reproduction should intervene; and we know of no species of multicellular animal, or higher plant, which reproduces indefinitely by asexual methods. Sexual reproduction intervenes sooner or later. The fact that asexual reproduction occurs does not, then, alter the general argument in regard to the inheritance of parental modifications.

The phenomena of regeneration would be of some interest in this connection, if we knew well-authenticated instances of animals regenerating their reproductive organs, forming from soma cells the new germ cells to take the place of those which had been lost. We do not know; however, that such regeneration is customary, or even possible, in any group of animals. Certainly it is not of sufficient frequency to be taken into account as a means by which soma cells might impress their character upon germ cells and thus secure the inheritance of parental modifications.

${ }^{1}$ As the diagram shows, the body (soma) of the "parent" and the body (soma) of the "child" are a sort of second cousins. or rather " first cousins once remored," being related only through the germ cells of the parent's parents. 
The relation of soma and germ cells in plants and the relation of the germ substance to the processes of regeneration in plants are more obscure than the similar relations in animals. It does not seem best to attempt to discuss them here.

The modifications of the soma, to which we must refer, are of two sorts, first, those produced by the effect of the environment upon the organism, and, second, those resulting from the reaction upon itself of the activity of the animal or plant. Let us illustrate each.

The direct influence of food and climate is often of such a nature as to produce changes in the individual. For example, plants, if grown in a warm moist climate and in rich soil, may be larger than if grown under less favorable circumstances. Will these plants have larger offspring as a result of inheritance of the increased size? Is the direct effect of the favorable environment (increased size) handed down to the offspring? If the offspring be large, as they probably will be, is their large size due to the fact that their parents became large under the farorable conditions in the midst of which they grew, or to the fact that the offspring themselves grow under the same favorable conditions as their parents and so, for this reason, are large? That is, is their size due to the inheritance of the increased size of their parents, or to the same favorable soil and climate that made their parents large? Is there at all any inheritance of increased size? How can we tell? We have at least one test which we may apply. When plants are taken from unfavorable conditions and are grown under the most favorable conditions, do they only gradually assume increased size, or are those of the first or second generation as large as 
those of the third or fourth or tenth or fiftieth? If parental modifications be inherited, the plants of the later generations should be larger than those of the first, the inherited effect of increased size accumulating from generation to generation. We do not, however, find this to be the case. It is not by this method that large plants have been produced by the gardeners. They have been produced by selecting the larger plants to breed from and continuing this process from generation to generation, the same process of selection that goes on in nature.

Let us look at an illustration of the reputed inheritance of the effects of use and clisuse and see if we can accept this influence as a factor in the evolution of the higher animals and plants. We have referred to the increase in size that follows the use of a muscle, and the decreased size that results from its disuse. Are these effects inherited by the offspring? Does the man who is strong because he leads an active life have stronger children than he would have if he led an inactive life? Notice this: The fact that he does develop strong muscles as the result of exercise shows that he must have had an innate capacity for developing strong muscles by exercise. If he inherited from his parents the ability to develop strong muscles under the stimulus of an active life, his offspring in turn will inherit from him the same ability. I blacksmith has a son who becomes an office clerk and takes no exercise. Does the son have any stronger right arm than he would have had if his father had been an office clerk? Of course the son will have the same capacity for developing a strong arm that his father had before him, but will the fact that the father developed this capacity and became strong give the son any greater strength 
than he would have had if the father, through inactivity, had allowed his capacity for strength to lie undeveloped? There is little, if any, carefully scrutinized and carefully recorded evidence in favor of an affirmative answer.

How can we test the case? It is very difficult. Experimentation has failed to show inheritance of the effects of use and disuse among the higher plants and animals, and we have practically no evidence in its favor except its apparent plausibility. But, when carefully scrutinized, is it as plausible as it seems at first thought? How can the use of the biceps muscle in the arm of the parent so affect the offspring that he will be not only stronger, but stronger in the biceps muscle, the particular part affected in the parent? The child is not the child of the biceps muscle of the parent, but the child of the germ cells of the parent, and these germ cells have little to do with the parent's biceps muscle. 'They are separated by a great space, and they do not, so far as we know, have any special mutual relation. If the increased strength gained by the biceps muscle of the parent is to be handed down to the offspring, the increase in size in the parent's biceps must in some way produce an effect upon the parent's distant germ cells from which the child is to develop; and this effect upon the germ cells must be of so particular and definite a kind as to produce not a general effect upon the offspring but a particular effect, namely; greater strength, and not only greater strength, but greater strength in a particular portion of the body, the biceps muscle of the right arm. The hypothesis, apparently so simple at first glance, is seen, when scrutinized, to involve a connection between muscle cells and the distant germ cells so intimate and so definite as to be marvellous beyond almost any known 
fact of biology. No greater assumption has ever been made as the basis of any biological theory, and it is pure assumption, for as yet we have no evidence of any such mechanism connecting muscle or nerve or bone cells with the germ cells. In the absence of evidence in favor of the inheritance of parental modifications among highly organized forms, and in the presence of the tremendous assumption upon which this hypothesis rests, I think it unsafe to accept this principle even as a working theory. We may get definite evidence sometime that will lead us to a different conclusion. The phenomena of biology are wonderful, and even this great assumption may yet be proven. It has not yet been proven or been shown to be probable.

Let us direct our attention to two further points in connection with this part of the discussion. Many of the most remarkable phenomena of nature we are sure have been developed without the aid of the inheritance of parental modifications, so we do not need the help of this hypothesis because natural phenomena are "too wonderful to be explained without it." The color of flowers is useful to attract insects. It has served its purpose when an insect has seen the color and has responded. The plant lies passive; the insect actively responds. How can the reactionary effect of the active response in the insect be inherited by the offspring of the plant? Or another equally absurd case: Many animals, rabbits for example, are protectively colored. This protective color serves its purpose, i.c. is used, when the fox fails to see the rabbit. How can the failure of the fox to see the rabbit produce such an effect on the germ cells of the rabbit that the offspring of the rabbit shall be still more protectively colored? Again: many seeds have spines or hooks 
on their outer surfaces, which become entangled in the wool of animals or the clothing of men, and so secure the scattering of the seeds at a distance. These hooks dry up by the time the seeds are ripe, and are nothing but dead hard tissue incapable of receiring any impression. They cannot, then, hand down the effects of their use to the next generation. This is all the more true, since, at the time of their use, they are separated from the plant of which they were a part, and so, of course, can have no effect on the germ cells of that plant. Of course, the dry seed coats can have no vital relation to the little embryo they enclose.

Again, the instincts of the bees, to which we have already referred, are wonderful. The worker-bees, which are the ones with the remarkable instincts, build the honeycomb, gather and store the honey, feed the young, control the queen, manage the whole hive in fact, with an intelligence, or in accordance with instincts, of the highest order. It is the workers alone who have these wonderful instincts, but the workers are practically sterile, very rarely having offspring; so, apparently, the instincts of the workers cannot have been developed through the inheritance of the effects of use. The workers have no offspring to whom they could hand down their instincts. The workers come from eggs laid by the queen, and it seems to have been natural selection, choosing for survival those hives in which the workers are most intelligent, or have the most perfect instincts, that has produced the complex activities of the present beehive. This has been urged by Weismann and others as an example of great development of instinct or intelligence which natural selection alone can have produced.

Now, while I believe that the remarkable instincts of the 
worker-bees have been developed through natural selection, I would suggest that the argument stated above is hardly conclusive. The sterility of the worker-bees is a character acquired within comparatively recent times. Their complicated instincts (or high degree of intelligence) may have been acquired before they became sterile. This possibility is suggested by the fact that the fertile females of certain wasps have most remarkable instincts, almost, if not fully, as wonderful as those of the worker-bees. Among the solitary wasps the fertile females never cease to exercise their special instincts. Among some of the social wasps, on the other hand, we find species in which the fertile females exercise these instincts for a time and later cease to use them. Dr. and Mrs. Peckham say of the genera Vespa and Polistes: "In the autumn the queens, having mated with the drones, creep away into crevices and sheltered corners, where they pass the winter. In the spring they may be seen seeking for suitable nesting places, and forming, from the fibres of weather-beaten wood, which are scraped off and chewed up, the first layer of cells. So much being accomplished, the queen deposits her eggs, one in each cell, and when these develop into grubs she feeds them, until at the end of a week or ten days they spin their cocoons and become pupx. In from eight to ten days the perfect wasp is formed and emerges from its cell ready to assume its share of responsibility in the work of the nest. These first wasps are always neuters, and hereafter all the duties which the queen has been obliged to perform, with the single exception of egg-laying, fall upon them." 'The neuters of these social wasps die when winter comes on. Should they live through the winter, there would be no need of the 
fertile females retaining their special instincts of nest-building and caring for the young. These activities might then be left wholly to the neuter workers, which would give us the condition found among the bees at present. It seems not improbable that this has been the general course of the development of the instincts of the worker-bees. I have given Weismann's argument because it is one so often quoted, though it is not conclusive. There are, however, many classes of phenomena whose development can be explained by natural selection but not by the inheritance of parental modifications, and these phenomena are as remarkable as any we have to explain. We do not need the hypothesis of the inheritance of parental modifications to explain nature because of natural phenomena being "too wonderful for any other explanation."

Finally, the inheritance of parental modifications, even if it occurred, would be wholly inadequate to explain the most fundamental feature of the phenomena of organic nature; namely, the adaptation of the organism to its environment. Adaptation is the key-note of organic nature, and it is exactly the thing natural selection secures, for those individuals which are not adapted to their environment are destroyed in the struggle for existence, leaving only the welladapted forms alive. The inheritance of parental modifications, on the other hand, could not produce adaptation to the environment, unless the influence of the environment upon each individual organism and the reaction of the organism itself were such as to produce adaptation of each individual to its environment, and we are far from having sufficient evidence that the direct changes produced in each individual by the influence of the environment are thus adaptive. For 
example, animals living in cold countries have thicker fur than tropical species. This might readily be brought about by natural selection, but we have little to indicate that the direct effect of cold upon each individual is such as to cause increased thickness of hair.

One more question naturally presents itself. If changes in the offspring are not produced by changes in the body (soma) of the parent, how do variations come to appear in the offspring? Variations arise in the germ cells and are transmitted from them to their offspring. Changes in the internal constitution of the germ cells will cause changes to appear in the young which arise from these germ cells. The character of every animal or plant is dependent upon the character of the germ cell from which it comes. ${ }^{1}$ A newlaid egg of a chicken almost exactly resembles a new-laid egg of a duck. The most careful study of the two would not show any trace of the differences which are to appear as the eggs develop; yet it must be that the two eggs differ in their constitution and that to this difference in structure is due the difference between the birds which will hatch from the two eggs. The character of the adult is predetermined by the character of the egg. Of course, then, anything which causes changes in the character of the egg may cause correlated changes in the adult which is dereloped from the egg.

But what can cause such changes in the egg or spermatozoon? It lies inside the body of the animal or plant which

${ }^{1}$ This is equally true whether we believe with Weismann that every organ of the future adult is represented by a corresponding differentiated though minute particle in the germ, or with Hertwig that the gern cell is more nearly homogeneous, differentiation appearing as growth proceeds. 
bears it, and is to a considerable degree protected from contact with the outer world. Why, then, does the egg change its constitution?

Those who are at all familiar with biological phenomena know that all living things and all parts of their bodies are constantly changing. No bit of living protoplasm is ever at rest. It liberates the energy used in its different life activities only by the destruction of some of its substance, and this constant waste has to be constantly repaired. For this repair food is needed and is digested and assimilated, being built up into new protoplasm to take the place of that which was destroyed. Changes in nutrition may cause changes in the constitution of the organism which is being nourished. The constitution of the germ cells may thus vary with the changing conditions of nutrition, and such changes in the structure of the germ cells may register themselves in changes in the organisms which arise from these germ cells. Variation in animals and plants may therefore be due to the conditions of nutrition of the germ cells from which they came.

Germ cells receive their nutriment from the blood or lymph in all higher animals. The blood may contain other substances than food which will affect the character of the germ cells. Changes in the blood other than those connected with nutrition may therefore cause changes in the germ cells, producing variation in the offspring. Such changes in the constitution of the blood may be due to the action of the somatic cells, since their waste products and secretions find their way into the blood. One can readily conceive, for example, that imperfect action of the renal cells (perhaps due to disease), resulting in impure 
blood, might so affect the germ cells as to cause the offspring which arise from them to diverge somewhat from the usual character. It is hard to see how this somewhat indefinite effect of soma upon germ could be avoided. We have, however, no evidence that the substances given off by the several sorts of soma cells into the blood affect the germ cells in such a way that when they give rise to new organisms these will repeat in their own bodies those peculiar modified somatic activities of their parents which gave into the blood the substances which caused the modification of the germ cells. So, while we recognize the probability that germ cells are constantly affected by changes in the blood due to the activity of soma cells, and while recognizing also that we may have here a real cause of variation, we still have no evidence that these somatic influences upon the germ are of such a nature as to cause the offspring to inherit the adventitious, accidental, or secondarily acquired somatic characters of the parent. We have here a probable cause of variation, but not a means for securing the inheritance in kind of modifications of the parental soma.

Again observe that when a spermatozoon unites with an egg in the process of fertilization, there are mingled germ cells from two different ancestors, each with its own hereditary potentialities. The organism resulting from the development of this compound cell will naturally be different from either of its parents, the hereditary tendencies received from one parent being modified by those from the other parent. For a proper understanding of the possibilities of variation which are involved in this fact of the union of two germ cells in the process of fertilization one needs to be familiar with some of the most intricate 
phenomena of cell structure and physiology, which it is not appropriate to describe here.

In closing this exposition of the theory of organic evolution it is well to call attention to one important point. The whole process of evolution centres in the processes of reproduction. Natural selection is the selection of the individuals who are to perpetuate the species, and not merely of the individuals who are to live out their own lives. Sexual selection is the selection of mates in breeding. Segregation is the prevention of free intercrossing in the breeding processes. Parental modifications can produce an effect upon the evolution of the species only when they are handed down by reproduction to the following generations. The offspring of the next generation, and not the adults of the present generation, are the goal in all the processes of evolution. Much inaccurate thinking has been due to the failure to clearly grasp this fundamental conception. Lloyd Morgan sums the matter up in the phrase, "To breed or not to breed. That's the question."

\section{SUMMARY}

In the foregoing rapid review we have noted the manner of operation of these

Factors of evolution :

Natural selection :

Heredity (Offspring tend to resemble their parents):

Variation (This resemblance is far from exact) :

The destruction, in the struggle for cxistence, of the individuals which are not adapted to their environment, resulting in a more and more perfect adjustment of organisms to the conditions in the midst of which they have to live. 
Sexual selection :

The exercise of choice in mating, observed among spiders, insects, and vertebrates. It results in the developing of courting habits, of conspicuous colors, ornamental appendages, beauty (?) of voice, etc., which tend to make the individuals of one sex (usually the males) attractive to those of the other sex.

Segregation :

By which the individuals of a species are divided into different groups which do not freely interbreed. The causes of segregation are various: geographical, climatic, physiological, resthetic, etc.

Inheritance of parental modifications:

This is probably an efficient cause of evolution among unicellular organisms, but apparently is not effective among higher animals and plants.

And we have seen that all of the processes of exolution necessarily centre in reproduction. 



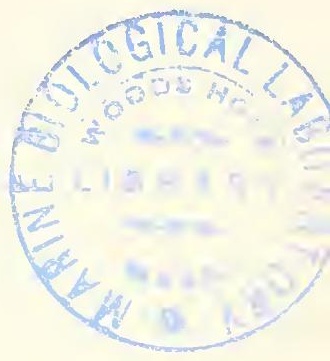

PART SECOND 



\section{THE PHENOMENA EXPLAINED BY THE THEORY}

WE have reversed the natural order in our treatment of the theory of evolution. It was the phenomena, to which we wish now to direct our attention, which first suggested the theory, and it was only by prolonged study of these phenomena that the theory was tested and established. For the sake of brevity in the presentation of the subject, we have chosen first to develop the theory and then to apply it to the phenomena upon which it bears.

For the purposes of our treatment the phenomena to which we wish to direct attention may be classified as follows: the phenomena of comparative anatomy; the phenomena of comparative embryology; the phenomena of paleontology; the phenomena of geographical distribution; and the phenomena of color in animals and in the blossoms of plants. A complete discussion of these subjects would still be but a partial treatment of the phenomena which have a bearing upon the theory. Many points of physiology, the phenomena of sterility, hybridization, instinct, habit, etc., etc., would still be omitted. We shall attempt but a very brief treatment of some of the phenomena of the several types mentioned in the classification given above. Do not, then, be under the impression that we shall have reviewed, even in outline, the whole subject. 
The phenomena of comparative anatomy in their bearing upon the theory of cuolution.

Classification.

All are familiar with the fact that animals and plants are of very many different sorts, and that the different kinds show

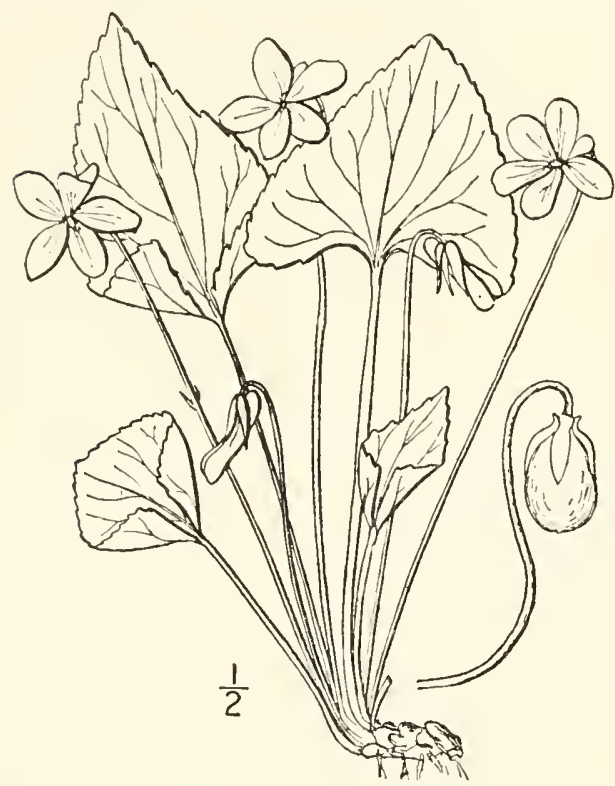

FiG. II. - I Zola cucullata. - From Britton and Brown's lllustrated Fiora of the Northern Stutes and Canada, by the courtesy of the authors and of Charles Scribuer's Sions. very different degrees of complexity in their organization. W' give expression to these facts in our classification of animals and plants. Forms which are closely similar almost to the point of identity we call members of the same species. For example, while hardly any, if any, two robins are so similar that we cannot detect some differences between them, still all robins quite closely conform to the same type, and their mutual differences are so slight that without hesitation we group them together in one species.

We see the same thing among plants. Such of our common blue violets as have rounded, heart-shaped, slightly pointed leaves, and scentless blue flowers of large size, having also very much shortened stems, we class under the one species Viola cucullata (Fig. I I). (There are other characters of the species besides those mentioned by which 
it can be recognized.) But we have other plants whose blossoms in their form so closely resemble those of the common Viola cucullata, and which in their whole appearance are so similar, that we conclude they are connected with this species; yet the differences are sufficiently great for us to be unable to assign them to this species. One kind of these violets have smaller blossoms with a much longer spur. Their stems are highly developed and branching, while their leaves are smaller and are borne upon shorter petioles (Fig. I 2). These we classify as Viola rostrata, indicating the difference between the two types by the different specific names, but at the same time calling attention to the resemblance between the two forms by giving them both the same genus name, Viola. There are

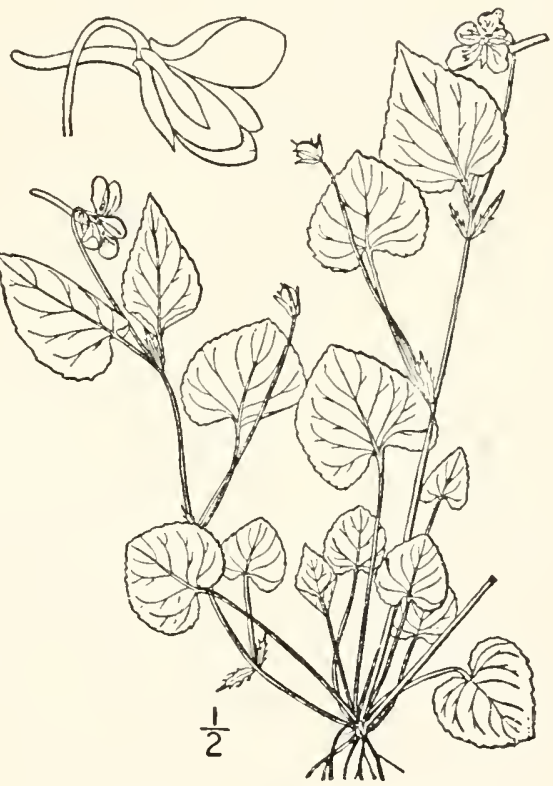

FIG. I2. - Fiola rostrata. - From Britton and Brown's Illustrated Flora of the Vorthern States and Canada, by the courtesy of the authors and of Charles Scribner's Sons.

a dozen or more species of the genus Viola found around Baltimore. In this same region is found an apparently very different plant with tall and branching stems, with coarse leaves and small greenish blossoms, a coarse, weed. like plant (Fig. I3). This form has been named Solea concolor. Now, great as are the superficial differences between this species and our violets, careful study shows that the blossoms of both are made up on the same plan, and 
that there are important fundamental resemblances between Solea and the members of the genus Viola. This fundamental resemblance in the midst of more superficial differences we indicate by classifying both Solea and Viola in a common larger group which we call the family, in this case the violet family or the Violacer. As we have several genera within the one family Violacea, so we have

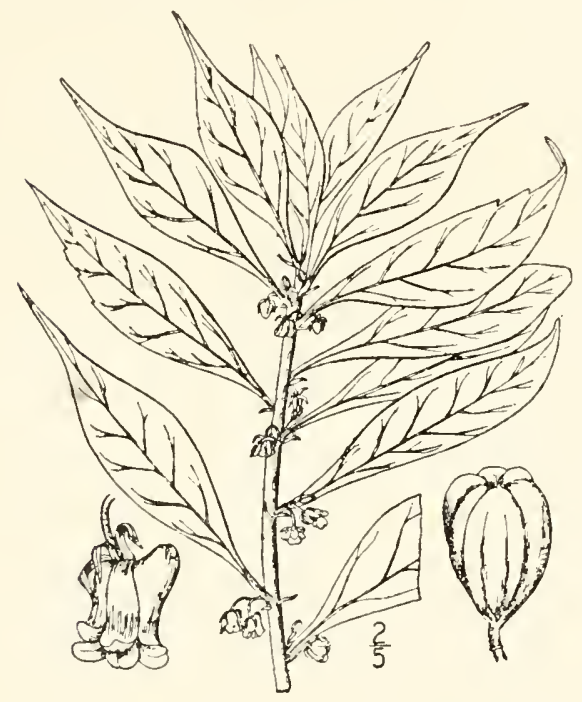

FIG. 13. - Solea concolor. - From An lllustrated Flora of the Vorthern states and Canada, by the courtesy of the authors and of Charles Scribner's Sons. many different families of plants, - the daisy family or Composita, the primrose family or Primulacea, the rose family or Rosacea, and so on. Now all these families mentioned have certain general resemblances to one another, such as the presence of blossoms and seeds. Many other kinds of plants are without either blossoms or seeds; ferns and mosses, for example. We distinguish the former as flowering plants or phanerogams, and the latter as flowerless plants or cryptogams. Thus we have different grades in the classification to indicate different degrees of resemblance and divergence.

Moreover, as we study the different groups of plants, we find them very different in the complexity of their organization, in the extent to which their organs and tissues are developed. Some, like the flowering plants, are highly organized, showing very elaborate structure, while others 
of the lower, flowerless plants, such as the yeast plant, or the Alga, are very simple in comparison. In the same way, among animals we find the lowly organized Amaba and its protozoan relatives, the more complex sponges and jellyfishes, the still more developed flatworms, the annulated worms, the Crustacea, the spiders, the insects, the Mollusca (snails, clams, oysters, etc.), the starfishes, and the vertebrates, including the fishes, Amphibia, lizards, birds, and mammals.

Now, what is the meaning of all this diversity of form and the various degrees of complexity? It is the theory of evolution which interprets these phenomena, showing us that the different degrees of resemblance and divergence between these forms indicate different degrees of relationship. Descent from common ancestors, with divergence under the influence of natural selection and the other factors of evolution, is the key to these phenomena. The taxonomic system, or the system of classification of animals and plants into varieties, species, genera, families, orders, subclasses, classes, subkingdoms, and kingdoms, is but an expression of relationships, the erection of a genealogical tree, in which the animal and plant kingdoms would be the two great branches, the lesser subdivisions corresponding to the smaller branches and the twigs. The sereral species of violets resemble one another because they are the descendants of common ancestors, and that is what we mean when we class them in the same genus I'iola. Fiola and Solea in turn have a still more remote common ancestor, a fact we express by placing the two genera in the same family, the Violacea. At some very much more remote period the flowering plants were derived from the flowerless plants, 
and we give expression to this fact when we establish the two major divisions of the plant kingdom; namely, Phanerogamia and Cryptogamia. These phenomena of taxonomy or classification were unintelligible until the theory of evolution gave us the talismanic word relationship.

\section{Homology.}

There are other phenomena of comparative anatomy fully as important to the student of evolution. The phe-

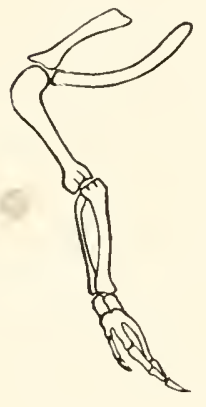

a

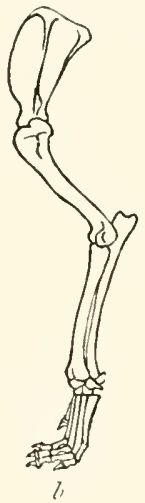

l)

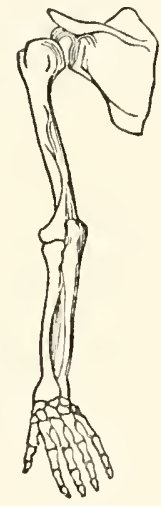

i

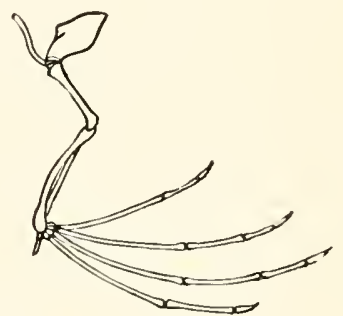

$d$

FIG. I4. - Skeletons of fore limbs of various vertebrates.

a. Wing of a bird. b. Fore leg of a dog. c. Arm of man. d. Wing of bat.

nomena of homology are of great interest. The wing of a butterfly and that of a bird serve the same purpose and are built on the same mechanical principle, but they are fundamentally different in their structure. On the other hand, the wing of a bird and the fore leg of a dog, while used for very different purposes and appearing superficially to be very different, are in reality very much alike in their fundamental structure (Fig. I4). Each has four chief divisions, - upper arm, fore arm, wrist, and hand, - and in each we find the same bones, except that the number of fingers has 
been reduced in the bird's hand. We find the explanation of this resemblance when we recognize that the bird and the $\operatorname{dog}$ are descended from common ancestors in which the leg was used for walking; that the dog has perfected the limb for walking, while the bird has modified and adapted it for the very different use, flying. The two organs are fundamentally alike because they are modifications of the same thing. They are superficially different because they are used for very different purposes. This fundamental resemblance founded on common descent is called homology, and the phenomena of homology, no less than those of taxonomy, lend much support to the evolution theory, being intelligible in the light of that theory, while without this theory they have no meaning to us. We might multiply almost indefinitely illustrations of homology based on genetic relationship; the illustration given, however, will show the line of evidence as well as is needed for our purpose.

\section{Vestigial structures.}

Among the most interesting of the anatomical evidences of evolution are the restigial organs found in so many animals and plants, organs once normally developed and functional, but now reduced, and, so far as we can judge, functionally insignificant. Certain snakes have very slightly developed hind limbs, reminding us of the fact that they are descended from forms which had well-developed limbs, their present limbless condition being secondary (Fig. I5). Whales also have vestiges of hind limbs, in the form of certain small bones lying beneath the skin and not in any way functional (Fig. I6). They are vestiges of the 
functional hind limbs possessed by the terrestrial ancestors of the whales. Similarly, the Apteryx of New Zealand, which has no functional wings, has vestiges of wings, recall-

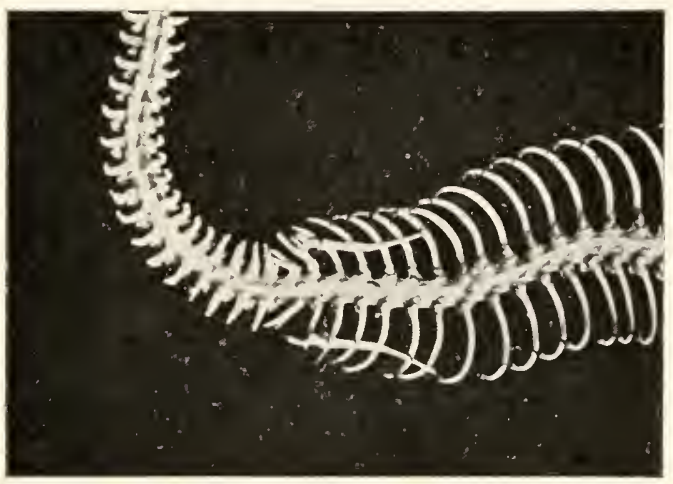

FiG. I5.- Part of the slieleton of a boa constrictor, showing the restigial bones of the hind limbs. - From a specimen in the United States National Museum. ing the typical bird condition (Plate 35). All these vestigial structures are without much meaning until we recognize that they point us to the ancestral forms in which they were important functional organs. We might give many illustrations of such vestigial organs. I will merely mention a few found in man: the muscles which move the skin, but in most persons are too weakly developed to do so except in

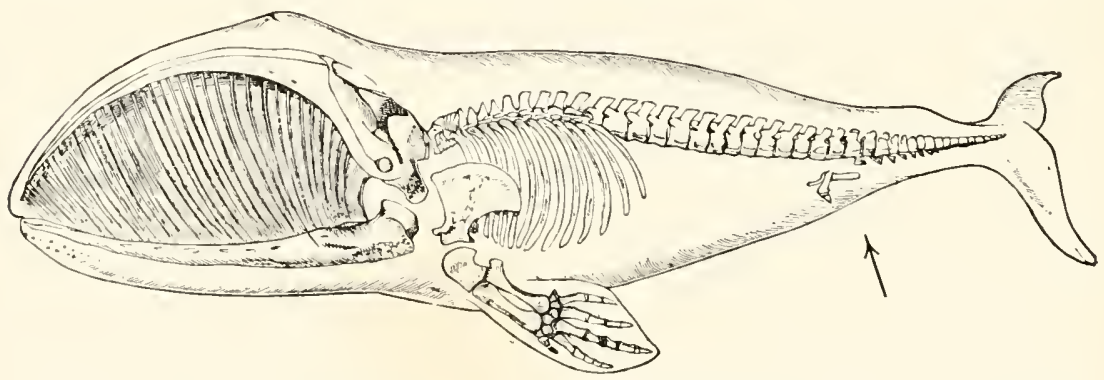

FIG. I6. - Skeleton of Greenland whale, showing the vestigial pelvic bones near the base of the tail. [From Romaxes, after Flower.]

the region of the face; the muscles that should move the ears but usually are not functional (Fig. I 7 ); the nictitating membrane, vestigial in man, but well developed as a third eyelid in reptiles and birds (Plate 36 ); the hair of the body, 

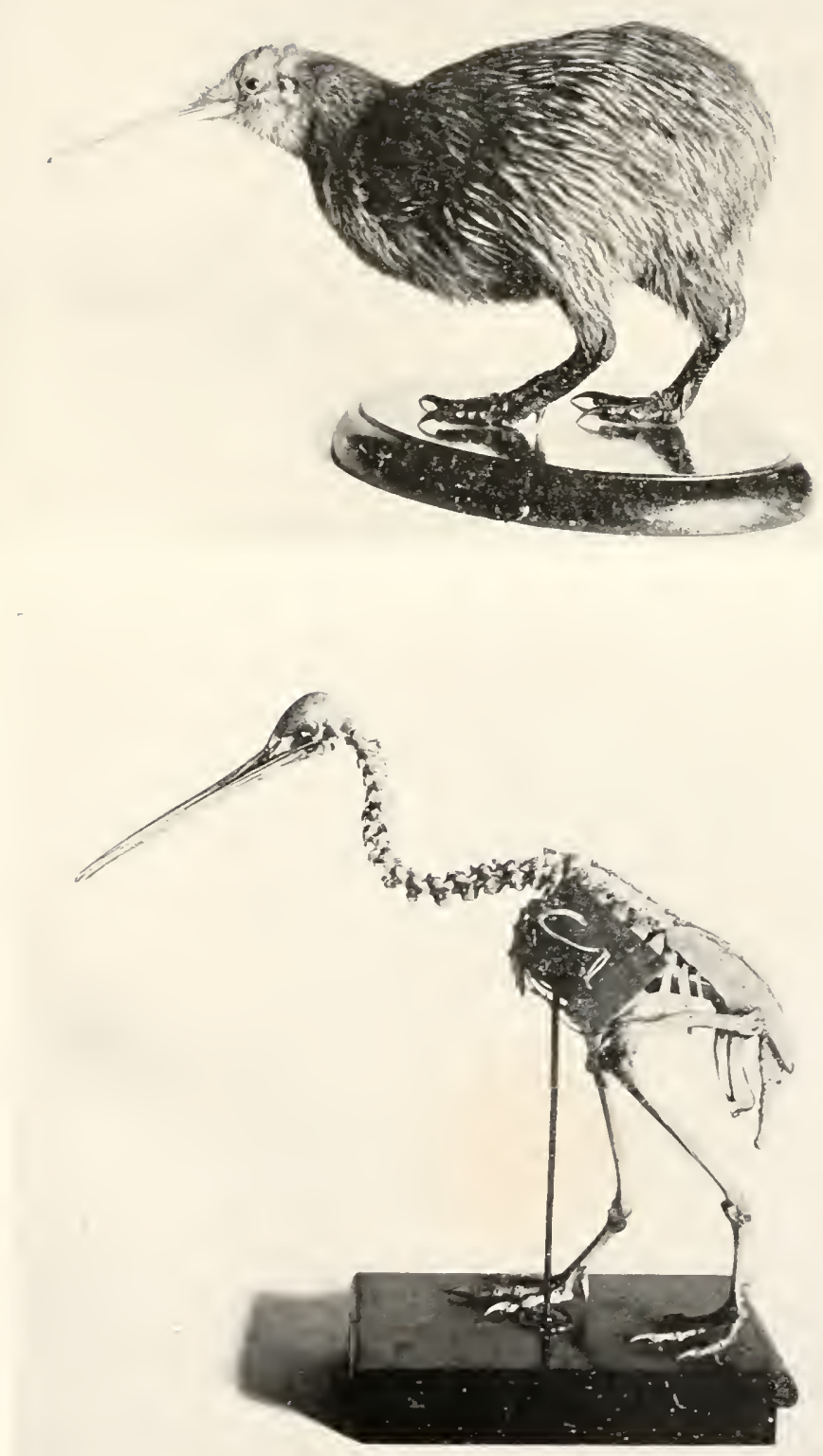

PLATE 35. - Ateryx australis.

The upper figure from a stuffed specimen in the Smithsonian Institution; the lower figure from a skeleton in the museum of 'Ihe Woman's College of Baltimore. A piece of black cardboard has been placed behind the skeleton of the diminutive wing. 


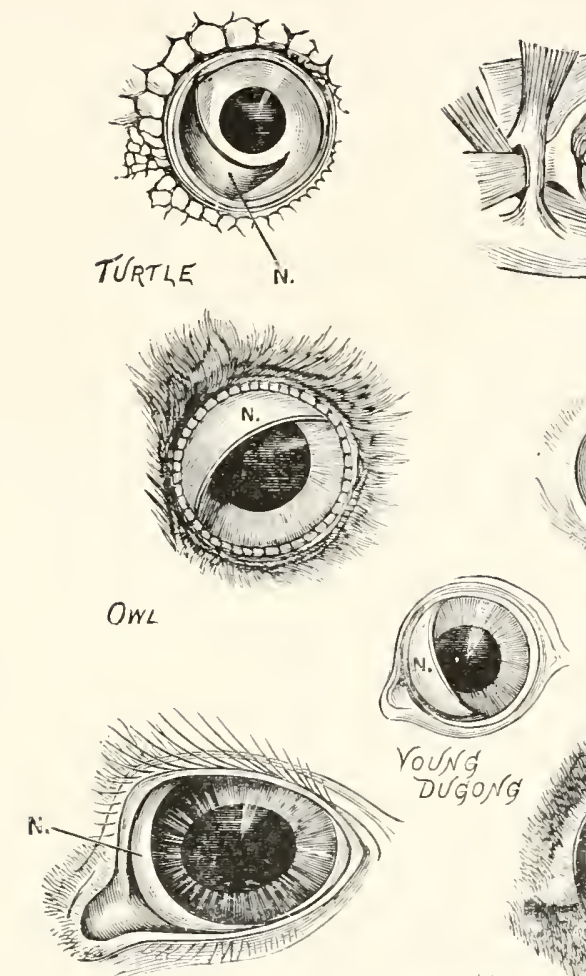

DUGONG

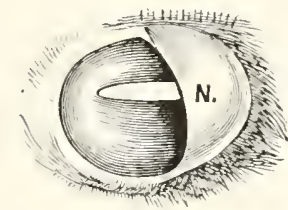

GALEUS

FROM INSIDE

EAGLE

From INGIDE

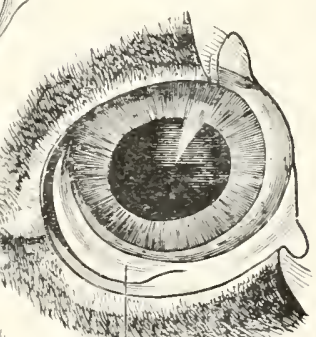

HORSE

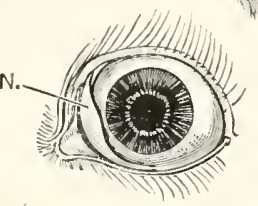

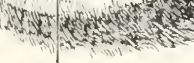

N.

OTARIA

SEA LION

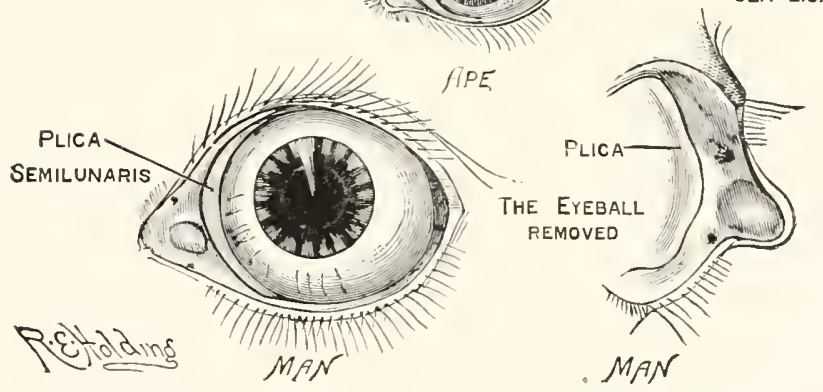

PLATE 36. - Eyes of various vertebrates, showing the nictitating membrane, indicated by the letter $N$. In some reptiles and birds the nictitating membrane can be drawn over the whole front of the eyeball. - From Romanes' Darwin and After Darwin, by the courtesy of 'The Open Court Publishing Company. 


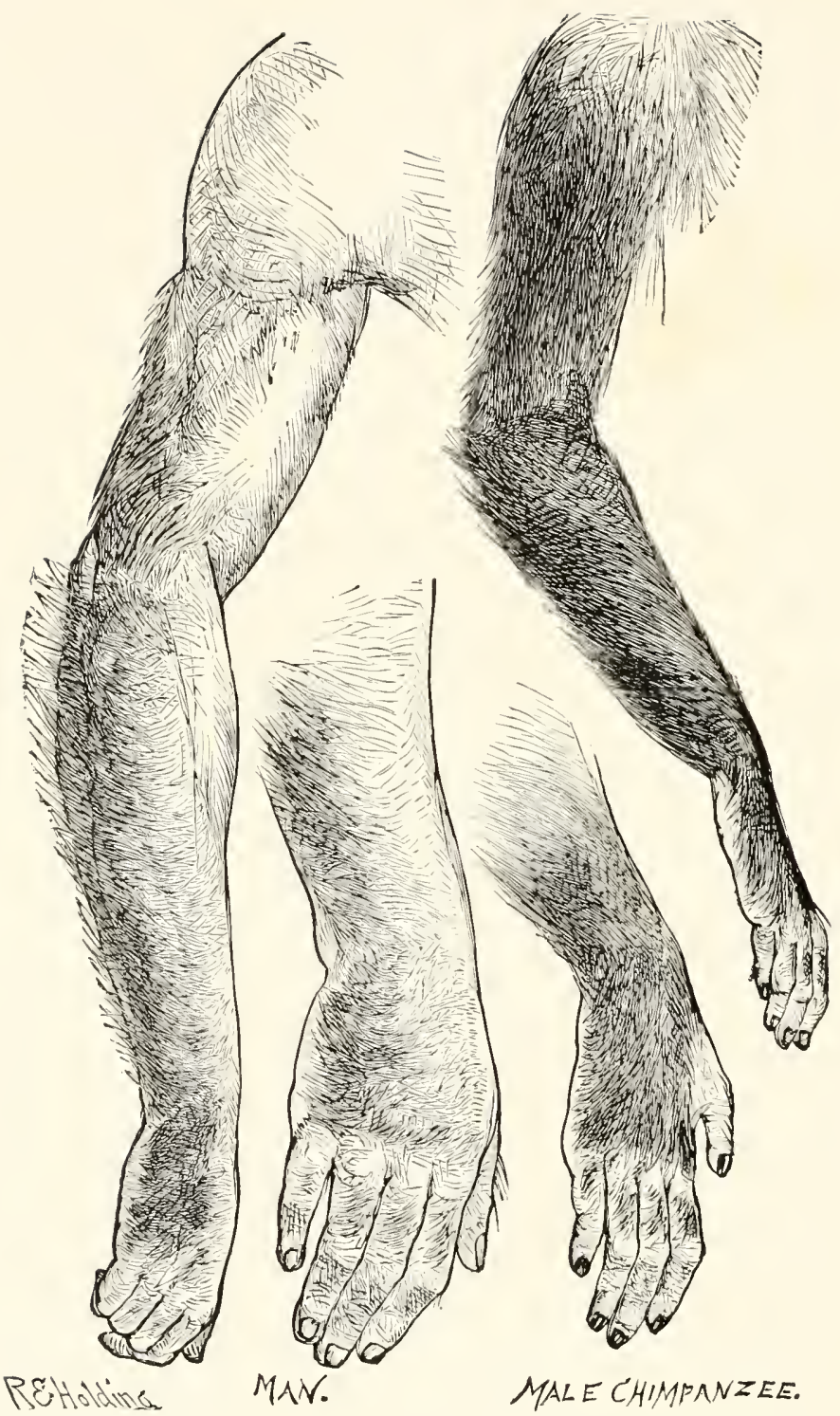

PIATE 37. - Hair tracts on the arms and hands of a man and a male chimpanzee. Drawn from life. Ohserve that in the corresponding regions the direction of the slope of the hairs is the same.- - From Romanes' Darwin and After Darwn, by the courtesy of 'The Open Court Publishing Company. 
reduced to a mere vestige of what we see in the apes, the nearest relatives we have (Plate 37).

The eyes of some caredwelling animals are among our best examples of restigial structures. In Mammoth Care, for example, there is an underground river of considerable size in which are found fish and Crustacea whose eyes are in different stages of degeneration (Fig. IS). Of course, living in total darkness as these animals do, they can have no use for eyes. The presence of eyes in a vestigial condition is an indication of the fact
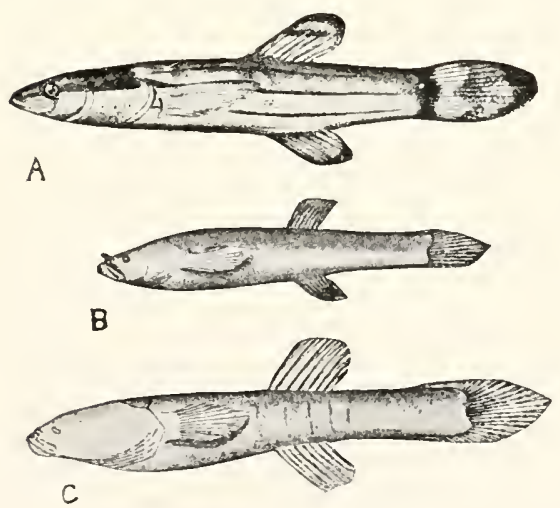

FIf. 18. - Three fishes, showing stages in the loss of eves and color. A. Dismal Swamp fish (Chologister avetus), thought to be the ancestor of the blind fish. B. Agassiz's cave fish (Chologaster agassizi). C. Cave blind fish (Typhlichthys subterraneus). - From Jordan and Kellogg's Animal Life, by the courtesy of the authors and of $\mathrm{L}$. Appleton \& Co.

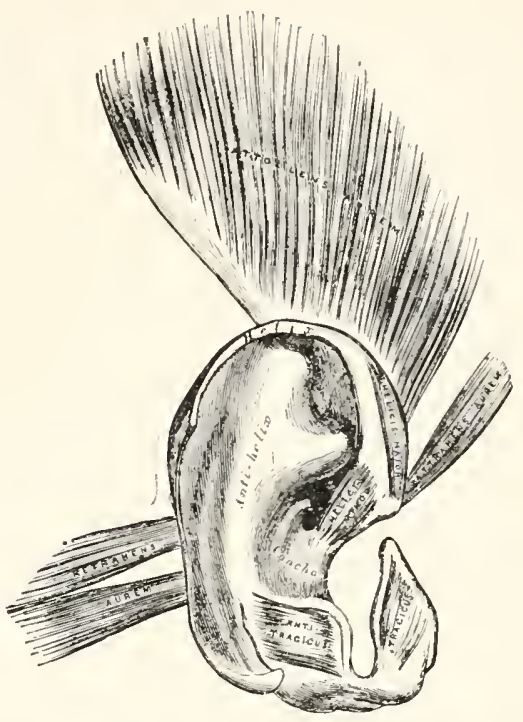

FIG. 17. - Muscles of the human ear. From Gray's Anutomy.

that these cave-dwelling species are descended from forms which once lived in the outer world. As eyes are useless to animals living in the dark, natural selection of course no longer will keep the eyes perfect, and the degeneration begun by the withdrawal of natural selection will go still further, because it is a positive disadvantage to any species to waste nutriment on useless 
organs: thus in time the eyes will become mere vestiges of their former selves. Weismann's theory of germinal selection also may apply here. ${ }^{1}$

The great variety of forms among animals and plants, their different degrees of complexity, the phenomena of homology and of vestigial structures, are readily explained by the theory of evolution, though without the aid of this theory they are apparently meaningless to us.

The phenomena of embryology as related to the theory of covolution.

In the study of the anatomy of different plants and animals we find, as alreacly stated, that they are of very different degrees of complexity. We judge in general that the simpler species are the more primitive and that the more elaborate have been evolved from simpler forms, perhaps from forms more or less like some we find living to-day. The study of embryology gives us additional evidence of the truth of this conclusion. We find that complexly organized animals and plants arise each from a single cell, the fertilized egg, and gradually acquire new organs and a more complicated structure, till finally the adult condition is reached (Fig. I9). The series of stages of increasing complexity, seen in the development of one of these higher forms, reminds us of the taxonomic series in our classification of plants and animals, in which we found all gradations in complexity from

'This theory of germinal selection can hardly' be stated briefly and simply. Weismann's own statement can be found in his essay "On Germinal Selection as a Source of Definite Variation." published by The Open Court Publishing Company. It will not be easily understood by one who has not followed Weismann's work. 
the lowly Protozoa and Protophyta to the vertebrates and flowering plants.

Not only do we find that there are these two kinds of series, the anatomical and the embryological, but we find that the two series often correspond to a remarkable degree. Take an illustration. Among the vertebrates, fishes are the

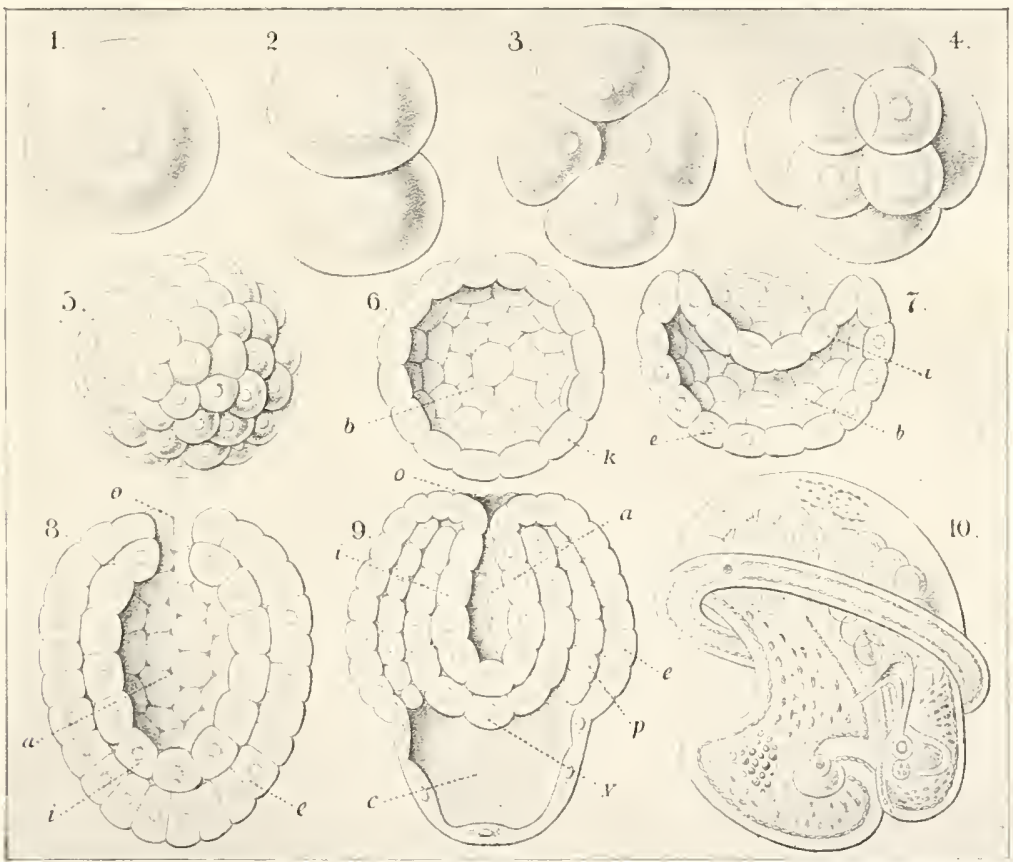

FIG. I9. - Stages in the development of the pond snail (Lymnceus). [After HAECKEI..]

simplest on the whole. The Amphibia are in general somewhat more modified in their organization. The reptiles and birds are still more so, and the mammals are in some regards the most highly developed of all. Now, as we study the embryology of the Mammalia, we find that in some features of their general organization and in the character of many of their separate organs the different stages in their 
development correspond to the conditions seen in the lower vertebrates (Plate 38 ). There is a stage when the mammalian embryo has gill-slits like a fish, also a simple tubular heart and a blood circulation much more fish-like than is the adult mammalian circulation. This we interpret as a reminiscence of the time when the ancestors of the mammalia were aquatic animals. Birds and reptiles show in their embryology a similar stage resembling the fish in many important regards. The frog and other terrestrial Amphibia are actually aquatic in early life, their tadpoles being very fish-like (Fig. 20).

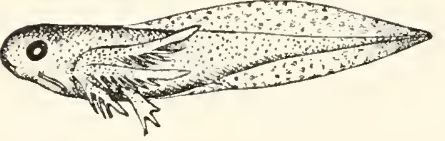

FIC, 20. - Tadpole of salamander (Amblystoma), magnified $2 \frac{1}{2}$ times.

In these different stages in the embryology of an animal we read the history of its evolution from simpler forms to its present state.

We say that the development of the individual tends to recapitulate the evolution of the race, and in studying embryology from this standpoint we are studying the racial history.

Many examples of the interpretation of race histories from the study of embryology might be given among both plants and animals. I will give but one more, chosen from the higher Crustacca. The Decapoda, the highest group of the Crustacea, includes among many others several forms familiar to us all: the lobster, the crawfish, and the crab. The lobster (Plate 39) has the posterior part of the body long and well developed, using it in swimming; and by its aid the lobster is able to leap through the water to considerable distances. We call this portion of the body the abdomen. It is filled with powerful muscles, and is divided into seven parts, or segments, which move freely upon one 


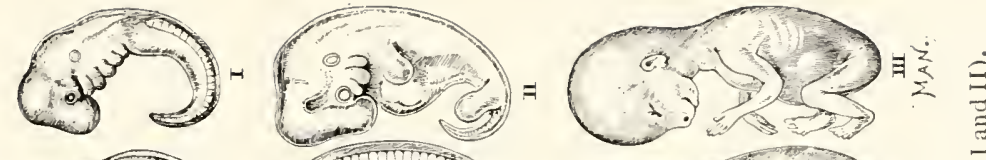

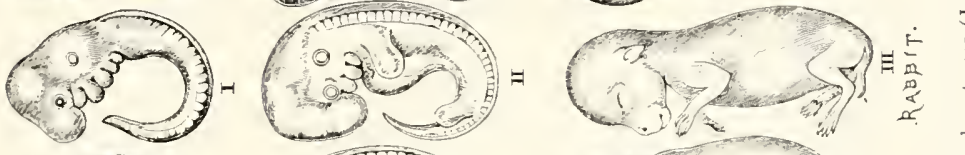

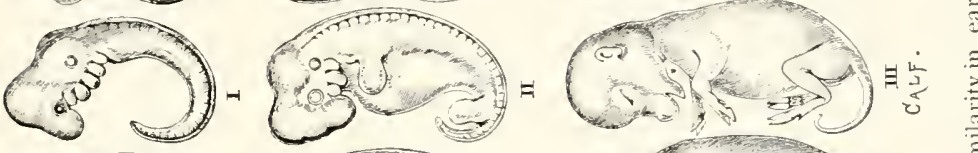

$\left(\begin{array}{rl}3 \\ 3\end{array}\right.$

竞

i

学

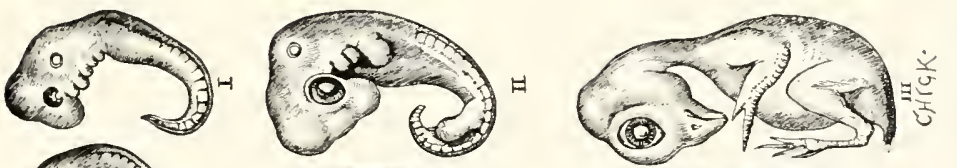

굴

른

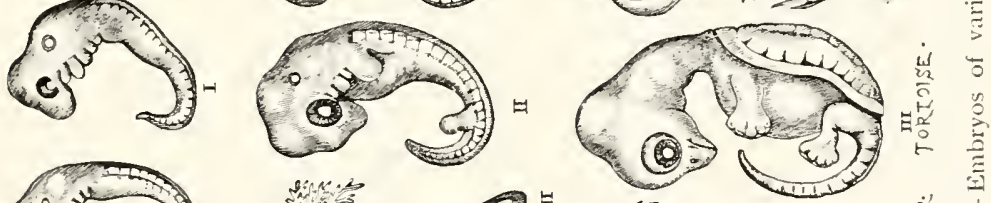

$\left.(0)^{3+2}\right)^{3}$ 



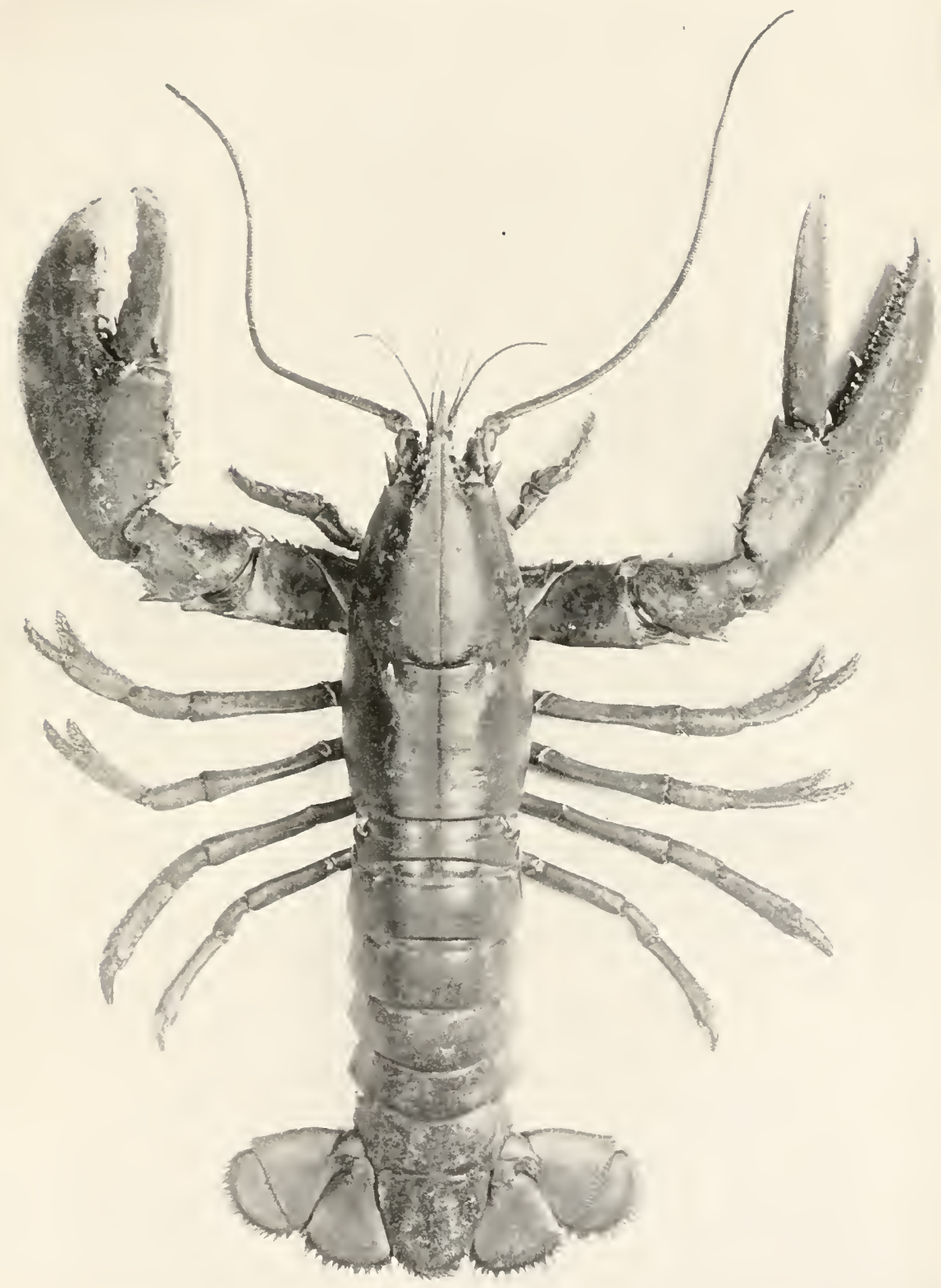

P'LATE 39. - Lobster (Homarus amcricunus), two-fiths natural size. 



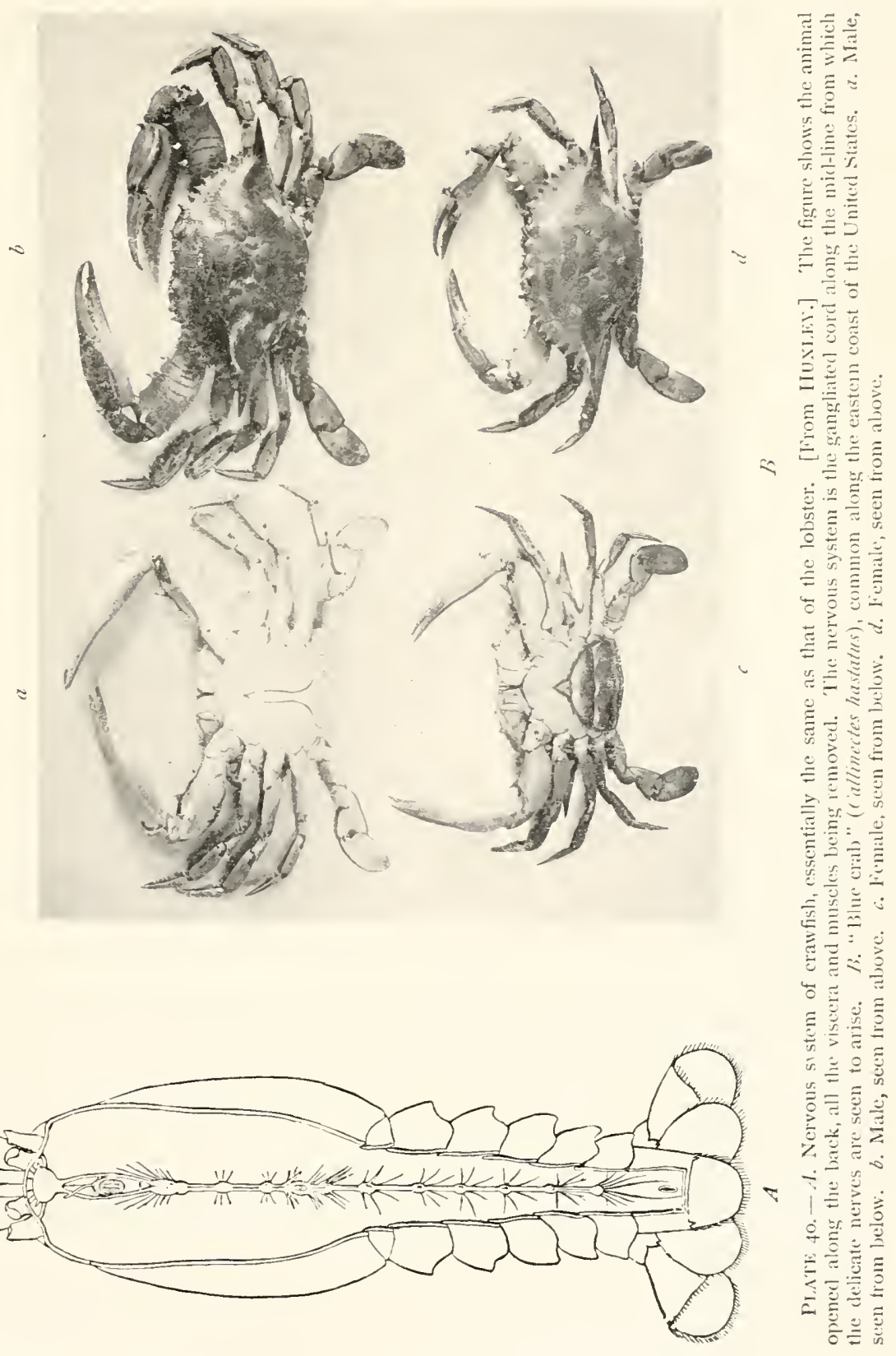




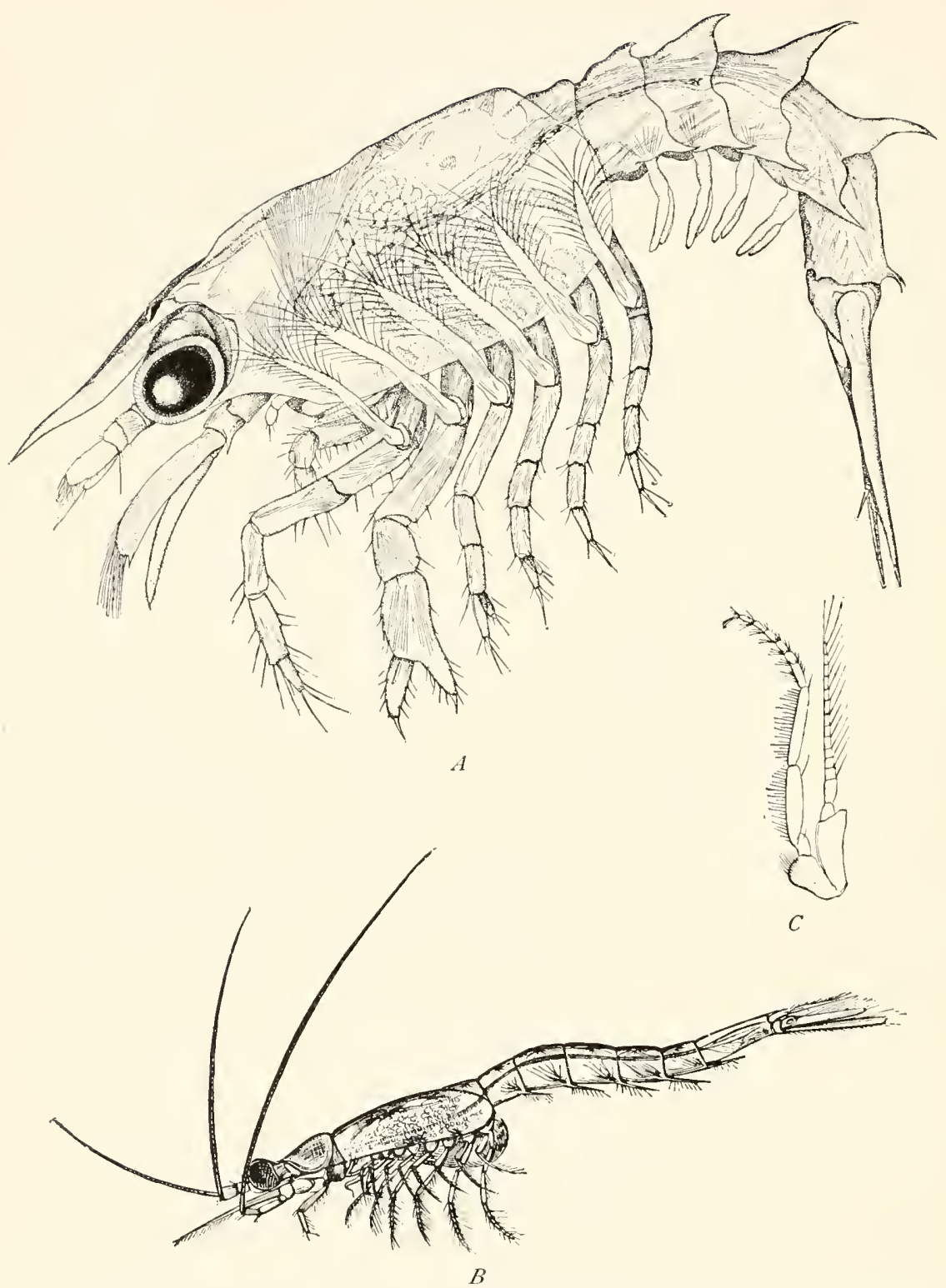

Plate 4I. $-A$. "Mysis stage" in the development of the American lobster. Each leg is seen to have two branches. [After HerRick.] B. Lysis stenolepis. [From Claus.] C. A single leg of Mysis, showing its two branches. [From LaNG.] 
another. In six of these segments are ganglia of the nervous system, controlling the action of the muscles of the several segments (Plate to, $A$ ). The crab appears to be very different (Plate $40, B$ ). 'There does not at first sight seem to be any abdomen at all, but turn the crab on its back, and we see on the under side a small structure clinging close to the under side of the body, which when carefully examined shows the same divisions into segments that we observed in the abdomen of the lobster (Plate $40, B, c$ ). It is the abdomen of the crab, but much reduced in size, and almost functionless. It contains no nerrous ganglia and is very different apparently from the abdomen of the lobster. But when we come to study the embryology of the crab we see that it passes through a stage when it has an elongated abdomen with ganglia in six of its seven somites (Fig. 2 I). This lobster-like stage in the development of the crab is a reminder of the fact that the crab is descended from ancestors resembling the lobster. Let us go a little farther. The lobster has legs like those of a crab, consisting of a linear series of joints. In the embryology of the lobster, however, we find a stage when the legs are double, not single, each leg having two branches (Plate $4 \mathrm{I}, A$ ). In this regard the lobster larva resembles another member of the group Decapoda, namely M/ysis, a small animal with which many may not be familiar (Plate $4 \mathrm{I}, B$ and $C$ ). We call the stage in the development of the lobster when its legs are biramous the Mysis stage, and conclude that it is an indication that the lobster is descended from Mysis-like ancestors. Some crabs have larve with biramous legs. Of course conclusions are not drawn from a single indication like the above, but the whole condition of the organism is studied. For the sake of 
simplicity we have noticed in each case but a single feature of the comparison.

The embryological repetition of the race history is generally much distorted by secondary modifications which

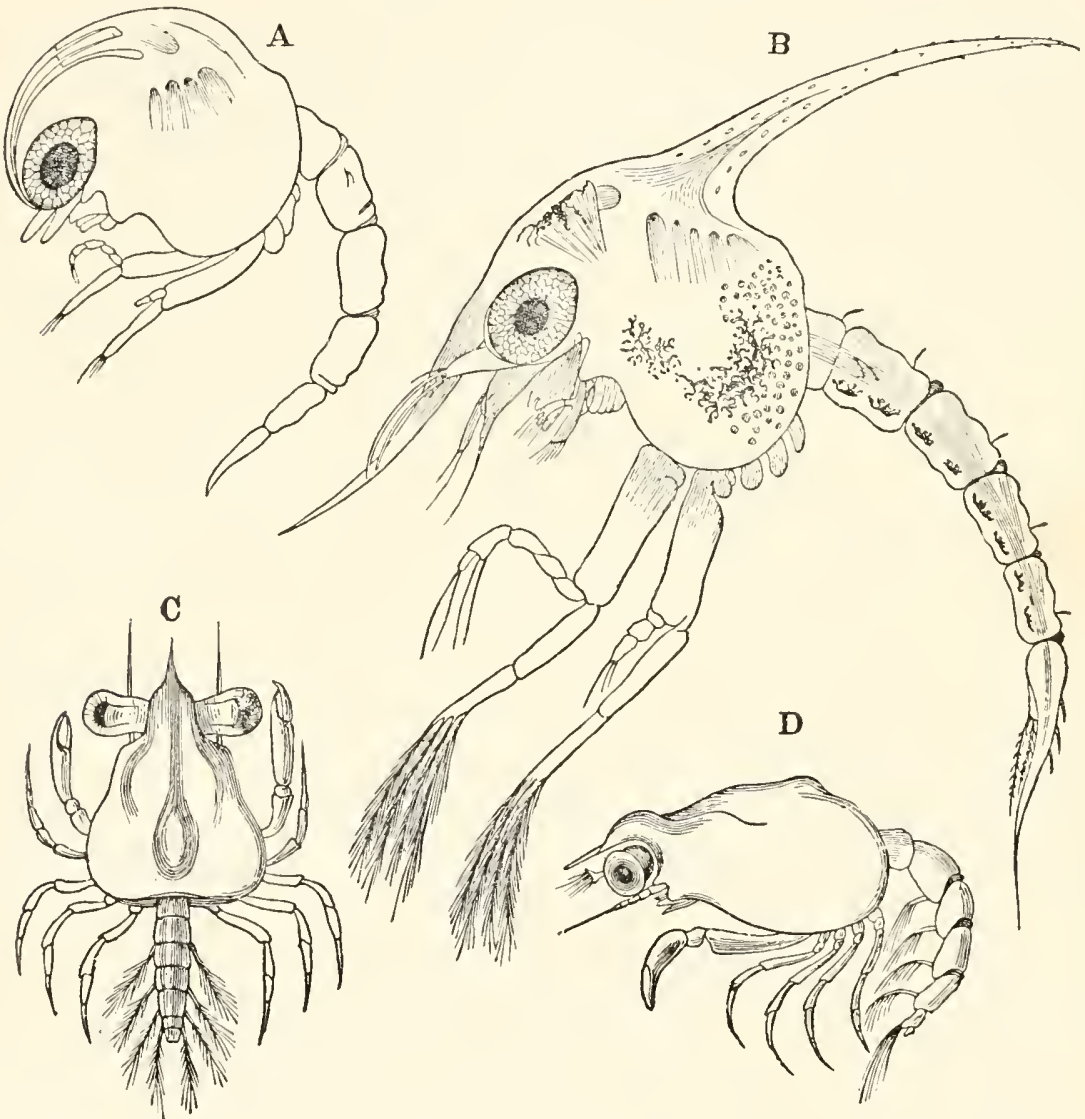

FIr. 2I. - Three stages in the development of a crab (Cancer fagurus). [After Huxlex.]

A. A newly hatched larva. $B$. An older larva. $C, D$. Much older larve. In all of these the elongated abdomen is shown. In the two earlier stages some of the legs are seen to be biramous.

cause all stages in the life history to become more perfectly fitted for their life conditions, but underneath these secondary modifications we can often see indications of the 
character of the ancestral forms to which the several embryonic stages correspond.

The phenomena of homology are as evident in the study of embryology as in anatomy. Many structures in the embryo can be properly understood only after comparison with similar organs in other forms to which they are related.

Another class of structures, which we may call nascont organs, appears in the embryology of very many forms. These are organs which begin to appear during the development of the animal or plant, but which never become fully cleveloped or normally functional, and soon disappear before the adult condition is reached. They recall some ancestral condition in which these organs were important, and are of interest as showing the racial history, but,

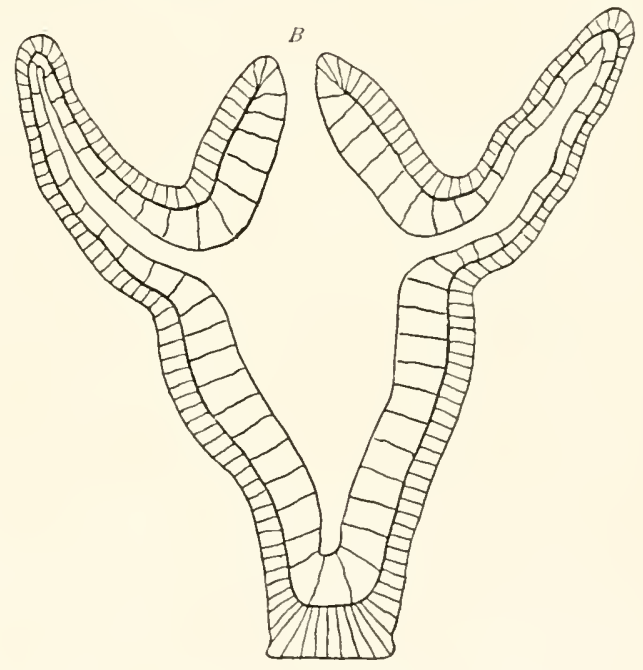

FIg. 22. - Hydra. A diagrammatic longitudinal section.

$B$. The single aperture (nouth anus) by which the digestive cavity opens to the exterior.

so far as we now can judge, the weakly dereloped rudiments of these structures are of little importance to their present possessors. Numerous examples might be given. I will mention but one.

The jellyfishes and their relatives have but a single opening into their alimentary canal, which serves both for the ingestion of food and the egestion of wastes (Fig. 22). Nost of the 
higher animals when adult have two apertures into the digestive tract, the mouth and the anal aperture, but in their development they pass through a stage when like the jellyfishes they have only the one opening (Figs. 23 and 24). This single embryonic aperture is called the blastopore and is a reminiscence of the jellyfish mouth. In certain of the lower vertebrates, the frog for example, we find the blastopore present in the embryo and well formed and functional (Plate $42, A$ and $B$ ).

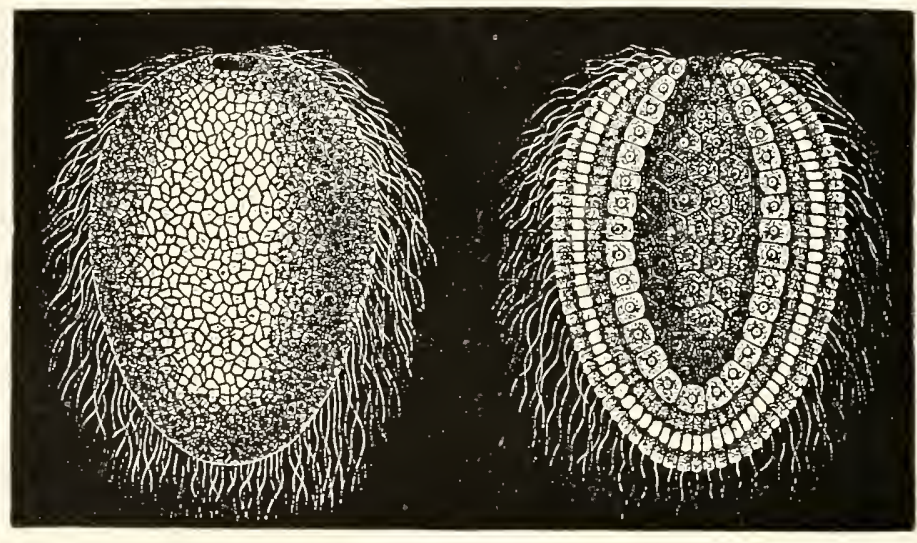

$a$

b

FIG. 23. - Gastrula of a coral polyp (Monaxenia darwinii). [After HAECkEL.] a. A surface view. b. A longitudinal section.

Later it closes and disappears. In the higher vertebrates, on the other hand, the blastopore does not become functional at any time during the embryonic life (Plate $42, C$ ). It is a nascent organ. It begins to appear, but never reaches normal development, and later disappears without ever having come to its typical condition. Its presence is of no use to its possessor, so far as we can see, but the fact that it is there in a rudimentary condition agrees with our principle that the development of the individual tends to recapitulate the evolution of the race. The ancestors of the vertebrates, 

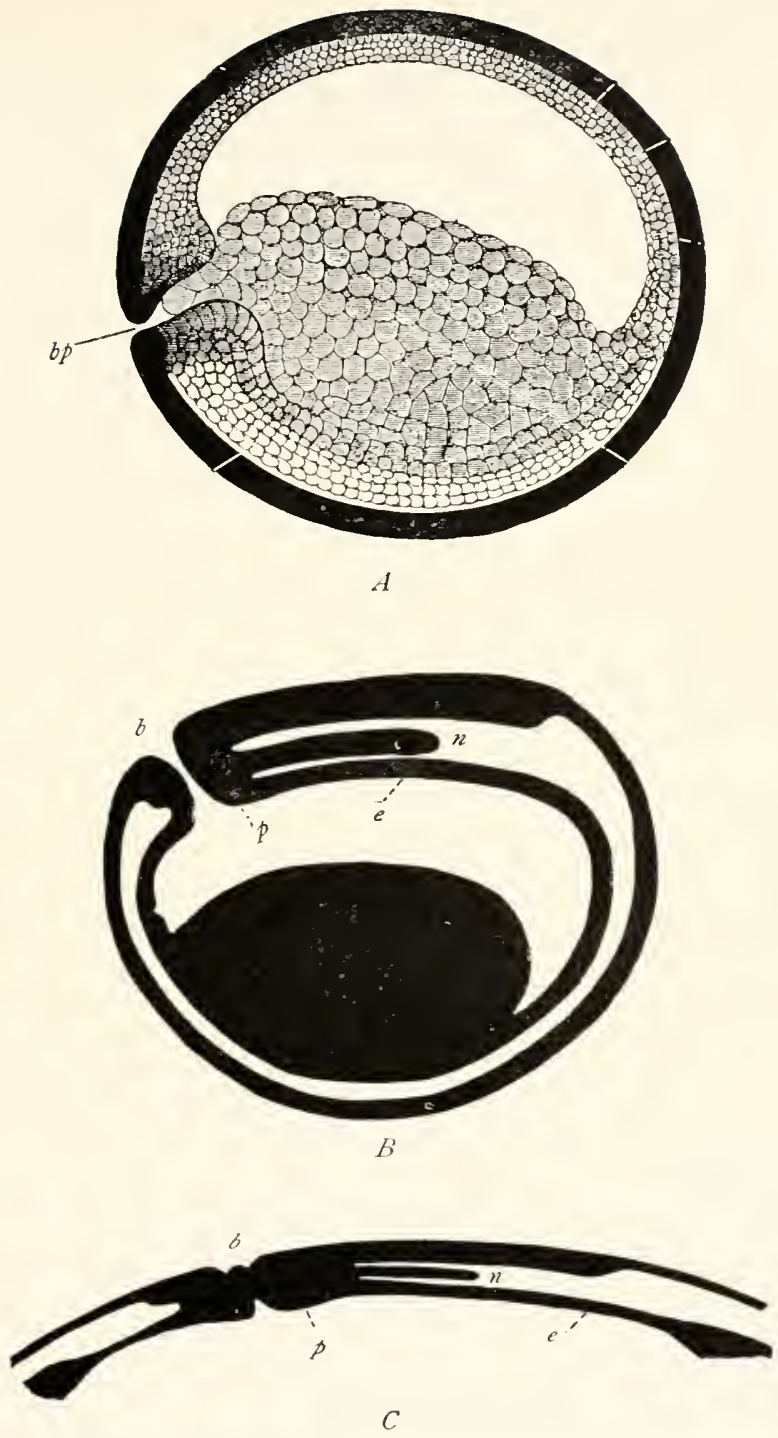

Plate 42. - A section of a gastrula embryo of a frog. bp. Blastopore. - From Marshall's Vertebrate Embryology, by the courtesy of Smith, Elder and Co. $B$. A diagrammatic longitudinal section of an older embryo of a frog. b. Blastopore. $e$. A layer of cells which will become the lining of the alimentary canal. n. A rod of cells (the notochord) which later is replaced by the vertebral column. $p$. The so-called primitive streak where the notochord and the lining of the alimentary canal fuse with the outer layer of the embryo, forming a plug of cells through which opens the blastopore. The thickened part of the outer layer of the embryo, on the upper side, will form the brain and spinal cord. $C$. A diagrammatic longitudinal section of the upper portion of an embryo of a bird. Reference letters as in Fig. $B$, with which this figure should be compared. The blastopore is very imperfectly developed and does not open. It is indicated only by a thin spot in the primitive streak, which soon disappears. 

we believe, had, like the jellyfishes, but a single opening into the alimentary canal. The lower vertebrates repeat this condition in the course of their embryonic development. The higher vertebrates no longer use the blastopore even while embryos, but they retain it as a transient rudiment. Of facts like these we have no satis-

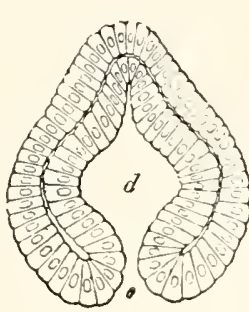

A

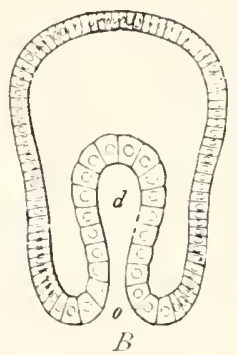

B

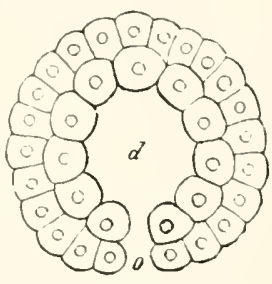

D)

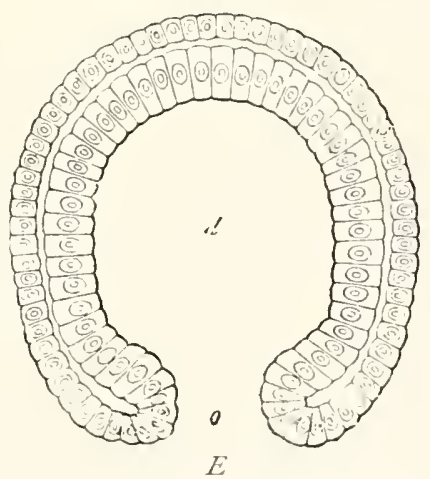

FIG. 2.t. - Longitudinal sections of gastrulæ of various animals. [After H.AECKEL.]

A. Of a worm, Sargitta. B. Of a starfish, Lraster. C. Of a crustacean. D. Of a snail, Lymnaus. E. Of Amphioxus, a lowly relative of the vertebrates. $d$. Digestive cavity. o. Blastopore. tual record of this evolution in the remains of the animals and plants which have lived in the past. The record is very imperfect, to be sure, but so far as it goes it is an actual record. Only very unusual 
circumstances will secure the preservation of any animal or plant as a fossil. An organism, or portion of an organism, to be so preserved usually must be hard; it must be buried beneath soil of the proper kind, and when buried must be impregnated with mineral salts or in some other way preserved from disintegration. When once converted into a fossil it must escape destruction at the hands of those agencies that are constantly destroying the rocks, heat, pressure, the disintegration that comes from exposure to the atmosphere, abrasion by ice, and especially erosion by water. The character of whole continents has been repeatedly changed by these agencies. No wonder, then, since fossilization is rare and the destruction of fossils when once formed so easy, that our record of past faunas and floras is so scant. It is a cause for congratulation that we have so much of a record as we do possess. Thousands of species of fossil plants and animals are known, and as yet but a small portion of the earth has been searched. We will give attention to but a few illustrations of the kind of record we find in the fossil-bearing rocks, choosing naturally records that are quite complete.

Let us first look at a table showing the order of formation of fossil-bearing rocks. At the bottom of the table are named the oldest of all the rocks in which fossils are known to be found, the Cambrian formation, about 24,000 feet, four and one-half miles, in thickness. In these rocks we find fossil remains of many different types, jellyfish, sponges, Polyzoa, brachiopods, echinoderms, Mollusca, and annulated worms, but no vertebrates. Numerous types are represented, but they were simple organisms in comparison with the representatives of the same types found in the 


\begin{tabular}{|c|c|c|}
\hline \multirow{5}{*}{ 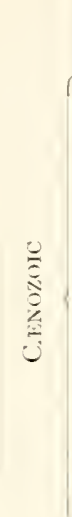 } & Epochs and Formations & Faunal Characters \\
\hline & PLEISTOCENE. & $\begin{array}{l}\text { Man. Mammalia principally of living species. } \\
\text { Mollusca exclusively recent. }\end{array}$ \\
\hline & Pliocene, 3,000 ft. & $\begin{array}{l}\text { Mammalia principally of recent genera - liv- } \\
\text { ing species rare. Mollusca very modern. }\end{array}$ \\
\hline & $\begin{array}{l}\text { MiOCENE, } 4,000 \mathrm{ft} \text {. } \\
\text { OLIGOCENE, } 8,000 \mathrm{ft} \text {. }\end{array}$ & $\begin{array}{l}\text { Nammalia principally of living families; ex- } \\
\text { tinct genera numerous; species all extinct. } \\
\text { Mollusca often of recent species. }\end{array}$ \\
\hline & EOCENE, IO,OOO ft. & $\begin{array}{l}\text { Mammalia with numerous extinct families and } \\
\text { orders; all the species and most of the gen- } \\
\text { era extinct. Modern type shellish. }\end{array}$ \\
\hline & $\begin{array}{l}\text { CRETACEOUS, I } 2,000 \mathrm{ft} \text {. } \\
\text { Chalk. }\end{array}$ & $\begin{array}{l}\text { Dinosaurian reptiles; pterodactyls (flying rep- } \\
\text { tiles); toothed bircls; earliest snake; bony } \\
\text { fishes; crocodiles; turtles; ammonites. }\end{array}$ \\
\hline & $\begin{array}{l}\text { JuRAssic, } 6,000 \mathrm{ft} \text {. } \\
\text { Oolite. } \\
\text { Lias. }\end{array}$ & $\begin{array}{l}\text { Earliest birds; giant reptiles (ichthyosaurs, } \\
\text { dinosaurs, pterodactyls); ammonites; clam } \\
\text { anıl snail shells very abundant; decline of } \\
\text { brachiopods; butterfly. }\end{array}$ \\
\hline & $\begin{array}{l}\text { Trias, } 5,000 \mathrm{ft} . \\
\text { New Red Sandstone. }\end{array}$ & $\begin{array}{l}\text { First mammalian (marsupial); 2-gilled cephal- } \\
\text { opods (cuttle-fishes, belemnites); reptilian } \\
\text { footprints. }\end{array}$ \\
\hline \multirow{5}{*}{$\stackrel{(}{=}$} & Permian, 5,000 ft. & Earliest true reptiles. \\
\hline & $\begin{array}{l}\text { Carboniferous, } 26,000 \mathrm{ft} \text {. } \\
\text { Coal. }\end{array}$ & $\begin{array}{l}\text { Earliest amphibian (labyrinthodont); extinc- } \\
\text { tion of trilobites; first crayfish; beetles; } \\
\text { cockroaches; centipedes; spiders. }\end{array}$ \\
\hline & $\begin{array}{l}\text { DEVoNiAN, i } \$, 000 \mathrm{ft} . \\
\text { Old Red Sandstone. }\end{array}$ & $\begin{array}{l}\text { Cartilaginous and ganoid fishes; earliest land } \\
\text { (snail) and freshwater shells; shellfish } \\
\text { abundant; decline of trilobites; May-flies; } \\
\text { crab. }\end{array}$ \\
\hline & SILURIAN, $33,000 \mathrm{ft}$. & $\begin{array}{l}\text { Earliest fish; the first air-breathers (insect. } \\
\text { scorpion); lrachiopods and } 4 \text {-gilled cephal- } \\
\text { opods very abundant; trilobites; corals; } \\
\text { graptolites. }\end{array}$ \\
\hline & CAMBRIAN, $24,000 \mathrm{ft}$. & $\begin{array}{l}\text { Sponges, jellyfish, annulated worms, Mollusca, } \\
\text { brachiopods, Polyzoa, echinoderms - no ver- } \\
\text { tebrates. }\end{array}$ \\
\hline
\end{tabular}

From Romanes' Darwin and afler Darwin, slightly modified. 
rocks of more recent formation. Take any group and compare a number of Cambrian fossils of this group with a number from the younger rocks and we find the younger fossils decidedly higher in their organization. In the rocks formed during the Silurian age, which succeeded the Cambrian period, we find the vertebrates, fishes, beginning to appear, and the earliest air-breathing animals, insects and scorpions, also animals of the same groups that we found represented in the Cambrian rocks, but of a more elaborate structure. In the Devonian period cartilaginous and ganoid fishes and terrestrial and fresh-water shells are among the most interesting forms. In the next younger rocks, the Carboniferous, appear the earliest Amphibia as well as more highly organized representatives of the several groups of invertebrates. The earliest reptiles appear in the Permian rocks, which follow the Carboniferous. Mammals and birds are found in the rocks of the succeeding two periods, and all of the groups of vertebrates and invertebrates continue to be represented by progressively more highly differentiated species, many of the more lowly types disappearing, until we come to the present age, commonly called the age of man. This general sequence of fossils, the simpler giving way to the more complex as we come down to the younger rocks, is a most impressive thing, and is one of the chief evidences that evolution has taken place.

Turning to a few illustrations of the origin of particular species or organs, we find the same principle of gradual increase in complexity as we come from the older to the younger geological formations. Our record of the evolution of branching antlers in the deer is fairly complete (Fig. 25). The first deer in the early Miocene had no 


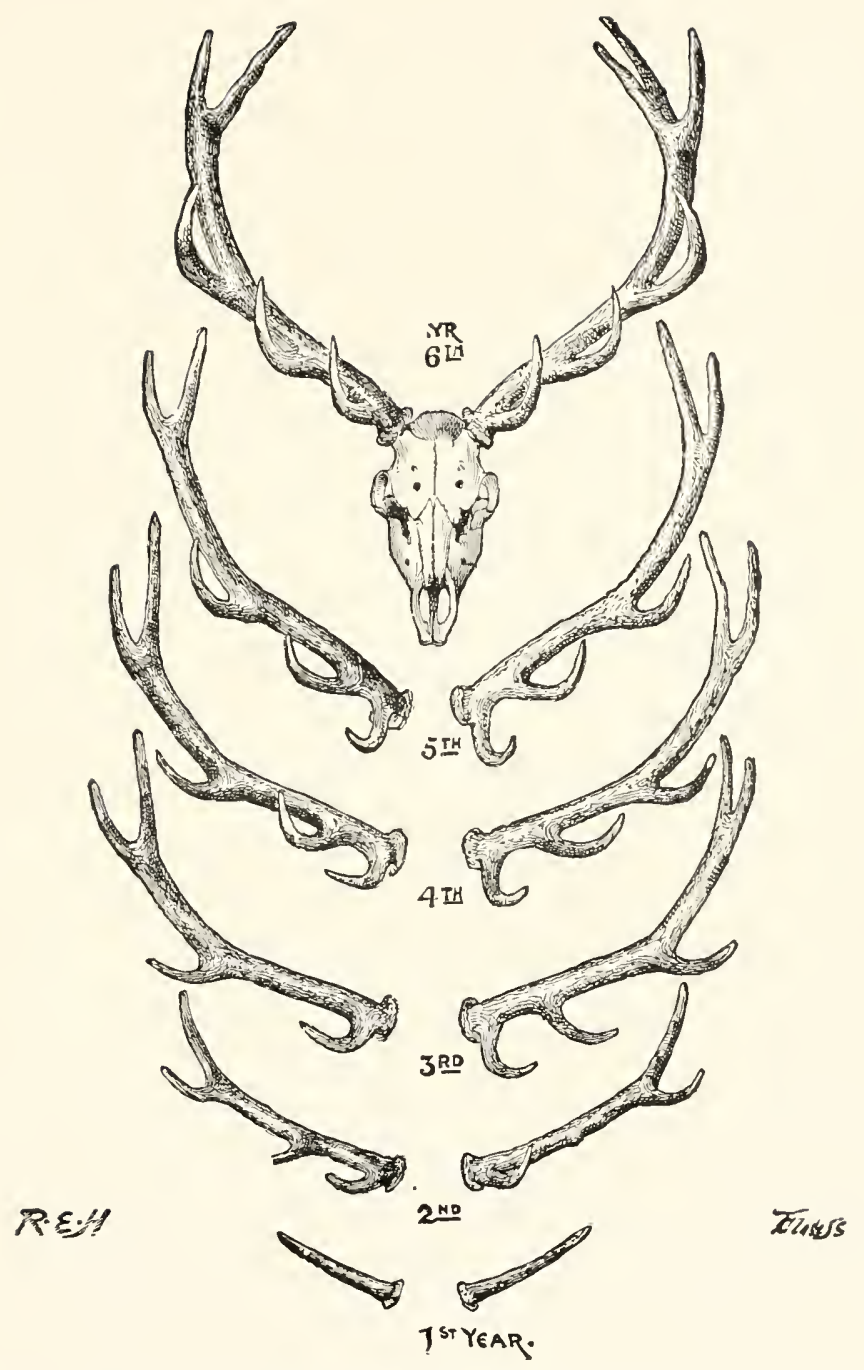

PI.ITE 43. - Antlers of a stag, showing the addition of new branches in successive years. From Romanes' Darwin and After Darwin, by the courtesy of The Open Court Publishing Company. 

antlers at all. In the middle Miocene we find deer with two-pronged antlers of small size (Fig. 25, $A$ and $B$ ). In the upper Miocene and lower Pliocene are found threepronged antlers somewhat larger (Fig. 25, $C$ and $D$ ). In the later Pliocene we meet four-pronged and five-pronged antlers and still larger (Fig. 25, E). In the Pleistocene clays we see arborescent antlers like those of the modern deer (Fig. 25, F). It is especially interesting to see that

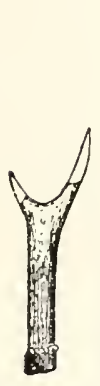

A

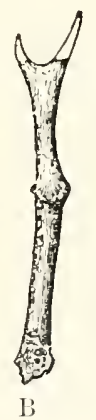

FIG. 25. - Fossil deer antlers.

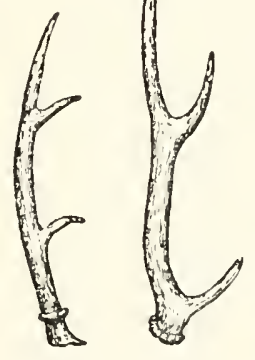

1)
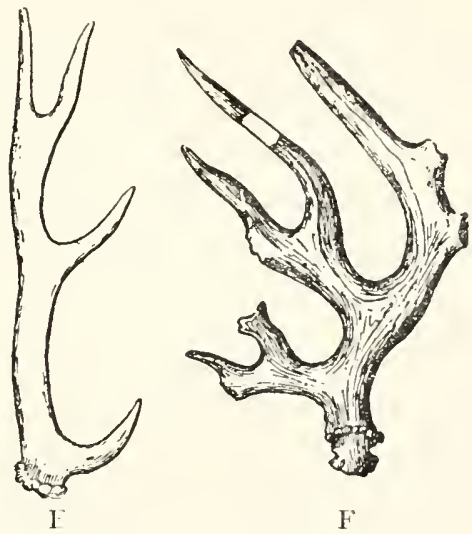

$\mathrm{F}$

A and B. Cervus dicrocerus. C. C. Matheronis. D. C.paradinensis, E. C. issiodorensis. F, C. sedgwickii.

the antlers of our deer, as the animal grows older, pass successively through the several stages we find in the series of fossils just referred to, new branches being added each year (Plate 43 ), thus again illustrating the fact that the development of the individual tends to recapitulate the history of the evolution of the race.

In Fig. 26 are shown drawings of seventeen different varieties of fossil Paludina shells, all from the same locality in Slavonia. Paludina is a fresh-water snail, and individuals similar to the variety figured in the last clrawing 
are living to-day in the lakes of Slavonia. These lakes have been gradually filled up by the silt brought into them by their tributary streams. Careful study of the deposits
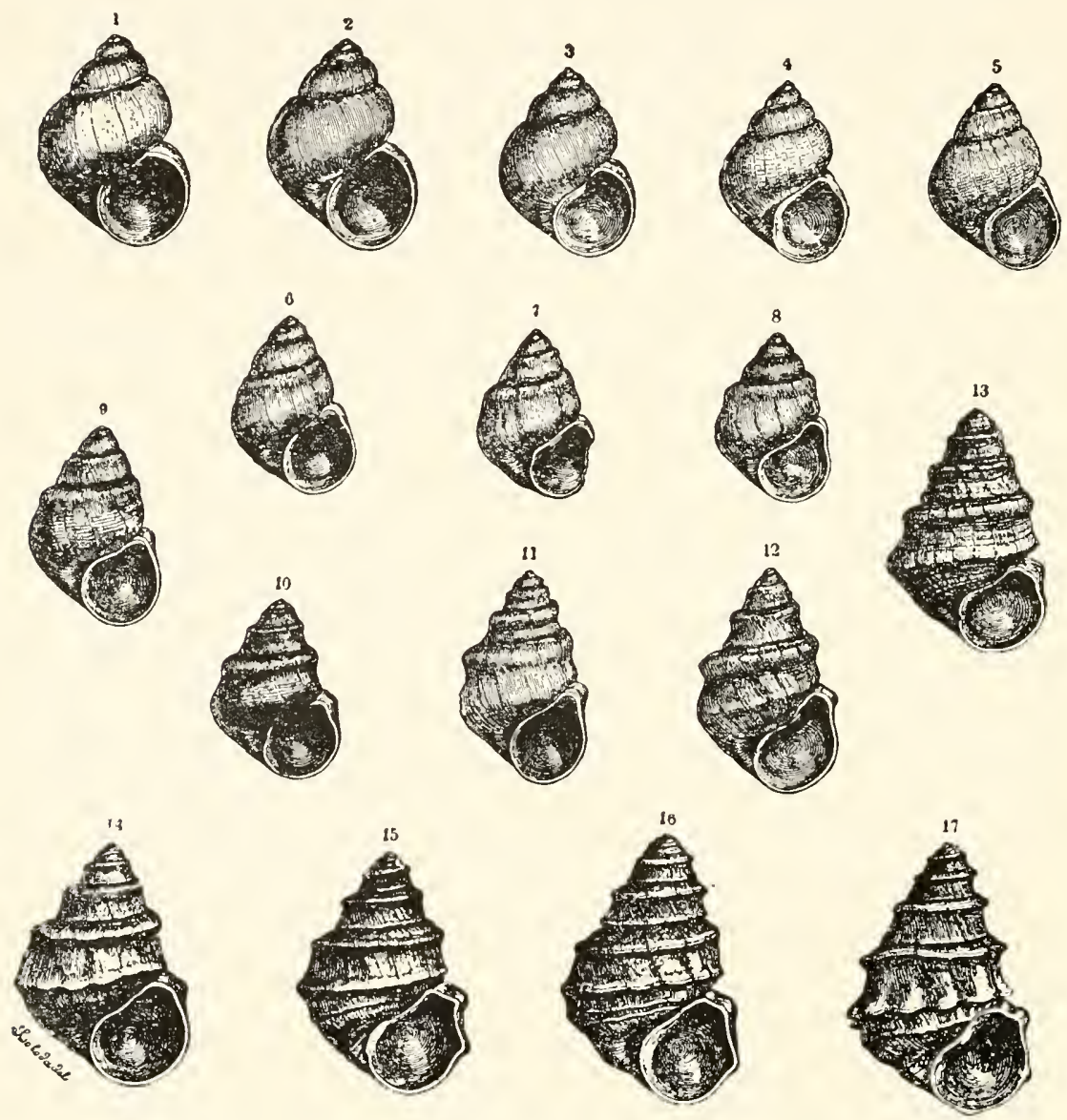

FIG. 26. - Successive forms of Paludina from the tertiary deposits of Slavonia. - From Romanes' Darwin and after Darwin, by the courtesy of The Open Court Publishing Company.

thus formed has brought to light a remarkably complete series of fossil Paludina shells. The uppermost of these, those nearest the surface and last deposited, are identical with the forms now living in the same region. As we go 


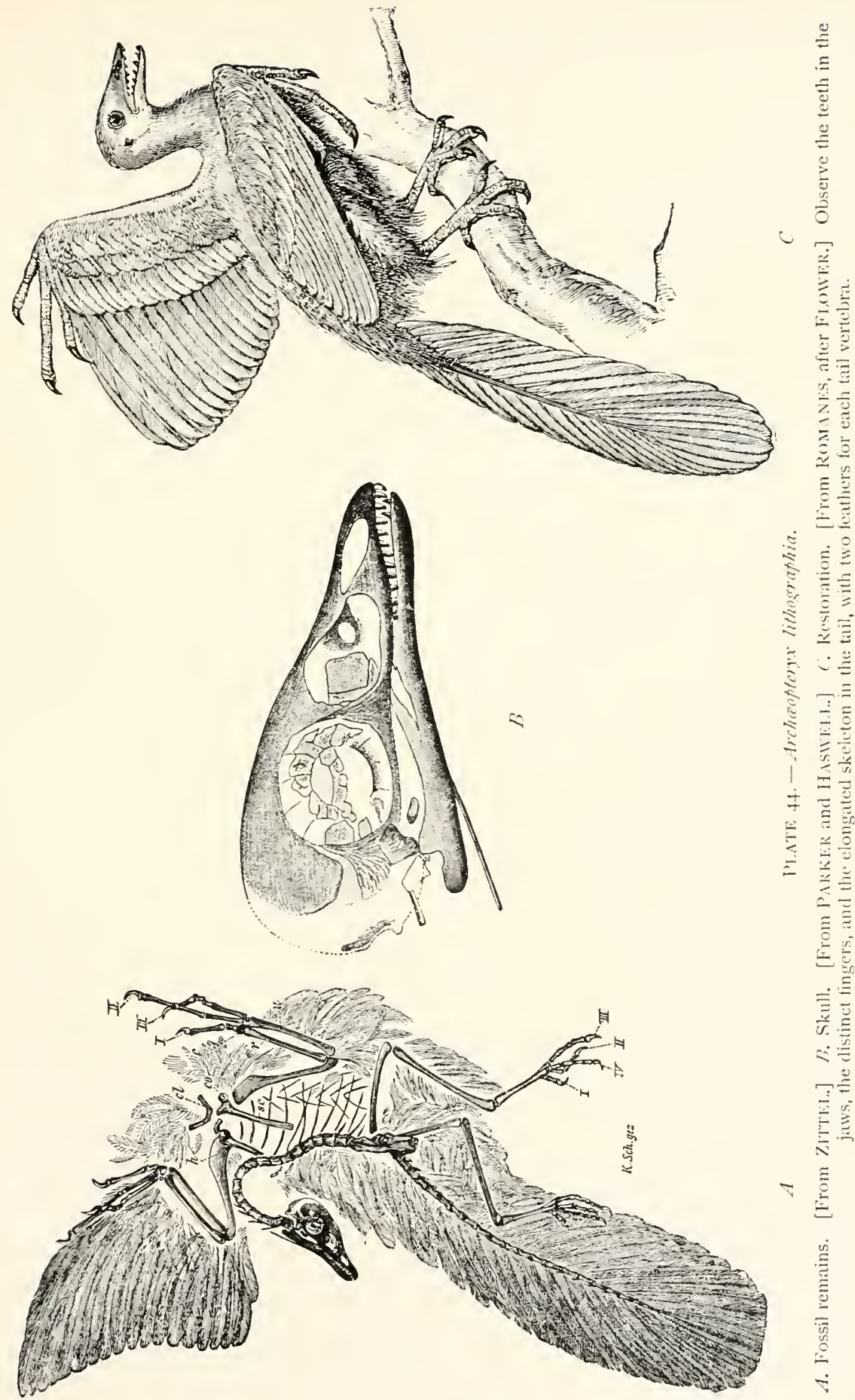




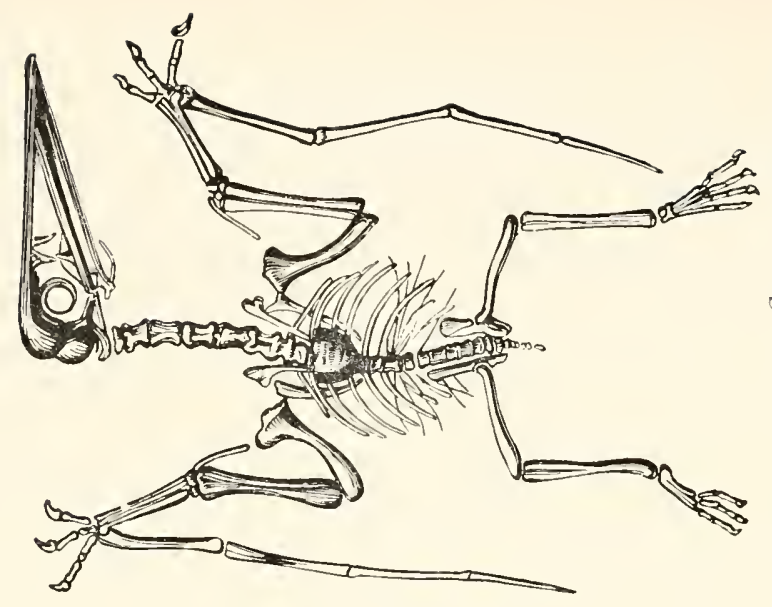

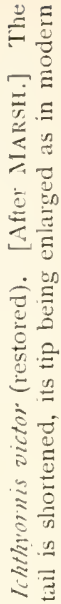

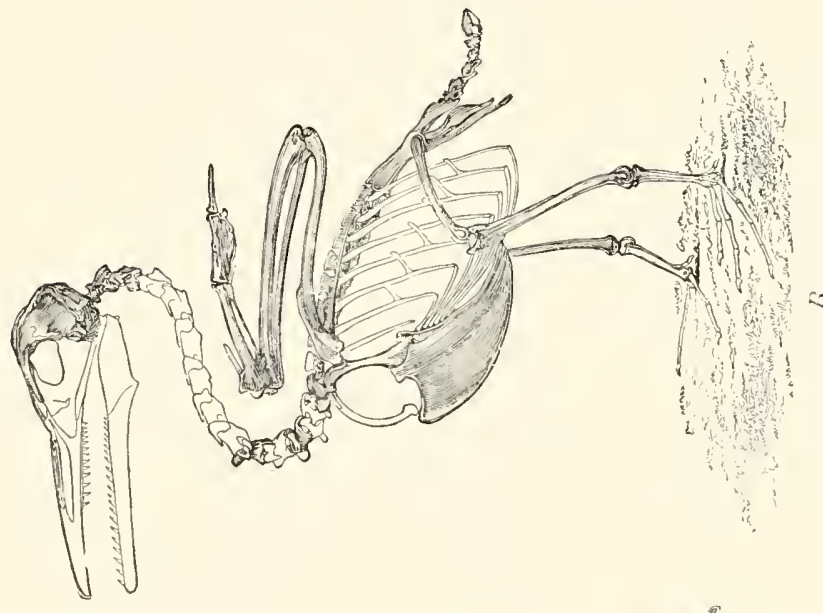

눙

范

$\frac{0}{\infty}$

$=\frac{0}{\bar{v}}$

江

$\therefore$

寻焉

$\therefore$ 列要

可.

焉富

言

$\overline{0}$

$\Xi$

今

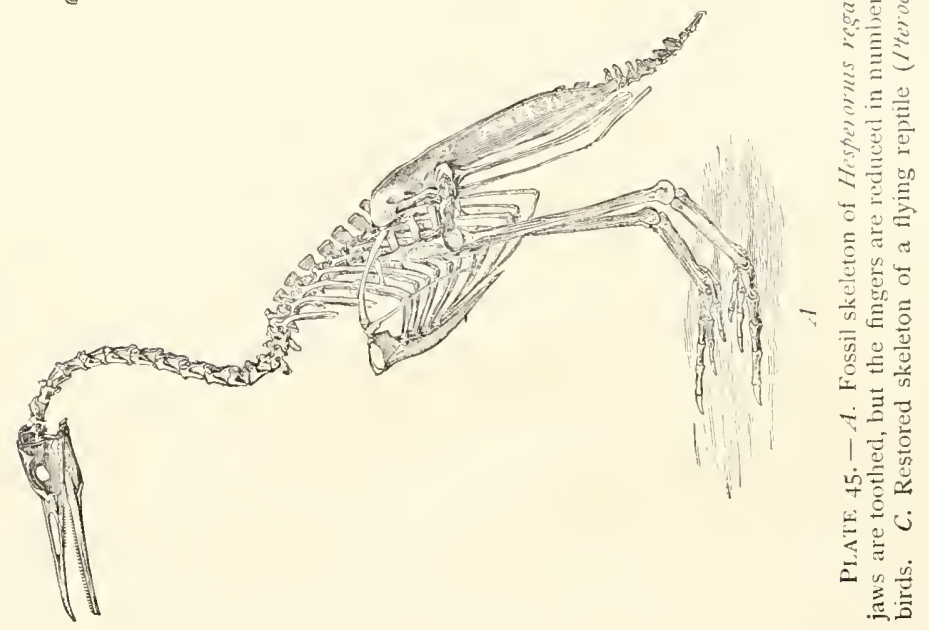


lower we find shells of a gradually simpler and simpler form, less corrugated and with less irregular aperture and less elongated from mouth to apex. We have here in these fossils a most complete record of the several steps in the evolution of the irregular, rugose shells of this species of pond snail. Such a series points almost indisputably to the theory of descent with modification for its explanation.

There are many indications of close resemblance between birds and reptiles, but the descent of the former from the latter is most clearly shown by the numerous fossil forms which bridge the gap between the two groups. Notice the accompanying drawings of three of these intermediate forms: Archaopteryx (Plate 44); Hesperomis (Plate 45, A); and Ichthyomis (Plate $45, B$ ). Compare these drawings with Plate 45. $C$, which represents the skeleton of one of the ancient flying reptiles, and with the skeleton of a bird as shown in Fig. 27. The intermediate forms first figured so approach the character of the flying reptiles as to strongly indicate that they are descended from the latter, but they are true birds. The fact of the development of the birds from the reptiles is very clearly indicated in the discovered fossils which are intermediate in structure between the two types.

One further illustration will be sufficient. The record of the origin of the horse, worked out by American paleontologists from American fossils, is probably the best example of paleontological evidence of erolution. The horse is especially peculiar in the character of its feet and teeth, and we will direct our attention to these points as shown in the accompanying illustrations. In the lower Eocene rocks we find an animal, Phenacodus, about the size of a fox, 
having five well-developed toes on each foot, and with short and but moderately corrugated teeth (Plate 46 ). This is one of the simplest known relatives of the hoofed mammals; and

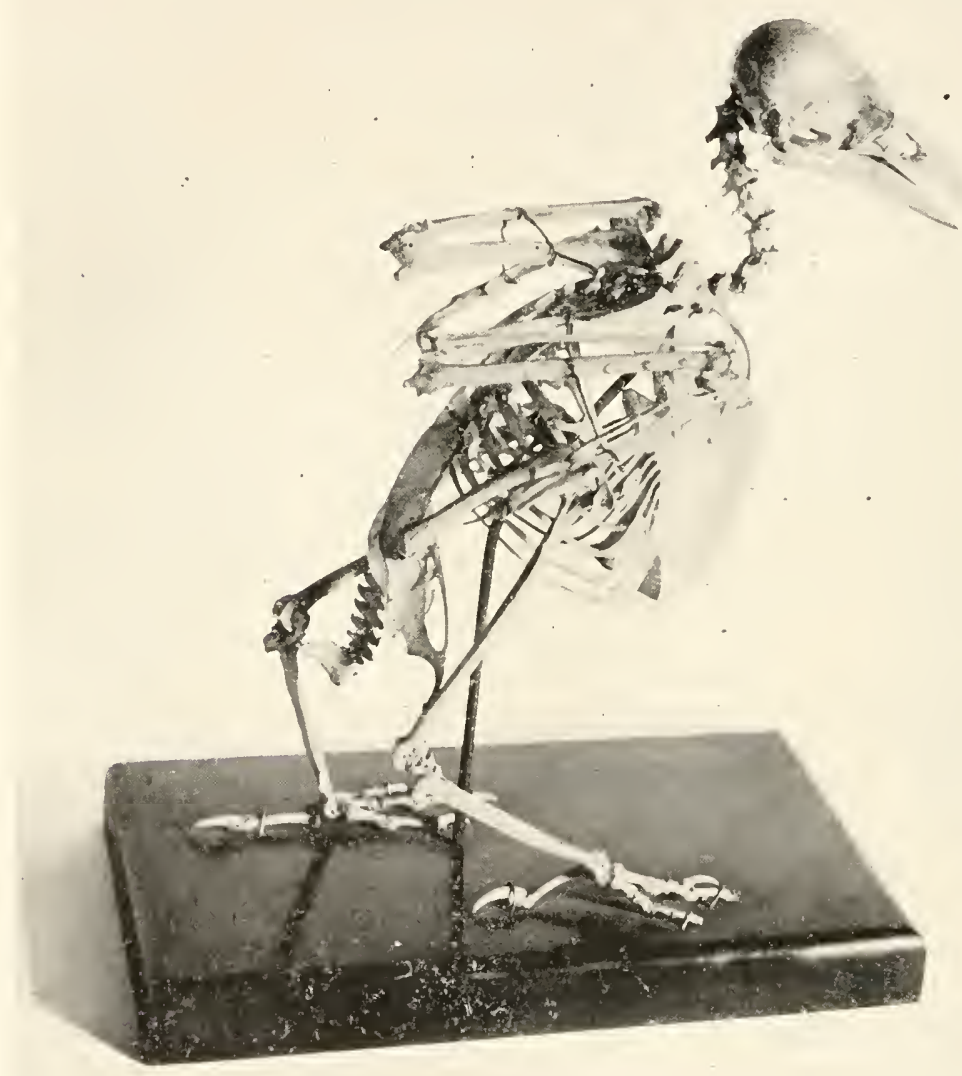

FIG. 27. - Skeleton of a crow (Corvus americana). Observe that there are no teeth in the jaws, that the fingers are reduced in number and partially fused together, and that the skeleton of the tail is short, ending in an enlarged bone (to which the chief tail feathers are attached).

from forms something like Phenacodus must have been developed the elephant, rhinoceros, hog, sheep, camel, and all the other hoofed mammals, including the horse and its long line of ancestors. Observe the steps in the transfor- 


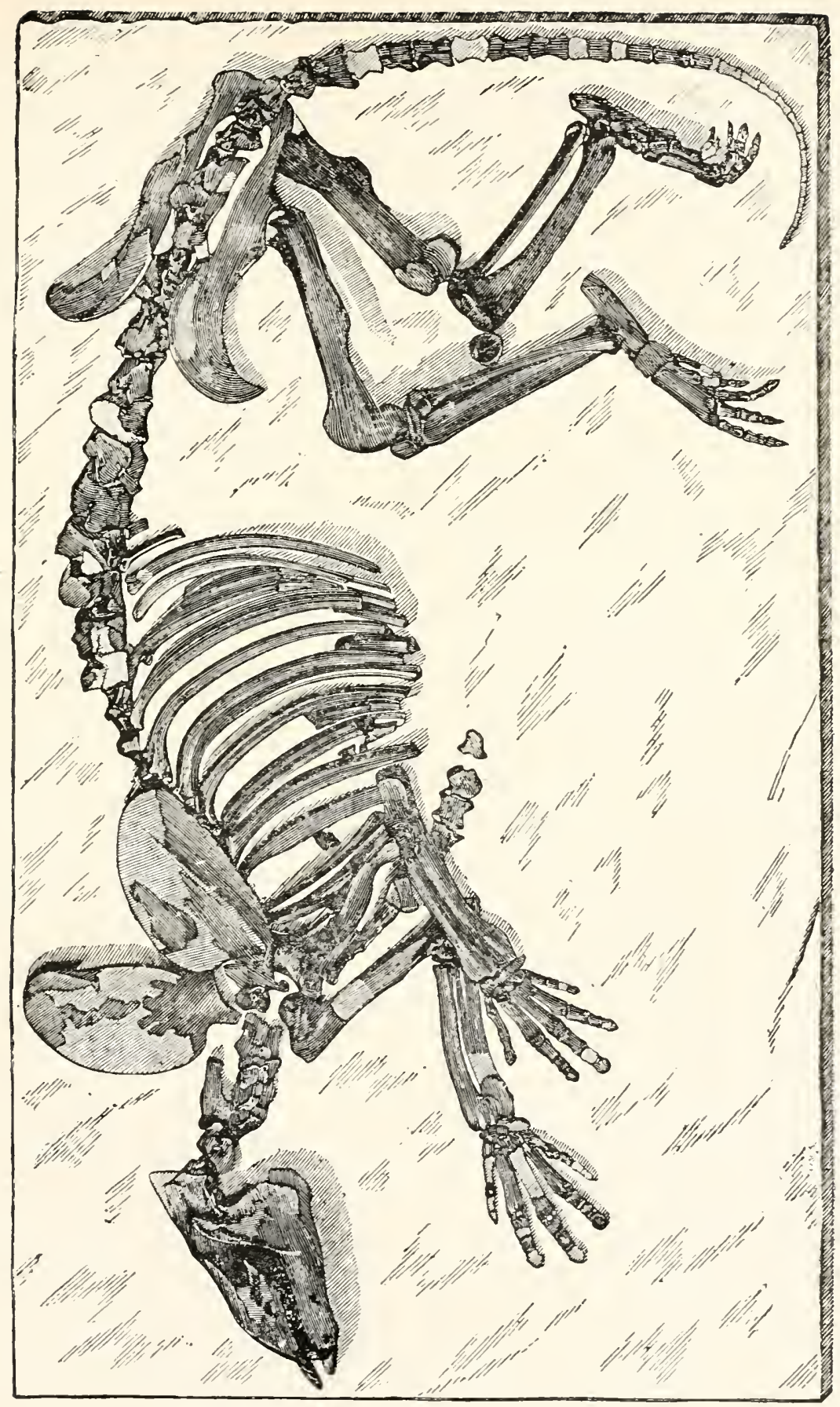

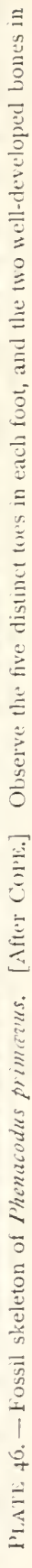




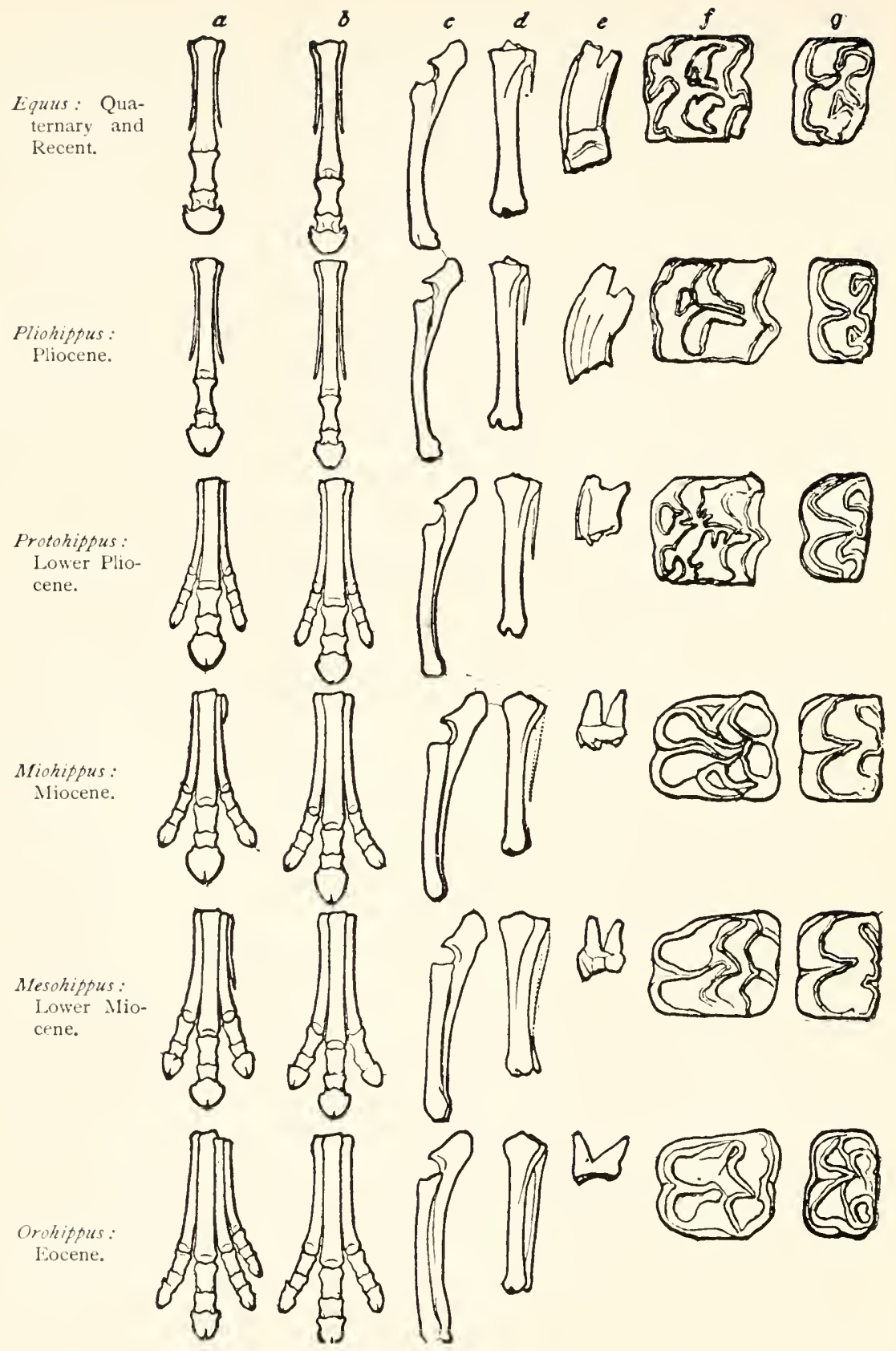

PLATE 47.- Diagrams illustrating gradual changes in foot structure and pattern of ridges on the crowns of the molar teeth in fossil and recent species of the horse family. [After MARsH.]

$a$. Bones of the fore foot. $b$. Bones of the hind foot. $c$. Bones of the fore arm (radius and ulna). $d$. Bones of the lower leg (tibia and fibula). $e$, side view of molar tooth. $f, g$. grinding surfaces of upper and lower molar teeth, showing the grinding ridges. 
mation of the fire-toed limb of a form like Phenacodus into the one-toed limb of the horse (Plate 47). Notice also the increasing complexity of the ridges on the grinding surface of the teeth of the same species from which the illustrations of foot structure are taken. We have here a very complete paleontological record of a profound change of structure, giving us the actual history of the evolution of the horse.

\section{GEOGRAPHICAL DISTRIBUTION}

The comparison of the phenomena of paleontology, anatomy, and embryology seems to point us very clearly to the theory of evolution as the solution of the problem of origin. It is interesting also to find that the distribution of animals and plants over the earth is such as this theory would lead us to expect. We find the character of the fauna and flora decidedly different in different regions of the earth, and these differences are not due solely to differences of climate and soil and other conditions of the environment. Similar environmental conditions do not produce similar animals and plants if the regions compared be separated from each other by sufficient distances or by barriers that prevent free migration and interbreeding. The phenomena of distribution, as we find them, agree with the hypothesis that the different species of animals and plants have each arisen at some particular place and have spread from that spot, becoming modificd to a greater or less extent during their wandering.

In general, we may say that the degree of intimacy in relationship between the faunas and floras of any two regions is in inverse ratio to the degree to which barriers 
are present between these two areas to prevent free passage from one to the other. There is also a correlation between the kinds of barriers present and the kinds of animals and plants held in check by them. Aquatic animals and plants are restricted by the intervention of land areas. Terrestrial organisms are held back by the presence of large bodies of water. Animals and plants adapted to warm climates may be unable to cross high mountain ranges whose summits will have a cold climate. Dry regions will check organisms which are adapted to life in fertile areas. Desert species will not readily pass a forest barrier or a region of marshes.

Observe the conditions on some of the islands off the west coast of South America. Their faunas and floras, while different from those of the mainland because of their isolation and different environment, are still quite closely related to those of the mainland, presenting just the conditions we would expect on the supposition that they are descended from forms which migrated from the mainland at some remote period, migration having since been suspended. Similarly we explain the resemblance between the fauna and flora of the west coast of North America and those of eastern Asia by the fact that at one time, when the climate of Alaska was mild, migration across Behring Straits was possible, and by our belief that the Asiatic forms once established in this country and American forms once having crossed into Asia, communication having then been broken off, the forms thus separated would diverge by evolution.

The flora of the higher altitudes in the White Mountains of New Hampshire shows a remarkable resemblance to that of Labrador. This suggests that the White Mountain flora 
is a remnant of the arctic flora which was spread over New England during the later glacial period, and that, as the ice melted and the arctic flora retreated northward, some species persisted in more southern latitudes by ascending the mountains, the cold of whose higher altitudes resembles the arctic climate to which these species are adapted.

Certain cases of distribution which at first glance seem to be anomalous are found on careful scrutiny to support our hypothesis. For example, the opossums of North and South America are very different from all the other mammals of the same region, so different as to be properly placed in a distinct subclass, the Marsupialia. In no other region are similar animals found except in Australia and its adjacent islands. In Australasia, however, there are, with two exceptions, no indigenous mammals except those belonging to the same subclass as the opossum. It seems at first sight absurd to postulate any communication between Australasia and America by which one may have become peopled from the other. It looks as if the opossum type must have arisen independently in the two areas, a thing which would be contrary to our knowledge of the ways of evolution. Paleontology here comes to our aid. The fossil fauna of America is rich in species of the opossum type, the opossums being the only living representatives of an at one time very extensive marsupial fauna. The marsupial type is more primitive than that of the other Mammalia. There is evidence that at one time, before the higher Mammalia came into existence, the marsupials were spread over the whole eastern and western hemispheres, and that as the higher mammals arose they exterminated the mammals of the more primitive marsupial type, except that in Australia the earlier forms persisted and in America the opossums remained. 
Why the opossums were preserved in spite of the competition of the more perfect higher Mammalia we cannot say, but we do know probably how the marsupials of Australia managed to persist. There is reason to believe that the continent of Australia, or the chain of islands to the north of it, was once connected with the Malay Peninsula, so that the mammals of that time, which we believe were marsupials, could readily pass from one region to the other. At this time apparently much of the earth was peopled by the Marsupialia. When, however, Australasia was separated from southeastern Asia by the formation of the deep straits southeast of Sumatra (Fig. 28), communication between the two continents was cut off and the marsupials of Australasia were thus protected from competition with the higher mammals which soon arose upon the larger continent. The mammals of the higher type spread over Asia, Europe, Africa, and North and South America, and replaced the marsupial forms. The peculiar distribution of the Marsupialia, therefore, instead of arguing for the independent origin of the marsupials in two regions, is a beautiful example of the support given to the theory of evolution by the phenomena of geographical distribution when studied in connection with the phenomena of paleontology, geology, and comparative anatomy. Other striking examples might be quoted, but this will suffice to show the general relation of these phenomena of distribution to the theory of evolution.

The fact that great weight is given by students of zoology and palæontology to the phenomena of geographical distribution is evidenced by a belief which is becoming more general among paleontologists; namely, that there was at one time a great Antarctic continent connecting South Africa, 
South America, New Zealand, and perhaps Australia. This belief is based upon the close resemblance in many remark-

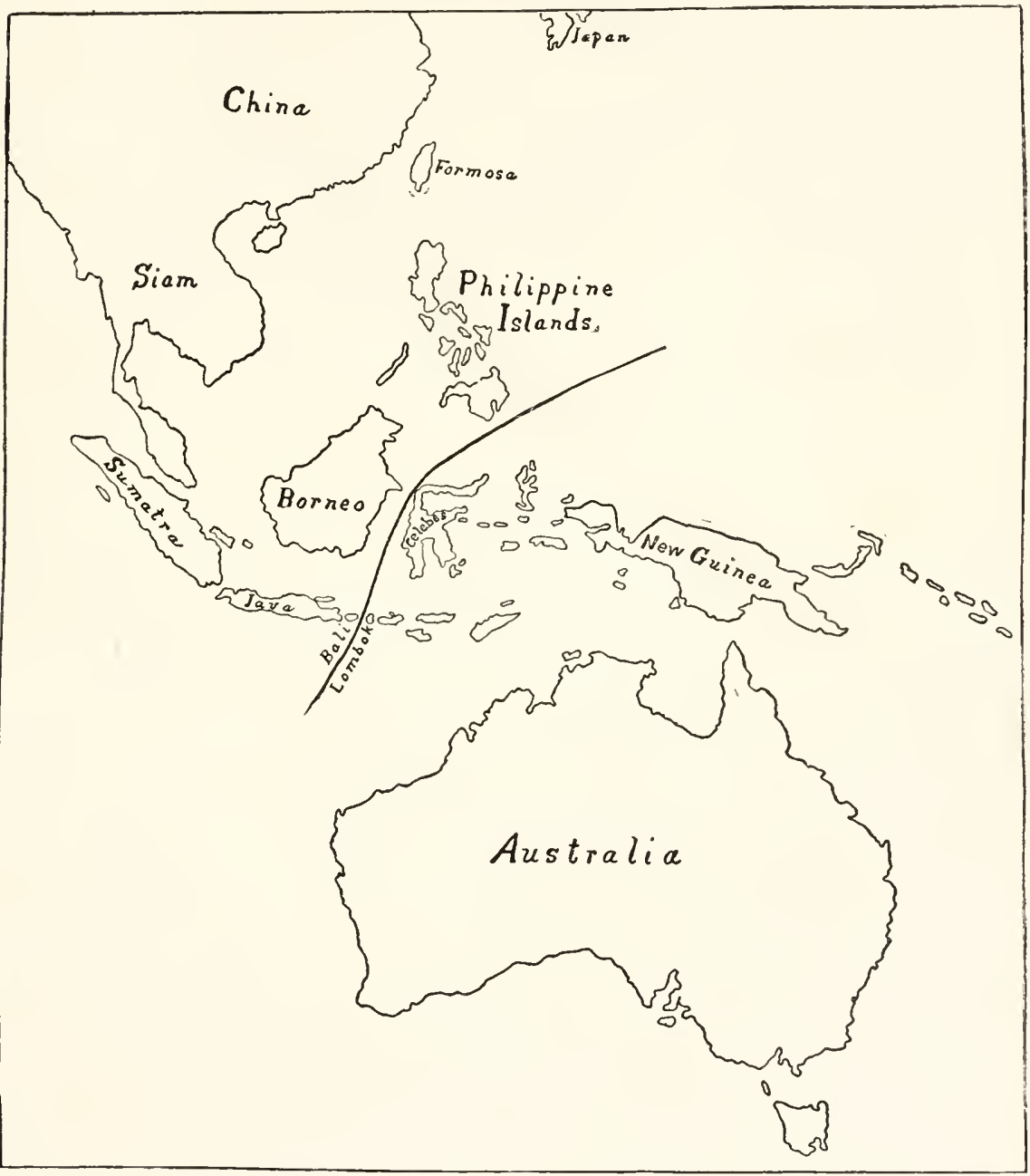

FiG. 28. - Map of southeastern Asia, the East Indies, and Australia. The heavy black line southeast of Bali, Borneo, and the Philippine Islands indicates the deep-water straits which separate the Asiatic fauna from the Australasian fauna. The sharp contrast between the terrestrial faunas in these two regions makes it probable that this line of demarcation is an ancient one.

able particulars between the fossil faunas of these several southern regions, no connecting links between which are 
found among the fossils of the northern hemisphere. It would at first thought seem preposterous to postulate the former presence of such a connecting continent with no more evidence in its favor than the resemblance between these fossil faunas. Yet this line of evidence has proven so trustworthy in other instances that some of our most conservative paleontologists are inclined to accept the evidence in this case and to believe that such a continent once existed.

\section{COLOR IN ANIMALS}

The phenomena of color in both animals and plants are among the most remarkable and interesting in the whole realm of nature. It is not so much the way in which the color is produced, whether by pigments or by refraction, that interests us in this connection, as it is the uses to which the colors are put. Let us first refer to the colors of animals.

According to the uses to which colors of animals are put, we may classify them, for purposes of description, as follows: ${ }^{1}$ -

Indifferent colors, not useful, so far as we can judge;

Colors of direct physiological value;

Protective colors and resemblances;

Aggressive colors and resemblances;

Alluring colors and resemblances;

Warning colors ;

Mimetic colors and resemblances;

$A$, Protective, $B$, Aggressive;

${ }^{1}$ In the main I have followed the classification used in Poulton's delightful book The Colors of Animals. 
Signals and recognition marks;

Confusing coloration;

Sexual coloration.

VTe are not interested, in this connection, in nonuseful colors, or in the direct physiological value of colors. The other uses of color, however, present a diverse series of phenomena very significant in the light of the theory of erolution.

\section{Protective coloration and resemblances.}

We referred in the early pages of this book to the severity of the struggle for existence and to the importance of any structure or character which enables its possessor to escape destruction. Carnivorous animals are so common and so roracious that, as we would naturally expect to find, their prey have adopted various means of defence. Among these some of the most important have to do with color. Animals which closely resemble their enviromment in color will escape the notice of their enemies and thus be preserved, while their less protectively colored neighbors will be seen, captured, and devoured. Natural selection will thus tend to produce protective coloration. The principle must be sufficiently clear. Let us observe a number of instances of such coloration.

Nany animals which live at the surface of the open ocean are transparent, so as to be distinguished only with difficulty from the water itself. This is true of many of the jellyfishes and their relatives the ctenophores and siphonophores, of most pelagic Crustacea and worms, of the pelagic tunicates, and many other less familiar forms, and of almost all marine larve. This invisibility must be 
a most effective means of protection to these transparent forms.

Fish are commonly dark-colored above and light-colored below. To any enemy, such as a sea-gull, looking down upon them from above, their dark color would cause them to harmonize with the dark appearance of the water, while another fish looking at them from below or from the side would be less likely to detect them than if they were dark-colored instead of light-colored beneath. Were the lower surface as dark-colored as the dorsal surface it would appear to be much darker still, because of its being in shadow. The light-colored sides and belly of most fish, when the light comes upon the fish from above, are shaded, and being in shadow appear about as dark as the dorsal surface. If the sides and ventral surface were actually darkcolored the added shadow would make them seem very dark and would make the fish conspicuous. The accompanying photograph of a bluefish, taken while the fish was swimming in an aquarium with the light coming from above, shows the really brilliant white sides and belly apparently as dark as the steel-blue back, because of their being in shadow (Plate $18, A$ ). The color of most fish resembles that of their enviromment. The flatfish and others which live upon or near the bottom often closely resemble the bottom in color (Plate $4 S, B$ ).

Most birds are so colored as to conform to the surroundings in which they live. Think for a moment of the sparrows, streaked and speckled browns and grayish browns like the grasses and bushes among which they are commonly found (Plate 49, $A$ ); of the whole grouse tribe, the quail (Plate 49, B), the pheasants, the ruffed grouse (Plate 

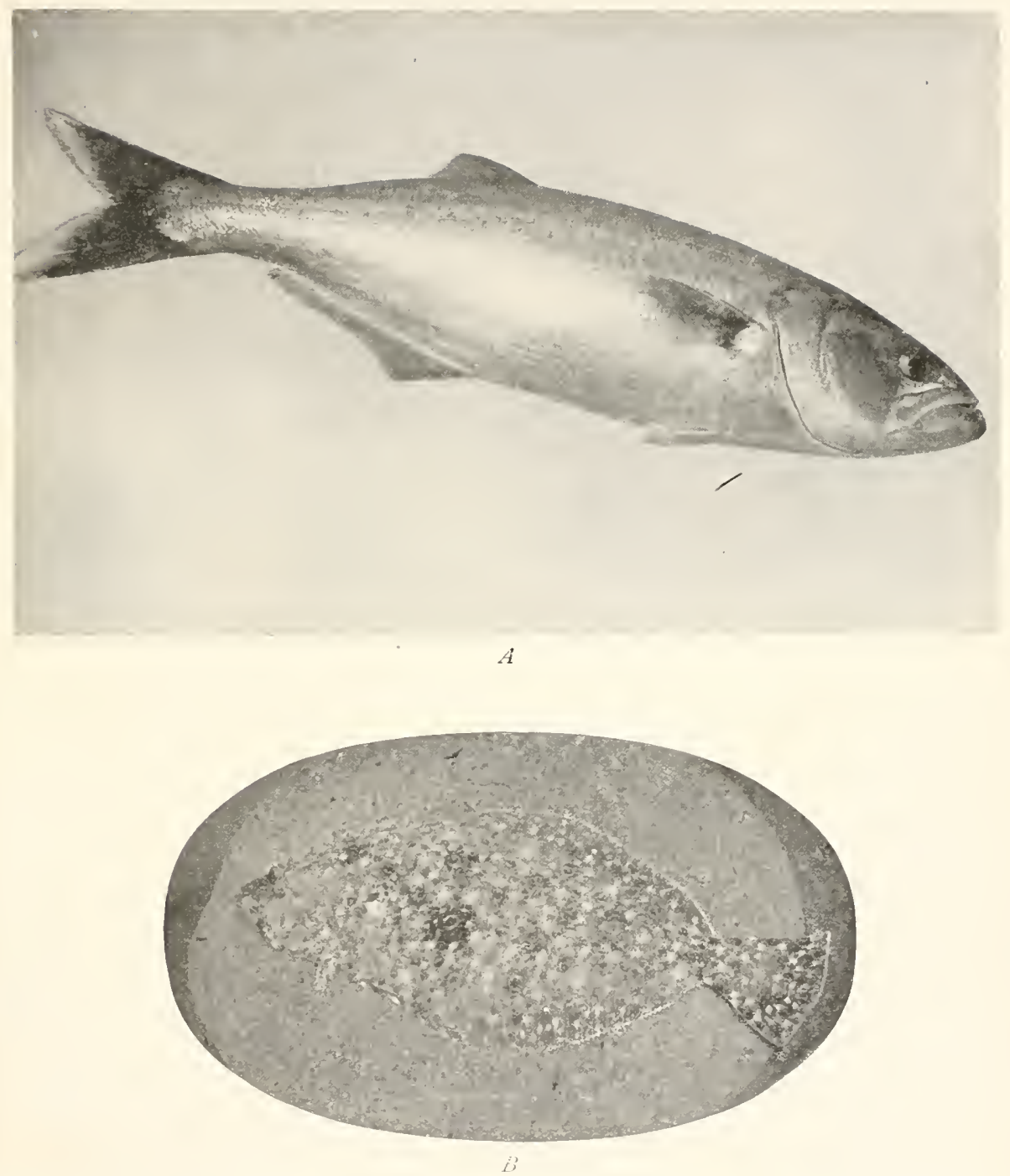

PLATE 48. - A. Bluefish (Pomatomus saltatrix). - From a photograph from life by A. R. Dugmore, published in Jordan and Evermann's fmerican Food and Game Fishes. By permission of Doubleday, Page and Co. B. Photograph of a living flat-fish, "sand fiounder" (Paralichthys dentata). It is lying upon clean white sand. Against an ordinary sand bottom its mingled grays, browns, and greens would render it almost indistinguishable. It is interesting to observe that the circular markings with dark centres closely resemble shadows of bubbles. The much darker "murl-flounders" are almost equally well protected by their resemblance in color to the dark mud against which they lie. 



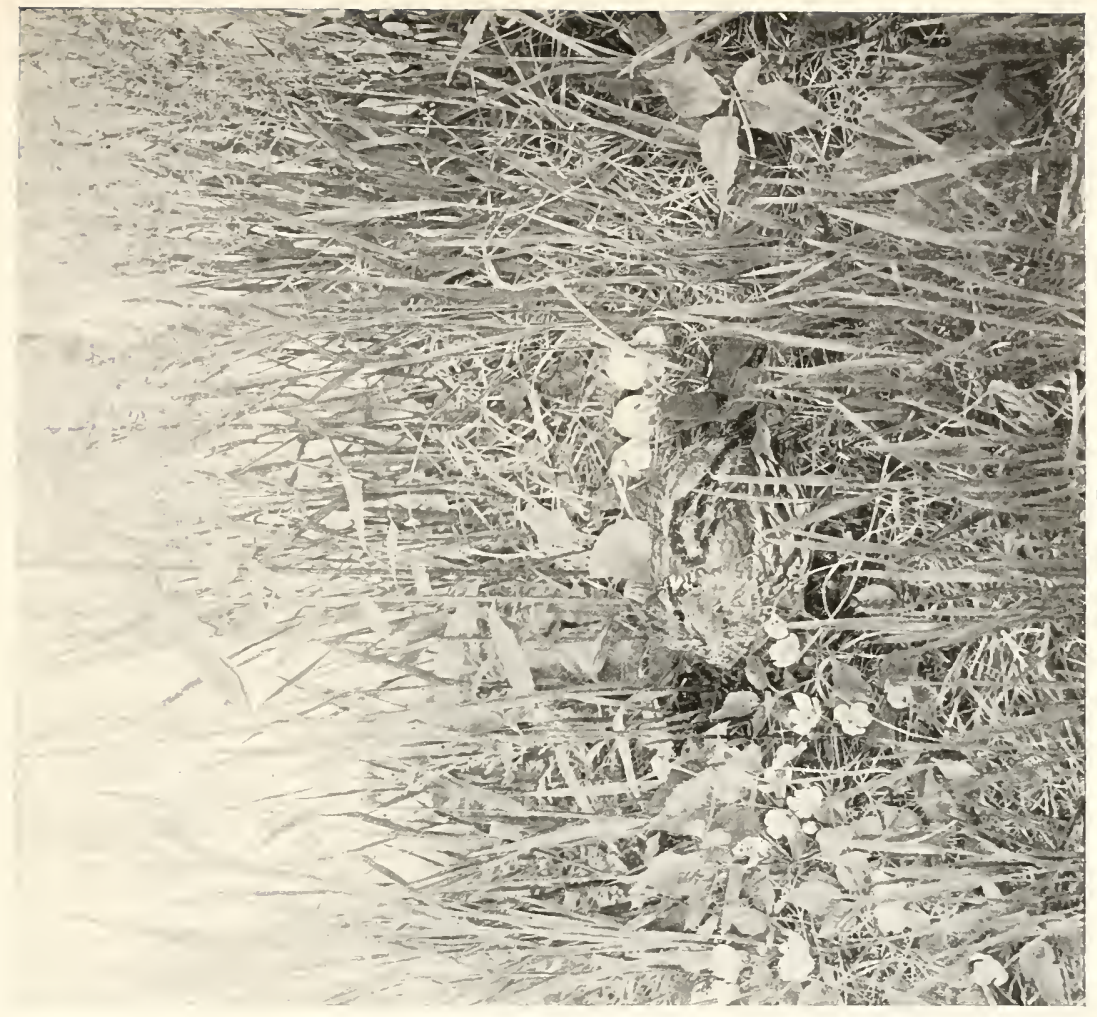





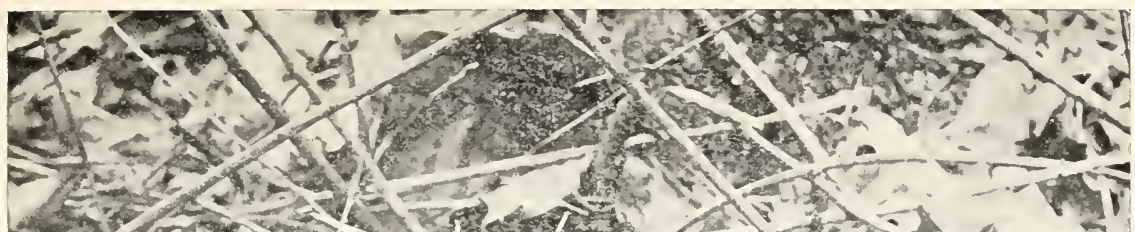

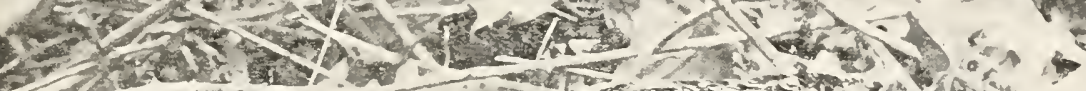

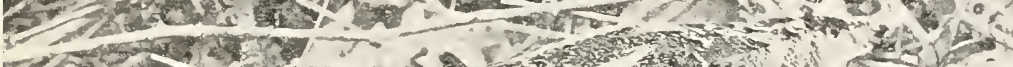

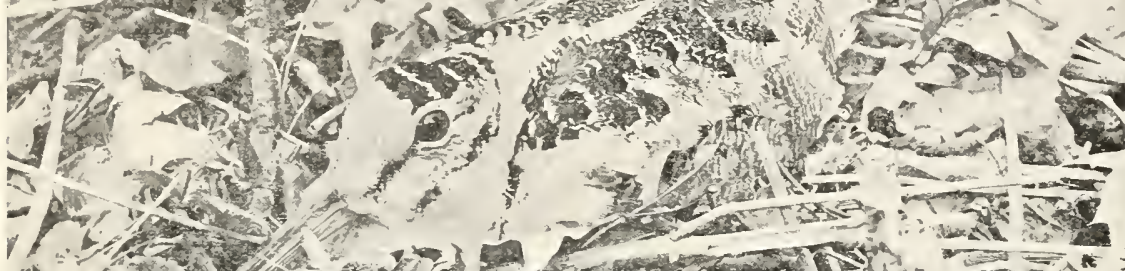

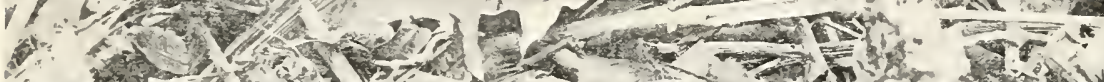
-

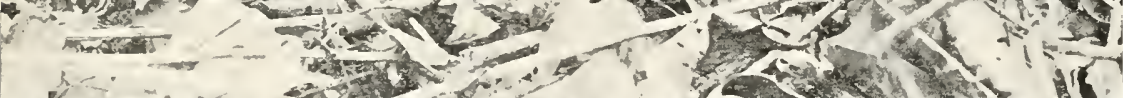

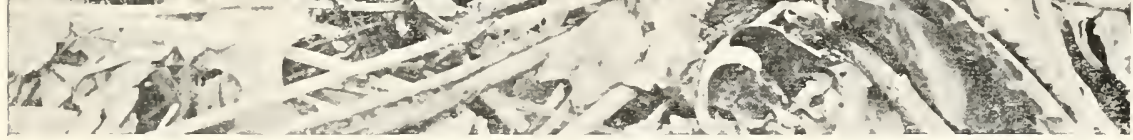

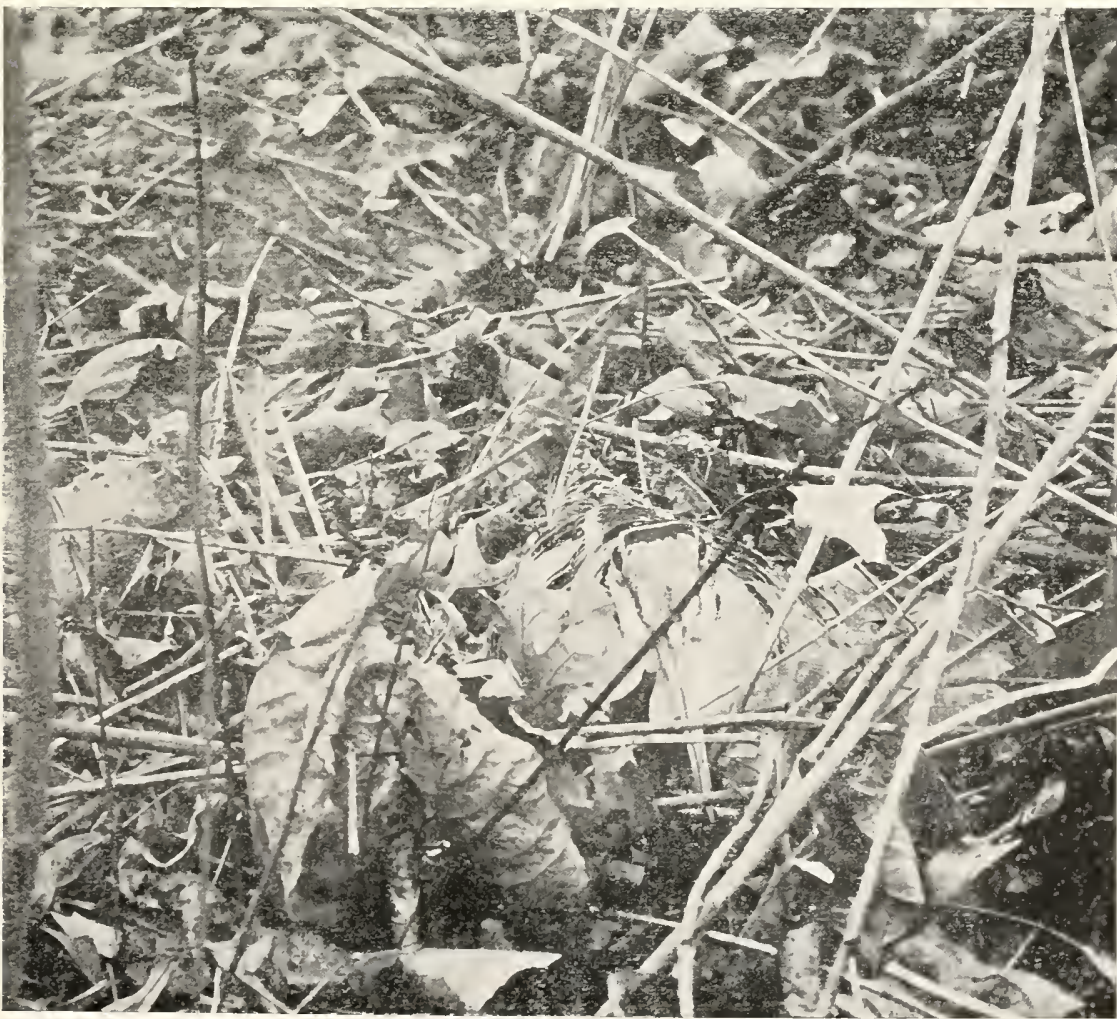

PLATE 50. - Woodcock (Philohela minor) on nest. - From photographs of the living bird, given 



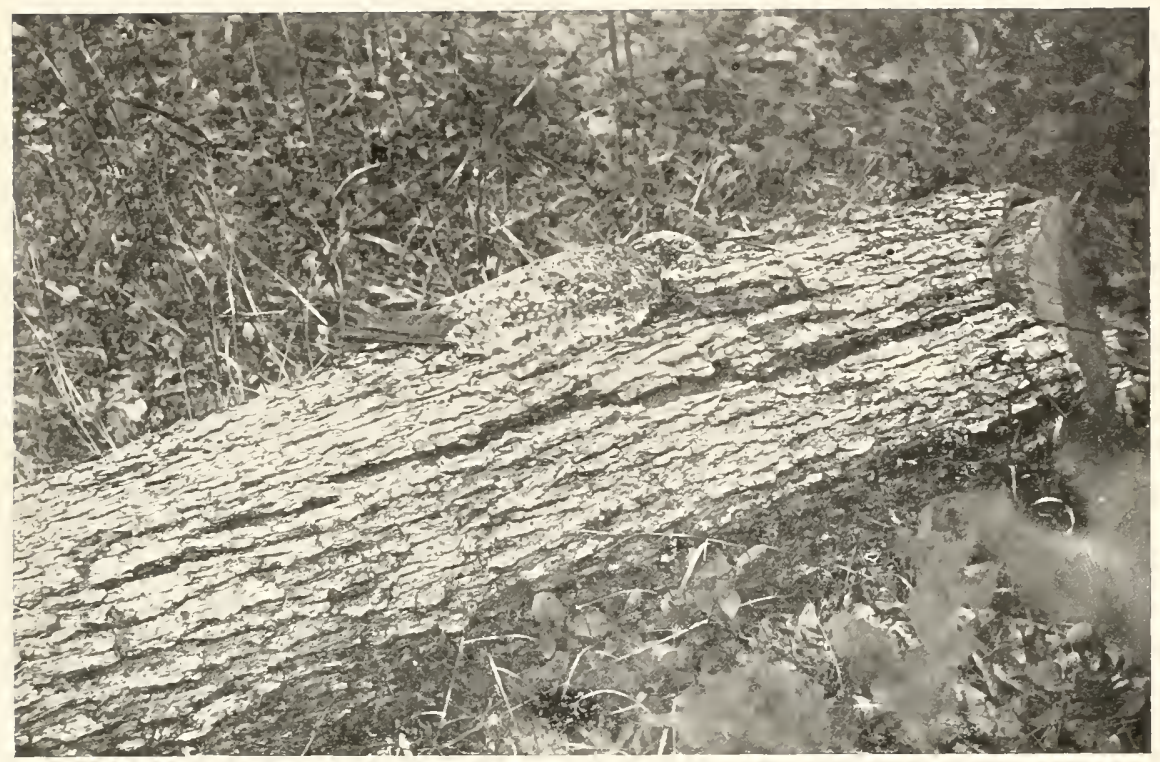

A

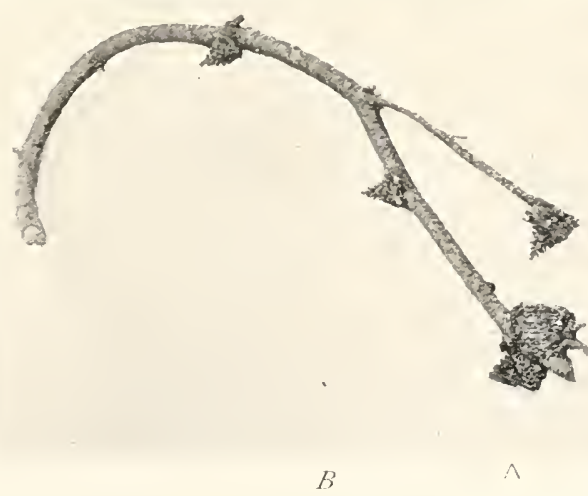

PLiTE 5I. - A. A nighthawk (dead) upon an oak log. B. A humming-bird's nest upon a pine branch. - From an exhibit in the United States National Museum. 

23), and the jungle fowl from which our domestic fowl are descended (Plate $\mathrm{i} 6, A$ ), all of which are colored more or less like the sparrows and have a similar habitat. Think of the snipe tribe, including the shore birds like the sandpipers, the curlew, and the woodcock. The woodcock in its native haunts is almost invisible (Plate 50). I have shot scores of them, yet have never but once seen one of them lipon the ground, and this too in spite of the fact that I have had a $\log$ with me on all of my shooting trips. and he would stand pointing the bird, often for a long time before the bird would rise.

The bright green color of some tropical birds, like certain of the parrots, is to them a most effective protection. In Jamaica there is a small bright green bird, the "green tody." While spending a summer in zoological study in Jamaica I wanted to shoot one and bring home its skin to show as an illustration of protective color. Often when out with my gun I heard the faint piping whistle of one of these little fellows and searched carefully for him, but always without success. They rarely fly when one is near them, seeming instinctively to rely for protection upon their color while they remain motionless among the green leaves. Once I thought I was at last to be successful, for I located a tody in a drooping branch of a tree where I could walk all around him and thoroughly inspect the whole branch. Yet, though I came within six feet of the branch, peering among the leaves in every part, I could not recognize the bird. Finally I drew away about five rods and fired into the branch, but the bird escaped, for I fired too high. He had been within six feet of my eyes during the whole of my closest search. (See also Plate 5I.) 
Most snakes, lizards, and frogs are protectively colored. Our common eastern tree-lizard, which is found often on the gray, lichen-covered bark of the scrub pines, is a mottled greenish gray and is hardly distinguishable from the bark (Plate 52). Most snakes, living as they do upon the ground,

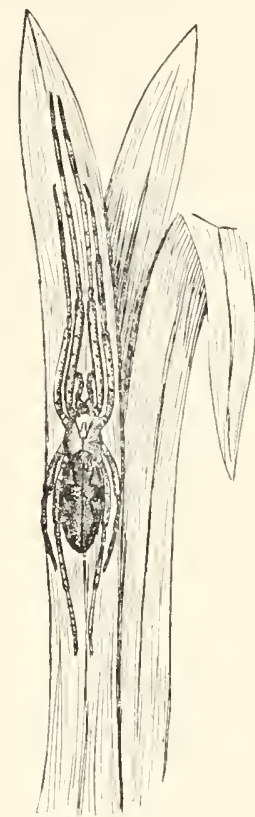

FI(x. 29. - A straw-colored spider ( Tetragnatha grallator) in its accustomed position on a blade of dead grass. - From a specimen given by $H$. IV. Britcher. are dull colored, gray or brown, or dull blackish, like the shadows among the bases of the grass stalks. One beautiful little snake, found throughout the eastern United States, is a bright green, and at first thought it seems very conspicuously colored, but it is a climber, living a large share of the time in the branches of low shrubs, where its color renders it inconspicuous among the green leaves. It is interesting to note that when disturbed this snake is very likely to seek safety by flight into the bushes rather than along the ground.

Deer, rabbits, antelope, wild sheep. and goats, and most other mammals, are dull-colored and resemble the region in which they live (Plates 53 and $54, A$ ).

Nost insects show protective coloration (Plates 55 and 56), and so do crabs, lobsters, crawfish, and most other crustacea. This is true also of the spiders, most of which are inconspicuously colored. Most species are dull brown or gray, like the dead leaves, bark, or lichens upon which they are found (Fig. 29); some are green, like living foliage (Plate $8_{5}, D$ ). The members of one family, which live usually within the blossoms of flowers, are 


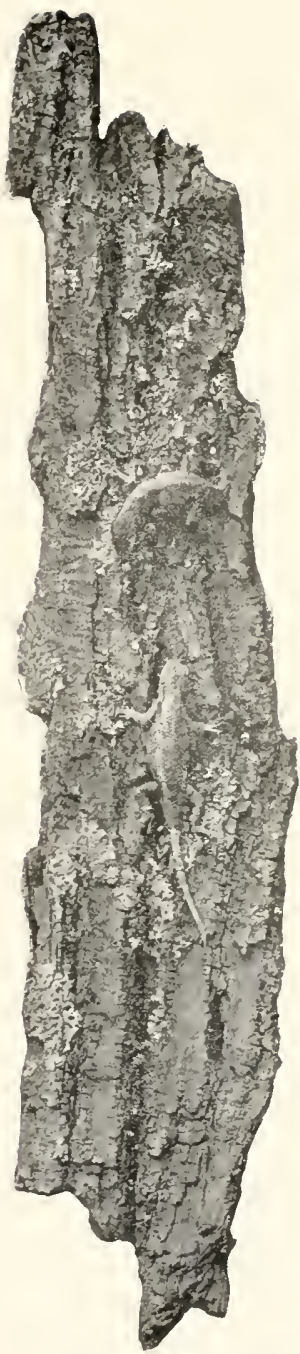

PLATE 52. - TREE LIZARIS (Sceloporus undulatus) ON O.AK BARK. 



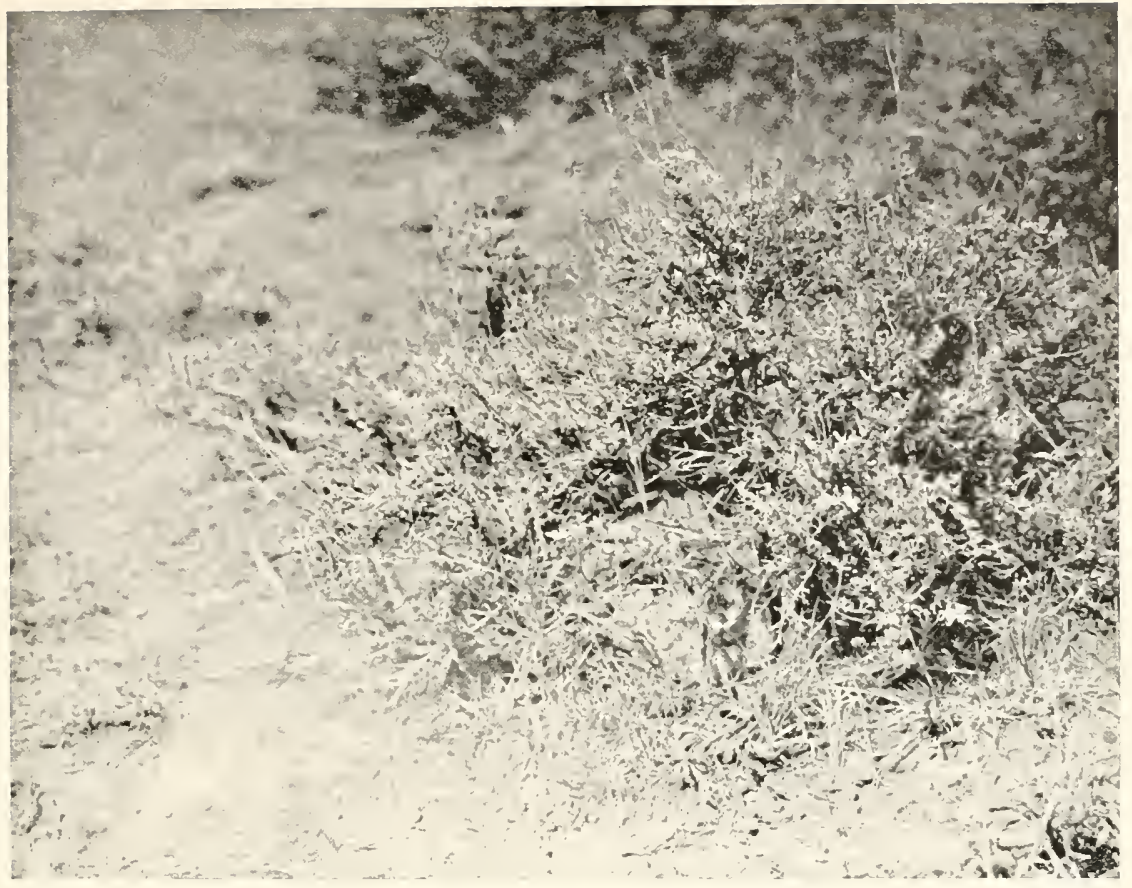

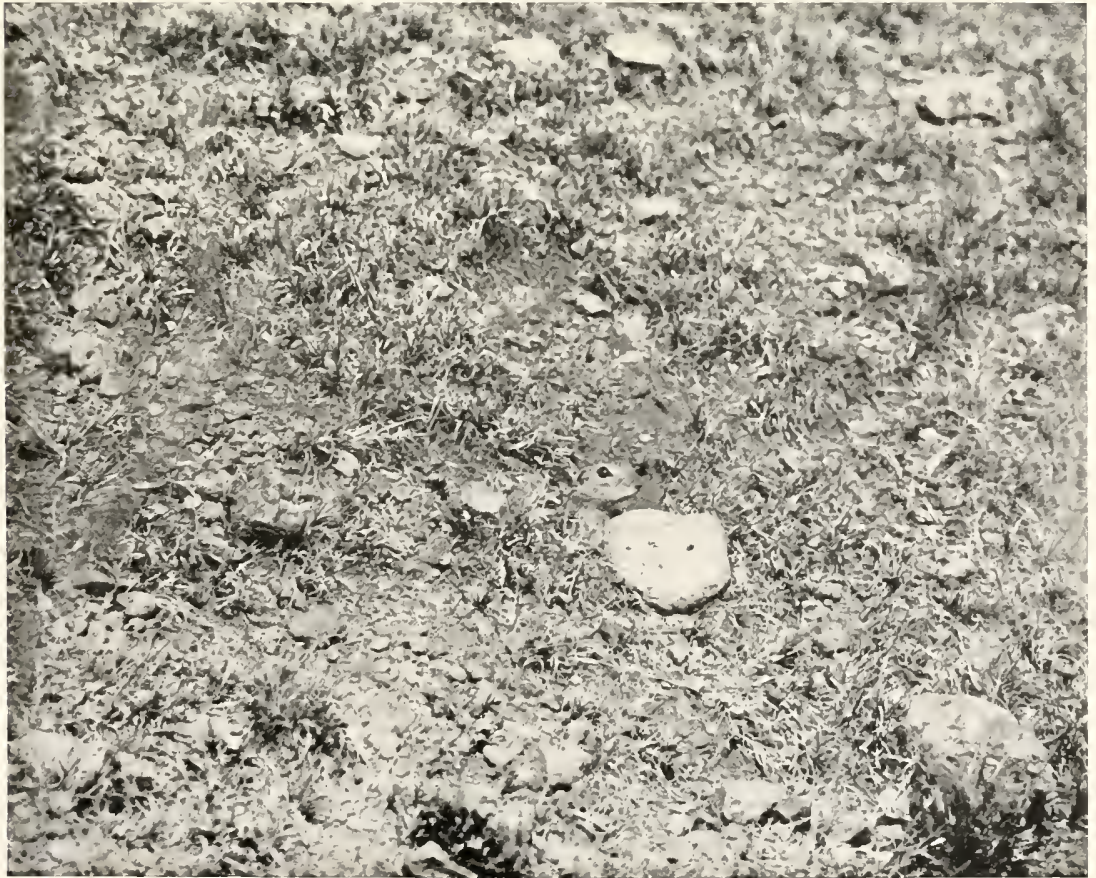




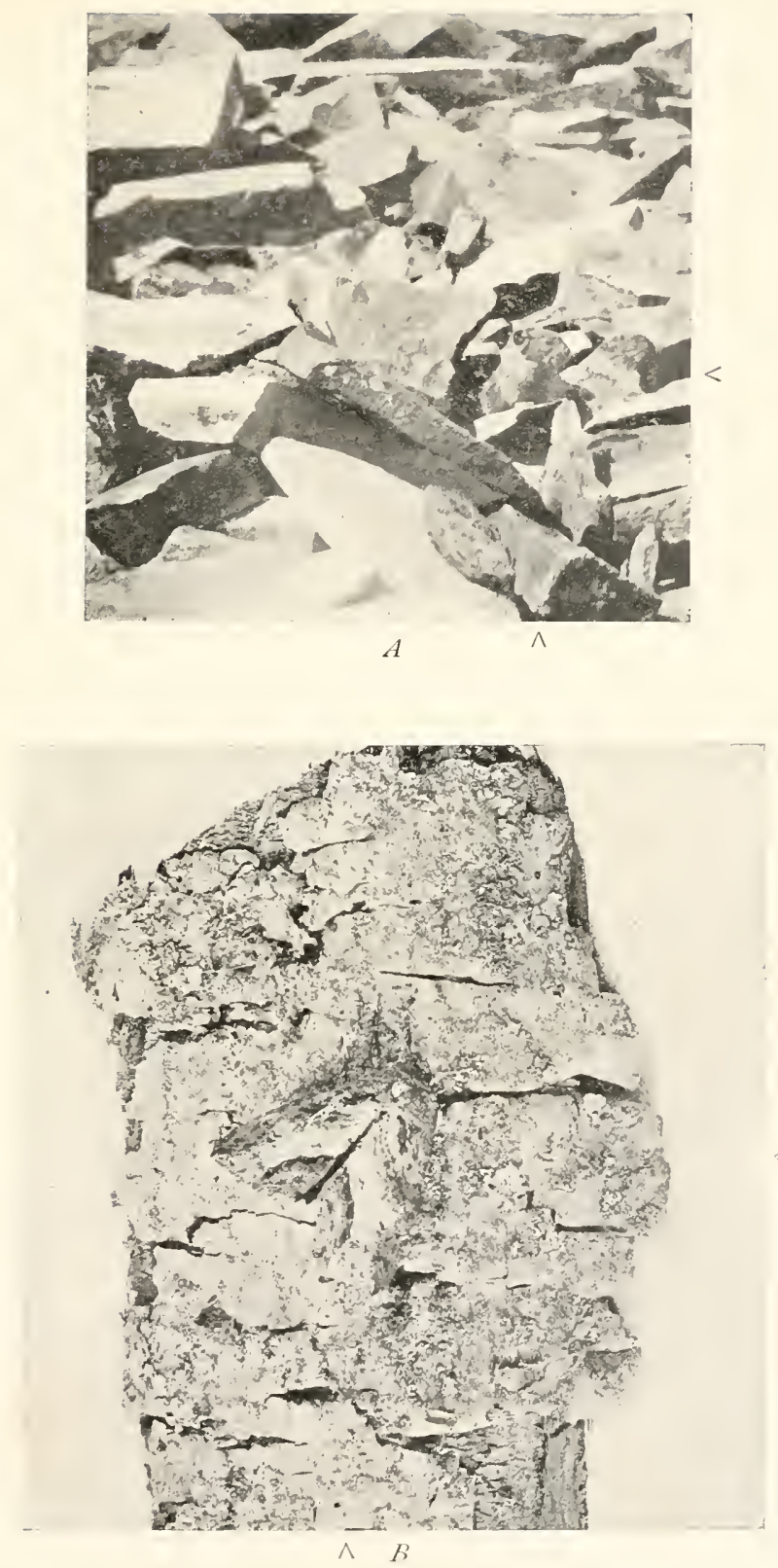

Plate 54.- A. A "cony" or "pika" (Otochona princeps) among rocks. - From a photo. graph by E. R. Warren. B. A protectively colored woods-moth (Homoptera edusa) on a piece of bark. 




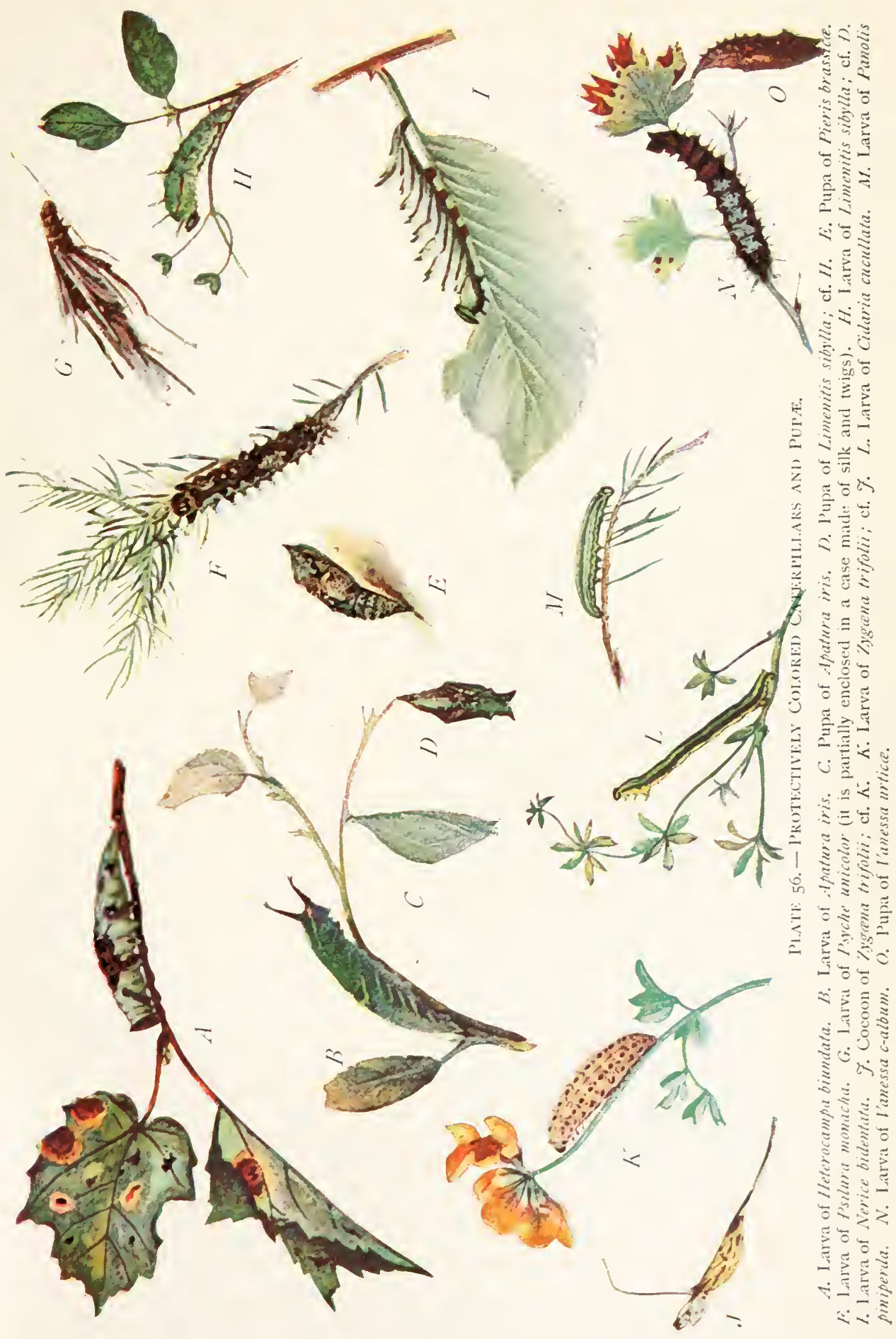




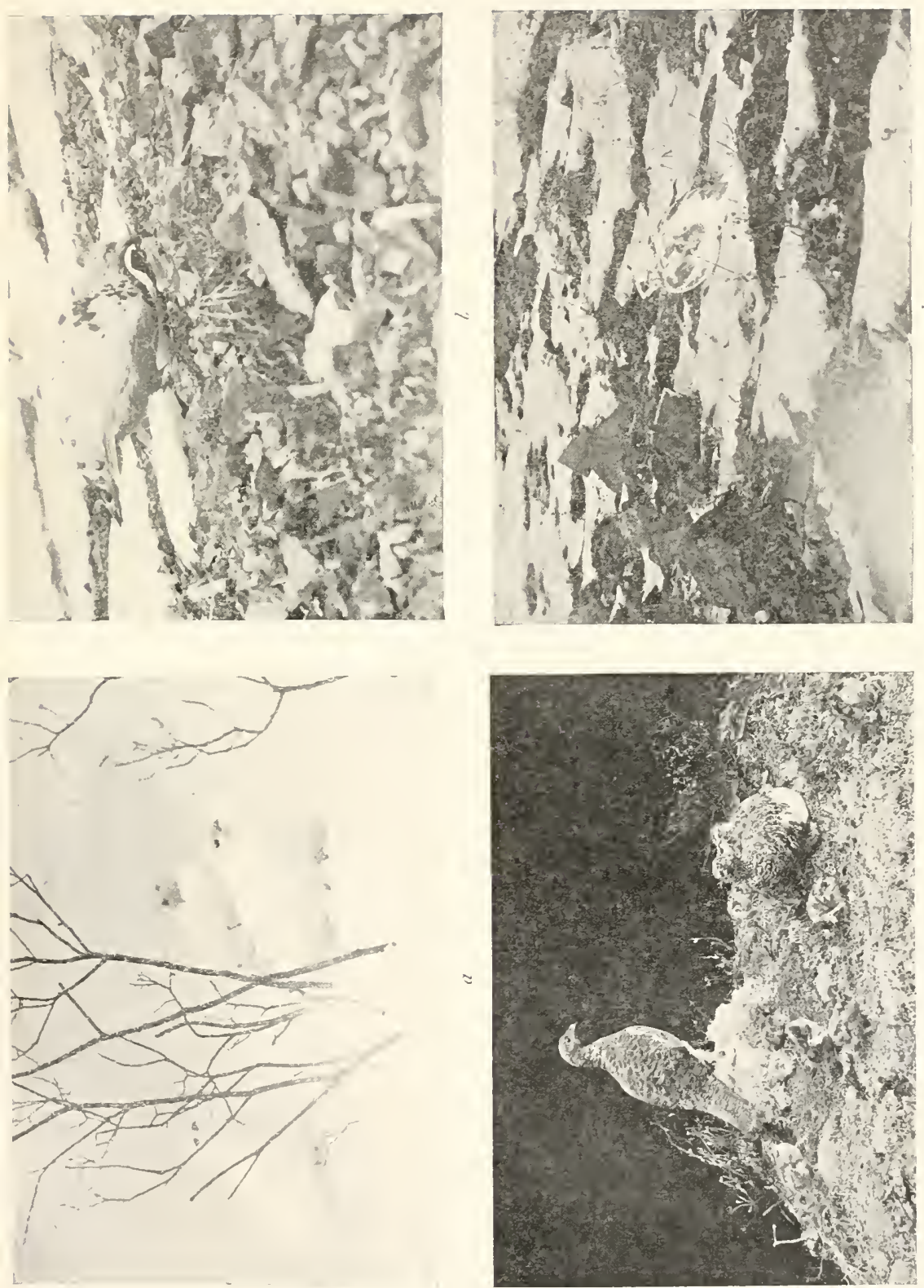

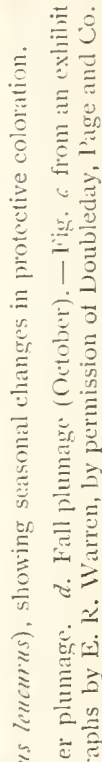

产苛

한

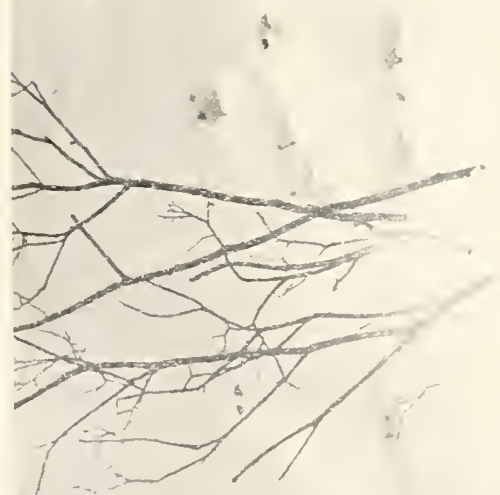

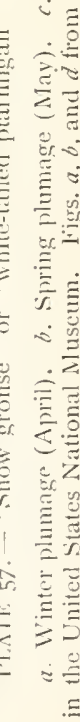






PLATE 58. - Grass porgy (Calamus arctifions), showing changes in color occurring in a few moments. - From photographs by A. R. Dugmore in Jordan and Evermann's dimerican Food and Game Fishes, by permission of Doubleday, Page and Co. 


brightly colored like the blossoms, their color rendering them inconspicuous (Plate $75, A$ ). Spiders are exposed to the attacks of enemies, especially of certain wasps, which capture them, paralyze them by stinging them, and then use them to provision their nests, the young wasps feeding upon the living spiclers. They therefore need protection.

Of special interest are the protective seasonal changes of color, seen in some northern animals; for example, several species of ptarmigan and the New England and Canadian hare, which are white in winter, resembling the snow, are grayish or brownish in summer like the dead leares and the rocks among which they are found, while in the spring and fall, while shedding their feathers or hair, they are a spotted gray and white or brown and white, bringing them into color harmony with their environment, in which patches of snow are scattered among the rocks or leaves (Plate 57).

Some animals are able rapidly to change their color, thus keeping them in harmony with the varying color of their surroundings as they move from place to place. The chameleon, the little Anolis of our southern states, some frogs, and many kinds of fishes, especially tropical fishes, have this ability (Plate 58 ).

It is well known that the pupxe of most butterflies are colored to correspond to their environment. Professor Poulton, experimenting upon two species (Vanessa io and $V$. urtica), has shown that by placing the full-grown caterpillars in boxes lined with different colored paper, pupe of colors corresponding to that of the paper with which they were surrounded, can be obtained (Plate 59).

There are many instances of special resemblance, in color or in form or in both, between a species of animal 
and some particular object, the animal escaping detection because of this resemblance. Often the animal has peculiar habits which make the resemblance more perfect. Among insects these special resemblances are not uncommon. One of the best examples is the caterpillar of the brimstone moth, which resembles a twig, and which remains motionless in just the position to make this resemblance most perfect. In

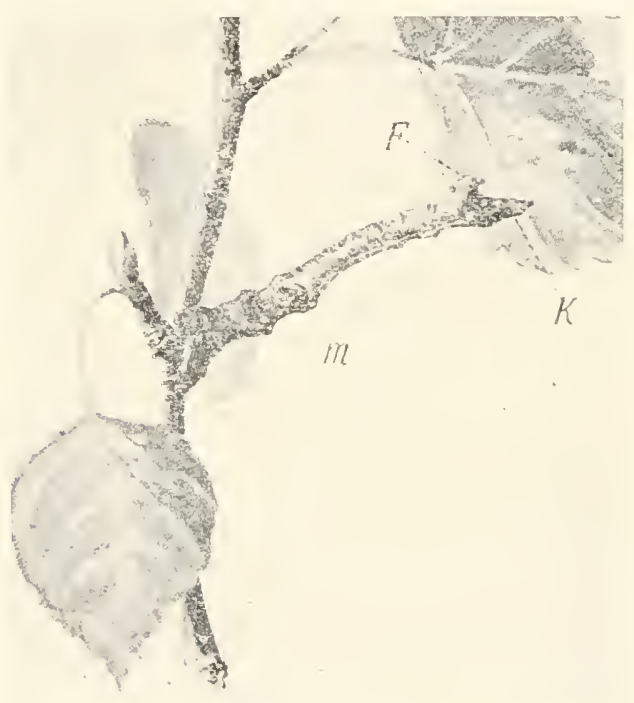

Flc. 30. - Twig-like caterpillar of the moth selenic tetralumarla, on a spray of birch. [After WEISMAXX.]

h. The heal. F. The feet. H. A mark resembling a bud scar. color, shape, and habitual position the resemblance is very exact. The caterpillars of many other species of moths show a similar resemblance to twigs ( $\mathrm{Iig}$. 30 and Plate 60). Some caterpillars resemble the ragged edges of the leares of their foodplant, both color and shape making a striking resemblance (Plate 56). Other caterpillars are green with brown spots, conforming closely in color and color pattern to the fungusspotted leares upon which they are found (Plate 56). Some adult insects resemble sticks; for example, the common "walking-stick" (Plate 6I, $A$ ). In Nicaragua there is found a walking-stick in which the deception is carried still farther by certain excrescences on the body and legs which cause it to resemble a bit of moss (Plate 6I, $B$ ). Belt, its discoverer, says it is found on moss. Many insects resemble 


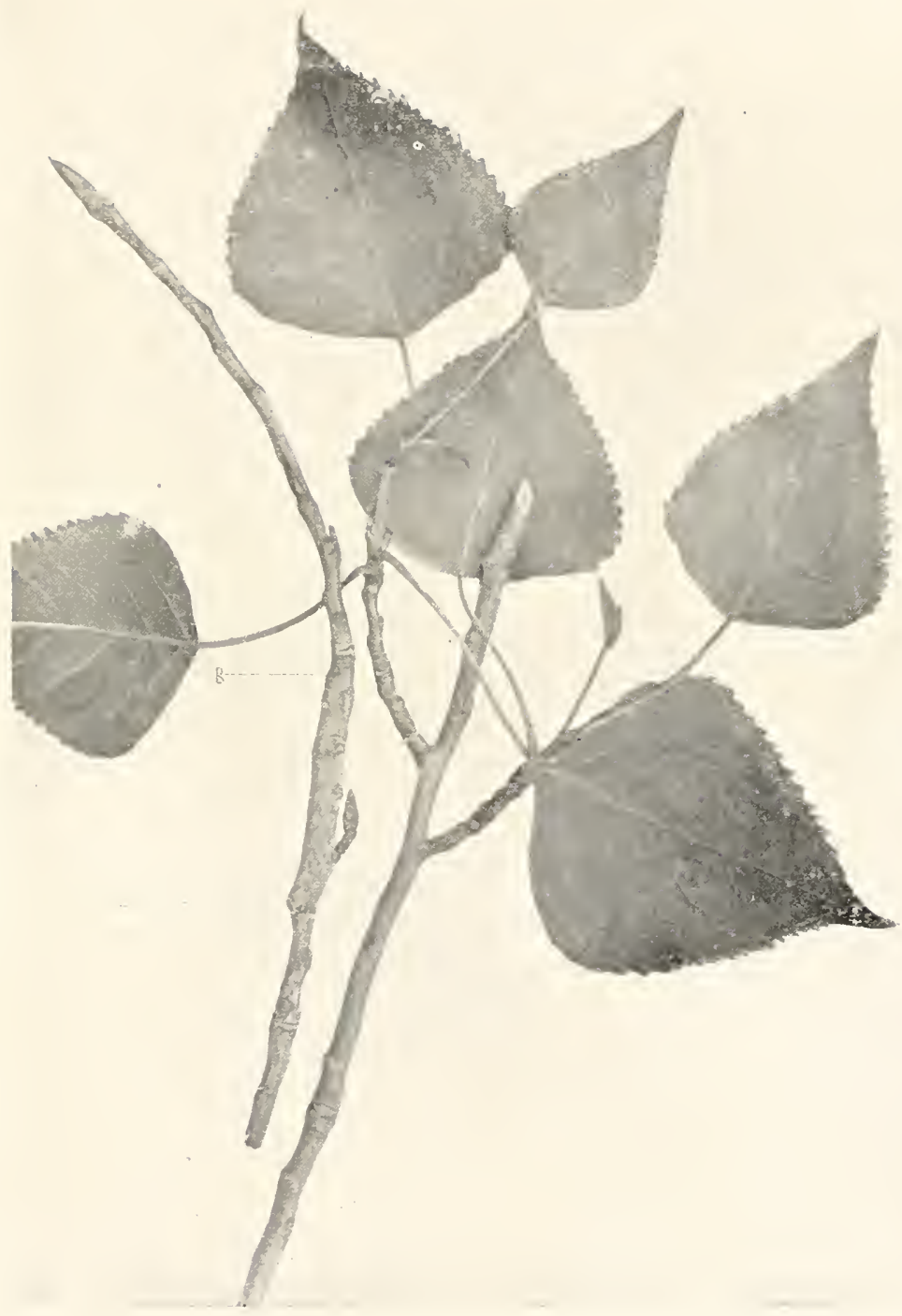

PLATE 6o. - Caterpillar of the moth Catocala amatrix, on a poplat wig.

a. Indicates its head. $b$. Its posterior end. The bark of the young twigs of this tree is of a peculiar purplish gray color. The caterpillar not only imitates this color to perfection, but it also has the habit of so flattening itself against the twig as to appear a part of the wwig itself. This caterpillar on a leafy spray, while alive, was handed at different times to four biologists with the remark, "Isn't that a fine example of protection?" and none of then saw the caterpillar. 


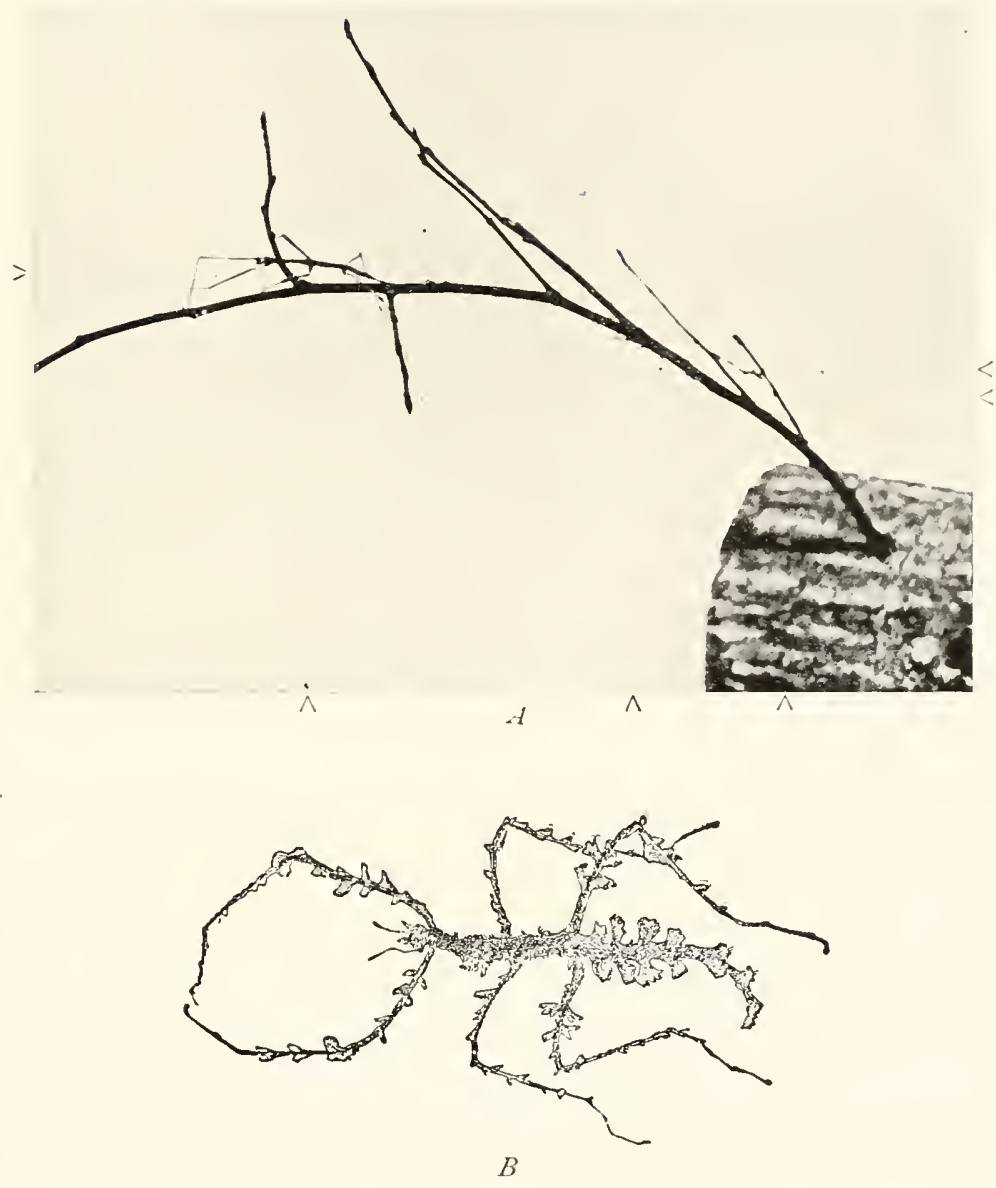

Plate 6I. - A. Three "walking-sticks" on a twig. The two larger ones are of the species Diapheromera femorata. - From an exhibit in the United States National Museum. B. An insect which lives upon moss and which closely resembles the moss in form and color (green). [After BELT.] 


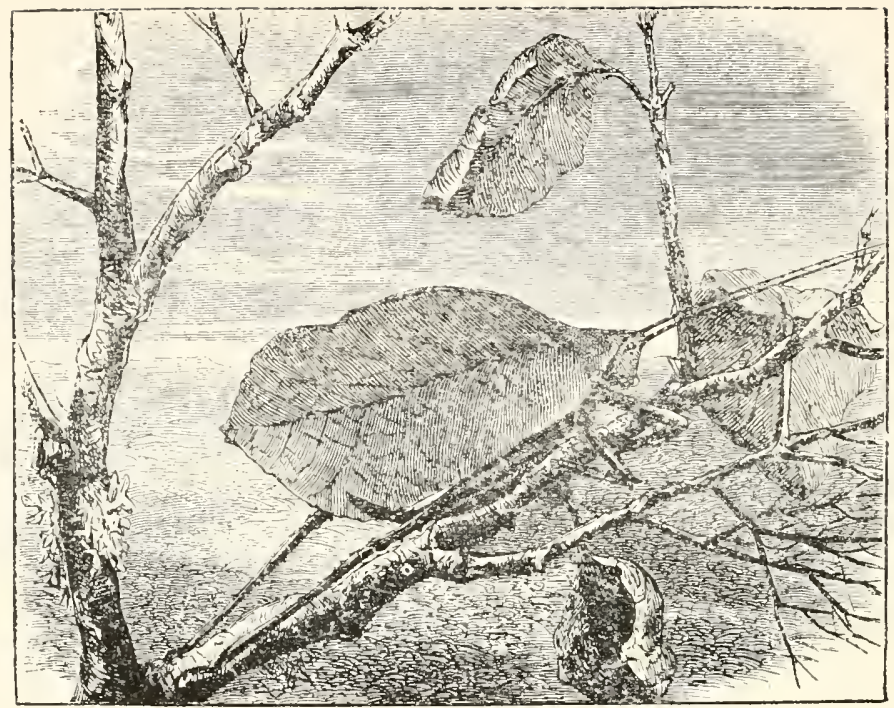

1
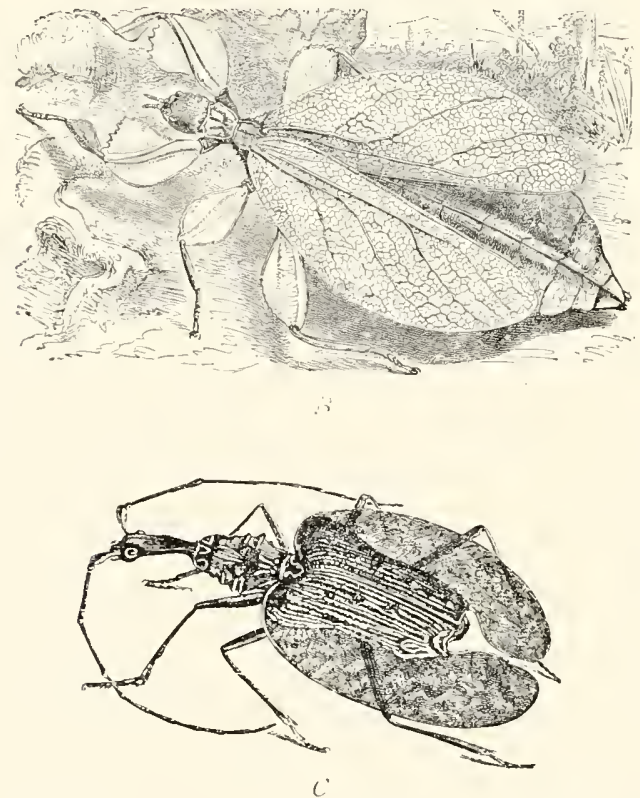

PLATE 62.-A. A green locust which resembles a leaf. It is probably a species of Cycloptera. [After BEIIARD.] B. A leaf-like mantis (Phyllium siccifolium). - From Brehm's Thierleben. C. A longicorn beetle (Mormolyce phyllodes). 

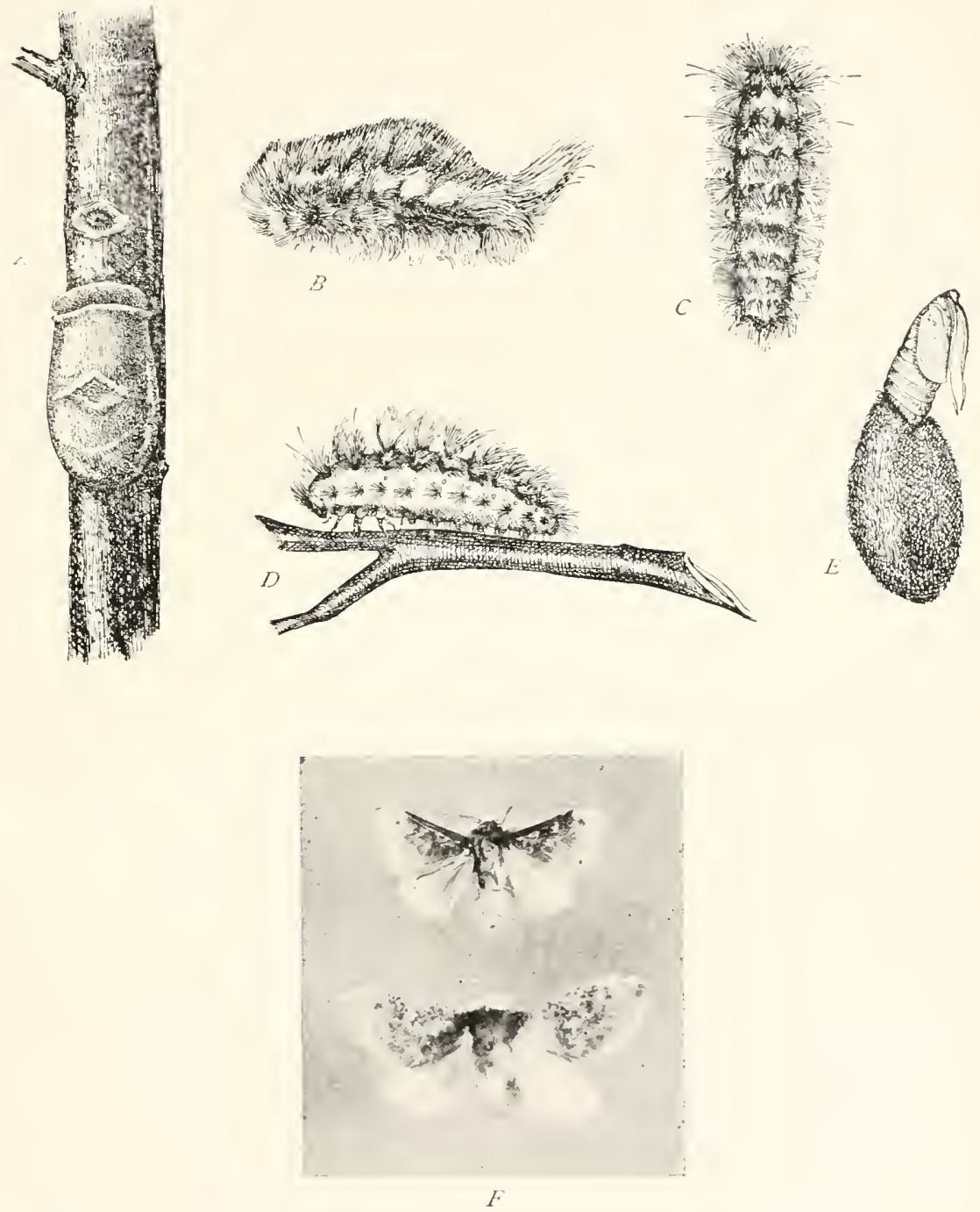

Plate 63. - Logoa opercularis and Logoa crispata. About natural size.

A. Cocoon of L. opercularis. B. Larva of L. opercularis. C. Dorsal view of larva of $L$. crispata. D. Side view of larva of L. crispata. E. Cocoon of L. crispata, with moth emerging. $F$. Imagines of $L$. opercularis: upper figure, male; lower figure, female. $B, C, D$, and $E$ drawn from specimens lent by the United States National Museum. 

leaves. WVe have leaf-like grasshoppers, leaf-like Mantides, leaf beetles (Plate 62), leaf moths, and leaf butterflies (Plate $\left.S_{4}, B, D, E, K\right)$. There are a number of the latter in this country, but the finest example is Kallima inachis, found in India. In this species the resemblance to a dead leaf is almost perfect when the wings are closed (Plate $\delta_{4}, A$ and $B$ ).

In the pupa stage of many insects we find remarkable special resemblances. Perhaps the finest example is furnished by the cocoon of the "waved-yellow moth," Logoa opcrcularis. The pupa of this moth lies inside a cocoon which in color and apparent texture closely resembles the bark of the alder and other twigs on which it is found (Plate $\left.6_{3}, A\right)$. At the top of the cocoon is a trap-door not noticeable until it opens to free the adult insect. At the middle of the cocoon there is a peculiar depression with rough elevated edges, giving an appearance almost identical with that of the winter buds of the alder twigs. Another species of the same genus (L. crispata) has a cocoon of quite different character (Plate $\sigma_{3}, E$ ), for, since it is found underground, there is no need of its having the peculiarities which so perfectly protect the cocoon of $L$. opercularis. The caterpillars of these same moths are also protected by great numbers of yellow or brown hairs. In L. opercularis the hairs so completely conceal the body of the caterpillar that one would not suspect its real nature (Plate $63, B$ ). In L. crispata the hairs, while present, are less thickly set, allowing the form of the caterpillar to be seen (Plate $6_{3}, C$ and $D$ ). Both in its larval stage and in the chrysalis L. opercularis is more perfectly protected than is L. crispata.

The examples of special resemblance thus far cited 
have all been taken from the insects. Examples could be found in other groups. Along our eastern coast is a small
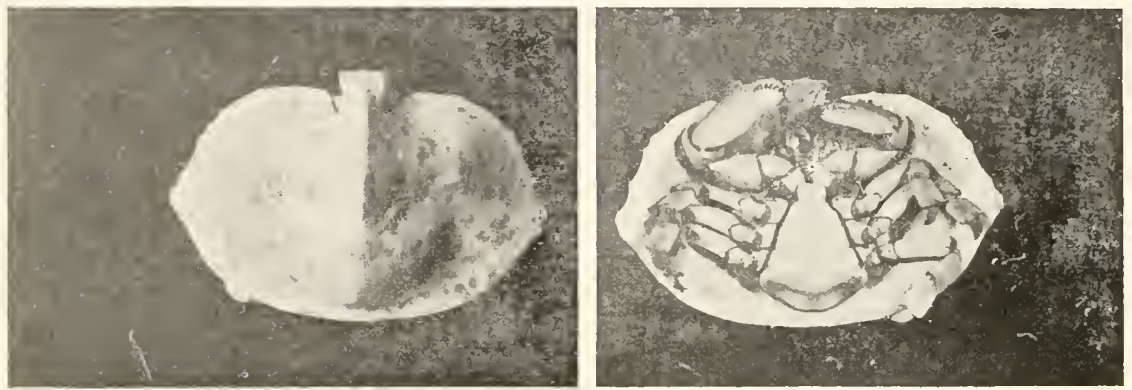

FIG. 3I. - A crab (Coyptolithodes sitchensis) which resembles a pebble. Its color is a bluish gray, resembling a piece of slate. - From a specimen collected in Puget Sound.

spider found very frequently on the little roadside rush, Juncus bufonius, which so closely resembles the buds of

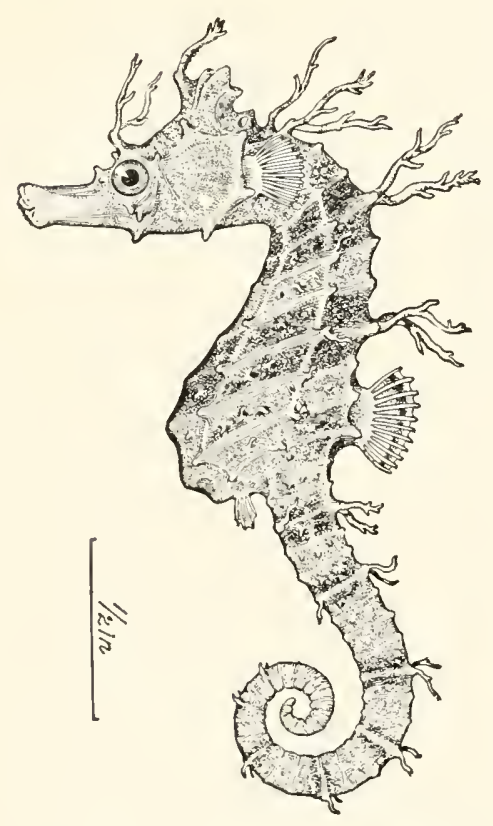

FIG. 32. - A "sea-horse" (Hippocampus molnikei), a fish which is highly modified to resemble the seaweed attached to which it lives. [After JORDAN, in the Proceedings of the United States National Mliseum.] the rush in color and shape that the most careful observer could be excused for not detecting the imposition (Plate $64, A$ ). Nany other spiders show special protective resemblances (Plate 64). One of the crabs found in Puget Sound is so exactly like the pebliles of the bottom along shore that no one would recognize it as a crab until he saw it in motion (Fig. 3I). In the tufts of floating seaweed, so abundant in the Sargassum Sea, there are small fishes of two species which in color are peculiarly like the seaweed itself (Plate 65). The seaweed is 




1'AIF 64. - SPHERS WHOSE COIOR AND SHAPF RENDFR THEM IHFFICLLT TO SJE.

1. Epeira stellata upon a rush (Funcus bufonius), natural size; from a specimen given by H. Wr. Britcher. When this spider rests with its legs folded, its resemblance to a seed pocl of the rush is very close. B. Alimmes attenmata, which resembies a stick. [From G. II. and E. G. PECKHAM, after CAMrkingE.] C. A spider which resembles a seed pod, natural size. $D$ and E. Carostris mitralis, which resembles a knot on a twig (magnified). [From G. W. and E. G. PEсkн.M, after Vissox.] F. Epeira prompta on a lichen-corered branch. [After G. W. and E. G. PEckil.M.] G. Cloborus plumites, with its cocoon ir its web on a twig of larch. [After G. II. and E. G. РескHA.M.] 



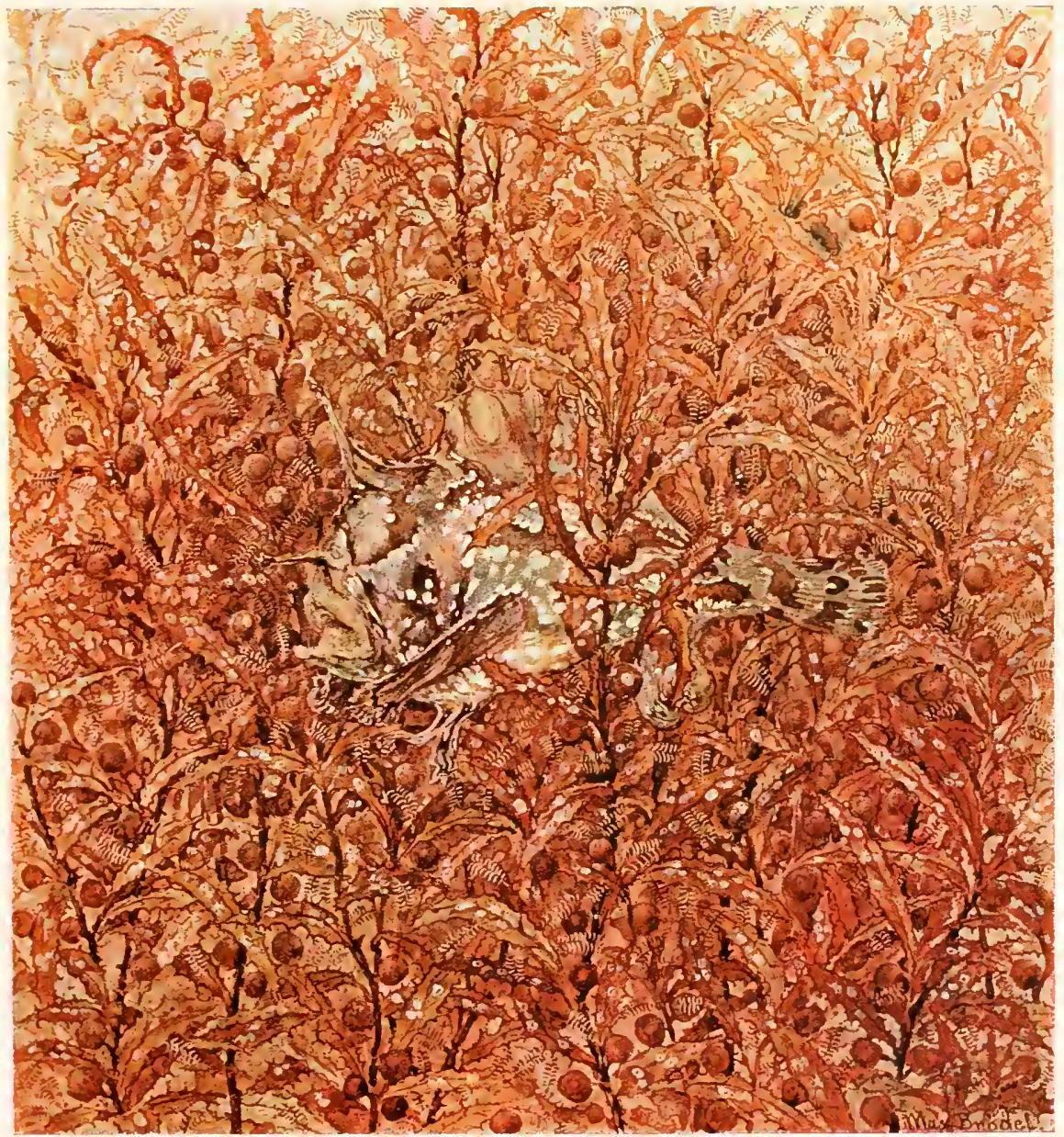

PLATE 65.- SARGASSUM Fish (Pterophryne hustrio) IN A TUFT OF FLOATING SEAWEEI).

The white spots on the fish resemble the spots of Bryozoa upon the seaweed. The fins of the fish are frayed out and irregular, resembling somewhat the fronds of the seaweed. Two pairs of the fins are modified to form clasping organs, by means of which the fish clings to sprays of the seaweed. 

mottled light and darker brown with small white blotches, and these colors are reproduced in the fishes and with the characteristic irregularity seen in the seaweed. (See also Fig. 32.) Nany other examples might be cited, but enough has been said to emphasize the remarkable nature and the prevalence of phenomena of protective color and resemblance.

Aggressive coloration and resemblance.

Let us next look at some instances of aggressive coloration and resemblance. Here we have phenomena very

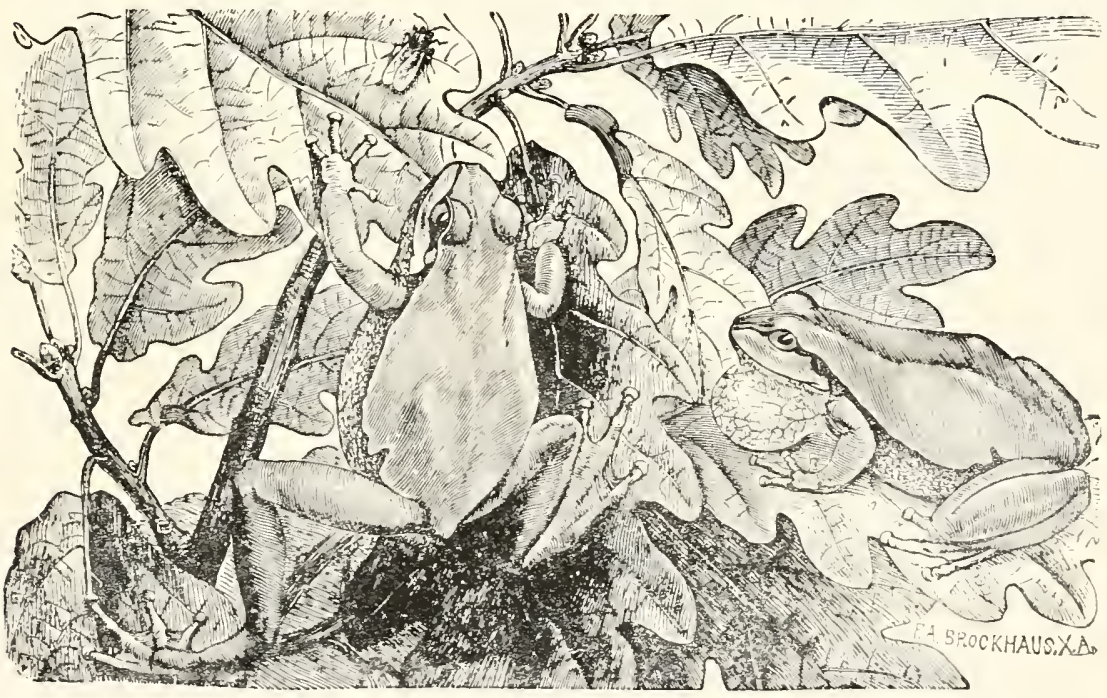

FIG. 33. - Tree-frogs whose backs resemble oak leaves in color and color pattern. [From BEDDARD.]

similar to those just illustrated, but the use of the color or resemblance is just the opposite to that which we have seen. Instead of enabling its possessor to escape its enemies the color or resemblance enables it to capture its prey. Anything which will render a predaceous animal less con- 
spicuous will aid it in stalking its prey, or, as it lies in wait, to capture it. Often the same color which protects an animal from its own enemies will also aid it in its search for food, so that the same characters will be both protective and aggressive. The dull color of the field sparrow (Plate 49. A) will cmable it to escape the view of the hawk, but also it will enable it unobserved to approach its insect prey. Many of the color characters already referred to probably have this double use; $c . g$. think of the insect-eating birds in general, the lizards (Plate 52), the frogs and toads (Fig. 33 and

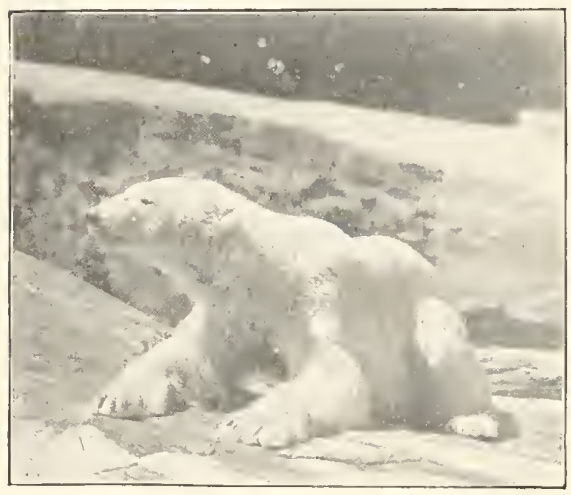

Fir. 3+. - Polar bear (Lrsus martimus).From a block obtained from the New York Koölogical Society.
Plate 66), the snakes, the leaf mantis, which is a predaceous form feeding upon small irsects (Plate 62, $B$ ); think of the numerous unobtrusively colored spiders (Plates $6_{4}$ and $S_{5}, D$ ), of the pebble-like crais (Fig. 3I), and the Sargassum fish (Plate 65). While the color of the animal often has this double significance, there are many instances in which the color is purely aggressive. To this class belong the colors of the polar bear, white like the snow (Fig. 34); of the arctic fox, white in winter and grayish brown in summer (Fig. 35); of the weasel (Plate 67) and of the snowy-owl, both of which show a similar seasonal change; of the wolf, the fox, the lion; of the tiger, tawny with dark stripes, resembling the vertical shadows of the reeds among which it lies in wait for the antelopes as they come to the waterside to drink (Plate 68, $A$ ); of the 


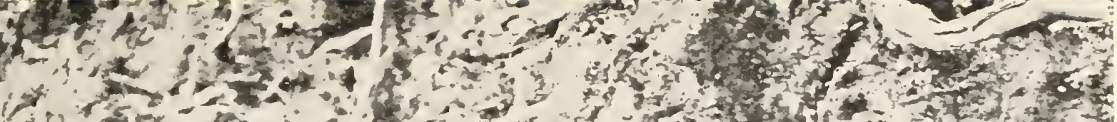

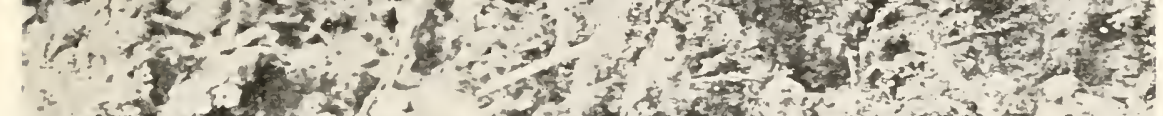

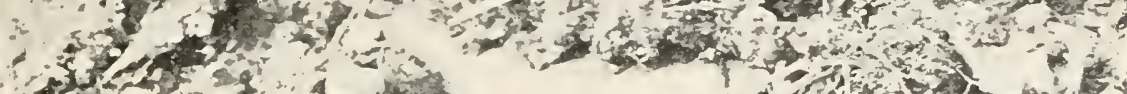

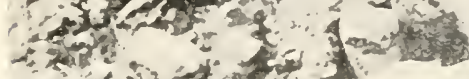

1)

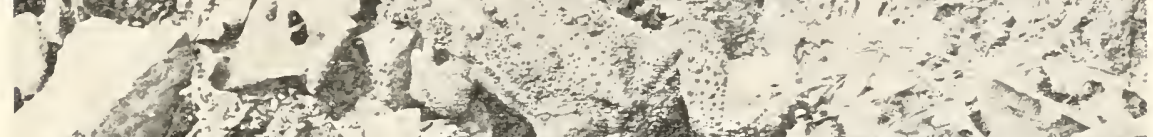

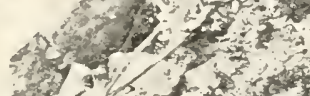
i.

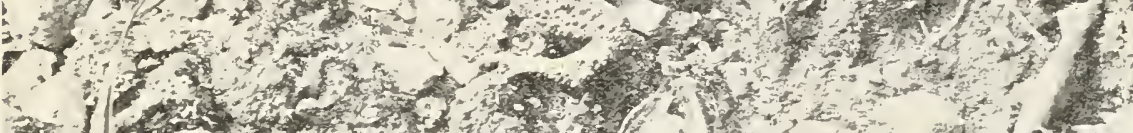
3 (3)

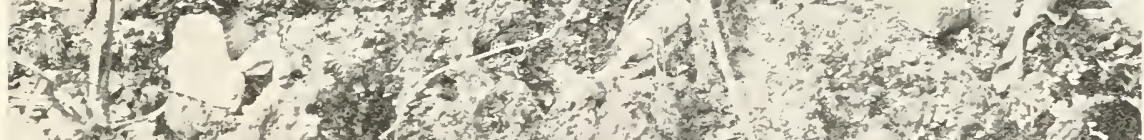

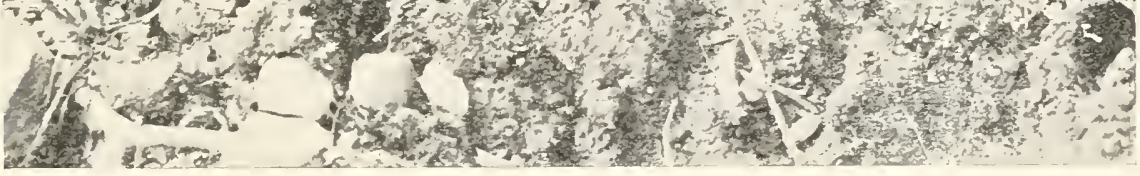

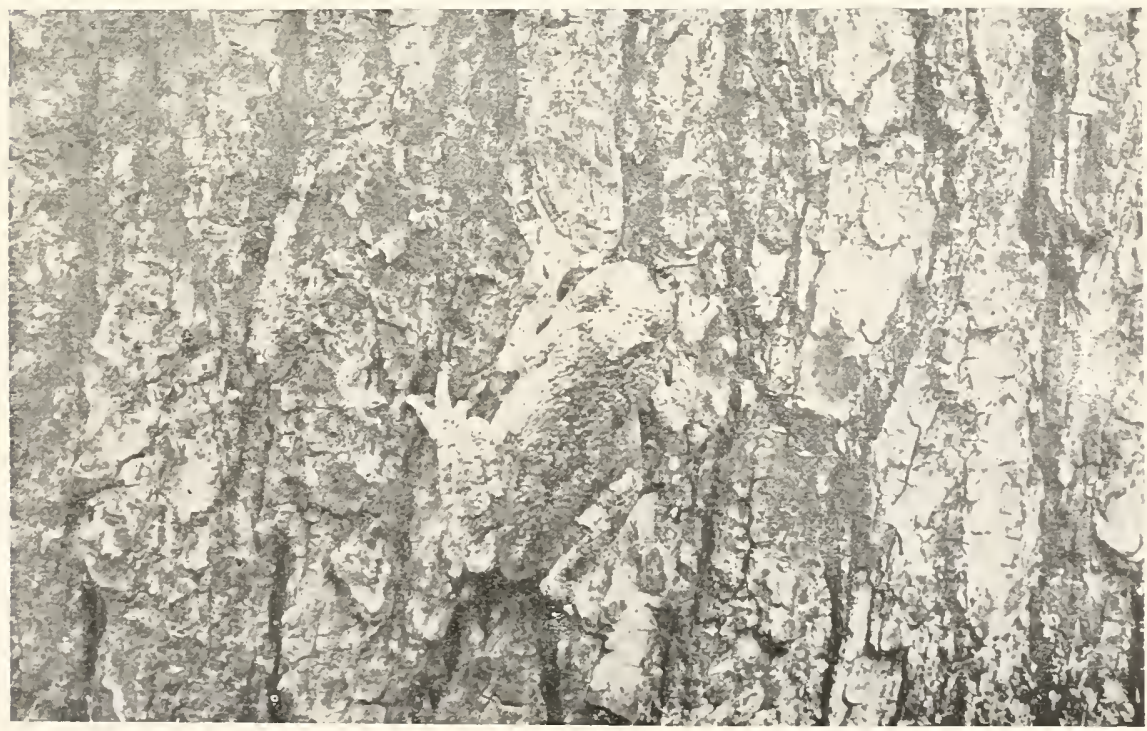





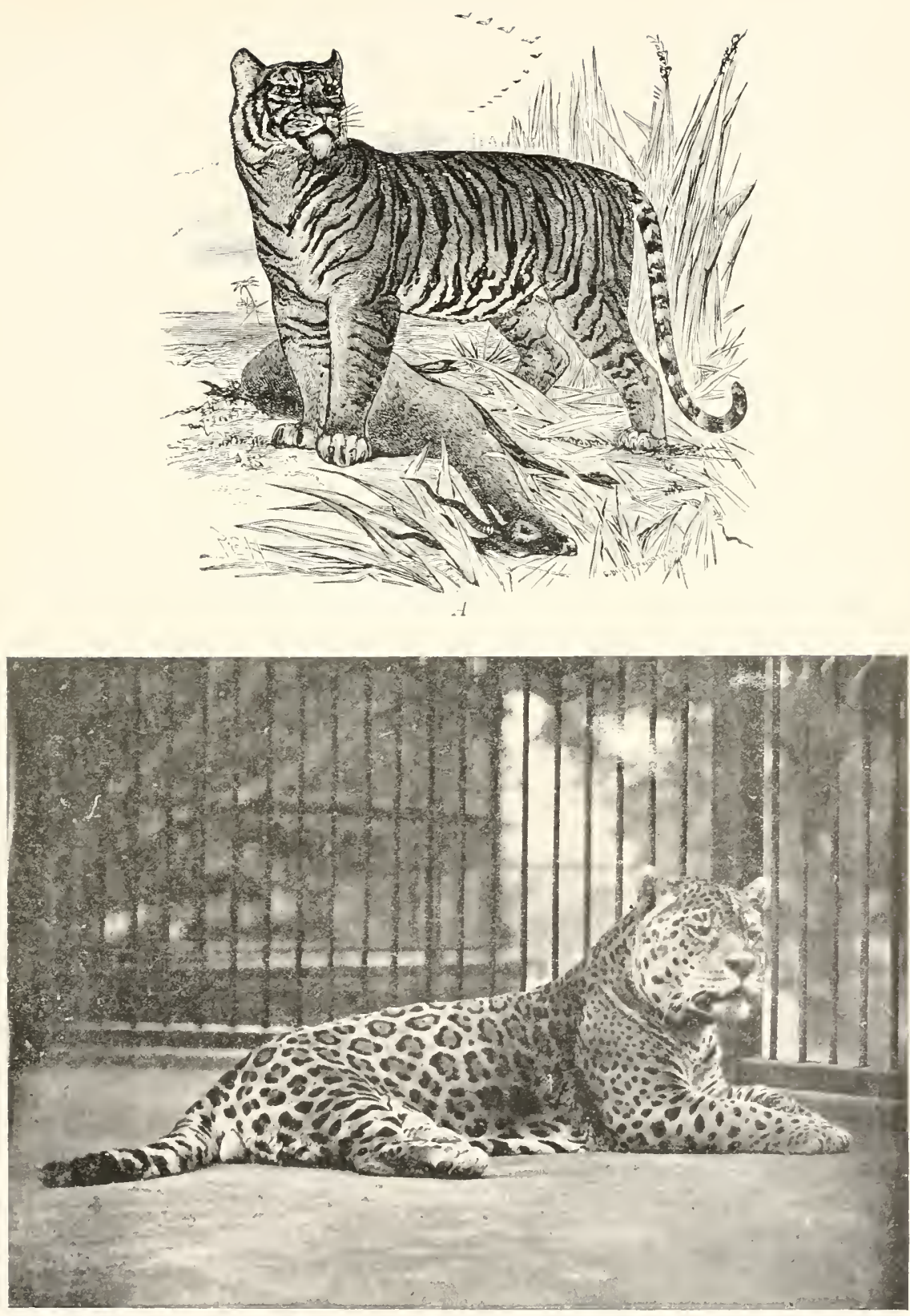

$b^{3}$

PLATE 68. - A. Tiger (Felis tigris). - From Flower and Lydekker's Mammalia, by permission of A, and C. Black. B. Jaguar (Felis onca). - From a photograph by Gambier Bolton, by permission of the Autotype Company. 

jaguar, a forest species and a tree climber; the blotches on whose skin resemble the confused shadows among the trees (Plate 68, B).

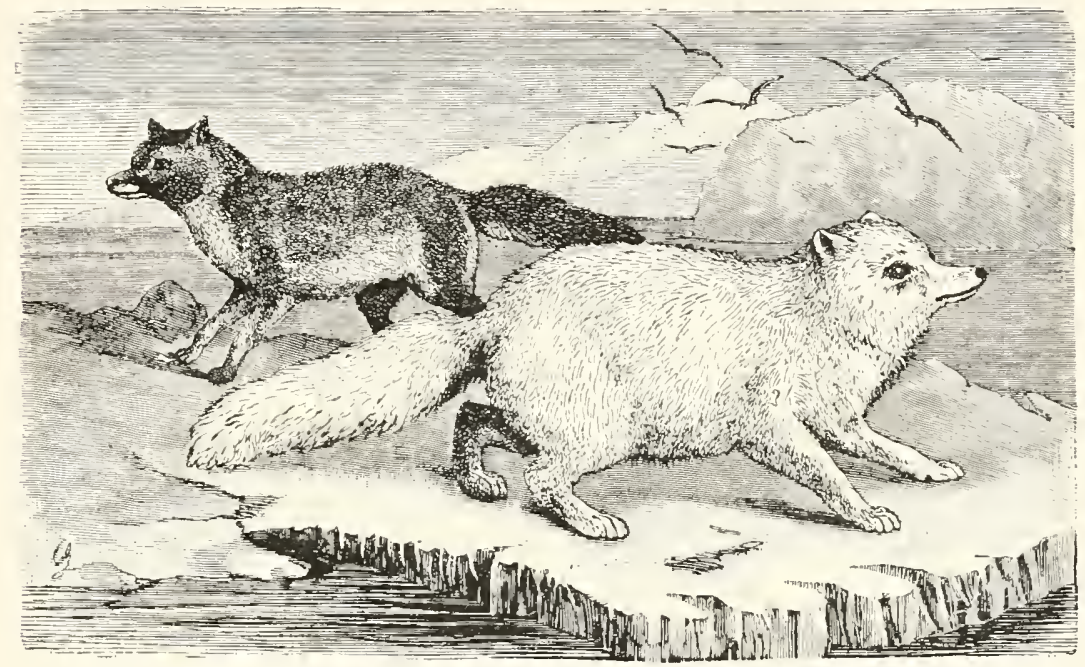

FIG. 35. - Arctic fox, in winter and in summer pelage. [After BEUDARU.]

Alluring colors and resemblances.

There are a few examples of a still more remarkable use of color and resemblance. In India there is a Mantis which in shape and color resembles an orchid blossom (Fig. 36). It deceives butterflies and other insects, which it captures as they approach the seeming flower. In Java there is a spider which resembles a bit of bird-excrement upon which butterflies are so apt to light. This resemblance enables it to capture the butterflies upon which it feeds. Forbes, in his interesting book, A Naturalist's Wanderings in the Eastem Archipelago, thus describes his discovery of this peculiar spider: "I had been allured into a vain chase after one of those large, stately flitting butterflies (Hestia) through a thicket of prickly Padanus 
horridus, to the detriment of my apparel and the loss of my temper, when on the bush that obstructed my further pursuit I observed one of the Hesporide at rest on a leaf on a bird's dropping. I approached with gentle steps but ready net... It permitted me to get quite close and

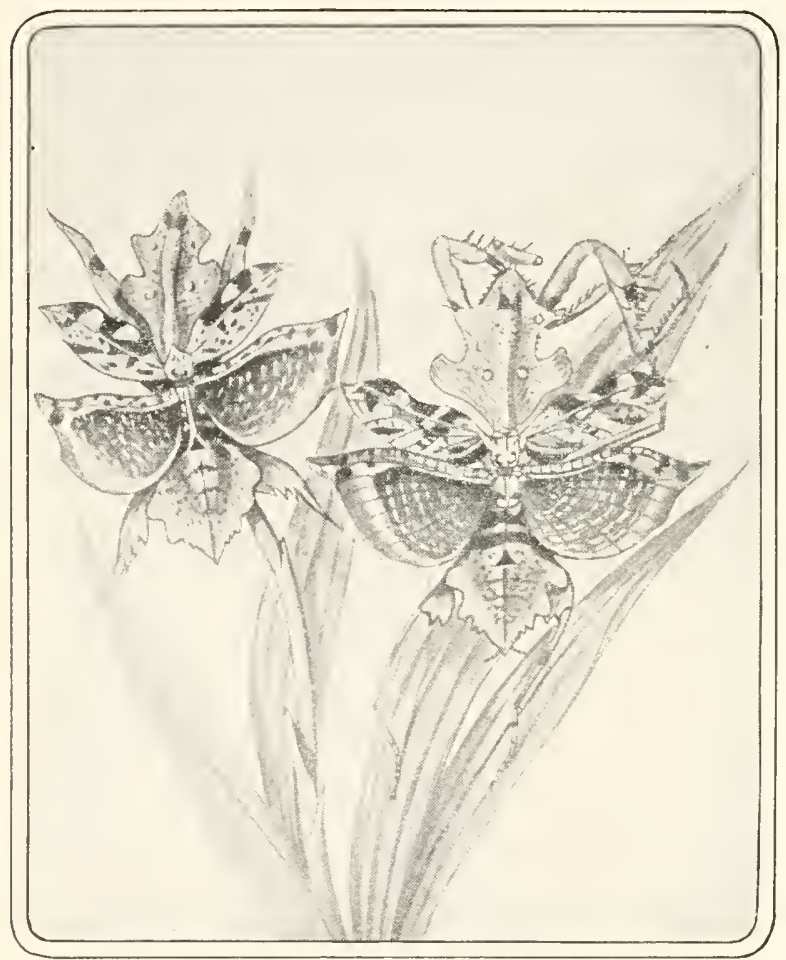

LIG. 36. - A manus (Hymenopus bicornis), which resemules an orchid blossom. even to seize it

between my fingers ; to my surprise, however, part of the body remained behind, ... a adhering, as I thought, to the excreta. I looked closely at, and finally touched with the tip of my finger, the excreta, to find if it were glutinous. To my delighted astonishment I found that my eyes had been most perfectly deceived, and that the excreta was a most artfully colored spider lying on its back, with its feet crossed over and closely adpressed to the body.

"The appearance of the excreta rather recently left on a leaf by a bird or lizard is well known. Its central and denser portion is of a pure white chalklike color, streaked here and there with black, and surrounded by a thin 
border of the dried-up more fluid part, which, as the leaf is rarely horizontal, often runs for a little way toward the margin. The spider, which belongs to a family, the Thomisida, possessing rather tuberculated, thick, and prominent abdomened bodies, is of a general white color; the underside, which is the one exposed, is pure chalk-white, while the lower portions of its first and second pairs of legs and a spot on the head and on the abdomen are jet black.

"This species does not weave a web of the ordinary kind, but constructs on the surface of some prominent dark leaf only an irregularly shaped film, of the finest texture, drawn out toward the sloping margin of the leaf into a narrow streak, with only a slightly thickened termination. The spider then takes its place on its back on the irregular patch I have described, holding itself in position by means of several strong spines on the upper sides of the thighs of its anterior pair of legs thrust under the film, and crosses its legs over its thorax. Thus resting with its white abdomen and black legs as the central and dark portions of the excreta, surrounded by its thin web-film representing the marginal watery portion become dry, even to some of it trickling off and arrested in a thickened extremity such as an evaporated drop would leave. it waits with confidence for its prey, - a living bait so artfully contrived as to deceive a pair of human eyes even intently examining it."

In Algiers is found a lizard which has at the corners of its mouth bright red folds of skin which are of the same color and shape as the blossoms of one of the desert plants. Insects are deceived and come to feed upon the nectar and pollen, but serve themselves as food for the lizard. These are examples of what we may call alluring coloration and resemblance. 


\section{Waming colors.}

IVarning colors are another important class. Many animals are dangerous because of some means of defence, or are noxious or nauseous as food, and many such are conspicuously colored, as if adrertising their dangerous or disagreeable nature. Many insects show conspicuous colors of this sort. Many of the bees, wasps, hornets, and yellow-jackets are conspicuously banded with yellow or white, or have a brilliant metallic lustre, like the blue wasps (Plate 74). That this conspicuous coloration is an actual protection to these stinging insects is readily shown by experiment. V'ery few insect-eating birds, lizards, frogs, toads, or mammals will eat these insects. Apparently they have learned that they are unpalatable. By experimenting with young birds which have never before seen bees or wasps we get evidence that the noxious character of the insect has to be learned, but it is learned with astonishing rapidity, and when once learned, scems not to be forgotten. Lloyd Morgan describes feeding a young chick with flies among which he placed a wasp. 'The chick took the wasp, was stung, and showed great agitation, wiping its bill and scratching it. Several days later, while again feeding the little fellow with flies, he offered it another wasp. The chick looked at the wasp, turned aray from it, and began wiping its bill, apparently remembering the disagreeable sensations which followed its former attempt to eat a wasp. Hundreds of experiments show a similar ability in other birds, in lizards, frogs, toads, and monkeys, to rapidly learn the unpalatable character of conspicuous insects. If the stinging Hymonoptera ${ }^{1}$ were less conspicuously colored, they would often be mistaken for edible forms and either be eaten or at least be grasped 

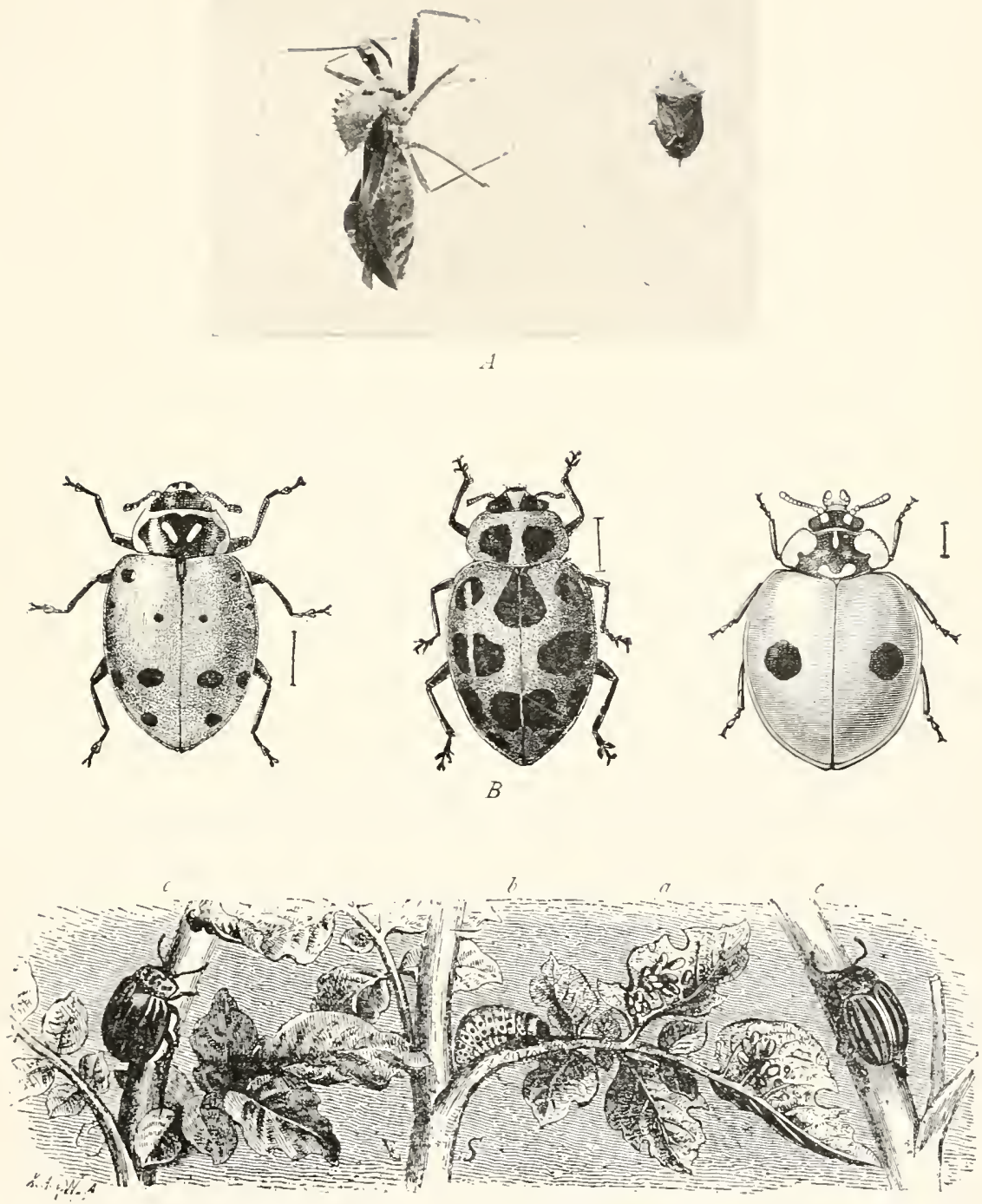

PLATE 69. - A. Two bugs (Prionotus cristutns on the left and Euchistus serius on the right) whose odor and flavor are disagreeable to insect-eating birds, lizards, toads, and frogs, and whose shape is easily recognized, causing them to be avoided. B. Lady beetles (Hiptodamia convergens, Megilla maculata, Adalia bipunctata). - By the courtesy of the United states Department of Agriculture. C. Colorado potato beetle (Dorythnra decemlineata); $a$, eggs; b, larva; $c$, adult. - By the courtesy of the United States Department of Agriculture. 

and injured, even if finally rejected without being eaten. Their conspicuous color is readily remembered, and, as it is associated in the minds of their enemies with their disagreeable character, it must serve to save many from injury or destruction. The coloration, therefore, is properly called warning coloration.

Often such warning coloration is associated with peculiar shape or distinctive habits which make the insect still more easy to recognize. The bees, wasps, yellow-jackets, and hornets have a peculiar buzzing flight, and when standing, they commonly teeter the abdomen up and down in a way that always suggests to us their excitable disposition. Apparently these habits produce much the same effect upon their bird, lizard, and frog enemies that they do upon us. The slender waist of the Hymenoptera is also a conspicuous feature.

As further examples of warning coloration we might call attention to the Hcmiptera, the bugs, many of which have a very disagreeable taste and equally disagreeable odor. These insects are frequently conspicuously colored, and they generally have a very characteristic and readily recognized body form (Plate 69, $A$ ). Many of the beetles are very tough and some are disagreeable in flavor; accordingly we find many conspicuously colored beetles. Perhaps the best example is the common Colorado potato-beetle, the adult of which is conspicuously marked with longitudinal stripes and whose larva is also bright-colored and conspicuously spotted (Plate 69, $C$ ). Both the adults and the larve are unpalatable to birds, lizards, frogs, and toads. Other examples among the beetles are the goldenrod-beetle and the lady-beetles, commonly miscalled ladybugs (Plate 69, B). Many conspicuously colored butterflies are inedible; for example, the common yellow and white 
forms, Pievida, found so frequently about wet places in the roads (Plate 59, A), and most of the swallow-tailed butterflies, Papilionide, which are our most conspicuous North American forms (Plate $76, D)$. Some moths show warning color (Plate 7o, $\left.A-K^{\prime}\right)$. The larve of many moths and butterflies are inedible, and these also are conspicuously colored (Plate 7 I).

Wallace, in his Daruinism, says: "These uneatable insects are probably more numerous than is supposed, although we already know immense numbers that are so protected. The most remarkable are the three families of butterflies-I - Iiconida [Plate $77, A-D]$, Danaida [Plate $76, A, E$, and Plate $S_{4}, E$ and $\left.F\right]$, and Acrcide [Plate 76 , $G, I$, and $77, I, L]$ - comprising more than a thousand species, and characteristic respectively of the three great tropical regions: South America, Southern Asia, and Africa. All these butterflies have peculiarities which serve to distinguish them from every other group in their respective regions. They all have ample but rather weak wings, and fly slowly. They are always very abundant; and they all have conspicuous colors or markings, so distinct from those of other families that, in conjunction with their peculiar outline and mode of flight, they can usually be recognized at a glance. Other distinctive features are, that their colors are always nearly the same on the under surface of their wings as on the upper; they never try to conceal themselves, but rest on the upper surfaces of leaves or flowers; and, lastly, they all have juices which exhale a powerful scent, so that when one kills them by pinching the body, the liquid that exudes stains the fingers yellow, and leaves an odor that can only be removed by repeated washings.

"Now there is much direct evidence to show that this 

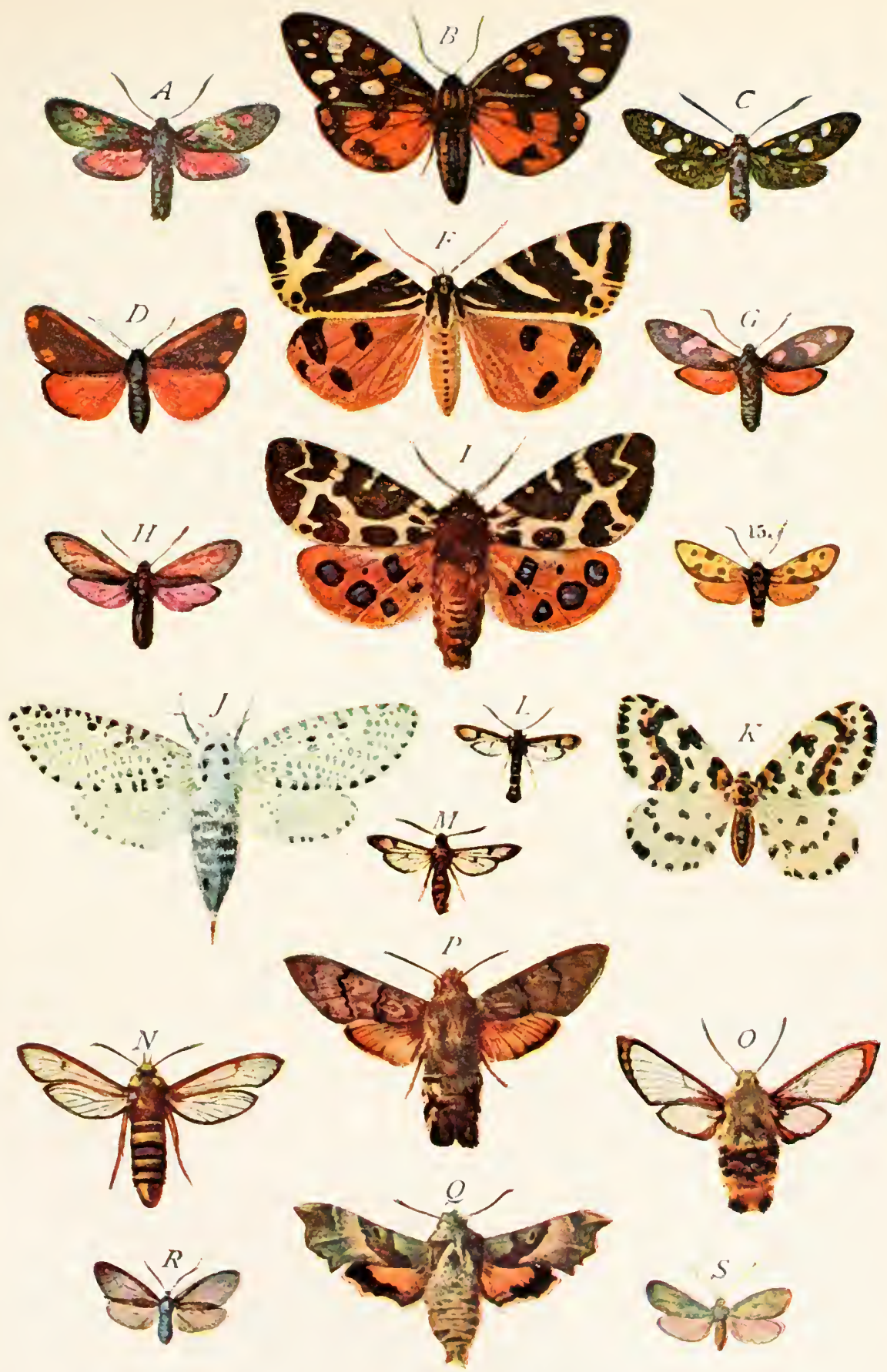

Plate 70.- WARNiNG Coloration AND MiMiCry in Moths.

$A-K$. Inedible moths, showing warning coloration. A. Zygana trifolii. B. Callimorpha dominula. C. Zygana epialtes. D. Emyda jacobere. E. Callimorpha hera. F. Zygana achillea. G. Zygena minor. H. Arctia caja. I. Zygena fausta. 7. Zenzera esculi. h. Abraxas glossularuata. L-O. Mimicry of bees and wasps by moths. L. Sesza culiciformis. M. Sesia tipuliformus. N. Trochilum apiforme. O. Macroglossia bombyliformus. P-S. Noths closely related to $L-O$, which do not imitate bees or wasps. P. Macroglossia stellatarum; cf. $O$. Q. Pteregon proserpina. K. Ino pruni. S. Ino statices. 



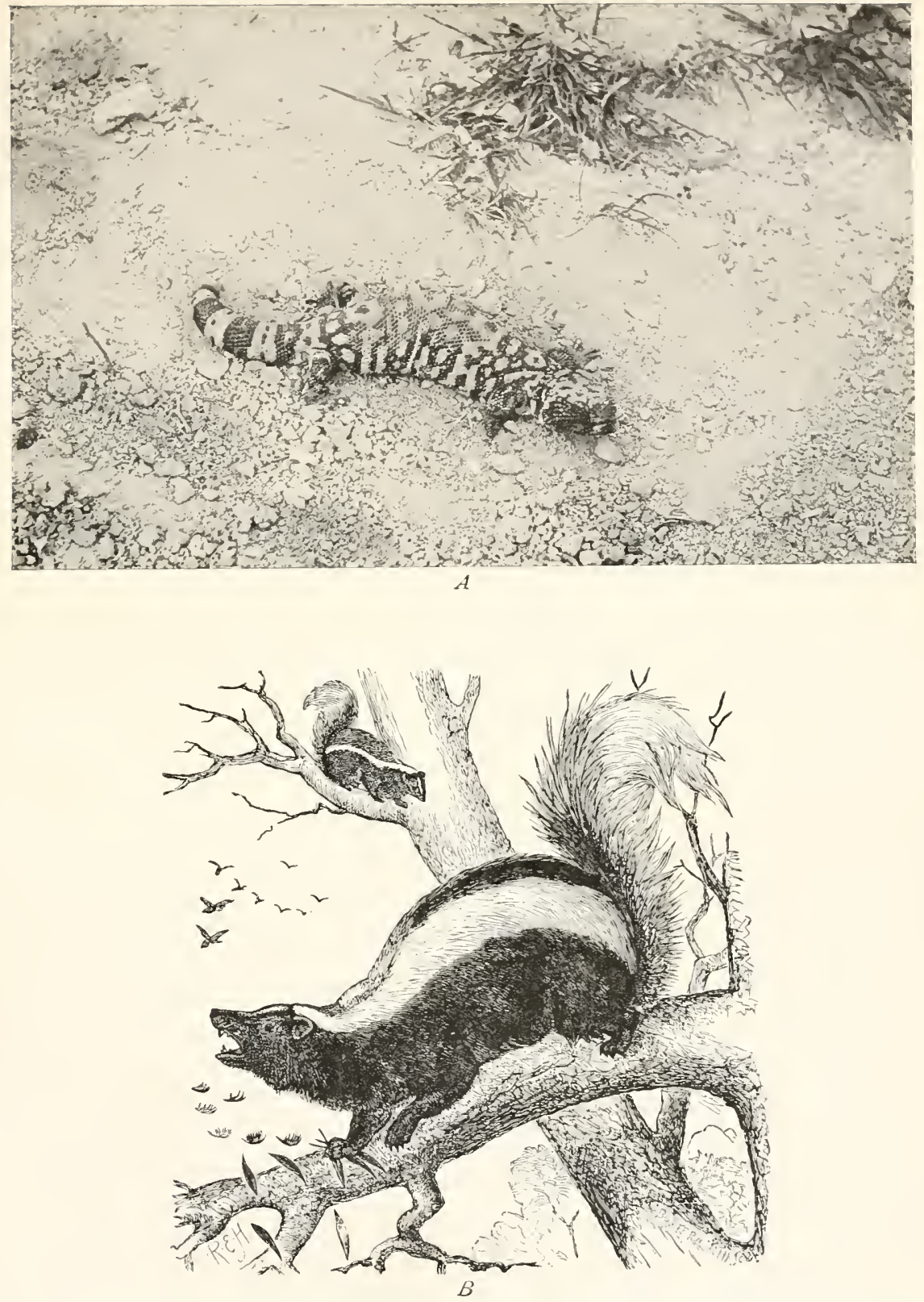

PLATE 72, - A. Gila monster (Heloderma horridum). B. Common skunk of eastern North America (Wephitis mephitica). - From Flower and Lydekker's Mammalia, by permission of A. and C. Black. 

odor, though not very offensive to us, is so to most insecteating creatures. Mr. Bates observed that, when set out to dry, specimens of Heliconide were less subject to the attacks of vermin; while both he and I noticed that they were not attacked by insect-eating bircls or dragon-flies, and that their wings were not found in the forest paths among the numerous wings of other butterflies whose bodies had been deroured."

Among the Amphibia the frogs are edible and are protectively colored. Toads are distasteful, but show a dull color which is probably aggressive, aiding them in capturing their insect prey (Plate $66, B)$. The salamanders, on the other hand, are night feeders and do not need to be aggressively colored, and we frequently find them very conspicuously spotted, since they are inedible (Fig. 37).

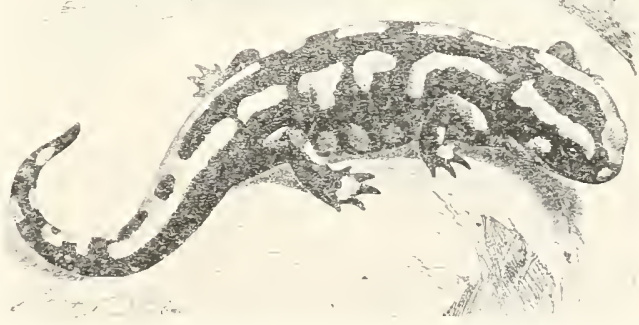

Fis. 37. - Salamander (Salamandra mazulosia). From Brehm's Thierleben.

Lizards, almost without exception, show dull colors, or colors that are in harmony with their enviromment, their coloration being both protective and aggressive (Plate 52). It is, therefore, especially interesting to find that the only known poisonous lizard, the Gila monster of our southwestern states, is a conspicuously colored form, salmon-pink with broad irregular black bands and blotches (Plate 72, $A$ ).

The Mammalia as a rule show aggressive or protective coloration in harmony with their surroundings; the skunk, however, which is so effectively protected by the foul-smelling 
secretion of its scent glands, advertises its disagreeable character by its conspicuous black-and-white color (Plate 72, B). There are a number of similar instances among the Mammalia. The black-and-white color of the skunk probably renders it inconspicuous when hunting its prey on moonlight nights, the black resembling shadows, and the white marks blotches of light. Its color, therefore, is probably both aggressive and warning coloration, aggressive by night, warning by day.

Similar phenomena of warning coloration are found among the different groups of marine invertebrates, but, as the forms are less familiar, we will not refer to them.

\section{Convergence in warning coloration.}

One very interesting feature is observed in the warning coloration of the inedible butterflies. Different inedible species, belonging to distinct genera or even to distinct families, in many instances show the closest similarity in color and in color pattern, and often also in shape (Plate $77, A-D)$. This was for a long time a puzzle to students of color phenomena, until Bates, an English naturalist, suggested that this convergence in coloration among unrelated inedible butterflies must decrease considerably the number of experiments necessary to teach young birds and lizards the evil character of the butterflies, since they are all of one pattern, and so save from destruction many individuals which would be sacrificed did their enemies need to learn a separate pattern for each inedible species. This suggestion seems plausible. It is, at least, the best we have yet found. 

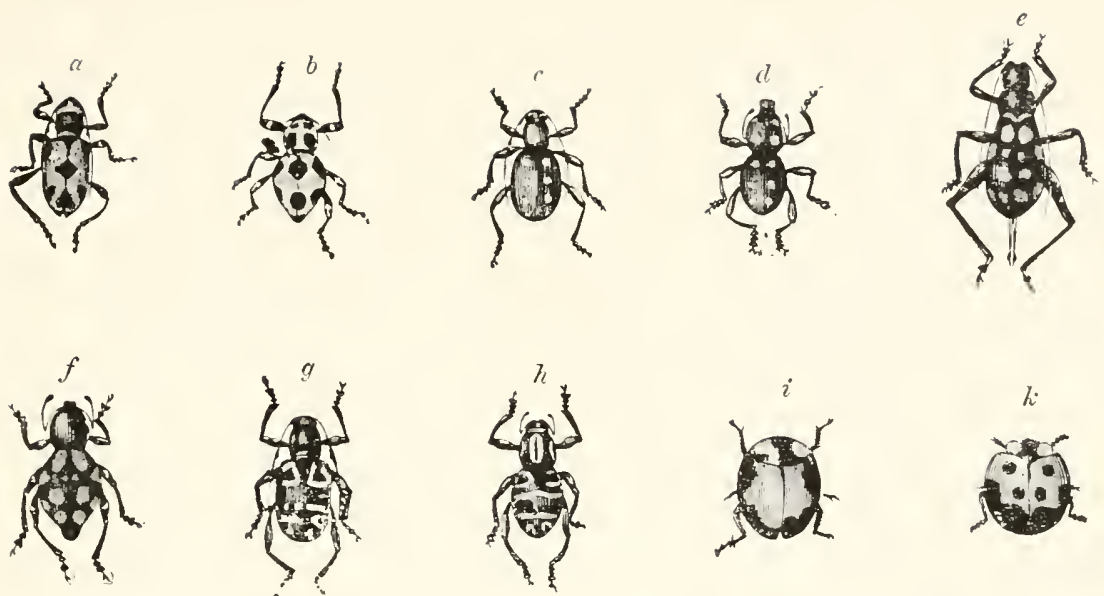

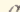
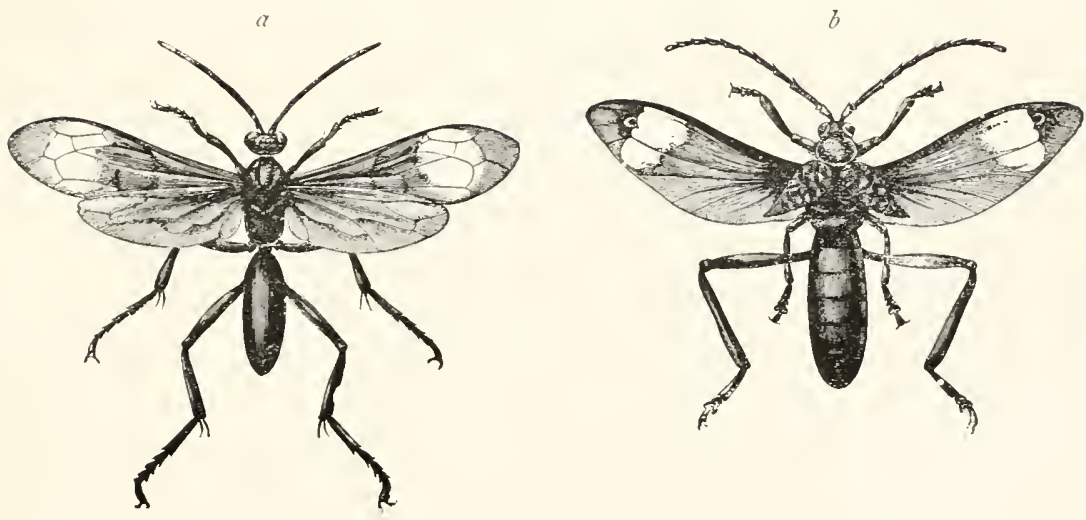

$B$

PLATE $73 .-1$. Inedible curculios and lady-beetles imitated by edible longicorn beetles and grasslıoppers. All from the Philippine Islands.

a. Dolıops sp., edible longicorn beetle which imitates b. Pachyrhynchus orbife, a hard curculio. c. Doliops curculionides, a longicorn beetle which imitates $d$. Pachyrhynchus sp., a hard curculio. e. Scepastus pachyrhynchoides, a grasshopper which imitates f. Apocy.tus sp., a hard curculio. g. Doliops sp., a longicorn beetle which imitates h. Pachyrhychus sp., a hard curculio. i. Phoraspis, a grasshopper which imitates $k$. Coccinella, an inedible lady-beetle. [From WALLACE.] The resemblance is exact in color as well as color pattern.

B. A wasp (a. Mygnimia aviculus) which is imitated by a longicorn beetle (b. Coloborhombus fasciatipennis). [From IVALLACE.] 

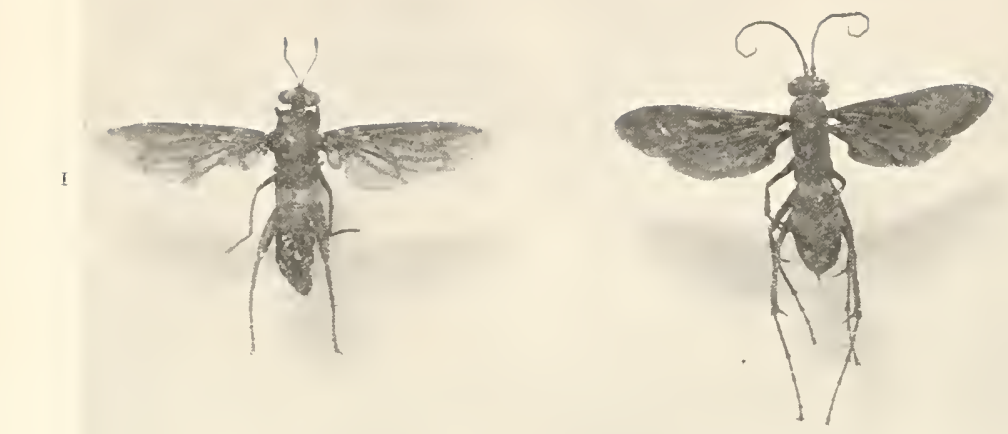

3, 4
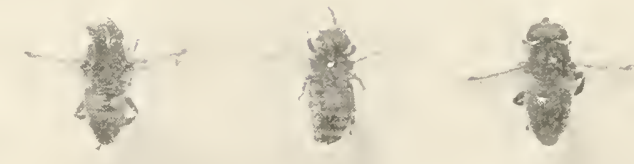

5,6

7
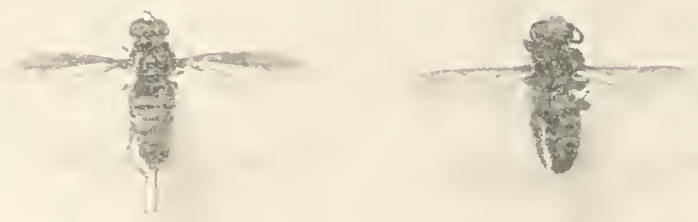

9,10
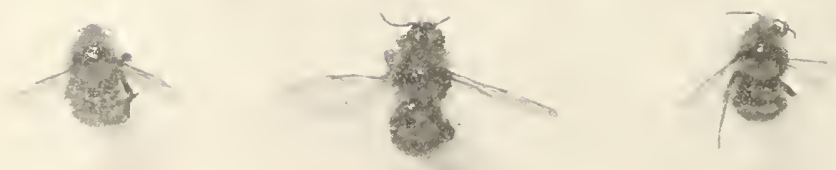

I I

I 2, 13
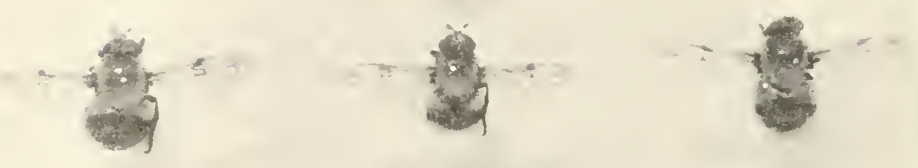

14

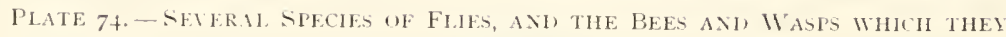
RESEMULE.

I. Mydas clavatus. 2. Pompilus atrox. 3 and 5. Apis mellifera. 4 and 6. Eristalis te'lat. 7. Spilomyia hamifera. facialis.

8. lespa accidentalis. 9-1I. Bombus a anconterensis. 12-14. lolucella 


\section{Mimicry.}

Some of the instances of protective, alluring, and warning coloration that have been described are sufficiently remarkable, but the phenomena of mimicry are even more surprising. Many animals which are not protected by stings, or disagreeable odors or flavors, and are really palatable to predaceous species, are protected from the attacks of such predaceous enemies by their resemblance to species which are incdible. Instances of such mimicry are very numerous among the insects, and are found also in other groups. Let us see some examples.

Many beetles are inedible, either because of their very hard outer shell, or because of some nauseous flaror, and we find many such forms to be conspicuously marked with strongly contrasted colors; $\epsilon . g$. the lady-beetles and curculios (Plate $73, A, b, d, f, h, k)$. There are edible beetles which mimic some of these warning-colored inedible forms (Plate 73 , $A, a, c, g$. The hard and unpalatable curculios are imitated also by grasshoppers (Plate $73, A, c)$. Certain grasshoppers also imitate the evil-flavored lady-beetles (Plate $73, A, i$ ).

Wasps, bees, hornets, and yellow-jackets are armed with stings which make them dangerous to attack, and their dangerous character is usually advertised by their conspicuous coloration. As we would naturally expect, we find that they are frequently imitated by other insects. We have longicom beetles which mimic wasps (Plate $73, B$ ). Very many flies mimic bees and wasps (Plate 74). One common kind of fly imitates the honey-bee so closely that one would hesitate to handle it even after being told that it is harmless. Other flies mimic bumble-bees in appearance and in manner of flight. In all of these cases, the resemblance is enhanced by 
the habits of the imitating form. The drone-fly, for example, which imitates a honey-bee, has the same kind of buzzing flight, and, when standing, occasionally teeters its abdomen up and down, as is characteristic of the bees and wasps. Some of these mimicking flies even protrude and withdraw the tip of the abdomen, as does an angry bee or wasp, making the imitation in habit as well as in form and color as perfect as possible.

At IVood's Holl one summer, while collecting insects from the blossoms of the common milkweed, I was struck by the resemblance of a moth to the large metallic blue wasp. When the moth was at rest upon the milkweed blossoms, this resemblance was not marked, but as one approached at all near, the moth sprang into the air, flying with a peculiar buzzing flight that seemed at once to transform it into a wasp. The blue wasps were common upon the same blossoms, and the deception was very perfect. As these moths are keen-sighted and easily startled, they must rarely be captured while at rest, and when flying they are likely to be let alone by insect-eating birds and dragon-flies. In the Alleghany Mountains I have found a large, blue-back longicorn beetle, which when in flight closely resembles one of the blue wasps. We have an American moth which similarly resembles a bumble-bee, only in this case the resemblance is almost as noticeable when the moth is at rest as when it is in flight (Plate 70,0 ). The body has the same shape, is banded with yellow, and is covered with similar long yellow hairs; the wings also are very different from those of most moths, having lost most of their scales and being transparent, like the wings of a bumble-bee. Many other moths mimic the stinging Hymonoptera (Plate 7 o, $L, M, N$ ). 


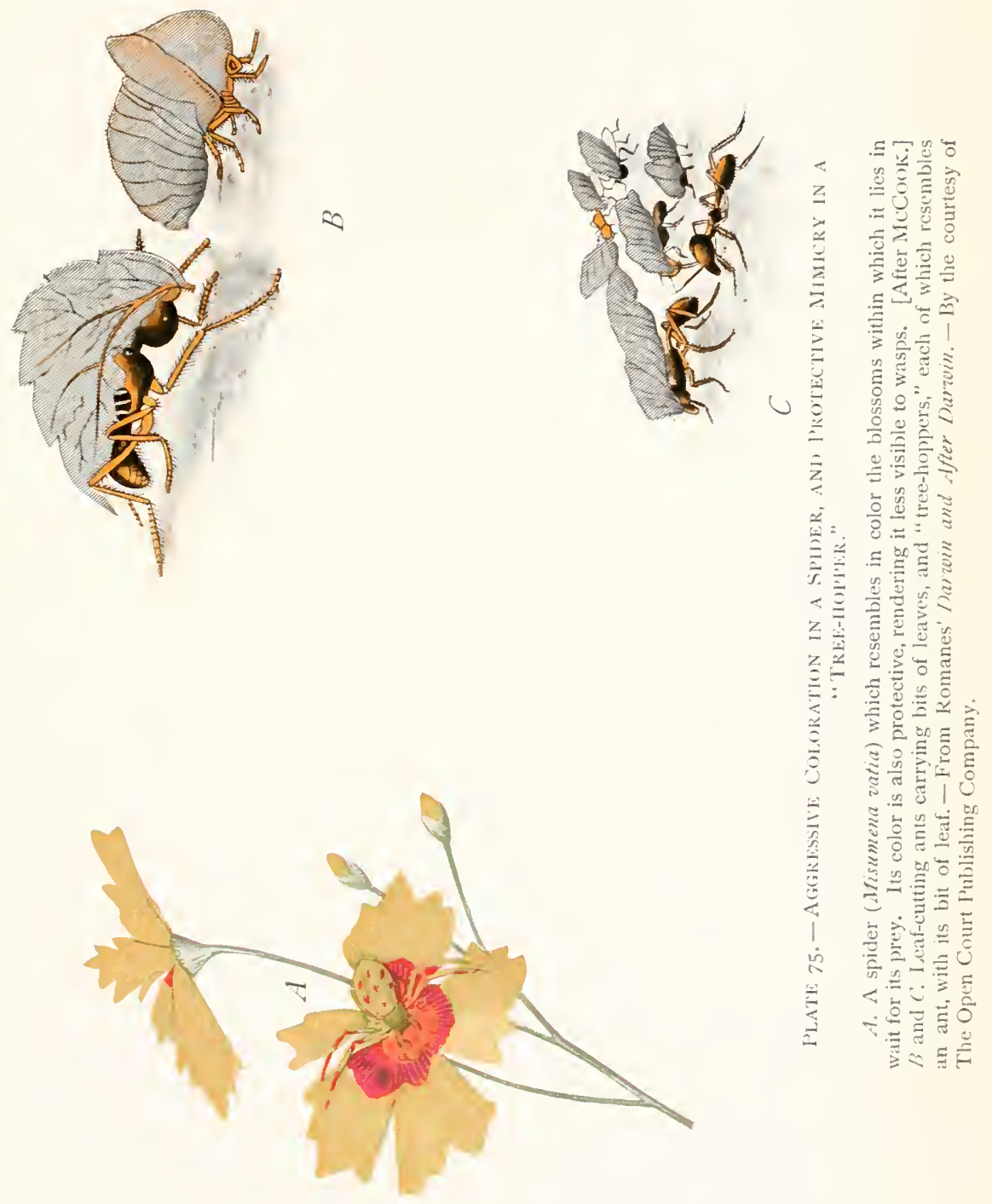



The ants, another group of the Hymonoptera, are hard, gritty little insects, with an acid flavor, and are not esteemed as food by insect-eating birds. Some even have stings, like their relatives the bees and wasps. In the tropics certain species of ants are in the habit of gathering bits of leaves from the trees and taking them to their nests to fertilize their fungus gardens. These leaf-cutting ants are often seen in great abundance, marching in procession from the tree which is being denuded to their nest, each with a piece of green leaf held in his jaws and hanging back over his shoulder. Among some of these leafcutting ants in the Amazon basin, Mr. Sclater, an English naturalist, observed an insect belonging

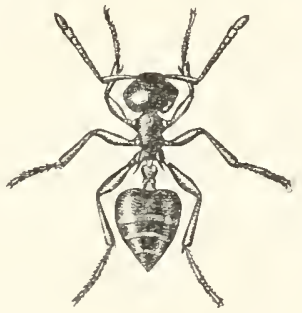

FIG. 38. - An ant (a) which in size, spread of legs, glossy black character of abdomen, and in general appearance at a littie distance, is imitated by a spider (b) which lives in the same nest. Both are quite smali. It is very difficult for one observing them closely to detect the spiders among the ants. -From specimens sent by H. IV. Britcher.

to a different order, a "tree-hopper," one of the Homoptcra, which mimicked the ant with its leaf (Plate $75, B$ ). Its body was brown below, like the ant, and above was drawn up into a narrow longitudinal ridge, irregular in outline on the upper edge and colored a bright green, giving the whole insect almost the exact appearance of an ant carrying a bit of green leaf. The ants being unpalatable, the bug which imitated them was protected from attack by insect-eating birds. Ants are also mimicked by spiders (Figs. $3^{8}$ and 39 ).

Many species of edible butterflies imitate the appearance of some of the ill-flavored butterflies. One of the best examples is found throughout the whole of eastern North 
America. The color and color pattern of the inedible Danais archippus is imitated by the edible Basilarcha disippus (Plate $76, A, B, C$ ). I have several times found these two butterflies flying together, and the first time I captured any of them I did not see until I reached home that I had two species, instead of one as I thought. The edible form is slightly smaller than the ill-flavored one, so that when once distinguished they can again be recognized without difficulty, but I much doubt if our insect-eating birds would

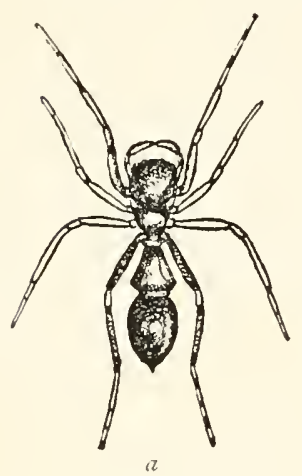

FIG. 39. - Spiders which mimic ants.

a. Symageles ficata. b. Synemosyna formica. [From G. W. and E. G. PECkHAM.]

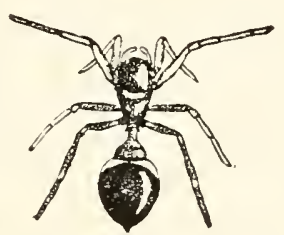

$b$ detect the difference. The inedible Helico-

nais by three varieties of females in one species of Papilio (Plate $76, D-J)$. Plate $77, I-K$, shows an instance of the imitation of an inedible butterfly of the family Acraida by two edible butterflies of different families.

Euplaa midamus, an inedible butterfly, is mimicked by Calamesia midama, a moth (Plate $\left.S_{+}, C, D, E, F\right)$. The male and female butterfly differ in color and in the pattern of their markings, and it is interesting to see that the male moth imitates the male butterfly and the female moth copies the female butterfly.

There are instances in which insects are supposed to be 

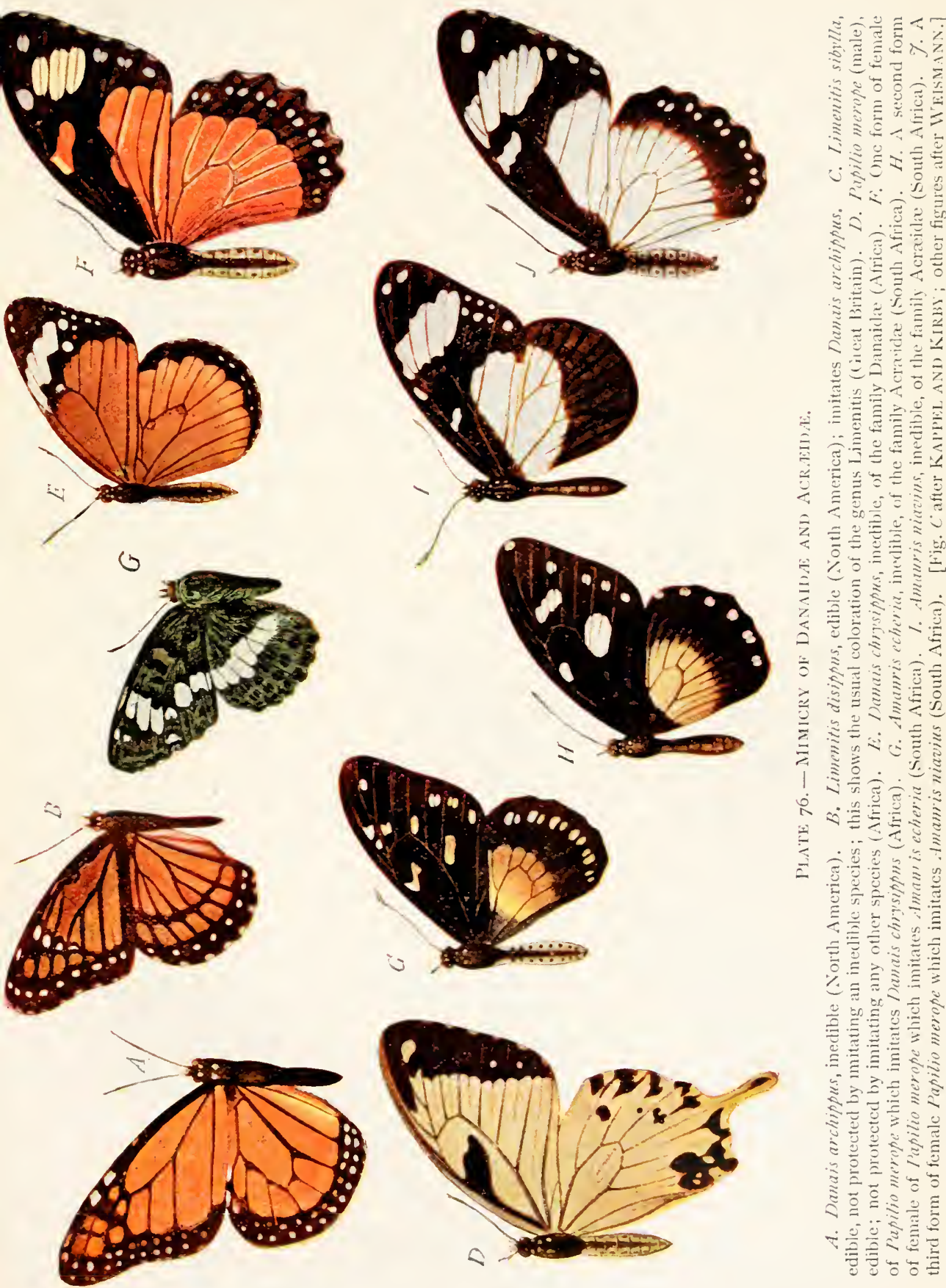



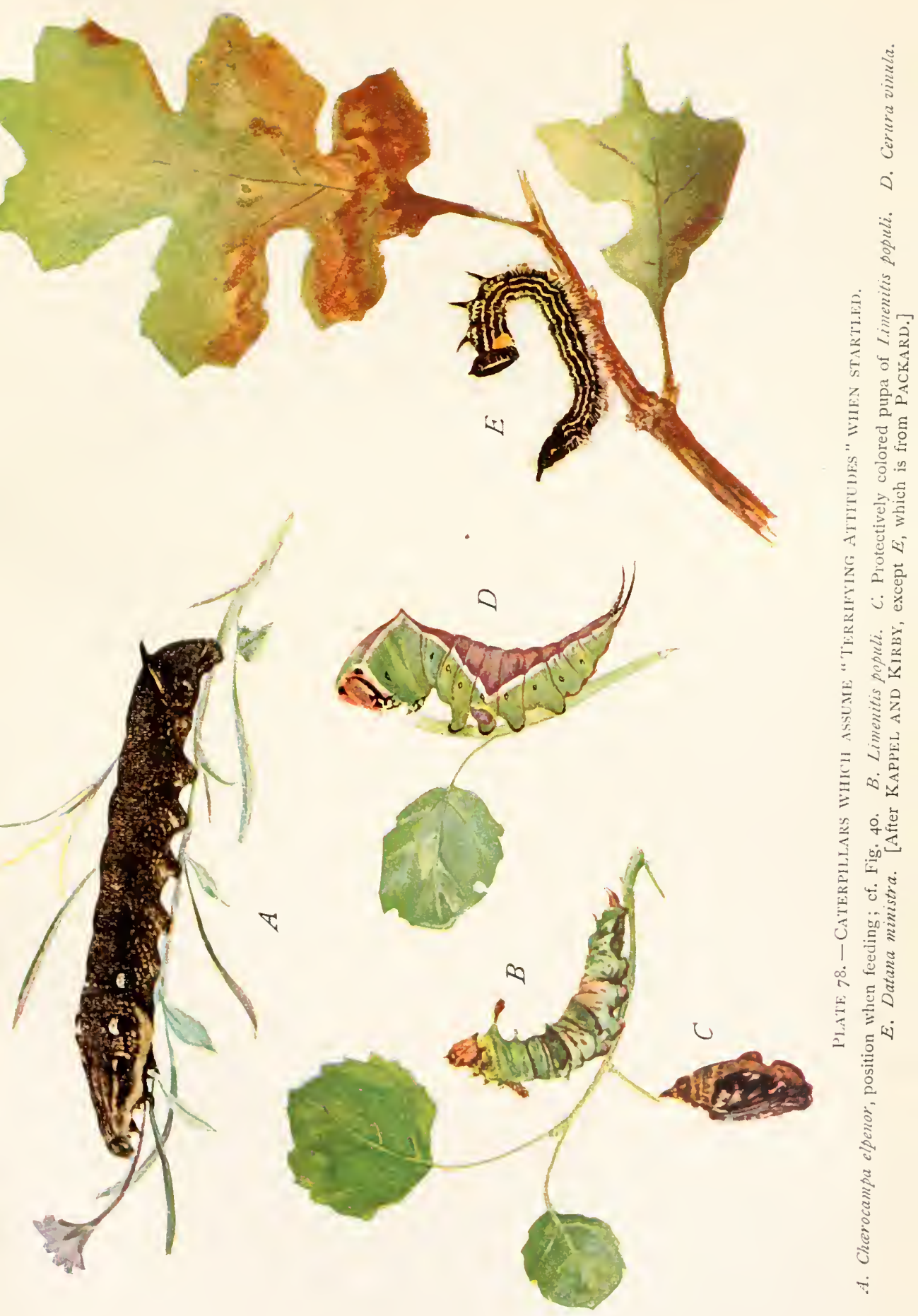



protected by an apparent resemblance to certain vertebrates. Let me quote from Professor Poulton's delightful book The Colors of Animals.

"Mr. Bates describes a South American caterpillar which startled him, and every one to whom he showed it, by its strong resemblance to a snake, and it even possessed the features which are characteristic of a poisonous serpent.

"Equally interesting examples are to be found among our British caterpillars. The brown (or occasionally green) mature larva of the large elephant hawk moth (Chrco. campa clpenor) generally hides among the dead brown leaves on the under parts of the stem of its food-plant, the great willow herb (Epilobium hirsutum) (Plate 7S, A). In this position it is difficult to see, for it harmonizes well with the color of its surroundings. It possesses an eyelike mark on each side of two of the body rings (the first and second abdominal segments), but these markings do not attract special attention when the animal is undisturbed.

"As soon, however, as the leaves are rustled by an approaching enemy, the caterpillar swiftly draws its head and the first three body rings into the next two rings, bearing the eyelike marks. These two rings are thus swollen and look like the head of an animal upon which four enormous, terrible-looking eyes are prominent (Fig. 40). The effect is greatly heightened by the suddenness of the transformation, which endows an innocent looking and inconspicuous animal with a terrifying and serpentlike appearance. I well remember the start with which I drew back my hand as I was going to take the first specimen of this caterpillar I had ever seen."

A good many different species of caterpillar show "terrifying "attitudes and motions. Poulton thus describes the 
behavior of the caterpillar of the puss moth: "The larva of the puss moth (Comra vimula) is very common upon poplar and willow. The circular domelike eggs are laid either singly or in little groups of two or three, upon the upper side of the leaf, and being of a reddish color strongly suggest the appearance of little galls or the results of some other injury. The youngest larva are black, and also rest upon the upper surface of the leaf, resembling the dark patches which
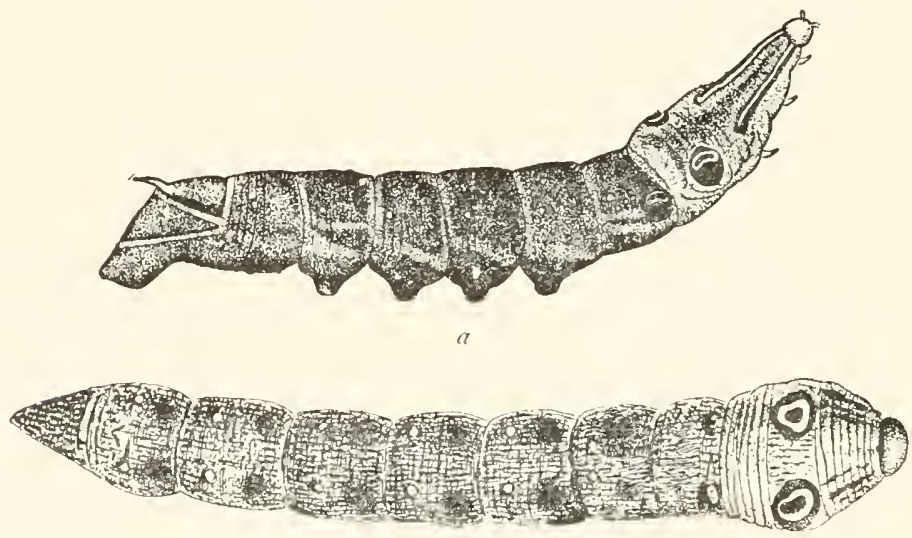

FIG. fo. - Caterpiliar of the largc elephant hawk-moth (Cherocampa elpenor). [After WeIsMANN and Poulton.]

a. In normal position when feeding. 8. In "terrifying attitude." Compare Plate 79, Fig. A. which show the same caterpillar in natural colors.

are commonly seen in this position. As the larva grows, the apparent black patch would cover too large a space, and would lead to detection if it still occupied the whole surface of the body. The latter gains a green ground-color which harmonizes with the leaf, while the dark mark is chiefly confined to the back. As growth proceeds the relative amount of green increases, and the dark mark is thus prevented from attaining a size which would render it too conspicuous. In the last stage of growth the green larva becomes very large, 
and usually rests on the twigs of its food-plant. The dark color is still present on the back but is softened to a purplish tint, which tends to be replaced by a combination of white and green in many of the largest larva (Plate $78, D$ ). Such a larva is well concealed by general protective resemblance, and one may search a long time before finding it, although assured of its presence from the stripped branches of the food-plant and the foeces on the ground beneath.

"As soon as the larva is discovered and disturbed it withdraws its head into the first body ring, inflating the margin, which is of a bright red color. There are two intensely black spots on this margin in the appropriate position for eyes, and the whole appearance is that of a large flat face extending to the outer edge of the red margin (Plate $78, D$. The effect is an intensely exaggerated caricature of a vertebrate face, which is probably alarming to the vertebrate enemies of the caterpillar. The terrifying effect is therefore mimetic. The morements entirely depend upon tactile impressions: when touched ever so lightly a healthy larva immediately assumes the terrifying attitude, and turns so as to present its full face toward the enemy; if touched on the other side or on the back it instantly turns its face in the appropriate direction.

"The effect is also greatly strengthened by two pink whips which are swiftly protruded from the prongs of the fork in which the body terminates. The end of the body is at the same time curved forward over the back (generally much further than in the figure), so that the pink filaments are brandished above the head."

Experiment showed that the terrifying attitude and motions were effective in frightening away enemies. I suspect 
that the suddenness of the change from one condition to the other when irritated has as much to do with scaring away enemies as does the reputed resemblance to the front part of a snake, for most insect-eating birds and lizards are very wary and easily startled.

This description is quoted in full, for it gives a remarkable instance of the combination of general protective resemblance, terrifying attitude, terrifying motions, with special appendages and mimicry. Two other caterpillars in

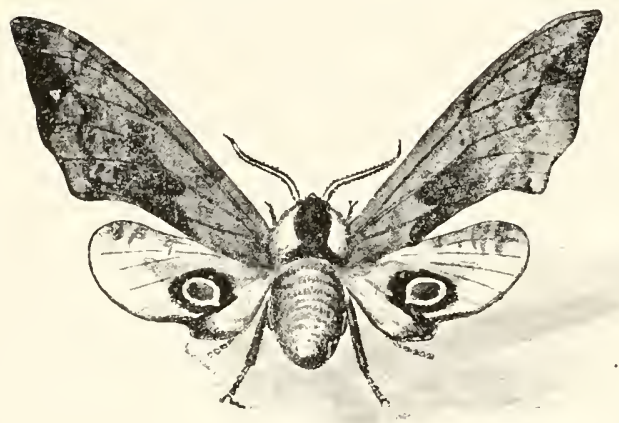

FIG. 4I. - "Terrifying attutude" of a moth (Simerinthus ocellata). [After WEISMANN.] "terrifying attitudes" are shown on Plate 78 , and in Fig. $4 \mathrm{I}$ is shown a moth in what is said to be its "terrifying attitude."

Another reputed instance of mimicry sometimes mentioned is that of the marking on the tips of the wings of some of the large moths, which very closely resembles the head of a cobra with its expanded hood, even the spectacle-like marks on the back of the hood being reproduced (Fig. 42). I know, however, of no experiments which test the effect of this appearance upon insecteating animals, and without such experiments we have no right to regard the fancied resemblance as significant.

There are examples of mimicry among the vertebrates. Several venomous species of Elaps, the coral snake, are conspicuously banded with red and black, or with red and black and yellow, and these venomous species are each imitated by other species of harmless snakes, belonging to 

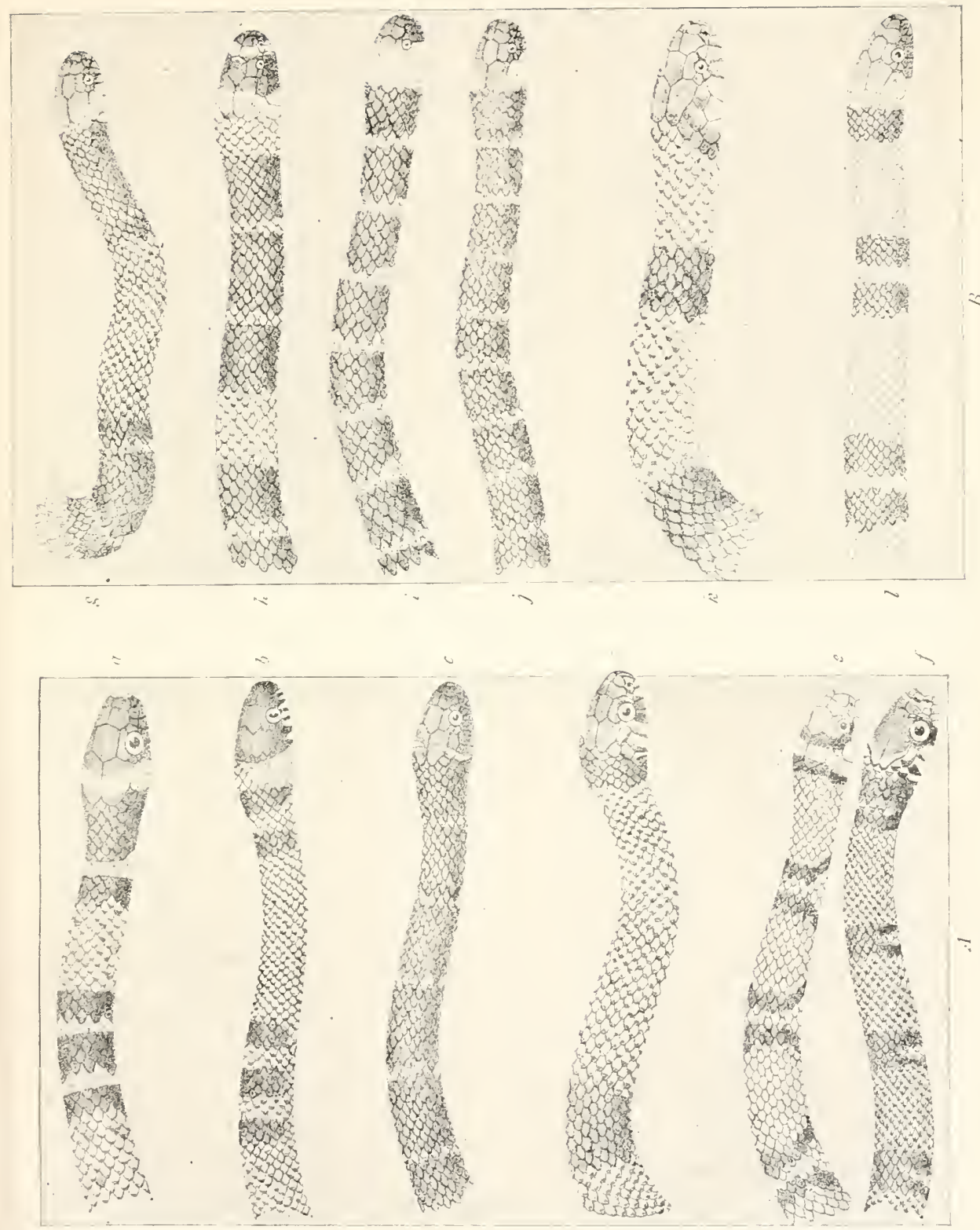

PLIIE 79 - Minncly in snates. Ilie snakes 14 group A have puisonous langs, those 111 group $b^{\prime}$ are harmless.

a. Elaps dumerili. New Granada. b. Elaps lemniscatus, Brazil. c. Elaps semipartitus, New Granda. d. Elaps psyche, Brazil. e. Elaps comalhmus, Brazil, Central America. f. Ophibolus doliatus, Southem North America and Cential America. g. Phocercus elapsides, Mexico. h. Oxwrhopus trigeminus, Brazil. i. Plincerus euryonus, New Granada. j. Ferthrolamprus esculapii, Brazil. $k$. Cemophora coccmea, Southern United States. l. Erythrolamprus venustissimus, Brazil, Central America. [Aster CopE.] 

different genera (Plate 79). Many of our common American snakes imitate poisonous serpents in one peculiar habit, though not in exact color. Poisonous serpents when cornered and irritated have the habit of flattening their heads

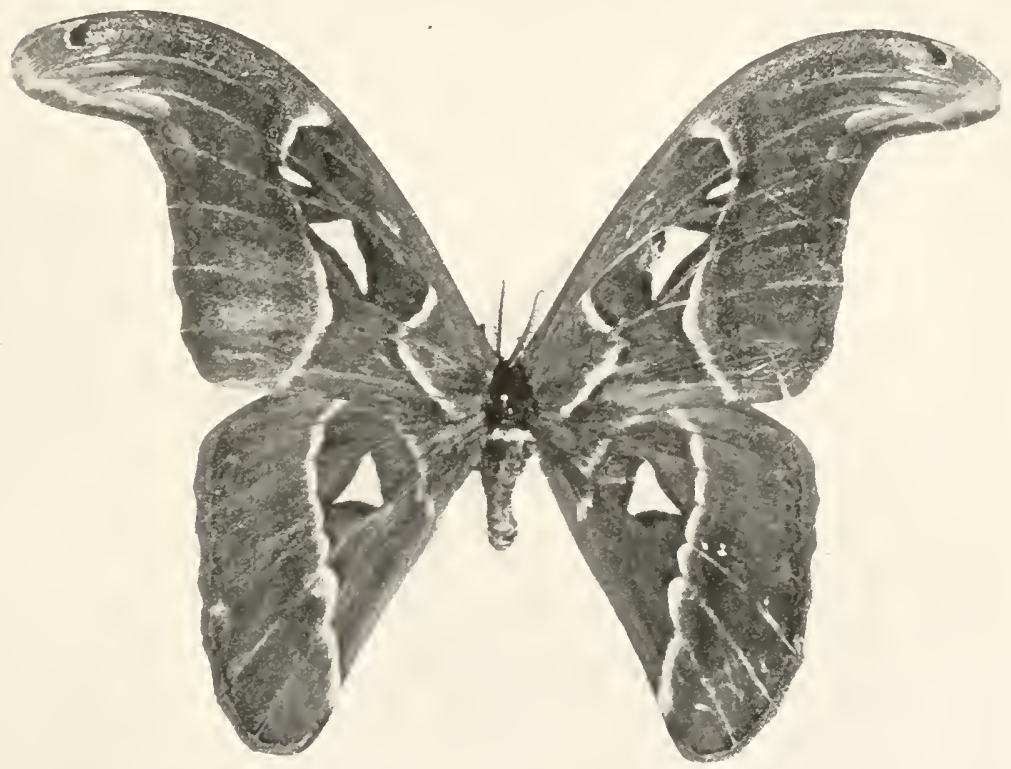

FIG. 42. - Moth from India (Attacus atlas), at the tips of whose wings are markings resembling those upon the head of a cobra.

so that they become even more triangular than when at rest, and they show a pugnacity that is very forbidding. Most of our little harmless snakes, when cornered, will behave in much the same manner, flattening the head and making it triangular, and by their hissing and striking they seem to suggest that they are dangerous. 
There are a few examples of mimicry among birds. Let me quote from Wallace's Darwinism a description of probably the best example. "More perfect cases of mimicry occur between some of the dull-colored orioles in the Malay Archipelago and a genus of large honey-suckers, the Tropidor-hynchi or 'friar-birds' (Plate So). These latter are powerful and noisy birds which go in small flocks. They have long, curved, and sharp beaks, and powerful, grasping claws; and they are quite able to defend themselves, often driving away crows and hawks which venture to approach them too nearly. The orioles, on the other hand, are weak and timid birds, and trust to concealment and to their retiring habits to escape persecution. In each of the great islands of the Austro-Malayan region there is a distinct species of Tropidorhynchus, and there is always along with it an oriole that exactly mimics it. All the Tropidorliznchi have a patch of bare black skin around the eyes, and a ruff of curious, paler, recurved feathers on the nape, whence their name of friar-birds, the ruff being supposed to resemble the cowl of a friar. These peculiarities are imitated in the orioles by patches of feathers of corresponding colors; while the different tints of the two species in each island are exactly the same. Thus in Bouru both are earthy brown; in Ceram they are both washed with yellow ochre; in Timor the under surface is pale and the throat nearly white, and Mr. H. O. Forbes has recently discovered another pair in the island of Timor Laut. The close resemblance of these several pairs of birds, of widely different families, is quite comparable with that of many of the insects already described. It is so close that the preserved specimens have even deceived naturalists, for, in the great French work, 


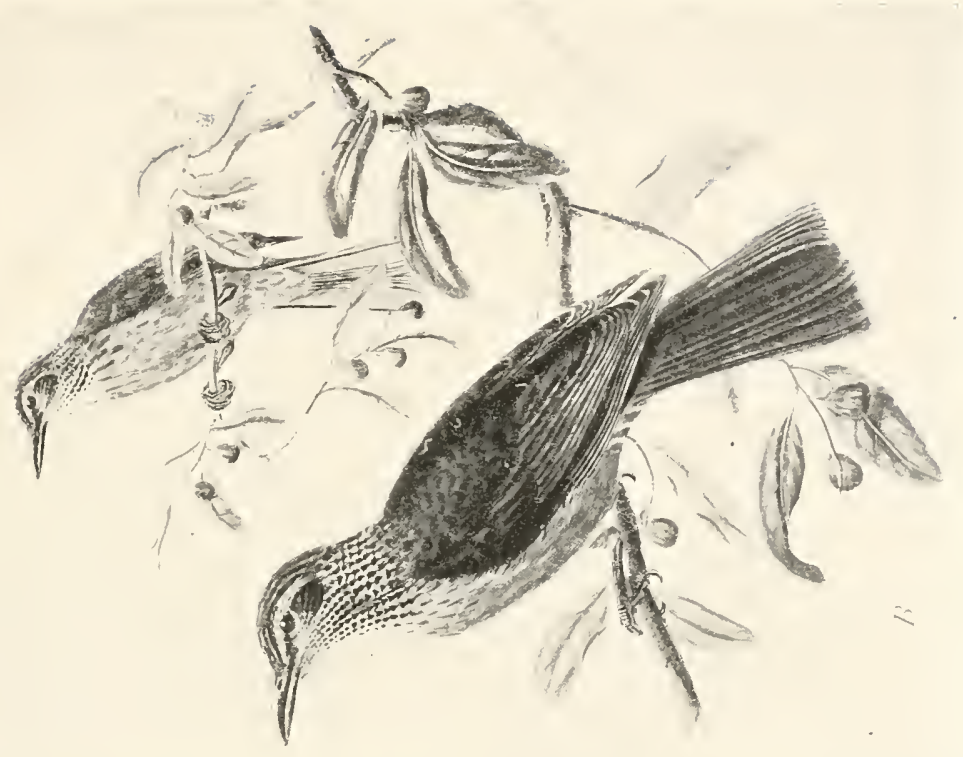

3
5
5
3

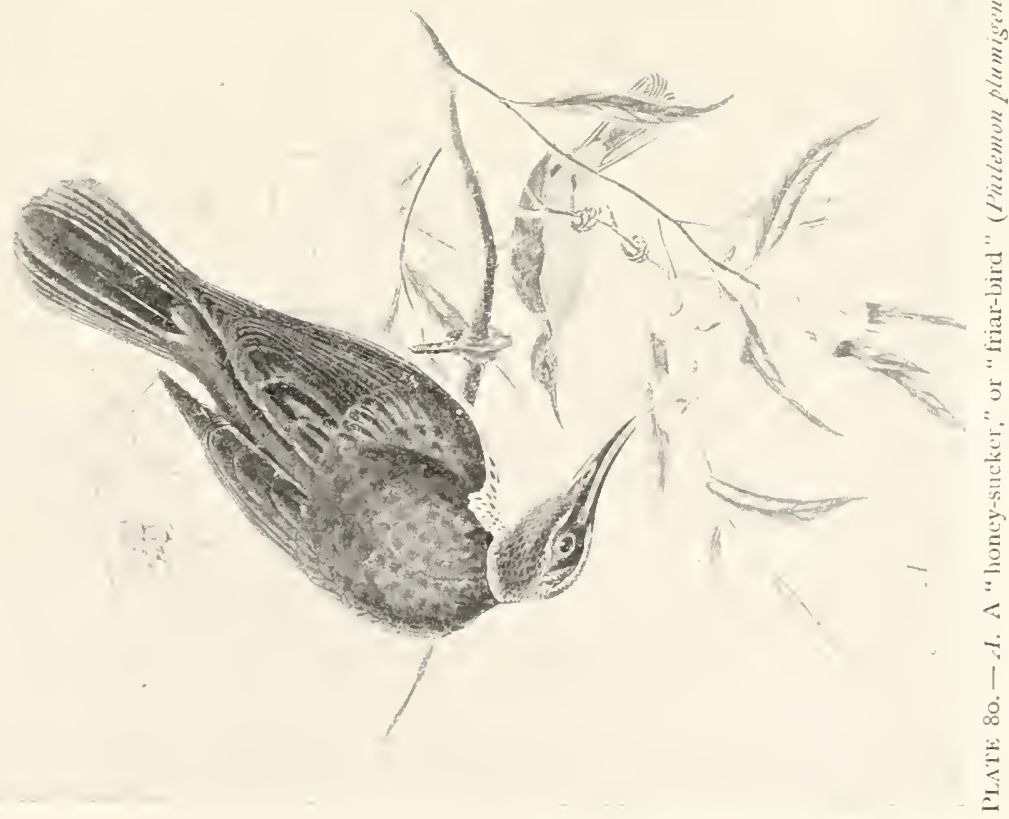



Voyage de l'Astrolabe, the oriole of Bourru is actually: described as a honey-sucker, and Mr. Forbes tells us that, when his birds were submitted to Dr. Sclater for description, the orioles and the honey-suckers were, previous to close examination, considered to be the same species."

Well-authenticated examples of mimicry among mammals, or other vertebrates than the birds and reptiles, are not numerous. Among the invertebrates, outside the classes of the insects and the spiders, there are some instances known, but as they are not very frequent, and, as they are seen in forms which are less generally known, we will not refer to them.

Wallace mentions five conditions which are always fulfilled in cases of mimicry. Let me quote his statement of these.

"I. The imitative species must occur in the same area and occupy the very same station as the imitated. "2. The imitators are always the more defenceless.

"3. The imitators are always less numerous in individuals. "4. The imitators differ from the bulk of their allies.

"5. The imitation, however minute, is external and visible only, never extending to internal characters or to such as do not affect the external appearance."

The instances thus far mentioned are all of protective mimicry. Of aggressive mimicry there are but very few instances known. Some of the hunting spiders are very like the flies on which they prey; possibly also the antlike spiders can more readily approach their prey because of their resemblance to ants which may not be so much avoided by small flies (Figs. 38 and 39). Certain insects, 
whose larve are parasitic upon other insects, closely resemble the form upon which their larve are parasitic, being enabled thus to escape detection when approaching to lay their eggs in the nests of the species whose members will become infested with their larve. These parasites live chiefly upon different kinds of bees.

\section{Signals and recognition marks.}

Signals and recognition marks are seen in many animals. Birds and mammals especially display these. Our com-

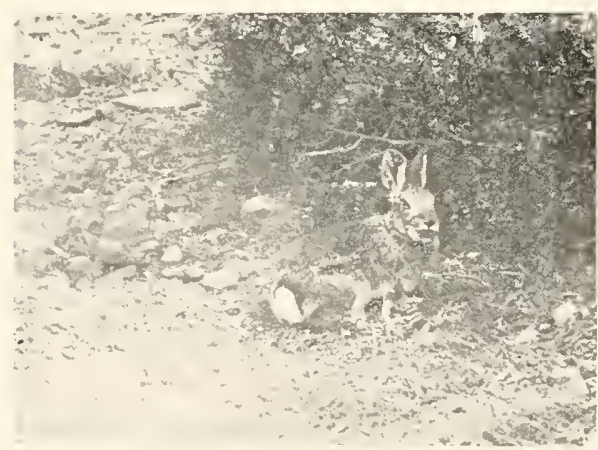

Fir. 43.-Common "cottontail" rabbit, which is startled and about to run. The tail is lifted enough to show a part of its white under surfice and the white rump patch. - From a photograph from lite by E. R. Warten.

impending danger (Fig. 43). Our common eastern deer have a similar white spot on the under surface and below the tail, which serves the same purpose. Some of the western American antelopes have upon the flanks a much larger patch of long white hairs, which when expanded by the contraction of the skin muscles and the consequent erection of the hairs, flashes out as a white signal visible on the plains for miles (Plate $S_{1}$ ). Similar white rump patches are found in some of the African gazelles. 


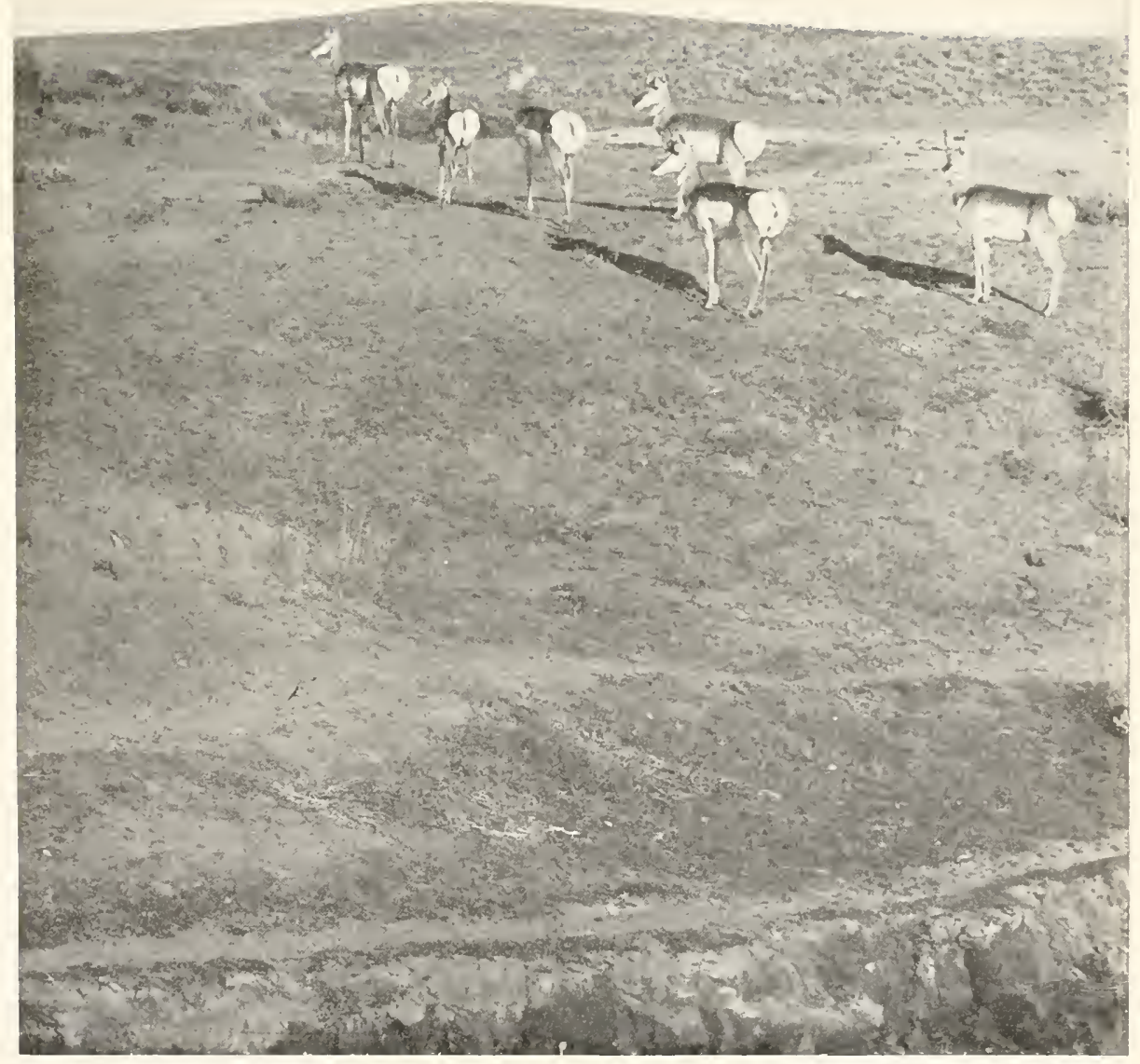

PLATE 8I, - Anteiope showing danger signal. - From Wallihan's Camera Shots at Big Game, by permission of Mr. Wallihan and of Doubleday, Page and Co. 


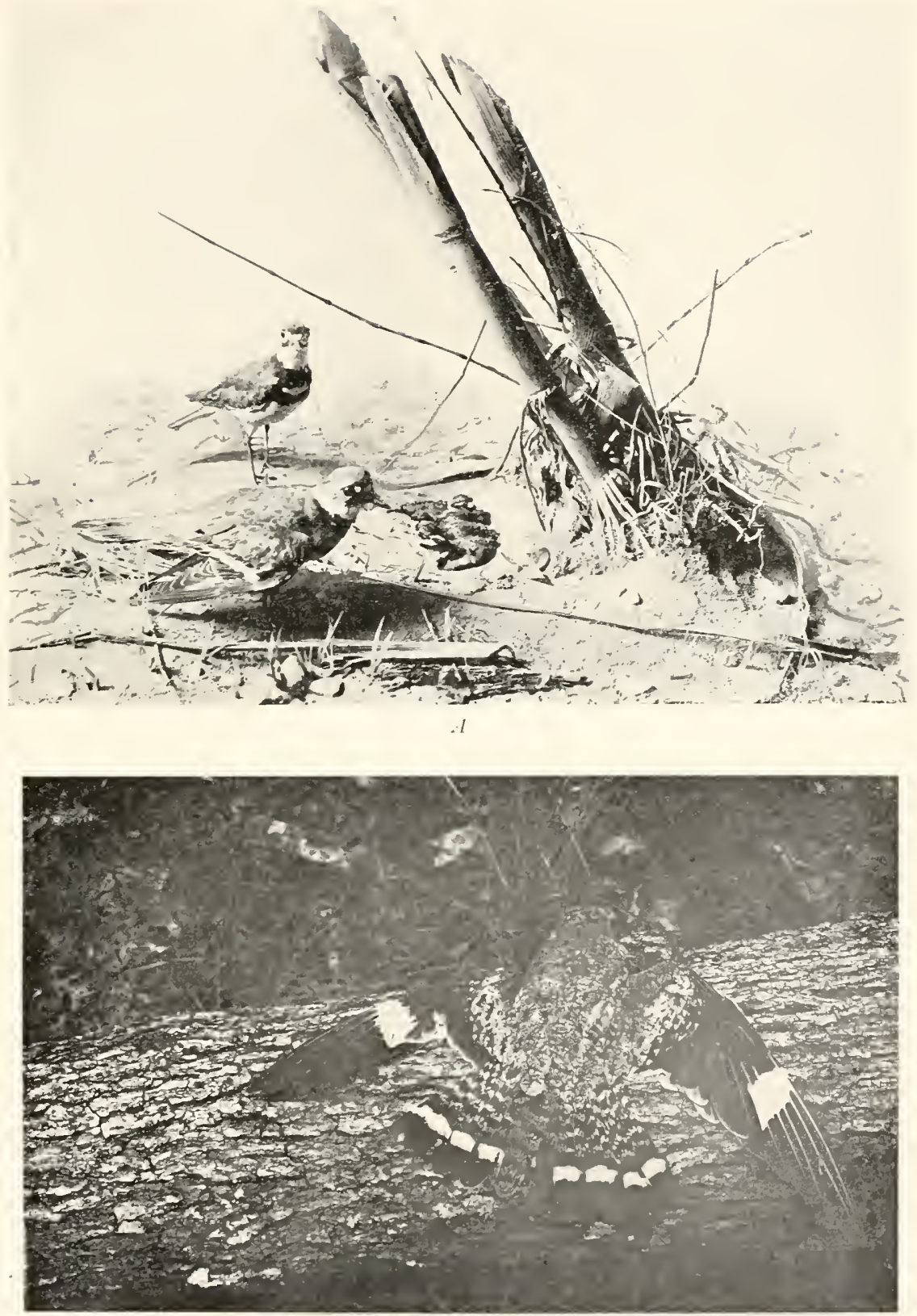

$B$

PLATE 82. - A. Killdeer, or ring-marked plover (Agialitis vocifer $a$ ). - From an exhibit in the United States National Museum. B. Nighthawk (Chorleiles virginianus) spread out on a $\log$ in such a way as to show the white marks on the wings and tail. 


Wallace interprets some of the very distinct marks on different birds, such as the white outer tail feathers which show in flight, and the streaks and spots about the head and neck, as recognition marks, by which the individuals of the same species recognize each other, often at considerable distances. Such marks are seen in our common killdeer and in the night-hawk (Plate 82). Probably this is a true explanation of one use of such marks.

Confusing coloration.

Dr. C. Hart Merriam has suggested another use for certain color markings that have sometimes been described as signals or recognition marks. All must have noticed that many of the butterflies have the upper surface of the wings brightly colored, while the under surface is dull, and that these forms, when at rest, close the wings, displaying the protectively colored under surface. This is markedly true of the beautiful leaf-butterfly, Kallima inachis, (Plate $s_{3}, A$ and $B$ ). These insects are very noticeable when in flight, but when they light and close the wings. their sudden disappearance is most startling and confusing. greatly increasing the difficulty of observing their resting. place. Many of the moths, which, when at rest, hold the posterior wings covered by the front wings, show a rery similar condition, the back wings being brilliantly colored above, while the front wings are dull (Plate $\delta_{3}, G, H$, and $K^{\prime}$ ). These moths do not fly by day, unless disturbed, and will be well protected by their dull color. In flight, however, the bright color of their posterior wings is very noticeable and serves to make their disappearance more disconcerting when they alight. The yellow or red under-wings of grasshoppers 
and their noisy, jerky flight render them very conspicuous when on the wing (Plate $S_{3}, L$ and $M$ ). This makes their sudden disappearance upon alighting all the more startling and confusing. Any one who has attempted to catch the common brown, roadside grasshoppers will, I am sure, accept this explanation of one use of the conspicuous color of their hind wings. When at rest they can be seen only by the keenest attention and closest observation, but when in motion they are seen by the most careless observer. The sudden mental change from careless observation of the brilliant color and noisy flight to the close scrutiny necessary to detect these grasshoppers when quiet is very difficult, and is a change one does not succeed in making without much practice.

Some birds which are in general inconspicuously colored have white or some other bright color upon the wing or tail feathers, which becomes visible in flight. Examples are the night-hawk, the Junco, the vesper-sparrow. The night-hawk is so colored as to be observed only with great difficulty when at rest upon a $\log$ or upon the ground (Plate $5 \mathrm{I}, A$ ). It often lies quiet, trusting to its inconspicuousness, until one nearly steps upon it. When flushed, however, it flies away with a jerky, zigzag flight, showing in the most conspicuous manner its clear white spots upon the wings and tail (Plate $\left.S_{2}, B\right)$. The great contrast between its conspicuousness in flight and its almost invisible character when at rest renders it very difficult to find when it has alighted.

Merriam would give a similar explanation of the use of the conspicuous bands seen upon the hips and tails of the desert Kangaroo rats and of the white uncler tail of the antelope, squirrel, cottontail rabbit, and some of the jack 
rabbits, all of which markings are invisible when the animals crouch. Some of the desert lizards are conspicuously banded on the under surface of the tail, which they elevate and arch over the back when startled, rumning with great rapidity for a short distance, then suddenly crouching, until only the protectively colored back is visible, or rather invisible, among the rocks and sand.

These animals, which show such confusing coloration, generally run or fly in an irregular course, and just before they come to rest they cover the conspicuous color and frequently dodge to one side, so that they lie unnoticed at some distance to one side of the spot where they were last seen by the observer.

It is of course possible that in many cases the same markings may serve the double purpose of recognition marks or signals and of increasing the startling effect of the sudden disappearance of their possessors when they come to rest.

\section{Sexual coloration.}

IVe have already had occasion, in connection with the discussion of sexual selection, to refer to the differences in the appearance of the males and the females of many species. These differences are often largely differences in color, and should be mentioned in any treatment of the phenomena of color in animals. The use of these sexual colors is, apparently, to render the male attractive to the female and secure her as his mate. In our discussion of sexual selection we said that these brilliant colors of the male are seen among birds, lizards, fishes, spiders, in many species of butterflies, and in some insects. We will stop here to mention but a few instances from these groups. Among birds 
think of the brilliant colors of the male and the more modest coloring of the female in the peacock, the common chickens (Plates I $2-$ I $_{5}$ ), the argus pheasant (Plate $24, A$ ), the birds of paradise, the oriole, cardinal, and bobolink (Plate 22), the bluebird, American goldfinch, and the indigo-bird. Even the robin and the common grackle, or blackbird, show brighter colors in the male than in the female. The humming-birds also are good illustrations (Plate 26).

The brilliant bronze-green-and-blue neck of the males of our common eastern tree lizards is an instance of sexual coloration. Other finer examples could be mentioned among tropical lizards. In many species of fish the males are much brighter colored than the females, and they display the brilliant colored parts of the body to full advantage when approaching the females in the breeding season.

Greater brilliancy of color in the male than in the female is a quite general rule among fishes, and it is important to note that, in those cases in which the courting habits of species with bright-colored males have been observed, the male has the habit of displaying to the greatest advantage his bright colors when he approaches the female.

Not only do we find differences in color between the sexes among the fishes; we also find instances of differences in form, the males having certain ornamental appendages not seen in the females, or the fins of the males being larger (Plate 32).

See also Plates $S_{4}$ and $S_{5}$ for illustrations of differences in coloration between the sexes in butterflies, moths, and spiders. 


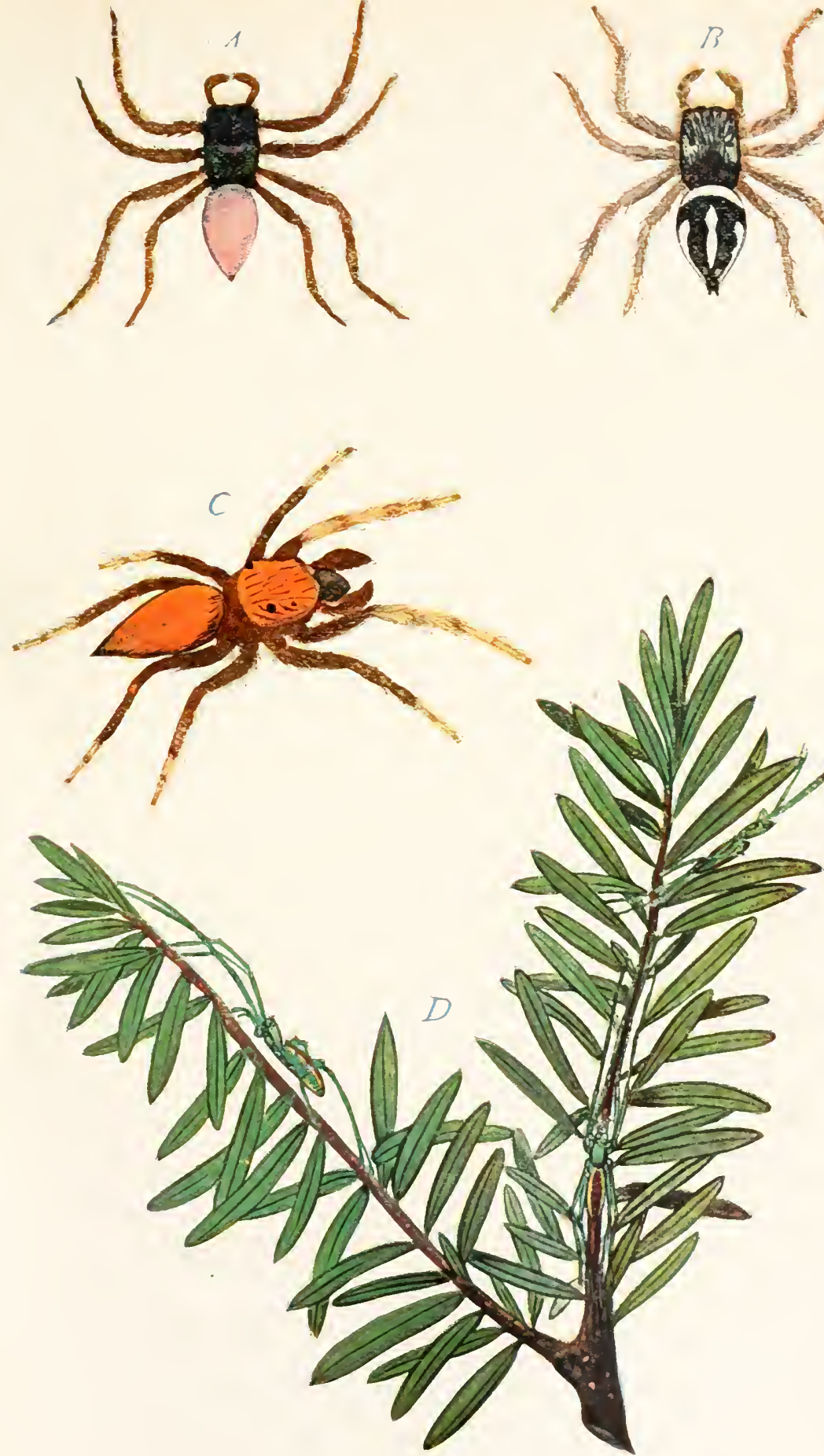

Plate 85. - Sexual Coloration and Protective Coloration in Spiders.

A. Habrocestum splendens, male. B. Habrocestum splendens, female. C. Phidippus cardinalis, male. D. Tetragnatha laboriosa. 



\section{Summary}

In recapitulation, then, we may say that, aside from their direct physiological value, many colors of animals are useful to their possessors in relation to their environment or to their special life habits. Such colors we may class as -

Protective, causing their possessors to harmonize in color with their environment, and so escape their enemies;

Aggressive, rendering their possessors inconspicuous, and so enabling them to capture their prey;

Alluring, serving to attract the prey of the forms which show the alluring coloration ;

Warning coloration, conspicuous, and rendering dangerous, noxious, or ill-flavored species readily recognizable, thus saving them from attack;

Mimetic coloration, by which an edtible species is protected from its enemies by its resemblance to a dangerous, noxious, or ill-flarored species (protective mimicry); or by which a species is brought to resemble its habitual prey or some species of which its prey is not afraid (aggressive mimicry):

Signals and recognition marks, by which individuals of a species may recognize their fellows or may warn them of impending danger;

Confusing coloration, which disconcerts an enemy by the startling difference between the conspicuousness of the individual when in motion and its inconspicuous character when at rest; and

Sexual coloration.

\section{COLOR IN PLANTS}

The color phenomena in plants are as interesting as those in animals, and are as intimately connected with the theory of evolution. They are, however, not so well understood in some of their aspects. Ne will consider the colors of plants, chiefly of plant blossoms, only as related to insects. It seems to be wholly probable that the colors of blossoms have been dereloped in connection with insects. The bright colors serve to attract insects and the insect risits are an advantage to the plants. 
All are familiar with the general structure of plant blossoms (Plate 86). Within the brightly colored floral leaves are found two sets of reproductive organs: an inner set, female, called carpels, or when united as they com-
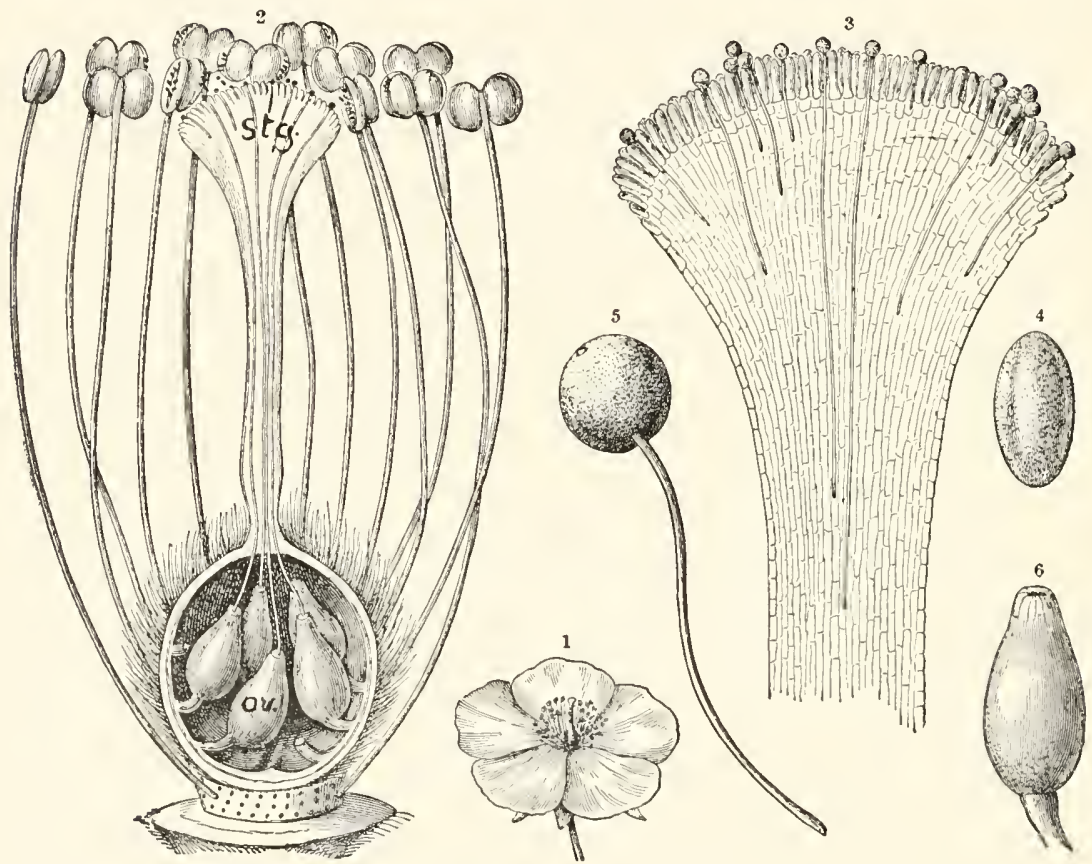

FIG. 4.4.- Fertilization in the rock-rose (Helianthemum marifolium). [After KERNFR.]

I. A single flower, natural size. 2. A flower, stripped of its sepals and petals, showing the pistil in longitudinal section. The pollen grains are seen upon the stigma, and their tubes are seen passing down the stalk of the pistil to reach the ovules. The tubes are indicated erroneously as going direct to the openings at the tips of the ovules; actually they follow a more devious course, first clown the inside wall of the chamber of the pistil and then up to reach the apertures in the ovules; $o v=$ ovule, sto. = stigma. 3 . A more enlarged drawing of the tip of the pistit, showing the pollen grains and the sprouting pollen tubes. 4. A dry pollen grain. 5. A moistened pollen grain developing its tube. 6. An ovule, showing the opening at its tip through which the pollen tube enters to effect fertilization.

monly are, together composing the pistil; and an outer whorl of stamens, or male organs. The ovules, or immature seeds, are formed within the pistil (Fig. 44, ov), while the pollen, by which the ovules are to be fertilized, is formed in the anthers at the tips of the stamens. 'To 

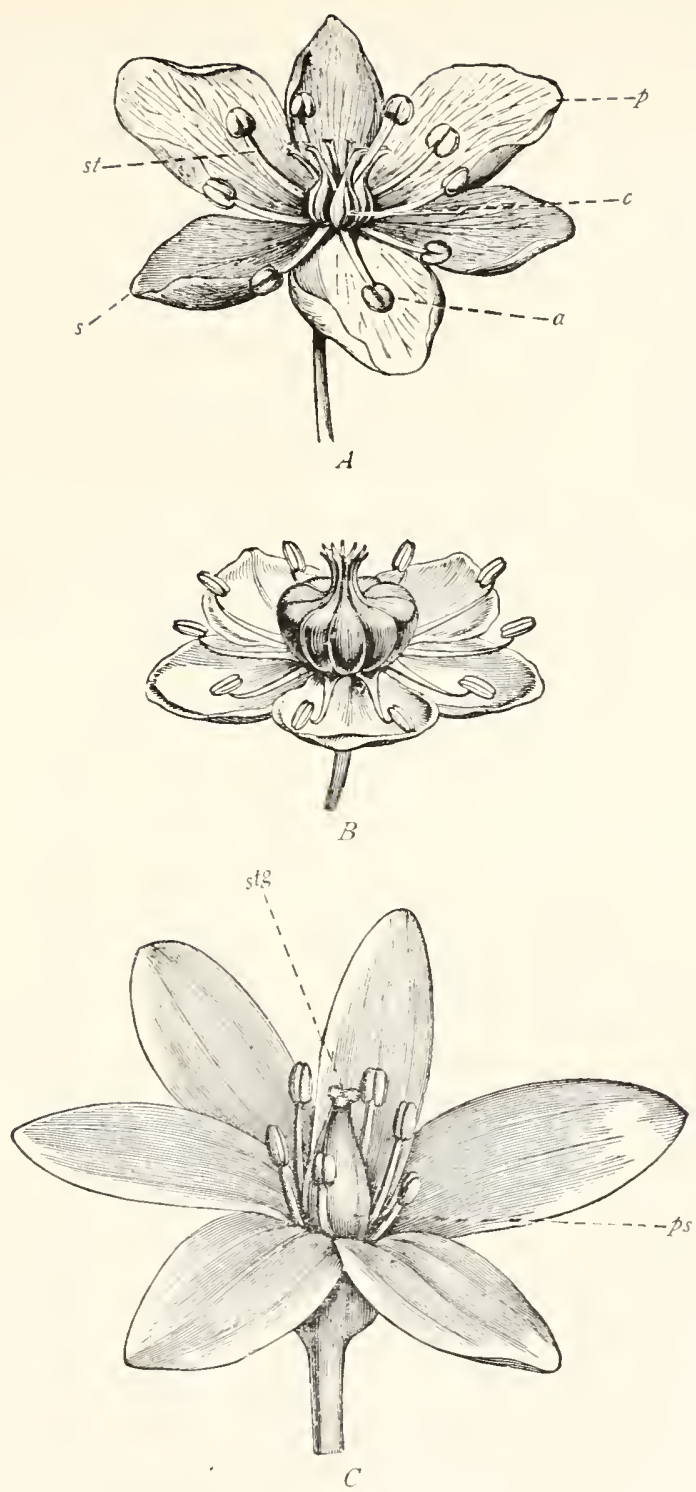

PLATE 86. - Diagrams of various flowers to show the arrangement of their parts. [After KERNER.]

A. Flower of Butomus umbellatus, in which all the parts are distinct. B. Flower of Phytolacca decandra, in which the five carpels are somewhat united to one another. C. Flower of Gagea lutea, in which the three carpels are united to form a single pistil with one style but a three-parted stigma.

$a$, anther; $c$, carpel (the carpels when fused to form a single structure are called a pistil); $p$, petal (the petals taken together compose the corolla); $p s$, pistil; s, sepal (the sepals as a whole compose the calyx); st, stamen, at the tip of which is the anther, which bears the pollen; stg, stigma, the tip of the pistil (it is adapted to receiving the pollen in fertilization). 


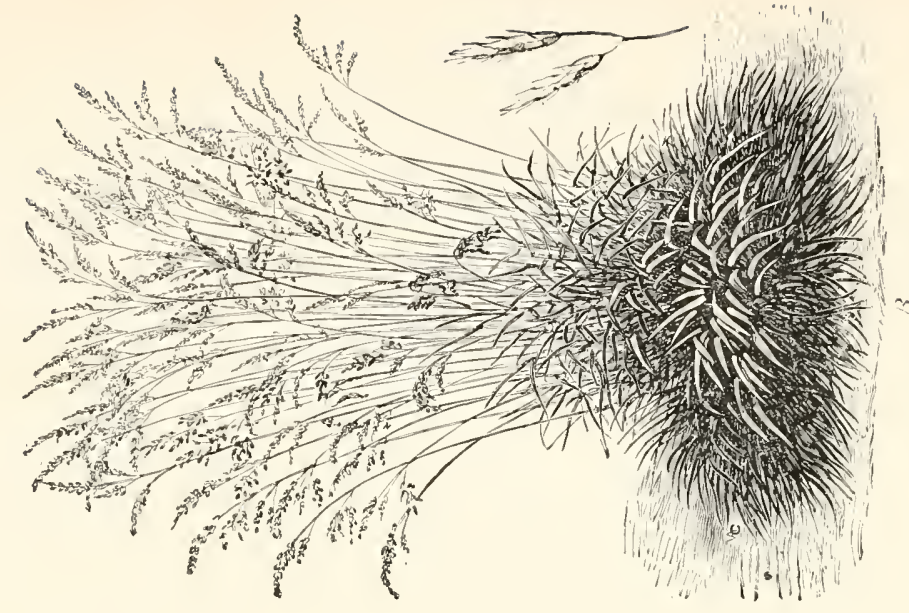

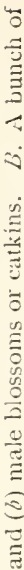

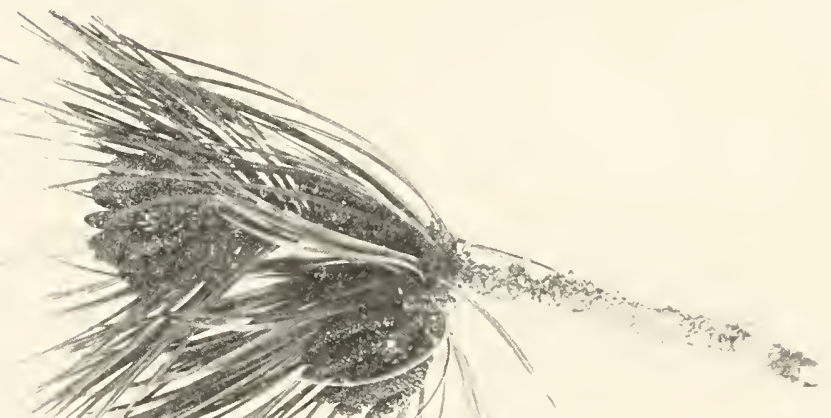

궁

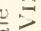

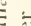

包

【

E.

on

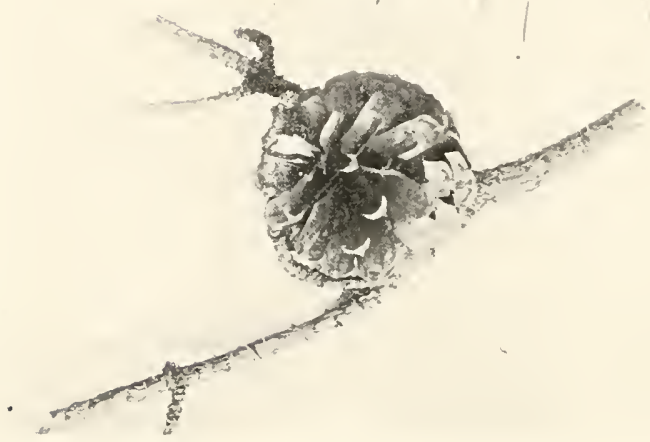


produce a seed which will grow and give rise to a new plant, pollen from a stamen must be deposited on the stigma, or tip of the pistil; here it will sprout and send down a tube within the pistil to reach and fertilize an orule (Fig. 44, 2, 3, and 5), which then becomes a seed capable of producing a new plant. Now, it has been observed over and over again that if a pistil is impregnated with pollen from another plant the new plants coming from the seeds thus fertilized will often be stronger and more rigorous than if they had been developed from seeds fertilized by pollen from the same plant that formed the seeds. Cross-fertilization, as it is called, is advantageous. Self-fertilization does occur, but it is important for most species that cross-fertilization should come in every few generations at least.

Different methods of fertilization are adopted by different kinds of plants. The flowerless plants have their own methods, and the flowering plants usually different ones. IVe are here interested only in the means of securing fertilization adopted by the flowering plants. Some of these, like the pines and other evergreen trees, have an enormous amount of pollen which is cast out into the air in great clouds and is carried by the winds to the female cones, there to fertilize the orules (Plate $87, A$ ). There are many such wind-fertilized plants, the palms and grasses, as well as the cone-bearing trees, being familiar examples. These do not use insects to aid in carrying pollen to fertilize their ovules, and so, as every one knows, they have no brilliantly colored blossoms (Plate $S_{7}, B$ ).

By far the larger number, however, of our common flowering plants are aided in securing fertilization by the 
insects which visit their blossoms. The petals of the Howers usually secrete nectar, which is attractive to insects, and many blossoms have an odor which also serves to attract insects. The nectar is a sweet fluid secreted by small glands, or nectaries, on the bases of the petals. It is this nectar which bees gather and make into honey. The odors of blossoms are caused by the presence of volatile oils usually also secreted by the petals. These

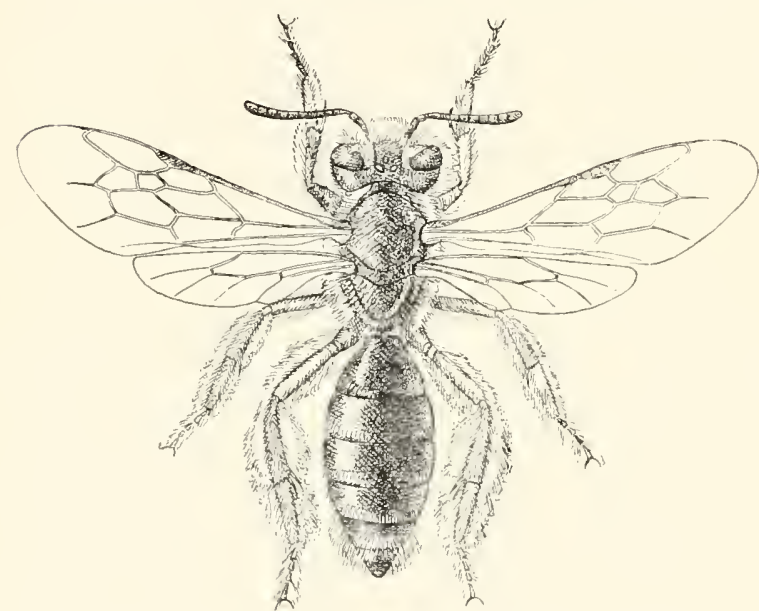

FIG. 45.-A bee, showing the hairs on the head, body, and legs. Pollen grains are shown caught in the hairs on the legs. odors may be such as are agreeable to our nostrils, as are the odors of the rose, the sweet violet, the trailing arbutus, or they may be to us disagreeable, like the odors of the carrion-flower and skunk-cabbage ; but, whether agreeable to us or not, they serve to secure the visits of insects, and it is apparently because of this attractiveness to insects, and the advantage of cross-fertilization in which the insects aid, that these odors and the nectar have been developed. Many insects also seek the pollen in the blossoms, using it as food, and most plants form more pollen than is needed to fertilize their orules, thus having a surplus supply upon which insects may draw without much or any injury to the plant.

The insects which come to the blossoms to gather pollen 
or nectar, as they go from plant to plant, will carry with them pollen dust clinging to their heads and legs and bodies (Fig. 45), and by means of the pollen thus carried the later plants visited will secure cross-fertilization. One might perhaps think that the insect visitor would scatter pollen from one plant on the pistils of the same plant, and thus cause self-fertilization as a general rule, but there are three chief ways in which this is commonly prevented.

Frequently the pollen and the orules of a single plant do not mature at the same time, so that self-fertilization is prevented.

Many plants have the parts of their blossoms so arranged that the visiting insect wili go to the nectar first, without coming into contact with the pollen until he is about to depart, when he will become dusted with the pollen and carry it away on his visit to the next blossom. Here, on the way to the nectar, he will brush against the tip of the pistil and give to it some of the pollen he has brought from the first plant, thus providing a means of cross-fertilization. Blossoms are often remarkably modified in form and structure to prevent in this way self-fertilization. In a moment we will consider a few instances of such modification.

The third and almost universal method of preventing self-fertilization is a physiological one, the pollen from any given plant being considerably slower to sprout on a pistil of the same plant than it is upon the pistil of another plant: thus, even though the pistil of any blossom be dusted first with pollen from the same plant, if, later, pollen from another plant be brought to the blossom, the laterreceived pollen is likely to be that which will effect fertili- 
zation, because of its more prompt sprouting and the more rapid growth of its pollen tube.

Let us now observe a few illustrations of special adaptions in the form of blossoms, by which plants secure crossfertilization.

The flowers of Mitchclla, the beautiful little partridge berry of our woods, are adapted to secure cross-fertilization by insects through having their stamens and pistils of different lengths (Plate S8). In all the blossoms of one plant the stamens will be long and the pistils short, while in all the blossoms of another plant these relations will be reversed, the pistils being long and the stamens short. An insect visiting these blossoms will have one part of its body clusted with pollen from the short stamens and another part with pollen from the long stamens. As it passes from blossom to blossom it will carry pollen from the short stamens of one flower to the short pistils of other flowers, and the pollen from the long stamens will be carried to the long pistils. In this way cross-fertilization will be secured, since long stamens and long pistils do not occur on the same plant, nor are short stamens and pistils found on the same plant.

Many orchids show an interesting method of using insects to secure cross-fertilization. In these species the stigma is in the centre of the flower, while the anther with its two pollen masses lies above the stigma (Plate S9, A, 2 and 3). The two pollen masses protrude a little, and at their protuberant ends are attached to a sticky "rostellum" (Plate S9, A. f). The corolla of the flower is so developed as to form a flat landing-stage for the visiting bee or other insect (compare Plate $9 \circ, C$ ), and the rostellum protrudes into the centre of the flower, above this landing-place, in such a way 


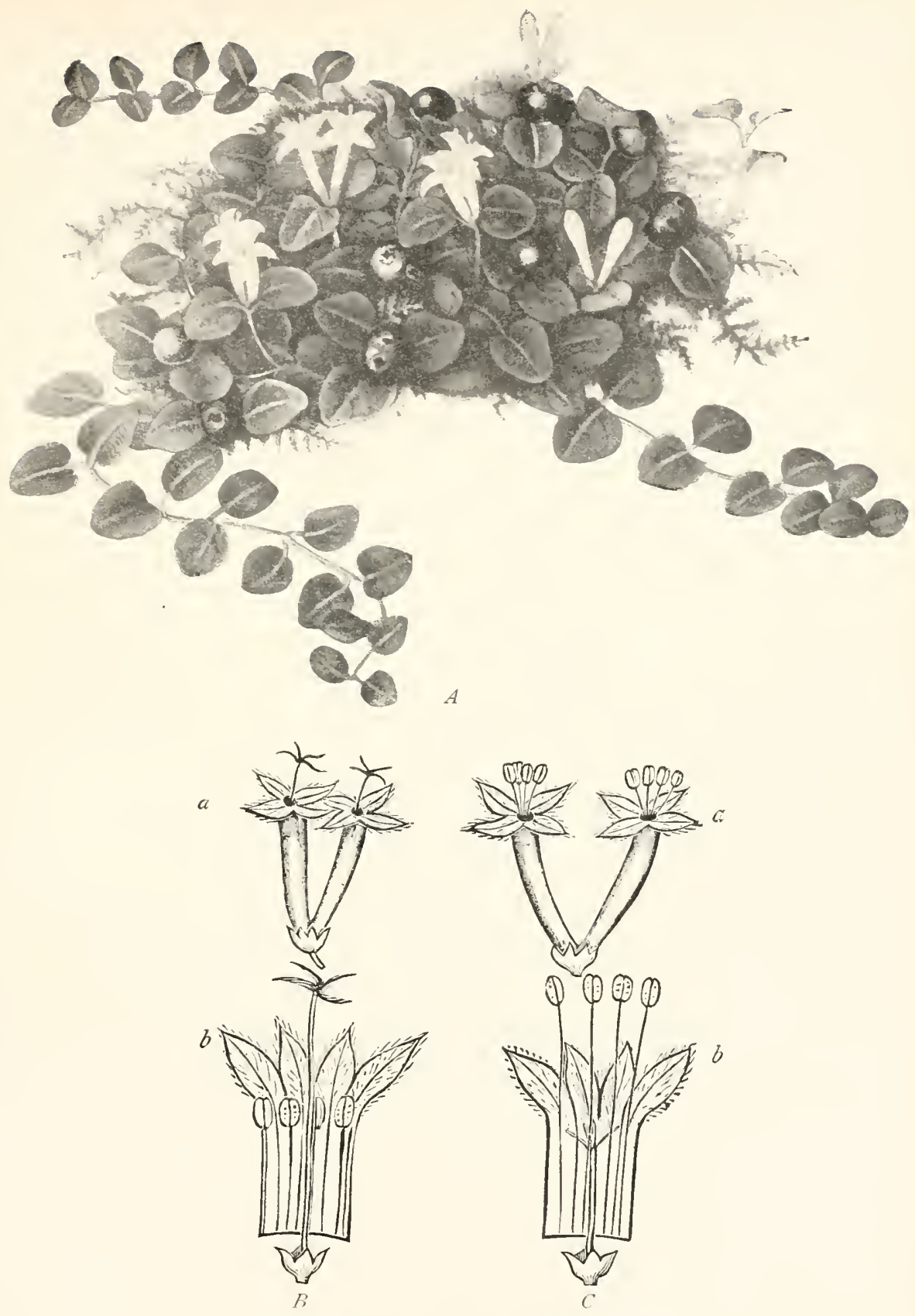

PLATE 88. - PARTRIIGE-HERRY (.Witchella repens).

A. Plant with blossoms and fruit. - From Goodale's IIild Flowers of America, by the courtesy of Bradlee Wridden. B. Blossoms with long pistil and short stamens. C. Blossoms with long stamens and short pistil. $-B$ and $C$ from Bastin's College Botany, by the courtesy of G. P. Engel hard and $\mathrm{Co}$. 


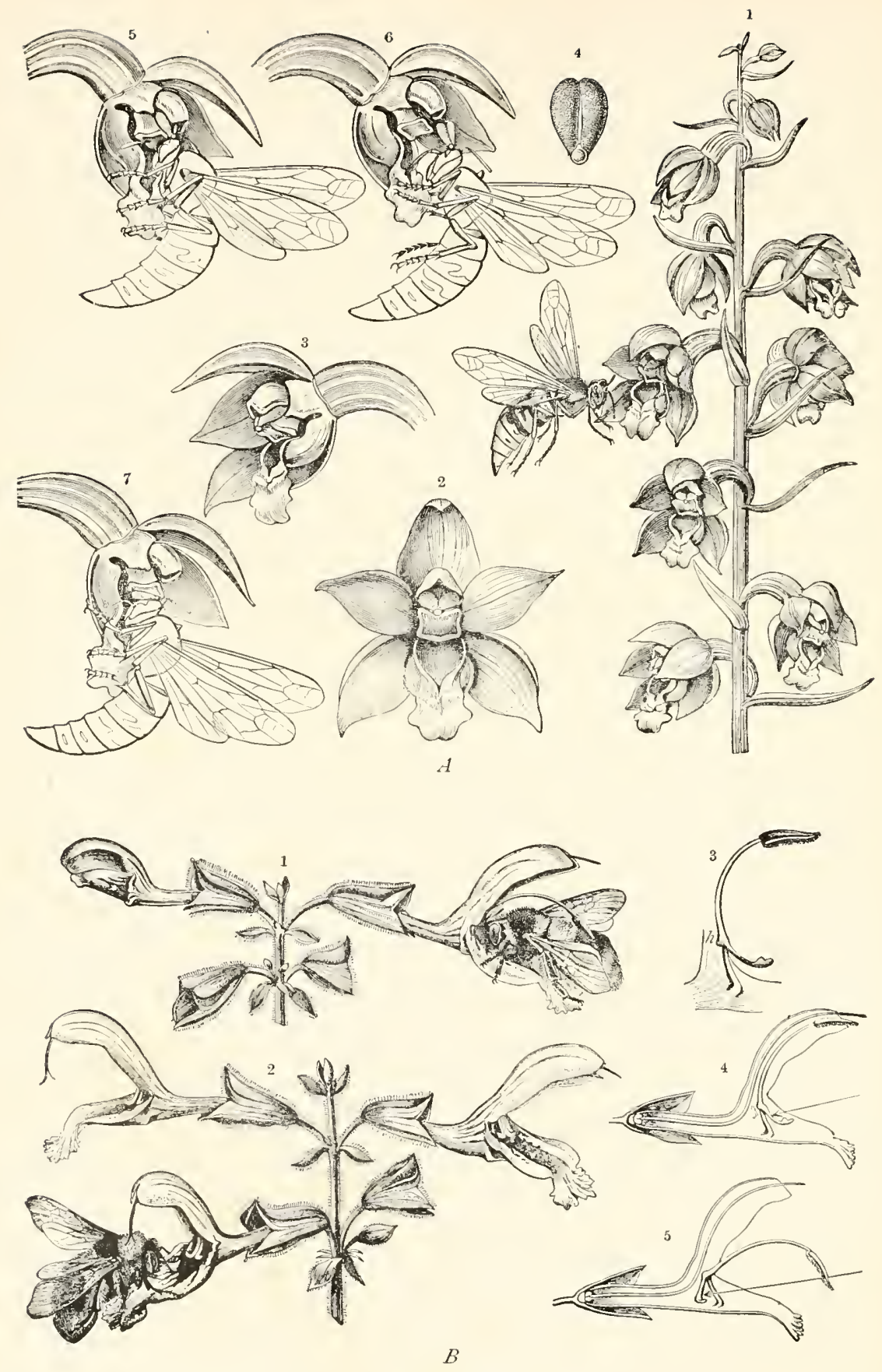

Plate 89. 
PLATE 89. - A. The fertilization of an orchid by a wasp. [After KERNER.]

I. Flowering spike of the broadleaved helleborine (Epipacty's latifolia) upon which a wasp is alighting. 2. Flower of the same seen from the front. 3. Side view of the same flower, with the half of the perianth toward the observer cut away. 4. The two pollen masses joined by the sticky rostellum. 5. The same flower being visited by a wasp which is licking honey and at the same time detaching with its forehead the tip of the rostellum together with the pair of pollen masses. 6. The wasp leaving the flower with the pollen masses cemented to its head; the pollen stalks are erect. 7. The wasp visiting another flower and pressing its forehead with the pollen masses (which in the meantime have bent down) against the stigma. I, natural size; the other figures, $\times 2$.

$B$. Fertilization of Salvia by a bumblebee. [After KERNER.]

I. Part of an inflorescence of Salvia glutinosa; the right-hand flower is being visited by a bumblebee, and the pollen-covered anther is in the act of striking the insect's back. 2. Another part of the same inflorescence with three open flowers in different stages of development; the lefthand flowers are slightly more mature than the right-hand flower; one of the flowers is being visited by a bumblebee which carries on its back pollen from a younger flower and is rubbing it off on the deflexed stigma. 3. A single stamen, showing the hinge $(h)$. 4. A vertical section through a blossom; the arrow indicates the direction through which bumblebees advance toward the interior of the flower. 5. A similar section, showing how the anther is bent downward by a bumblebee pushing against the bottom of the stamen. 


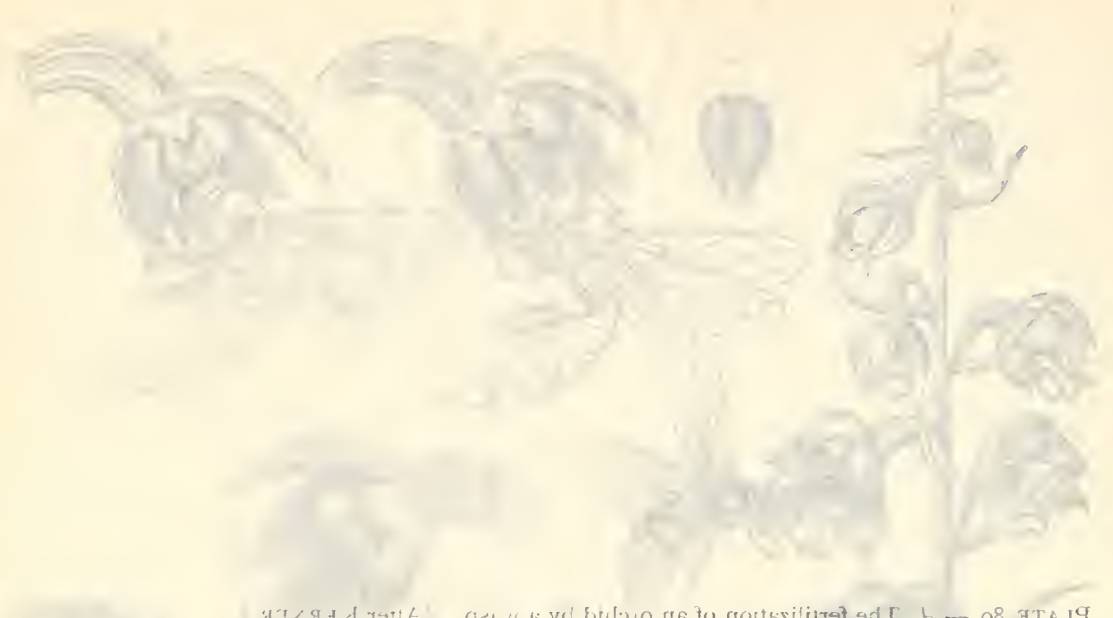

मा/

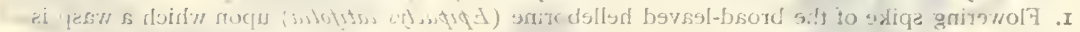

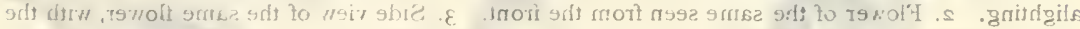

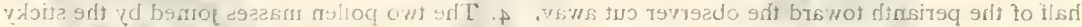

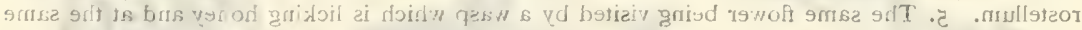

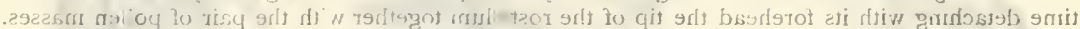

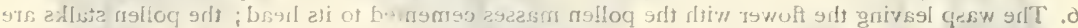

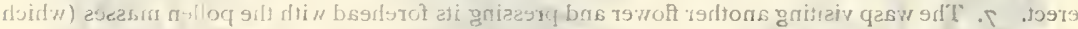

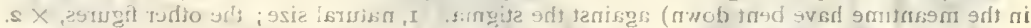

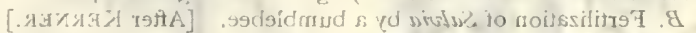

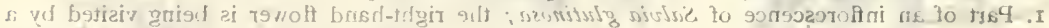

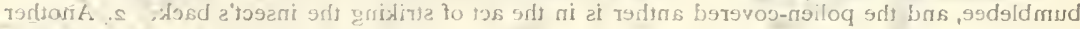

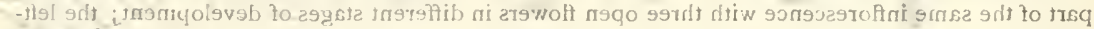

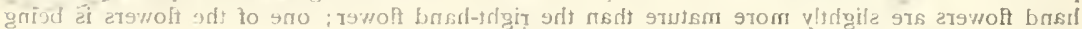

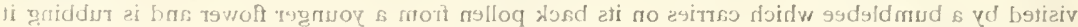

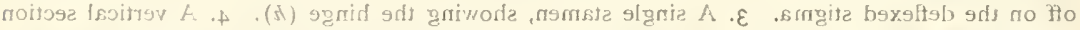

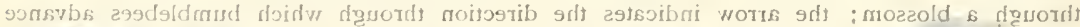

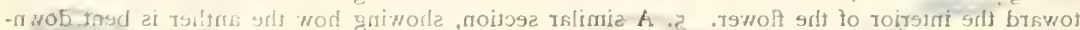

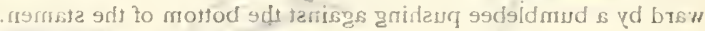

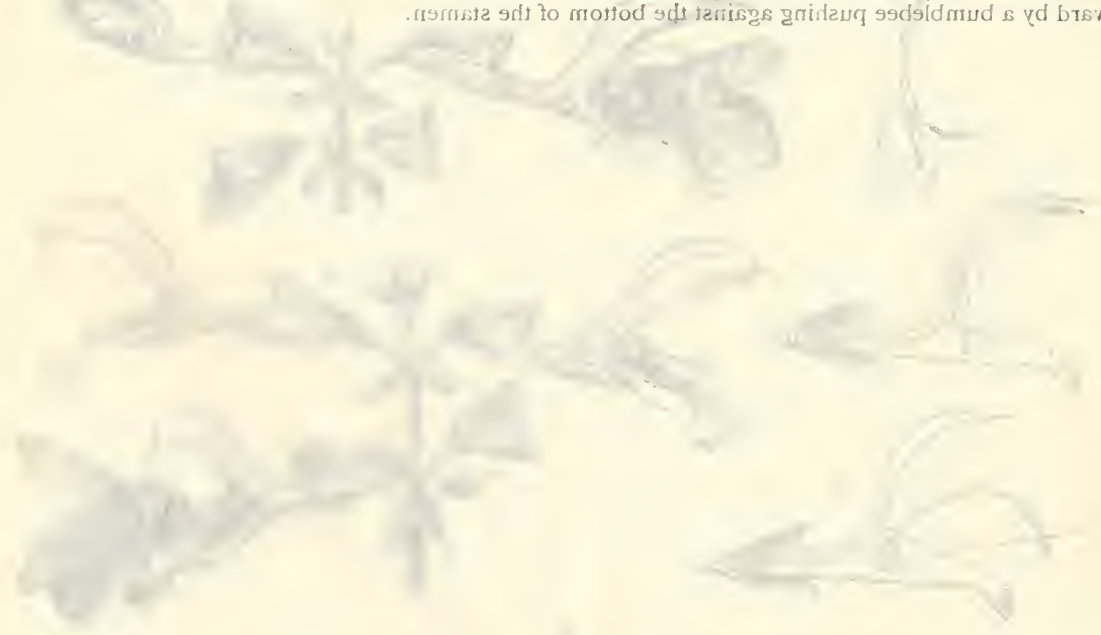




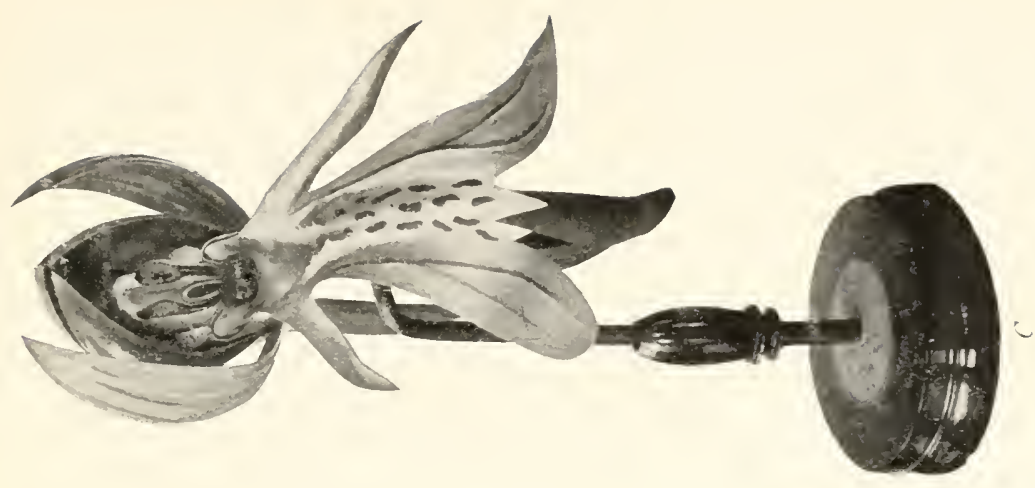

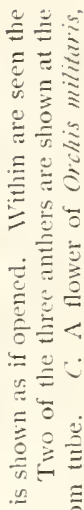

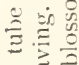

컬

记

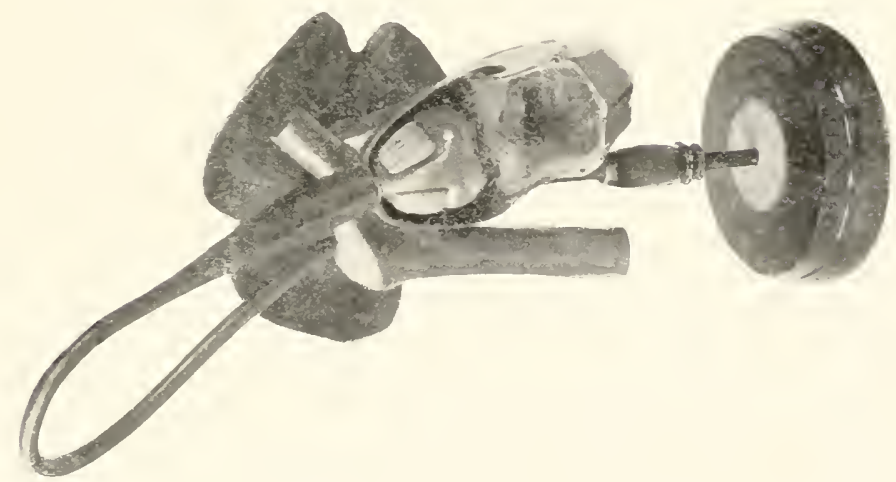

을

$\cong \bar{\Xi}$

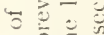

二三

$\therefore \stackrel{\Xi}{\Xi} \equiv$

兽㐫

$\approx \overline{0}$

$\Xi 2$

纱

运跣

के

를

है)

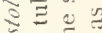

氖它

के

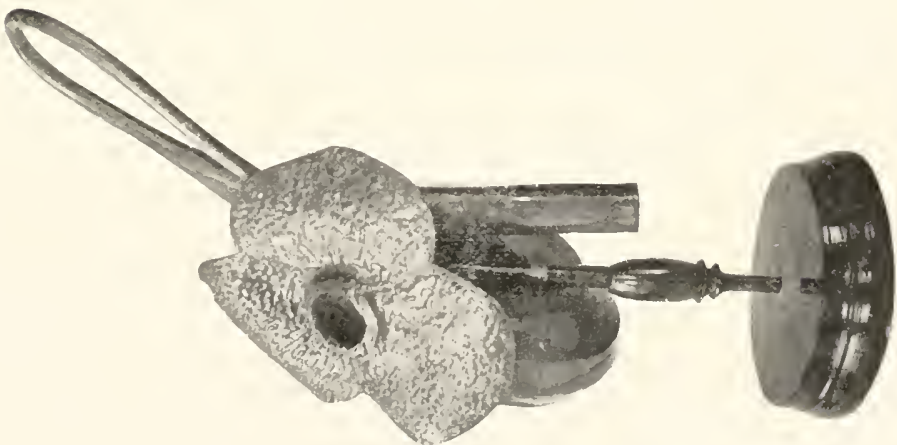

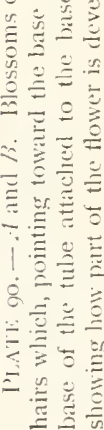



that the bee in entering the flower to reach the nectar will press its head against the rostellum (5). When the bee withdraws, the rostellum, with its two pollen masses, sticks to its forehead (6), and the pollen masses are thus carried to the next blossom visited. At first the pollen masses stand erect upon the forehead of the bee ( 5 and 6). but, as the bee flies through the air, the stalks of the pollen masses dry slightly and bend downward (7), so that, when the bee enters another flower, the pollen masses are pressed against the stigma. Thus cross-fertilization must be frequently effected, the bees carrying the pollen not only from blossom to blossom of the same plant, but also from one plant to another.

The flowers of Saliza have adopted another and equally interesting method of reaching the same result. In these blossoms the stamens are hinged, and the lower end of the stamen, below the hinge, is so placed that a bee, in entering the blossom, will push against it, and in doing so will cause the other end of the stamen with its pollen to drop down and dust the back of the bee with pollen (Plate S9, B, I, 3, f, and 5). This pollen will be carried to the next flower visited by the bee. Frequent cross-fertilization is secured by another simple character of these blossoms. The pollen is mature by the time the blossom bud opens, but at this time the pistil is short and lies arched in the upper part of the blossom (I). As the flower grows older, the pistil elongates and bends downward, so as now to come into contact with any insect which may visit the flower with its load of pollen, thus securing fertilization (2). As the pollen and the pistil are not ready for fertilization at the same time, no blossom will be self-fertilized; and, as the insects pass frequently from plant 
to plant, as well as from blossom to blossom of the same plant, cross-fertilization between plants must frequently result.

Aristolochia sipho illustrates another method of securing cross-fertilization through insects. The flowers of this species are in the form of a bent tube with a flaring end, something like a trumpet (Plate 9o, $A$ ). Flies enter the opening of this tube, but find their egress prevented by a mass of hairs (Plate 9o, $B$ ) which fills the tube, pointing toward its base, allowing the flies to enter but not to depart. The stigma of these blossoms is a large top-shaped structure, nearly filling the base of the tube. Behind it, and inaccessible to the flies, are the three biscuit-shaped anthers with their pollen. The swollen stigma shrinks as the flower grows older, and if the flies which have entered have brought pollen with them and have fertilized the stigma its shrinking is hastened. After the stigma has shrivelied, the flies, as they wander about their prison, can reach the pollen and will become well dusted with it. Now the hairs which have prevented their departure dry and shrivel and the flies are set free to seek another blossom and fertilize its ovules.

Each of these general methods of securing cross-fertilization which we have illustrated is used by a considerable number of plants, and there are scores of other devices to which we have not space to refer. Many of these are vividly described, with good pictorial illustrations, in Kerner's The Natural History of Plants, the English translation of which, by Oliver, is published by Henry Holt \& Company.

Enough has been said to emphasize the importance to the plant of insect visits. We have seen that by the secre- 
tion of nectar and odoriferous oils, and by the formation of a surplus supply of pollen, plants invite the visits of insects, and that they sometimes adopt remarkable means to secure cross-fertilization by the aid of the visiting insects. Careful experiments have been made by numerous competent students to determine if color in itself is recognized by insects of different sorts. These have established the fact that color is recognized by insects of many kinds, and that to certain species of insects different colors have different degrees of attraction. Also it has been shown that the most attractive color is not always the same for two species of insects.

Lord Avebury's experiments upon bees are worth our attention for a monent, as an illustration of the methods which have enabled us to draw these conclusions. In a very brief summary of an extended series of experiments Lord Avebury says: "I placed slips of glass with honey on papers of various colours, accustoming different bees to visit special colours, and when they made a few visits to honey on paper of a particular colour, I found that if the papers were transposed the bees followed the colour." Describing another series of experiments, he says: "I took slips of glass of the size generally used for the microscope, viz. three inches by one, and pasted them on slips of paper coloured respectively blue, green, orange, red, white, and yellow. I then put them on a lawn, in a row, about a foot apart, and on each put a second slip of glass with a drop of honey. I also put with them a slip of plain glass with a similar drop of honey. I had previously trained a marked bee to come to the place for honey. My plan then was, when the bee returned and had sipped for about a quarter of 
a minute, to remove the honey, when she flew to another slip. This then I took away, when she went to a third; and so on. In this way - as bees generally suck for three or four minutes - I induced her to visit all the drops successively before returning to the nest. When she had gone to the nest I transposed all the upper glasses with the honey, and also moved the coloured glasses. Thus, as the drop of honey was changed each time, and also the position of the coloured glasses, neither of these could influence the selection by the bee.

"In recording the results I marked down successively the order in which the bee went to the different coloured glasses. For instance, in the first journey from the nest, as recorded below, the bee lit first on the blue, which accordingly I marked i; when disturbed from the blue, she flew about a little and then lit on the white, which I marked 2; when the white was removed, she settled on the green, which was marked 3 ; and so on successively on the orange, yellow, plain, and red. I repeated the experiment a hundred times, using two different hives - one in Kent and one in Middlesex - and spreading the observations over some time, so as to experiment with different bees and under varied circumstances. Adding the numbers together, it of course follows that the greater the preference shown for each colour the lower will be the number standing against it.

"The following table gives the first day's observations in extenso:- 


\begin{tabular}{|c|c|c|c|c|c|c|c|}
\hline "JotrNeys & Blue & Green & Plain filass & OR.ANGE & RED & $W_{\text {hite }}$ & Yellow \\
\hline I & 1 & 3 & 6 & + & 7 & 2 & 5 \\
\hline 2 & 5 & 4 & 7 & 6 & I & 2 & 3 \\
\hline 3 & 1 & + & 7 & 6 & 5 & 3 & 2 \\
\hline$t$ & 2 & + & 6 & 7 & 5 & I & 3 \\
\hline 5 & I & 4 & 7 & 2 & 6 & 5 & 3 \\
\hline 6 & I & 2 & 3 & 6 & 5 & 4 & $\tau$ \\
\hline 7 & 2 & I & t & 7 & 3 & 5 & 6 \\
\hline 8 & 3 & 4 & 6 & 2 & 7 & 5 & I \\
\hline 9 & 5 & I & 7 & 4 & 6 & 3 & 2 \\
\hline 10 & I & 6 & 7 & 5 & 3 & 2 & 4 \\
\hline \multirow[t]{2}{*}{ I I } & 4 & 6 & 5 & 2 & 7 & 3 & 1 \\
\hline & 26 & 39 & 65 & $5 I$ & 55 & 35 & $37^{\circ}$ \\
\hline
\end{tabular}

The order of preference here indicated is, we see, beginning with the most farored, blue, white, yellow, green, orange, red, and the plain glass. I much larger number of experiments by the same method gave the following figures: blue 275, white 349, yellow 405, red 4i 3. green 427, orange 4to, plain glass 49I. Me may say, then, that bees show a strong preference for blue, that they like white next, and that yellow, red, sreen, and orange are about equally attractive, and are all preferred to uncolored objects.

Other experiments by Lord Arebury show that wasps have a decided color sense and are able to distinguish vermilion, orange, blue. white, yellow; and green, but that they do not show a very decided color preference. Similar results have also been obtained by Dr. and Mrs. Peckham. Experiments upon most other insects are more difficult to perform, for they do not have nests in which they live together and to which they return after each hunting trip. or in which they store honey, returning time after time to 
the flowers for nectar. Most insects eat their fill and then fly away and do not return. It is possible, though, by observation of flowers in nature to determine what kinds of insects are their most frequent visitors. In this manner we can determine that "white flowers are especially visited by small flies; that flowers which depend upon beetles for fertilization are frequently yellow; that those which especially bid for the favor of bees and butterflies," the nectar gatherers par cxccllence, "are usually red, purple, lilac, or blue." 1

Since the visits of insects are so valuable to plants in securing cross-fertilization, it is easy to see that natural selection would be likely to bring about the bright coloration of flowers; and, as insects of different kinds have different color preferences, the color of any sort of flower is likely to be such as to attract the kind of insect best adapted to secure its cross-fertilization. And, in general, we may say that the observations upon the colors of flowers agree with these conclusions.

The most assiduous honey gatherers are the bees and the butterflies, and it is interesting to observe that the most highly specialized flowers in the different families of plants are usually red or purple or blue, being thus especially attractive to these insects whose preference is for these same colors.

Much has been written about other principles in the coloration of blossoms, their original color, the order of development of the several colors, the way in which new colors arise, the parts of the petals upon which these new colors are most likely to appear, the meaning of variega- 
tion in the colors of petals, the colors of degenerate blossoms, and many other subjects of much interest; but, as the conclusions to be drawn from the great number of observations are still somewhat in dispute, it seems unwise for us to attempt further discussion along these lines.'

There is one further thing in this connection to which it is well to call attention. Many highly specialized flowers have developed unusual shapes so as to cause the risiting insects to enter the blossoms by the path most likely to bring them into contact with the pistil and the pollen in such a way as to insure cross-fertilization, and have provided special lighting spots or platforms for their visitors (Plate 9o, $C$; compare Plate S9), and these are often spotted and streaked in such a way as to make them conspicuous. More interesting still is the fact that these streaks are usually so arranged as to point the way to the nectaries, guiding the insect along the right path, the pistil and the anthers being so placed as to come into contact with the body of the insect in the most adrantageous manner as it passes along this prescribed way.

\section{MAN IN RELATION TO EVOLUTION}

Naturally the subject of the relation of humankind to evolution is one of particular interest to us. Study of human anatomy shows mankind to be probably a single species, belonging to the Primates, a group of the Mammalia, including, besides man, the lemurs, and the apes and

1 The reader will find Grant Allen's The Colours of Flowers, which treats of these subjects, a most interesting and sugrestive book. 
monkeys of the eastern and western hemispheres. Man is most nearly related to the Simizde, the tailless apes of Asia and Africa, including the gibbon, the orang, the chimpanzee, and the gorilla. It is usual to place humankind in a distinct family of Primates, Hominide. It is now the general consensus of opinion that we should recognize but a single species and distinguish as subspecies the sereral races of men.

As an illustration of some of the reasons for asserting that men are primates and are closely related to the Simiida, glance at the illustration of the skeletons of representatives of four genera of Simiida and of man (Plate 9I, A). Part for part the skeletons are the same in all fundamental regards. Look at but a single group of bones, those composing the pelvis (Plate 9I, $B$ ). 'The larger bones, the sacrum, and the coccyx show the closest resemblances in man to what we see in the gorilla. The relative size and shape is slightly different, and man has lost one of the coccygeal bones still seen in the gorilla, but in all essential features the two sets of bones are closely similar. Similar comparisons with a similar result might be made between the hands, feet, sterna, ribs, spinal columns, teeth (Plate 92, 4 , bones of the skull, etc.

But let us turn to structures other than the skeleton. Passing by the close resemblance between the vital organs, the muscles, and the other important organs (Plate 92, B), observe again some of the remarkable similarities in certain minor details, to some of which we have before referred. IVe think of the hairiness of the apes as distinguishing them rather sharply from man, but in reality the whole of the human body is covered with hair, save the palms of the 

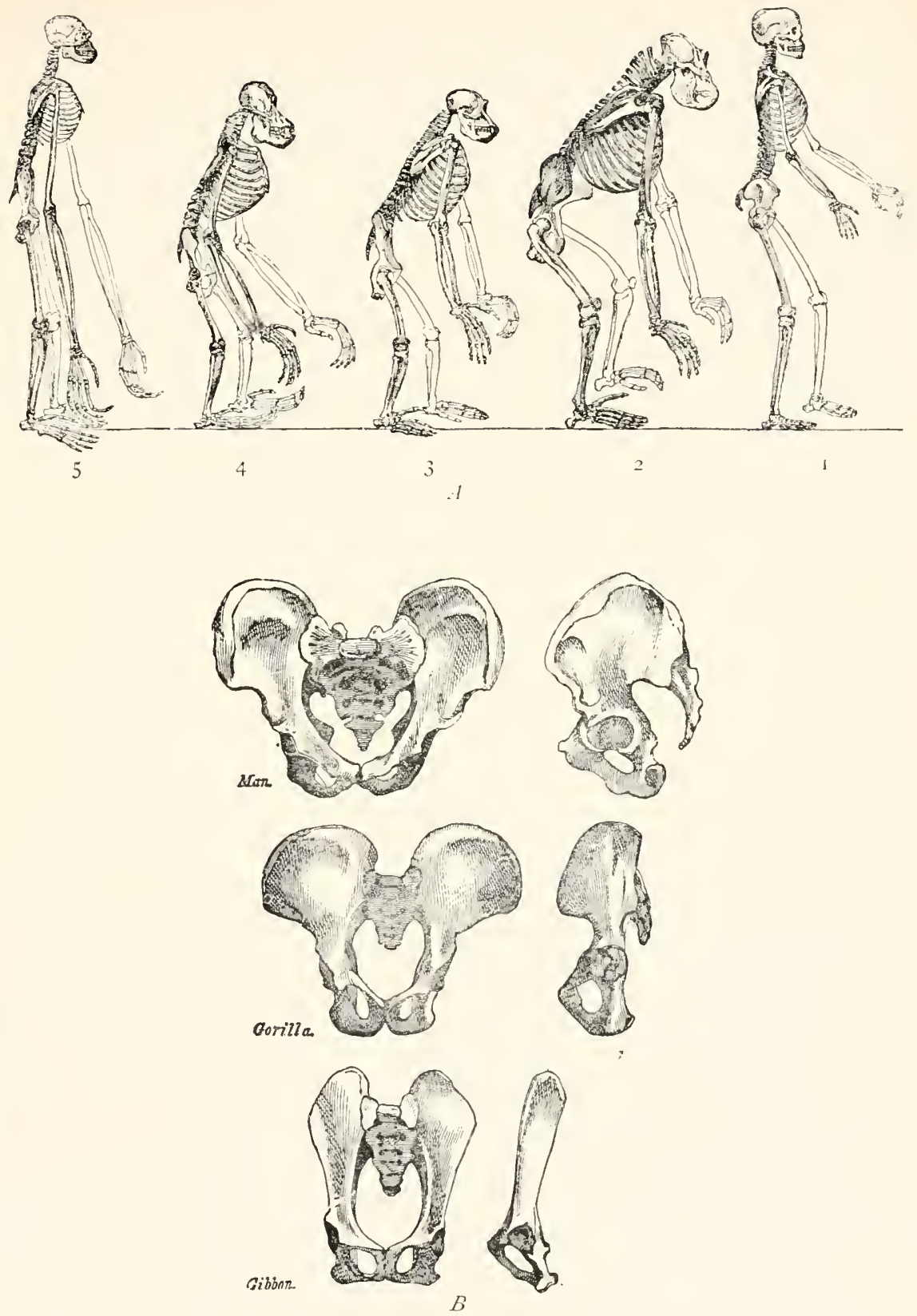

PLite 9I. - A. Skeletons of man and four apes. [After Huxi,er.] I. Man. 2. Gorilia,

3. Chimpanzee. 4. Orang. 5. Gibbon. B. Pelvis of man, gorilla, and gibbon. 

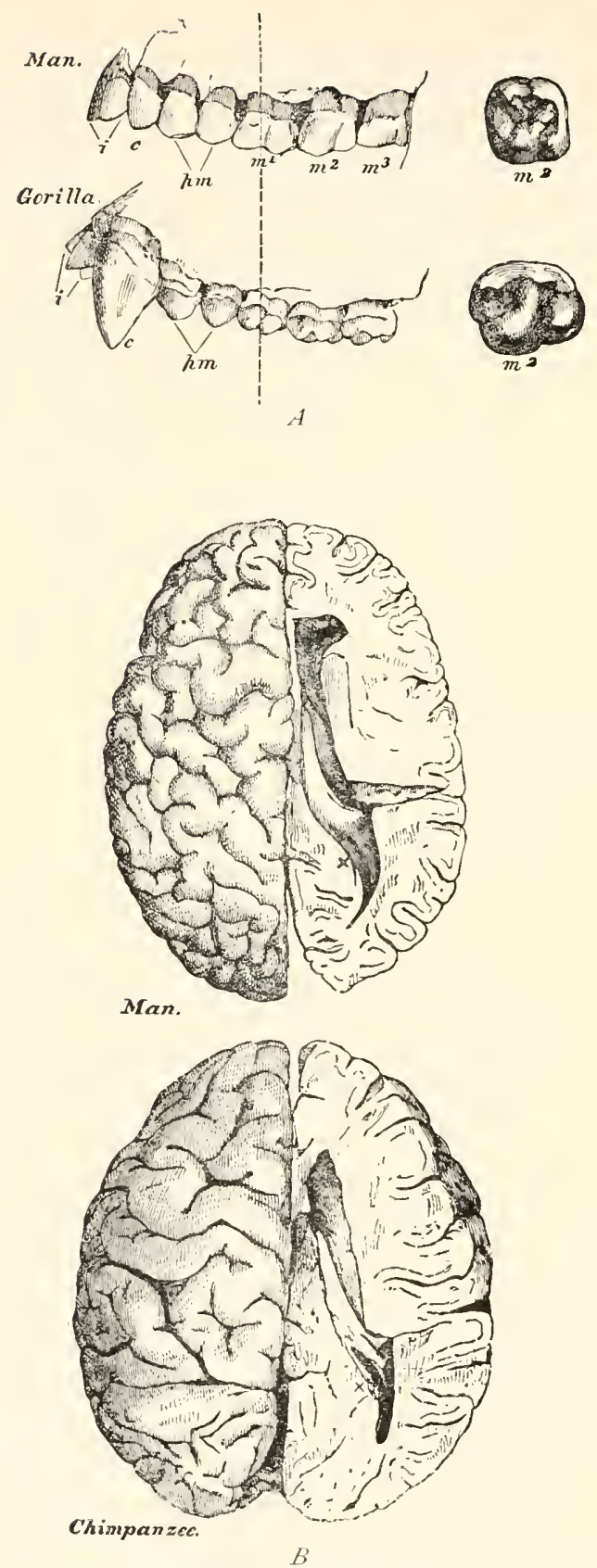

PIATE 92 - A. Teeth of man and gorilla. [After HuxiEY.] B. Cerebral hemispheres of man and chimpanzee. [After HUXLEY.] 


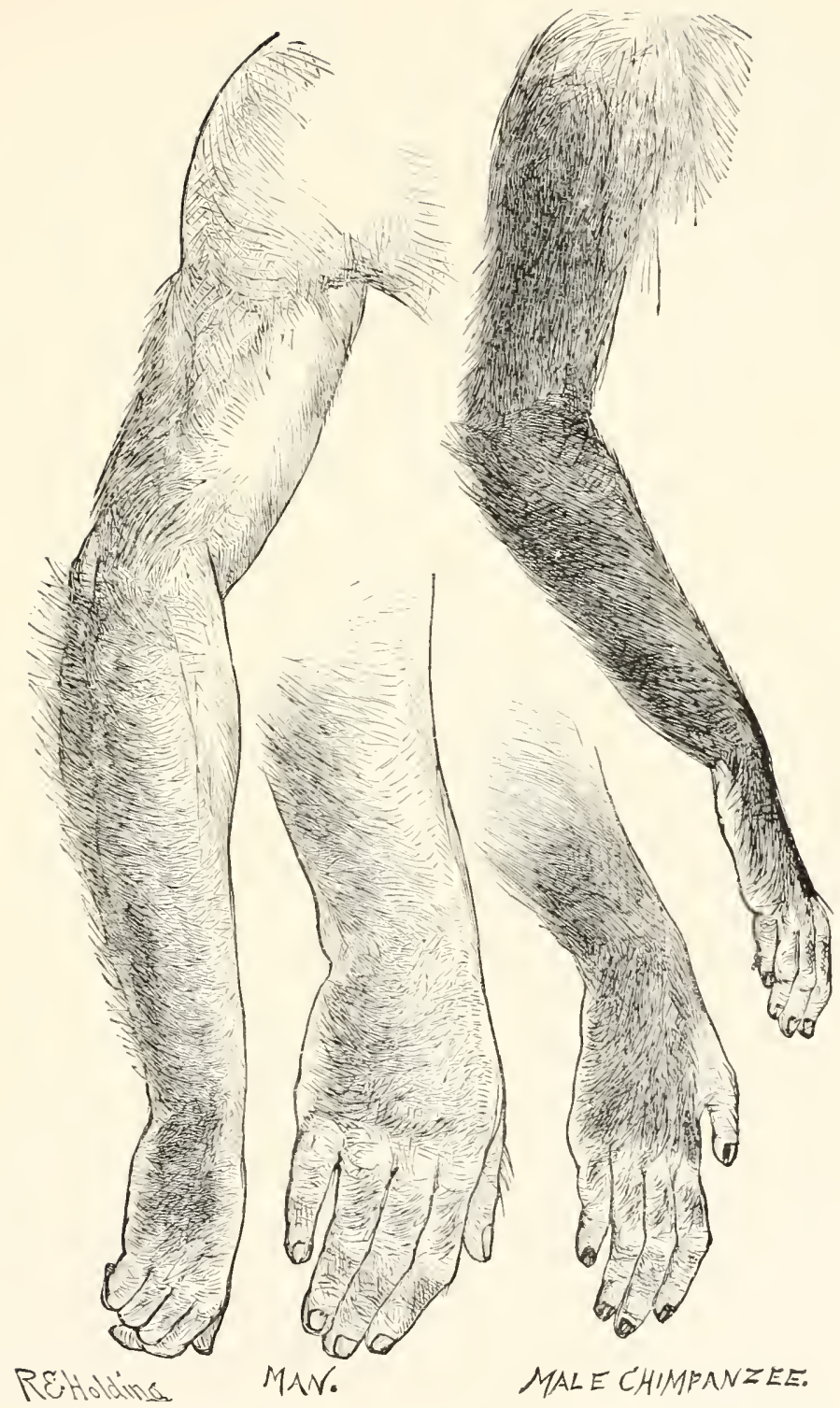

PLATE 93. - Hair tracts on the arms and hands of a man and a male chimpanzee. Drawn from life. Observe that in the corresponding regions the direction of the slope of the hairs is the same. - From Romanes' Darwin and After Darwin, by the courtesy of 'The Open Court Publishing Company. 


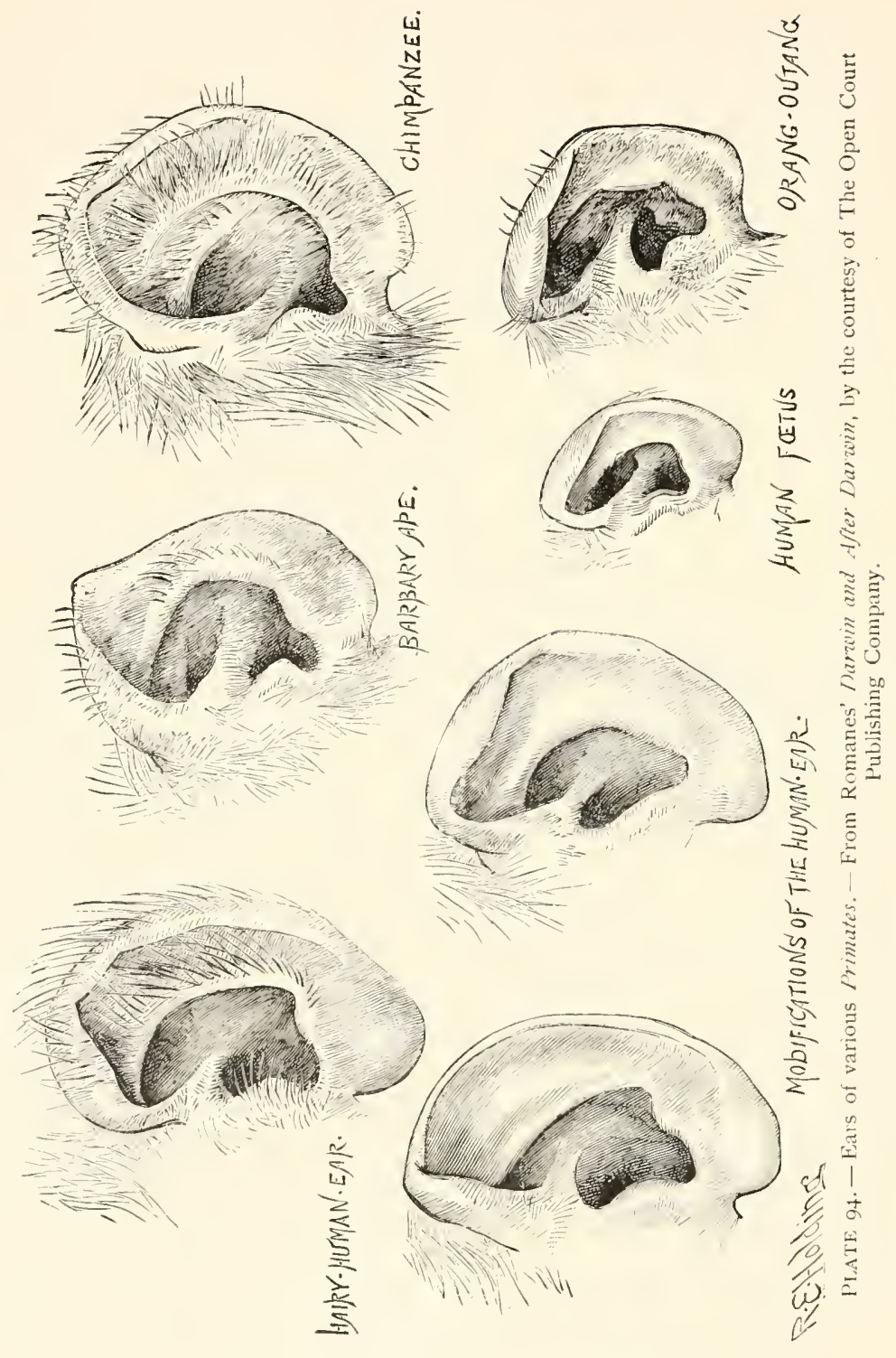



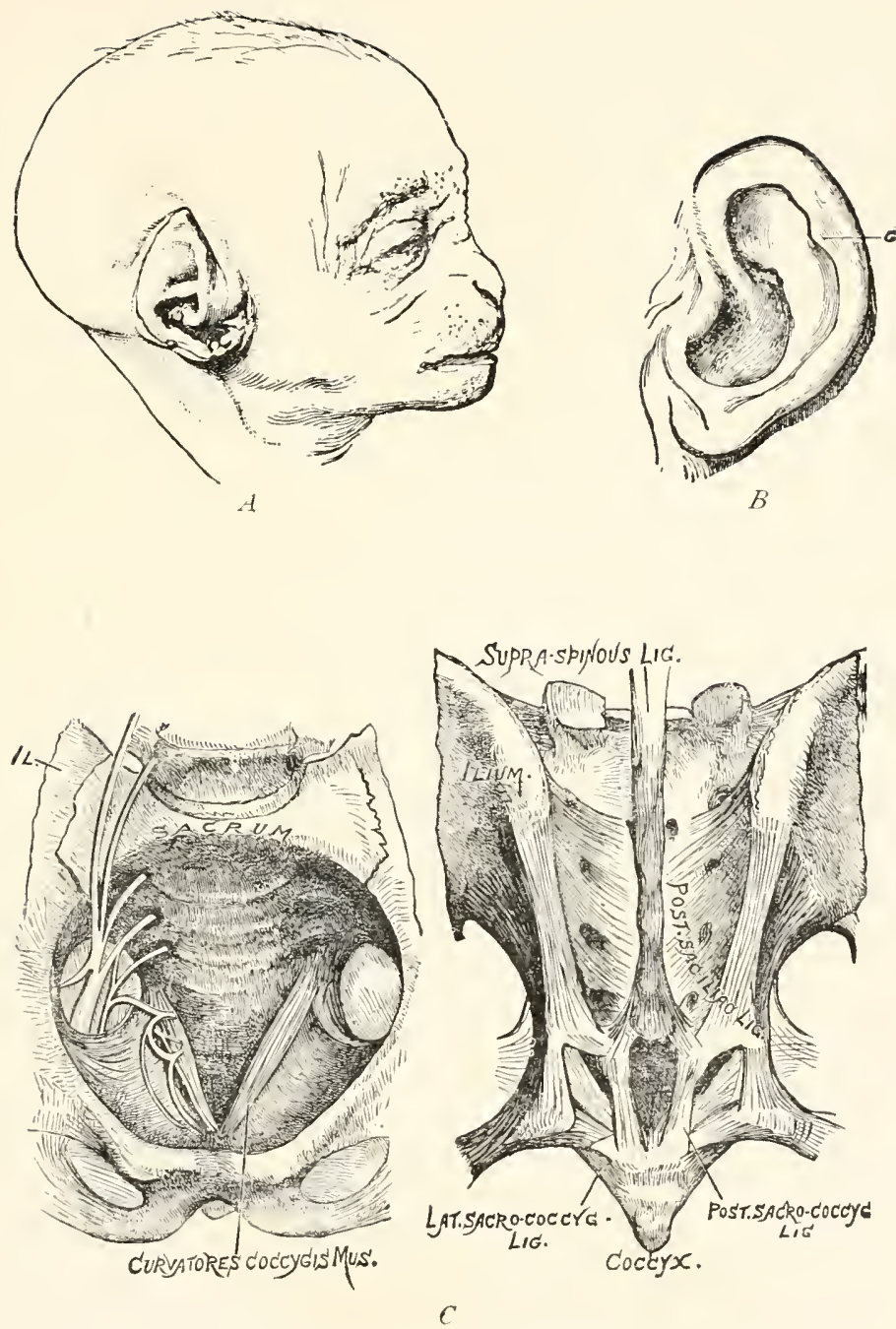

PIATE 95. - A. Head of fotus of an orang-outang; observe the pointed ear. [After DARWIN.] B. A human ear in which a point is present upon the recurved edge. [After DARWIN.] $C$. Front and back view of an adult human sacrum, showing an abnormal persistence of vestigial tail muscles. - From Romanes' Darwin and After Darwin, by the courtesy of 'The Open Court Publishing Company. 

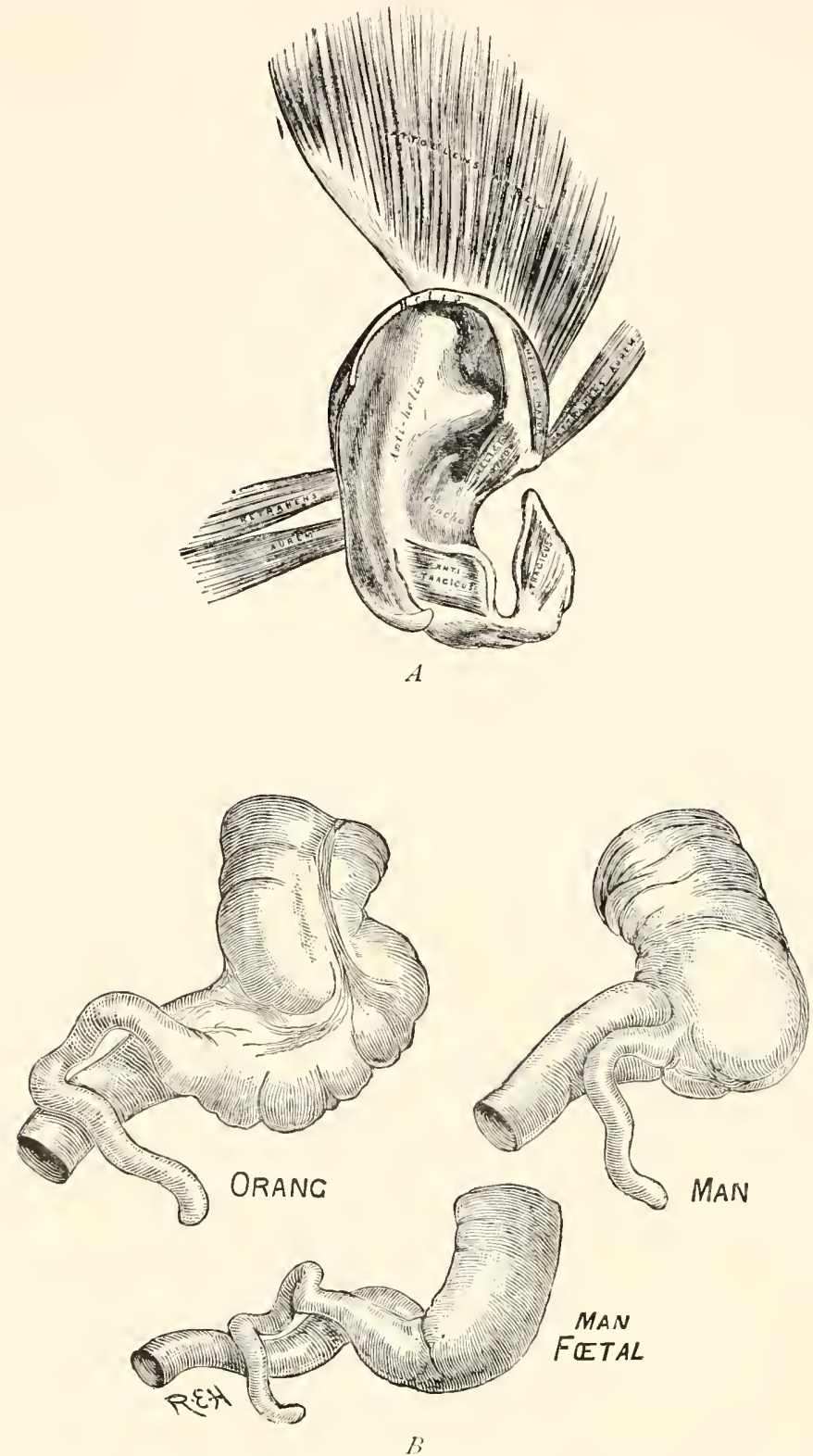

PLATE 96. - A. Muscles of the human ear. - From Gray's Anatomy. B. Vermiform appendices of orang, man, and human fœetus. - From Romanes' Darwun and After Darwin, by the courtesy of The Open Court Publishing Company. 
hands, the soles of the feet, and the backs of the terminal joints of the fingers and toes; and these same portions are naked in the apes. Not only does hair clothe the whole human body, the slant of the hair in the several regions of the body is the same that we observe in the apes (Plate 93). Therefore, even to minute details, the apes and man can be compared as to the presence and slope of hair; the only considerable difference in the condition of the hair in the two being in the length and the coarseness of the individual hairs.

Observe another minute characteristic, one often seen in human ears (Plate 94). In many monkeys the ears are pointed and do not show any recurved edge such as is seen in the ears of apes and men (ear of Barbary ape, Plate 94). On the recurved edge of the human ear and that of apes there is often a portion slightly more developed than the rest, showing as a wider place (Plate 94), or even a point (Plate 95, $A$ and $B$ ) on the reflected edge. This corresponds to the point seen in the ears of the lower monkeys. only in their ears the point is erect, the edge of the ear not being folded over.

The apes and man have the tail greatly reduced, it being representer merely by the coccys, a reminiscence of the ancestral condition when functional tails were present. It is interesting to know that there have been instances in which a human being has retained in an abnormally highly developed condition the muscles which represent the functional muscles of this ancestral tail (Plate 95, C). In a similar manner, while our ears are slightly, if at all, movable, we retain in a vestigial condition the muscles which in some ancestor must have served to move the ears (Plate 96, $A$ ). 
The vermiform appendix is less developed in man than in the apes, and in an adult man is relatively smaller than in the human foetus (Plate $96, B$ ).

At the inner angle of the human eye is a fold of tissue called the plica semilumaris. This is a remnant of that third eyelid which in many lower vertebrates, notably the birds, is greatly developed and can be drawn over the whole eyeball, inside the outer eyelids (Plate 97).

These vestigial structures in man have little or no meaning until in them we recognize the traces of an earlier condition through which our ancestors have passed.

In human embryology there is every indication that we must regard man as closely related to the rest of the animal kingdom. A little study of the illustrations of the embryos of man and a number of other vertebrates will bring out this resemblance in their embryology, and the fact that the human embryo, in the earlier stages of its growth, has many features which are a reminiscence of its fishlike early ancestors (Plate 9S). In the later development of the human child, after birth, there are a number of things that are instructive in this connection. In a baby the spinal column has a single curve, as it does in the apes and monkeys, instead of the S-shaped curve seen in the adult human being (Plate 99). The feet are held in a position characteristic of the apes (Plate IOo). For a few weeks after birth, the child has a remarkably strong fingergrip, recalling the strength with which the young apes grasp the mother's hair, as she climbs with them among the trees. The young human baby is able to sustain its own weight by its hands, and, when hanging thus, shows often a position of the legs which is strikingly apelike (Plate 100, $B$ ). 


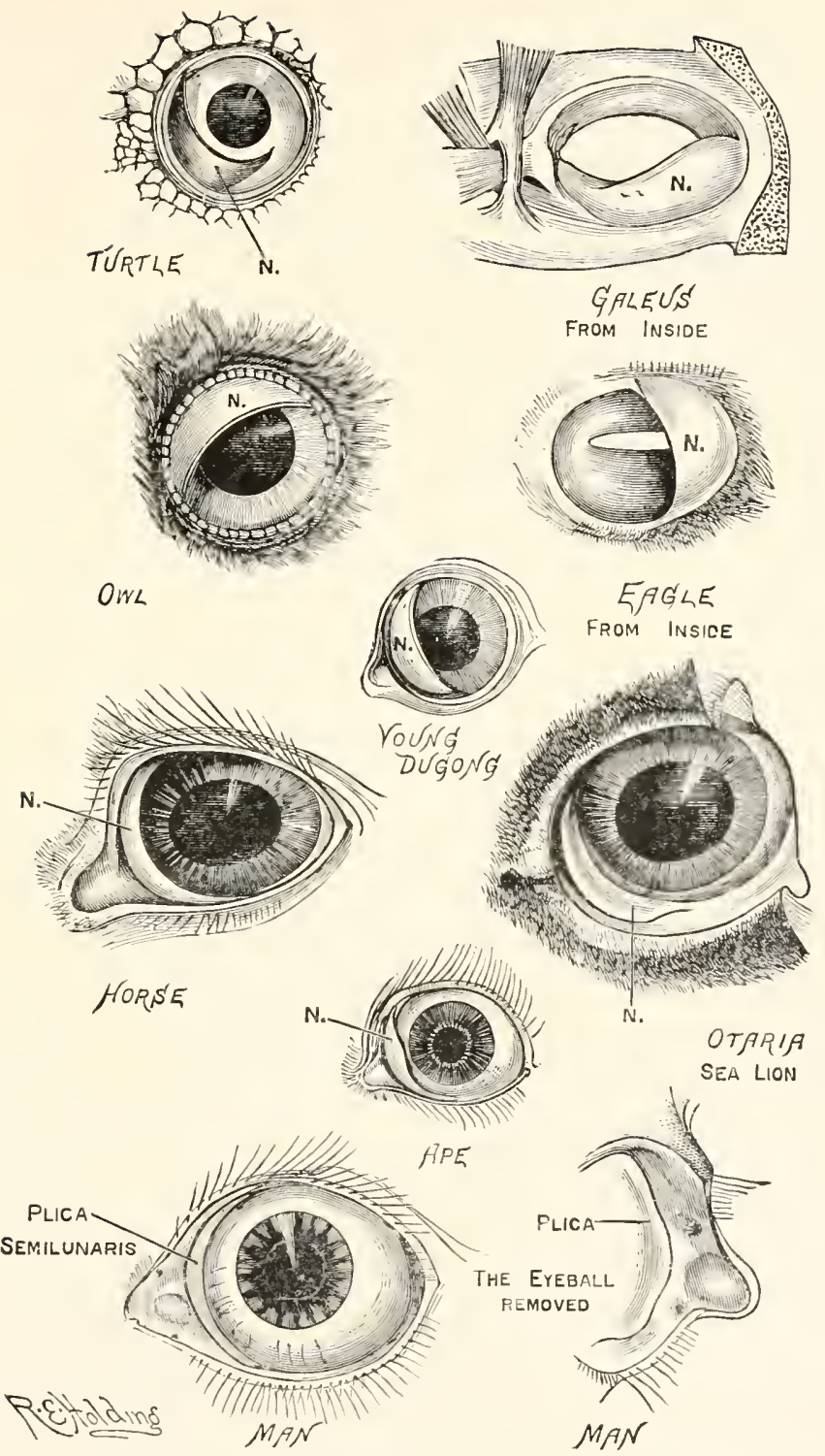

PLATE 97. - Eyes of various vertebrates, showing the nictitating membrane (third eyelid), indicated by the letter $\mathrm{N}$. - From Romanes' Darwin and. After Darwin, by the courtesy of The Open Court Publishing Company. 


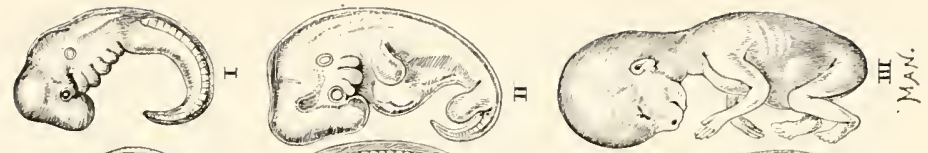

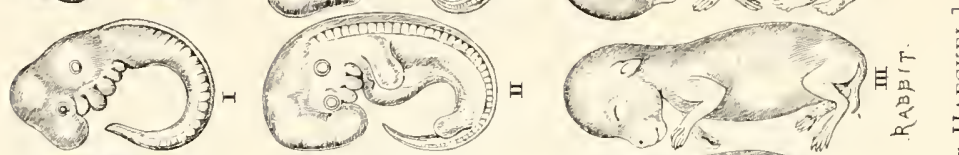

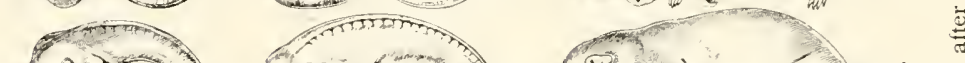

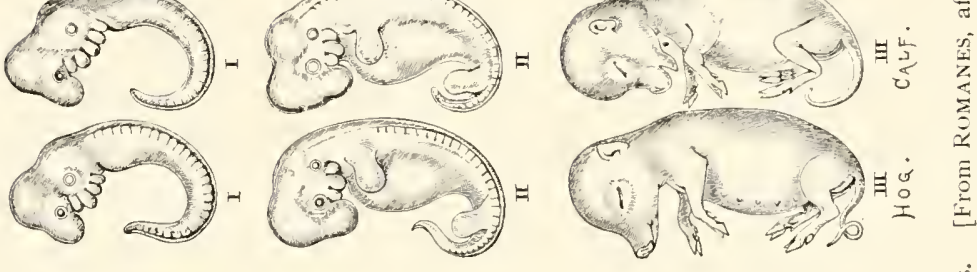

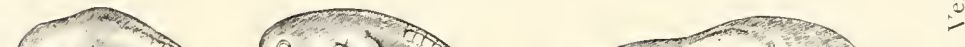

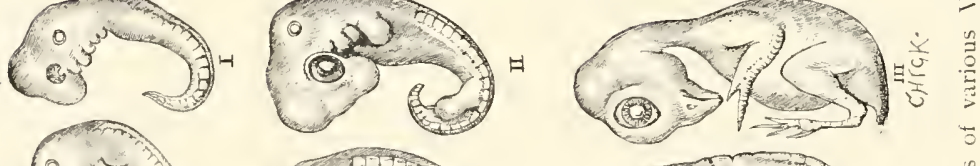

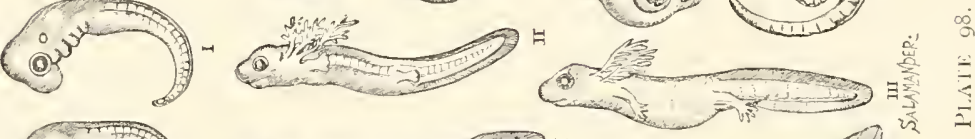

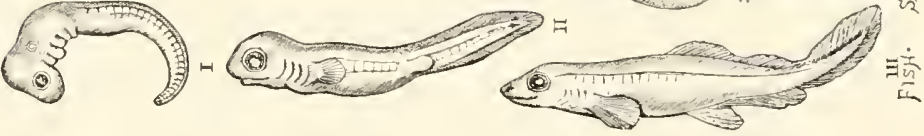



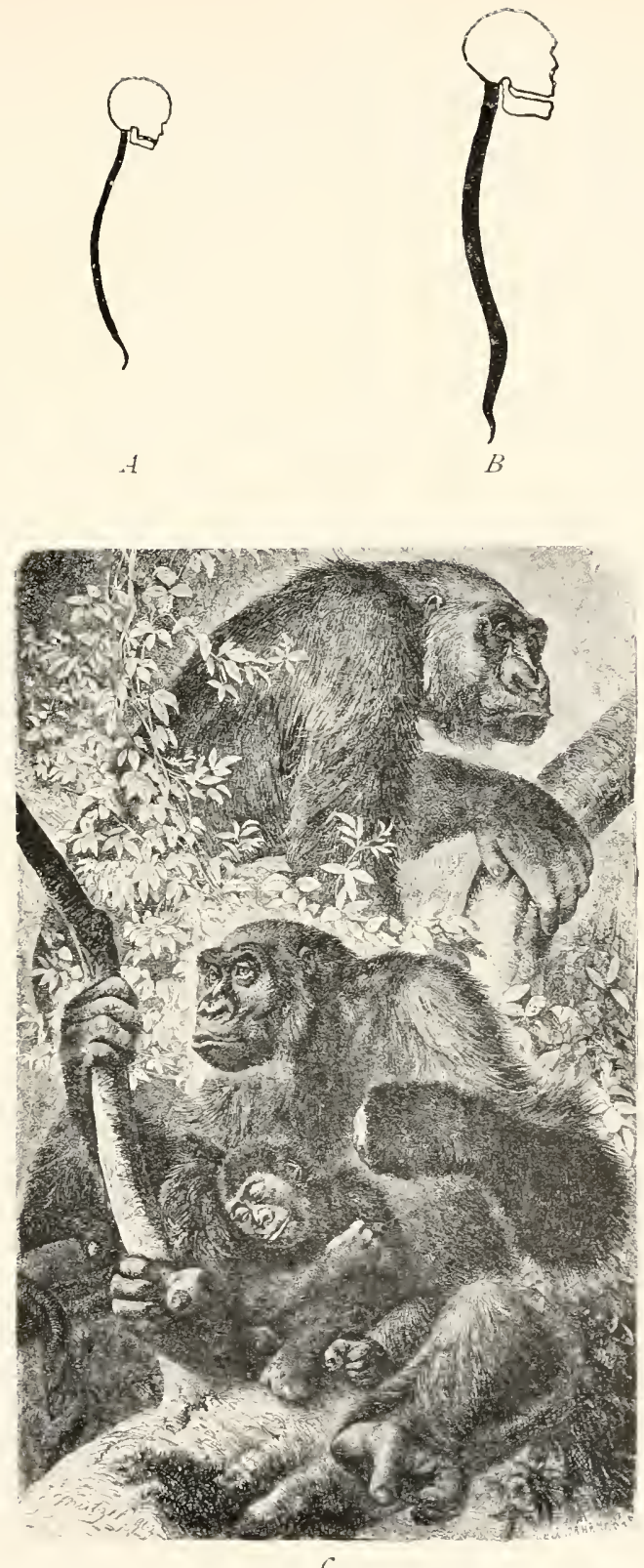

PLATE 99. - $A$ and $B$. Diagrams illustrating the curvature of the spinal column in a human infant $(A)$ and an adult man $(B)$. The curvature of the spinal column in an ape $(C)$ resembles that in the human infant. (Compare the upper figure in cut $C$ of this plate.) $C$. A group of gorillas, male, fenale, and young; observe the position of the feet in the female and in the young gorilla. - From Brehm's Thierleben. 

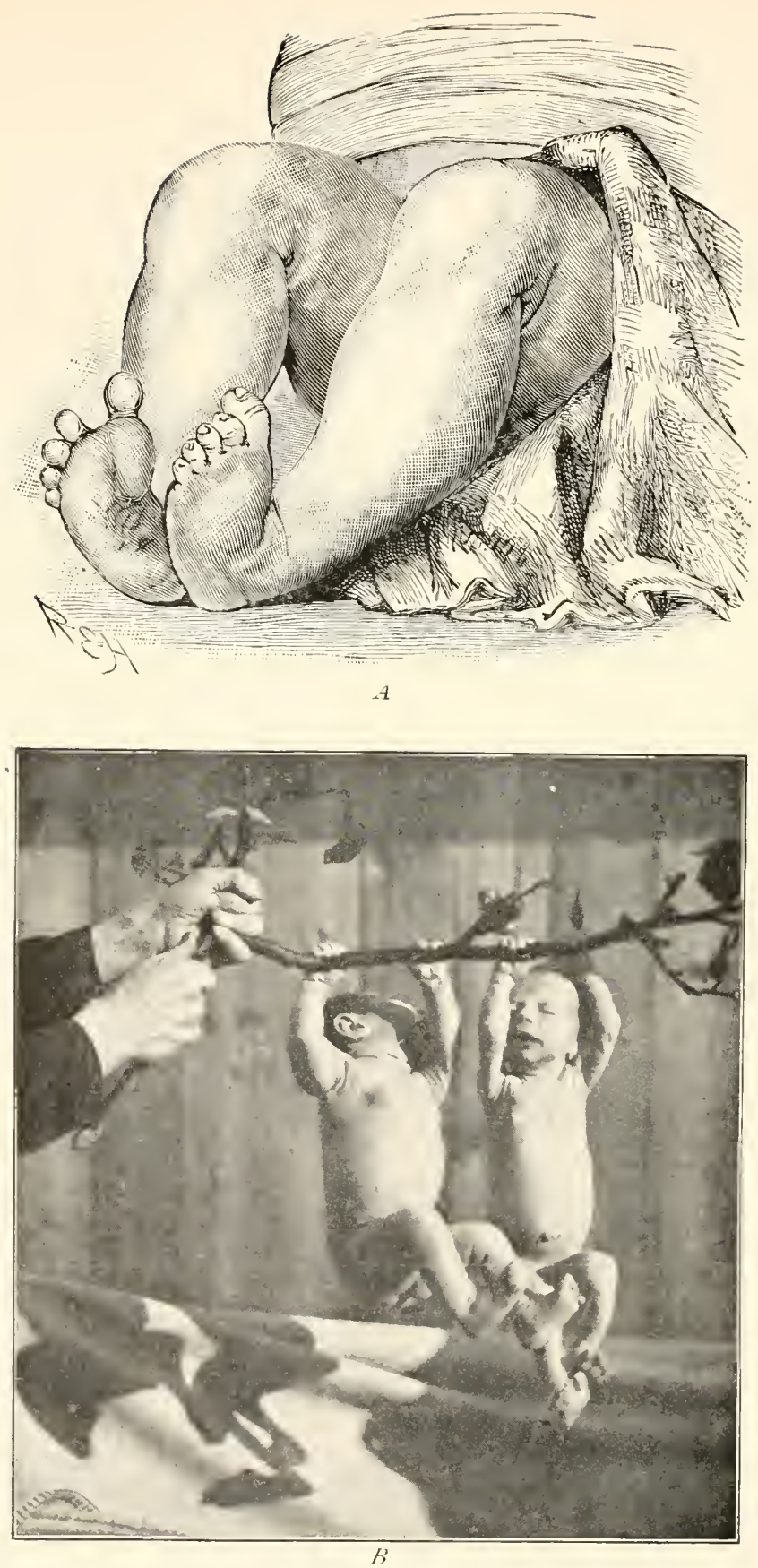

PLATF IOO. - 4. Foot position of a human infant. - From Romanes' Darwin and After Darzim, by the courtesy of The Open Court Publishing Company. B. Two human infants, ten and thirteen days old respectively, supporting their weight by their hands. - From a photograph by Dr. Louis Robinson, by the courtesy of The Open Court Publishing Comp.ny. 
The position of the legs after birth is, however, probably largely due to the prenatal folded position of the legs.

We might develop to an indefinite extent these points of anatomical and embryological resemblance between man and other vertebrates. The character of the evidence, however, has been sufficiently illustrated. I know of no scientific reason for separating man from the rest of the animal kingdom as regards the processes of evolution. His whole structure shows that he has arisen by differentiation from lower vertebrates. $\mathrm{W}$ e do not understand all the stages by which his body has been thus evolved, nor do we know in detail by what steps his mental faculties have arisen from the lower condition of mind seen in other vertebrates; yet we have, apparently, no reason for believing that the method of their evolution has been different in any fundamental regard from the methods by which the minds and bodies of other animals have been developed. Comparative psychology is as yet in its infancy, and we are not at all prepared to discuss the relations between the mind of man and the minds of lower animals, much less to attempt to describe the steps in the evolution of the human mind. We must wait a good many years before our curiosity in this regard can be satisfied. There appeais, however, no sufficient reason for believing that the development of man's mind has been anything other than natural and in accordance with the principles that apply in the development of the minds of other species. So far as we can judge, man is the result of the same processes and factors that have produced the bees with their wonderful instincts and the tiger with his superb physique.

Not only has man been produced under the influence 
of the factors of evolution, he is still subject to them and is still being modified by them to-day. Disease and unfavorable climate kill those who are unable to resist them, while the stronger survive. Men fail in the struggle for existence and become submerged and disappear. Natural selection is constantly removing those who are unable to resist the pressure of the adverse conditions of life. This is the same process we have seen among the lower animals and the plants, and has the effect of making man more fit for his surroundings by eliminating the less adapted.

Sexual selection also is operative, more so among mankind than in any other group of animals. There is closer scrutiny and more careful choice is exercised in human marriage than in the mating of any of the lower animals. There is an important clifference to notice. Among humankind, at least among more highly civilized men, choice in marriage is based more largely upon intellectual and moral attractions and less upon physical attractions than is the case among lower animals. Among lower forms sexual selection secures chiefly ornamentation or fine voice. Among men it is more those of good intellect, of pleasing disposition, of right character, who are chosen; sexual selection thus serving to increase and perpetuate these characteristics.

Segregation also is an important factor in human evolution. The fact that the Chinese live in Asia and the negroes in Africa, has prevented intercrossing between these two races, which, if it had taken place, would have changed the character of both races. In any community there are many important segregating factors. There is in America a wellnigh universal distaste toward marriage between negroes and Caucasians, and this has had an important effect upon the 
development of the two races. Intermarriage between those of different social strata is unusual, culture and wealth thus effecting segregation. Religious belief has had an important effect in causing segregation in marriage. It would be impossible to enumerate all the efficient causes of segregation among humankind.

Let us look a little further at man's relation to natural selection and sexual selection. First as to natural selection: While man, like all other animals, is subject to natural selection, he is less so than any other species, so far as physical factors are concerned. Our great intellectual development enables us to escape from many phases of the struggle for existence. We build houses which protect us from the inclemency of the weather. IVe have fires to protect us from the cold of winter. We cook our food, thus largely escaping the internal parasites which so commonly infest the lower animals. Tre have physicians who enable us to survive diseases which otherwise would destroy us. By cultivation of the soil and by raising flocks and herds we increase the productiveness of the earth, making it support a far greater population than would otherwise be possible. IThen crops fail in certain localities, whole nations are saved from extermination by the great development of our means of transportation, which bring food from distant regions to save the starving. In thonsands of ways we are relieved by our greater intelligence from much of the stress of the struggle for existence. Natural selection plays a less prominent part among men than among plants and the lower animals.

Of course this partial elimination of natural selection is a very great advantage, producing inestimable good to man, 
yet there are disadvantages as well. By means of our wellwarmed houses we protect ourselves from rain and cold, and thus save from death many delicate ones who would otherwise perish. But by preserving these weaker ones we allow them to hand down to the next generation their weak constitution, and so the race will average less robust than it would be if the weak ones had been allowed to succumb to the cold and so had never had offspring. Similarly the physician saves from death many a weakling whose children bring down the average of physical efficiency in the next generation. Physical deterioration has resulted from the partial elimination of natural selection. Invalids are rare among the lower animals: they are rare among savage races. How common they are among us! The invention of spectacles has allowed our ejes to deteriorate without putting us at a serious disadvantage. The skill of the dentist has tended toward unsound teeth for civilized man. Such instances might be multiplied.

One point here should be clearly seen. Natural selection seeks the highest efficiency of the species as a whole, and to this end sacrifices innumerable defective individuals, lest they and their children bring down the average of efficiency. We, on the other hand, seek the welfare of the individual and preserve and cherish the weak, though we know that by so doing we in the end decrease the vigor of the race. Because of our charitable and altruistic tendencies we preserve also the intellectually and morally weak, and thus cause a certain intellectual and moral deterioration in the race average. I believe this is very largely compensated for by other considerations, yet the deterioration is no less real.

A good illustration of the effect of natural selection in 
connection with disease is seen in the relation of savage peoples to certain mild diseases prevalent among civilized races. Measles is not very serious in civilized communities. It has long been a common disease. Those, in the past, who were unable to resist this disease have died; and, as it is mostly a disease of children, they have died before reaching adult life and becoming parents. They have, therefore, not transmitted to the next generation their constitution with its slight powers of resistance to this disease.

Many of those children, on the other hand, who have been strong enough to survive attacks of measles have reached maturity and have handed down to their children something of their natural ability to resist its attacks. There has thus been developed among civilized peoples a considerable degree of power to throw off this disease.

But among savage races, the North American Indians, for example, measles has often been a fearful scourge. It has not been prevalent among them for many generations, as among the white peoples, and they have not acquired through natural selection the ability to resist it. Therefore, it was but natural that when introduced among them it should wipe out whole communities, slaying adults as well as children.

Were vaccination now to be universally given up, it is possible that small pox would be more dangerous than it used to be before Jenner found a way to save us from its ravages; though perhaps vaccination has not been used long enough to allow much deterioration in the power of resistance to small pox which was to a degree acquired during those centuries when the disease had free course.

How far will the deterioration which results from par- 
tially freeing ourselves from the action of natural selection go? It cannot go on indefinitely. Natural selection still eliminates those who are physically very defective; so also sexual selection will operate against the perpetuation of physical deformity and great physical weakness. We need not fear the extermination of the race through freeing ourselves from the action of natural selection. I think, however, that we must anticipate a still further physical deterioration of humankind, not only in such minor points as our teeth and eyes, but in all regards, invalidism becoming more and more prevalent as medical skill advances.

There is another profitable inquiry as to our relation to natural selection. What is the nature of our environment to which we must conform in order to survive and prosper and succeed in giving our children favorable opportunities? The enviromment of lower aninials and plants is made up of many elements that have a bearing upon their lives climate, food and drink, enemies, disease, etc. IVe have the same elements in the physical environment to which we have to relate ourselves, but in addition we have another factor, perhaps as important as any, namely, public opinion. Unless we conform to a certain standard of intelligence, moral character, and good taste we find ourselves at a disadvantage in life, and have to struggle hard to maintain ourselves and care for our children. The man who in any or in all of these ways is far in advance of his fellows, or the one who falls much below popular standards, feels the pressure of life more than he who conforms to the popular ideas of right character and good taste. Conformity to public opinion is of great importance if one desires the 
best chance of survival for himself and family. Public opinion is a vitally important part of our environment.

It is not only important as regards natural selection; it is perhaps even more important in relation to sexual selection. A man or woman, to be desired as a husband or wife, must, in general, be one whose ideas of right living conform to those of the community, one whose character and disposition are such as to command respect. These characteristics have more influence upon choice in marriage than do merely physical characteristics.

It may be worth our while to ask one further question. Under present conditions, how is the race to make desirable progress? How can we influence the evolution of the race, so that it shall take the right direction? Notice, first, that the very asking of this question indicates an interesting condition. We can, to a considerable extent, control our own evolution. The lower animals cannot do so. They lack the intelligence which gives us this power.

How shall we secure the evolution of the race in desirable directions? Before attempting to discuss this question it is important to distinguish clearly between human evolution and social progress. By evolution, as we here use the term, we mean a change in innate character. Social progress may be secured by training the individuals of each succeeding generation to higher and higher standards of living, even while no change in the innate character of the race has been brought about.

The distinction we would emphasize can be easily illus. trated. If a savage should receive some suggestion that should cause him to improve his standard of living, his 
whole family would be benefited. The son born into this family would receive by education the knowledge of the better way of living. He would, naturally, during his own lifetime, learn still more, making the life of his family a little more comfortable than was that in his father's home. His son would therefore be born into a more favorable family environment than that in which he passed his own early life. Thus from generation to generation, through experience, the results of which would be handed on by education, the standard of living would be improved in the families of the descendants of this savage. Great progress might be thus made without any change in the inborn nature of the children from generation to generation.

Continuing the illustration, we may suppose a child of the tenth (or thousandth) generation to be stolen from its parents at birth and removed from the improved family environment, to be taken to a primitive savage home similar to that of his savage ancestor with whom our illustration started. We have no reason to believe that under these circumstances the higher culture of his ancestors for nine generations would cause him to lead any better life than if his ancestors had remained primitive savages. The nine generations of advancing culture secured by education need not have produced any change in innate character in the ciescendants. The social progress may have been secured without any real evolution.

Social progress and evolution may, therefore, be very different things. The former is secured chiefly through the transmission by education of the knowledge and moral tone reached through experience, and by the summation generation after generation of these increments of progress. Evo- 
lution of the race, on the other hand, is a fundamentally different thing. It will be secured by the same methods which are operative to produce evolution among the lower animals, i.c. through natural selection and sexual selection, influenced of course by segregation. We have seen that it is, to say the least, very doubtful if parental modifications are inherited. WTe have no reason to believe that the progress in culture, secured by education in one generation, will directly improve the innate character of the children of the next generation.

Were the effects of education inherited, human evolution should be rapid, but it has been slow; how slow perhaps few of us realize. We speak with pride of the advance in human civilization, of our progress in the arts and in useful knowledge, of the improvement in morals and the growth of altruism, and this all makes us blind to the fact that since the dawn of history there has been no very great real evolution of mankind. We reach larger results in the problem of life than did our progenitors five thousand years ago, but we are able to do so because we build upon their experience and that of all the generations between.

Have we much greater innate powers? Are we at birth endowed with characters having much higher possibilities and much higher tendencies physically, intellectually, and morally? Have we to-day men of much greater physical prowess than the ancient conquerors of the world, than the builders who constructed the monuments of Egypt? Have we more adventurous spirits or more successful explorers than the Phœnicians, who without compass sailed the ancient seas, reaching the whole Atlantic coast of Europe and the British Isles, also passing southward even around the tip of Africa? 
Are there among us to-day men of keener inventive genius than the one who first used fire, or the inventor of the lever or of the wheel, or than the man who first made bronze or smelted ore? Our modern engines have been invented screw by screw by successive builders, each building upon the others' work. Have we to-day men of much larger legal and social understanding than the ancient lawgivers who forged the legal systems which still are the basis of our most enlightened governments? Have we poets whose genius greatly transcends that of Homer or of the authors of the books of Job and Ruth? In asthetic appreciation and in the power of artistic expression in sculpture and architecture we are degenerate compared with the Greeks.

Even in innate moral character have we greatly advanced? We are learning the lesson of altruism, but are we born with a sturdier moral sense? If we could take hundred thousand infants from London or Chicago and, turning back the wheel of time, place them in the homes of ancient Babylon, would they reach a higher standard of righteousness or of altruism than their neighbors? How little evidence we have of real evolution of mankind since the first emergence of the race from the darkness of prehistoric times!

Whether or not we believe that man has advanced in innate character during the last five or ten thousand years, we can certainly say that the advance has not been rapid. The zoologist thinks of the problems of evolution in periods of geologic time, not in years. He sees decided change in the ancestors of the horse, when he compares the Eocene and Miocene fossil famas. He would hardly expect to find great progress in evolution indicated in the fossils found in the last few feet, say, of the Miocene strata, which would 
represent a period of time equal to the five to ten thousand years of human history.

Is it then hopeless? Is there no probability of securing real advance for man in innate character? Must we content ourselves with merely a veneering of civilization over the fundamental savage nature?

The questions asked in the last few paragraphs force themselves upon the attention of any candid student of human evolution. The author does not claim to be able to furnish a complete answer to them, but he would make a few suggestions.

Setting aside the inheritance of parental modifications. of which we have no evidence, and whose reality seems so improbable, we have the two factors - natural selection and sexual selection, aided by segregation. From the action of natural selection we in considerable measure escape. (Compare pages I69 to I72.) Even from the action of public opinion, one of the most important elements in our environment, we in part escape by our adaptability. One whose innate character is unsound may be trained to so conform, at least outwardly, to the standards of the community that he will be held in esteem and will succeed in rearing his family in conditions of comfort. On the other hand, a boy of naturally more desirable character may, by wrong training, be brought into such relation to the community that he will be destroyed. Survival in the struggle for existence among humankind is influenced not by innate character alone, but by what this character comes to be through training. 'This greatly complicates the problem of securing, through survival of the best adapted, an advance in innate character, i.e. true evolution. The plasticity, or educability, of the human 
being preserves him from destruction in the struggle for life. Natural selection secures the preservation of the more plastic, and this, in turn, makes it still more difficult to secure advance in innate character.

Likewise sexual selection, choice in marriage, among humankind is based not alone on innate character, but upon what the character has become through training. This again hinders advance in innate character through sexual selection.

But however powerful training may be in determining the character of the adult man or woman, still the innate character does count, and in the long run both natural selection and sexual selection should tend to modify it. The child with weak body may by training become a strong man, yet, in general, it is true that the strong children make the strong men. So also a child of inferior intellectual endowments may by proper culture become a man of considerable intellectual development, yet on the whole it is true that men of high mental power were probably boys of good intellectual capacities.

We know less about innate moral character, still it seems to be true that men differ greatly in their innate moral soundness and moral sensitiveness. There is much evidence in favor of the belief that one of mediocre moral endowments may by proper training become a man of moral power, yet here again it seems to be true that, in general, innate moral capacities are correlated with high moral attainments.

If, therefore, there is such a general correlation between innate capacities and attainments, whether physical, intellectual, or moral, it must follow that, in so far as natural and sexual selection operate, they will tend gradually to modify innate character in these three aspects. 
Believing then that, in spite of all deterrent influences, both natural selection and sexual selection do operate slowly to produce modification in innate character, let us ask again the question: Can we so control this evolution that it will be in desirable directions, and, if so, how can it be controlled?

Let us elevate the standards of public opinion by every means in our power, and then natural selection and sexual selection, which are greatly influenced by public opinion, will secure the evolution of the race. The progress will be slow, painfully slow, but it will be real. This does not mean that we shall cease trying to improve individuals. Each individual, who is led to a more desirable attitude toward life, will act as leaven in the community in which he lives, raising somewhat the standards of the whole community. I believe that in the continued influence of Jesus we find the greatest force tending to the improvement of the individual character and to the elevation of public opinion, and so to the evolution of mankind in desirable directions.

Improvement in social conditions, even though reached through improved education, generation after generation, rather than by advancing the innate qualities of the race, is of course a most worthy object for which to labor, and it is comforting to find that there is hope that such efforts may, in the course of thousands of years, improve also the innate fibre of the race through the effect which the advance of public opinion will have upon natural and sexual selection. To those who have faith in immortality, work for the improvement of the individual assumes added importance irrespective of its relation to evolution.

We have referred to the relative importance of sexual selection, choice in marriage, in the evolution of mankind. 
This point deserves practical emphasis. In choosing a wife a man is selecting the mother of his children as well as a companion for himself, and he should think as much and more of those qualities that tend to make a good mother as of those which will make an agreeable companion. A woman in accepting the responsibilities of marriage should look forward to her children's welfare and think as much of the father she is giving to her children as of the husband she is accepting for herself. I believe that love is the chief consideration, and that it would be a serious misfortune to have this relegated to the background, as it is among so many peoples. Fortunately this seems unlikely ever to occur in America. Yet all important as is love, the essential foundation in marriage, it is not the only thing. The welfare of the coming generation is bound up in the choices in marriage of the present generation, and this fact should never be forgotten. There are those who because of physical, intellectual, or moral disability should not be parents, and there is need of a general public sentiment which will recognize it as a $\sin$ against society for such to seek their own happiness in marriage when unable properly to meet the responsibilities of marriage, of which the bearing and rearing of children are a vital part. In spite of the sentiment in much of our poetry, our novels, and the drama that love is supreme and therefore all else should be sacrificed for it, it is really selfish and evil to regard only present happiness and forget the coming generation.

I believe that gradually this ideal of responsibility to the race will work its way more and more into the social mind, and a larger thoughtfulness before entering into marriage will result. It will come first in our great literature, but it 
will leaven all society in time. More strict statutory limitations upon marriage may ultimately be wise, but these will not now secure the desired result. This will be reached only through a larger general recognition of the responsibilities in marriage, and the worthiness and beauty of unselfishness here as everywhere else. Thus, in time, choice in marriage may do much to counteract the hurtful influence of having freed ourselves from the stress of the struggle for existence.

One good influence upon choice in marriage is being felt through a comparatively recent change in the lives of women, outdoor sports and outdoor life in general having become so much more popular. Riding, tennis, golf, the bicycle, bird study, nature observation, and the love of nature, all are tending to take more and more women into the open air. These things are perceptibly changing the ideas of what constitutes attractiveness in a woman. It is now somewhat the case, and seems likely to be more largely true, that the girl who, because of physical incapacity, cannot share in this vigorous, healthful, outcloor life, will be at a social disadvantage. This is but one way of saying that considerations of physical vigor will increasingly influence choice in marriage, and this, of course, will be for the welfare of the race.

It is interesting to think what might be the result if there were started a sect in which careful choice in marriage, under the advice of those most able to discern hereditary tendencies, should be regarded as a sacred obligation. looking toward an increasing perfection of the race in all respects, physical, intellectual, and moral. It would probably be easy thus to raise human stature to eight or nine feet or more, to very greatly increase muscular power and agility, to very largely do away with invalidism, to increase the mental capacity to an indefinite extent, and at first thought it would seem easy to 
secure a race with finer and firmer moral fibre. Yet there would be serious difficulties in the way. This, which is the logical goal of socialism, would be likely to mar the beauty of family life, which is dependent upon a peculiar mutual attraction between individuals, that cannot be dictated. The time may possibly come when individuals will so cordially recognize their responsibility for the advancement of the race that choice in marriage will look to the welfare of the race as a whole, rather than to that of the family, as the chief goal; but this will not come in our day or before there has been wrought in men a most far-reaching change in life ideals. We have reached the stage in which there is more or less general recognition of the fact that in marriage the welfare of the family rather than that of the individual should be sought by all inteliigent and right-minded persons; but it seems impossible that the welfare of the race can ever be secured at the sacrifice of the beauty of the family life; and it is a question whether the advancement of the race physically, intellectually, and morally, by choice in marriage, directed chiefly to that end, can be secured without lessening the beauty of family life. The elevation of general standards of opinion as to what constitutes attractireness in a man or woman, so that these shall include physical, intellectual, and moral soundness and beauty, will cause choice in marriage to operate for the perfection of the race along these lines, desire and duty combining to pro. mote the progress of the race. It is apparently hopeless to accomplish much in this direction by cultivating the sense of duty at the expense of love. A family founded upon the sense of duty and not upon love would not be the best soil in which to cultivate the most beautiful elements of character.

An objection might be made to the idea of evolution among men through the action of sexual selection similar to that which was made to the effectiveness of sexual selection among lower animals, - namely that, to secure evolution in the desired direction, public opinion must be so strong that few but those possessing the desirable qualities shall succeed in marrying, a condition of whose coming we see no present signs. But this objection is really without weight. If men of fine stamina, physically, intellectually, and morally, seek to marry and are accepted by women of similar character, their children will in the end predominate over the off- 
spring of the physically, intellectually, and morally weak, no matter how many of the latter may marry, or how large be their families. Comparatively few people are living to-day who will have any descendants a thousand years from now, and these are men of vigor and soundness, not only physically, but intellectually and especially morally, for nothing will more surely bring a line of descendants to its close than moral unsoundness. If the best among us should marry the best, and generation after generation keep the strain free from taint of weakness, real evolution in desirable directions would be much more rapid. We need a more wholesome ideal of character, so that we shall delight in real strength, delight in men and women who in each phase of their character have stamina and power. Strengthening this ideal and spreading it among men is the hope of evolution into larger manhood.

\section{SOME GENERAL CONSIDERATIONS}

In closing this discussion of evolution let us emphasize three general considerations. First, we should remember that natural selection, the great factor in erolution, produces adaptation to the conditions of the environment, and that this does not by any means always imply an advance in complexity of organization in plants and animals, or greater development of the mind in animals. On the contrary, degeneration, in the sense of simplification, often results from the action of natural selection. To make this point more vivid, let us look at an example of extreme degeneration, so far as complexity of structure is concerned, and see 
how, by its changed character, the animal in question is more perfectly adapted to the environment it has chosen, and is thus benefited.

Among the simpler Crustacea, in the same group with the common ship-barnacles and goose-barnacles, there is a genus of parasitic forms called Sacculina. These are frequently parasitic upon the common crab. When seen upon the crab they appear to be little more than soft bags full of eggs, and no one would suppose that they were in reality Crustacea and related to the crab itself (Plate Io , C. Sacc.). They show no hard outer covering, such as is seen in all normally developed Crustacea, and from which the group derives its name. They have no jointed legs as do other Crustacea. There is nothing in their adult anatomy to suggest that they are Crustacea. No one would think for a moment of so classifying them, were it not for their embryology, which clearly shows that they are descended from forms which closely resemble goose-barnacles. In the course of their embryology we see a larva, which is like that usually found in the Crustacia, the so-called Nauplizis (Plate Ior, $A$ ). This is followed by another stage in which we see the animal resembles Cypris, one of the Ostracoda, a group of lowly developed Crustacca (Plate Iо I, $B$ ). Soon the little Sacculina larva passes through this stage and comes to a higher condition when it is practically a little goose-barnacle. Now it leaves its independent, free-swimming life and becomes attached to a crab, or occasionally some other animal (Fig. 46, A). Living attached to the crab, as it does, the parasite has no use for legs or any locomotor organs, and these are cast off. Sense organs are not needed, and these are lost. There being no 

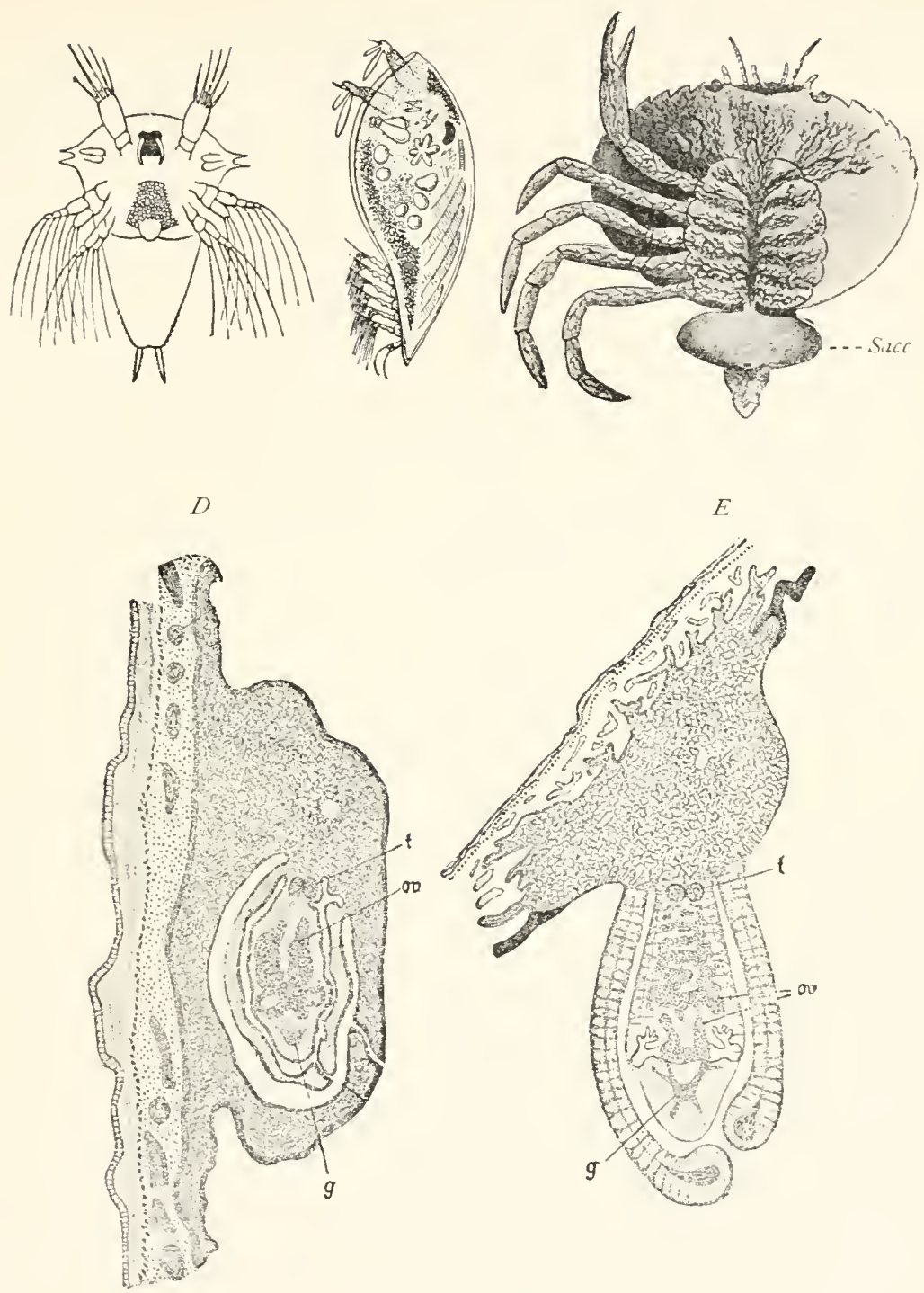

Pi.ATE IOI. - Sirculina.

A. Its nauplius larva, $B$. The Gipris stage in its development. C. The adult Sacculina parasitic upon a crab, to the under side of whose abdomen it is attached, and whose body is penetrated in all directions by the root-like processes of the sacculina. [From IIEIsM.N., alter DEI.ACF.] D. A larva which has crawled into the interior of the body of a crab wlaere it is rapidly growing as it feeds from the blood of the crab; it is now an almost shapeless mass of cells. E. A section through a mature sacculma. Most of its body has been pushed out from the inside of the crab and now protrudes to the exterior. There are no appendages or sense organs, and the nerrous system $(g)$ is greatly reduced. The body contains little but the ovaries (ov.) and testes (t.) fuli of eggs and spermatozoa. [After DELAGE.] 

sense organs and no muscles to be controlled, the useless nervous system becomes very much simplified (Fig. 46).

Apparently because of the protection thus afforded, the Sacculina penetrates now within the tissues of the crab, becoming an internal parasite instead of an external parasite as at first (Plate IOI, D). While thus parasitic it gets its food from the blood of the crab, which of course contains much digested food ready to be assimilated. As digested food is supplied for its use, the Sacculina has no need of
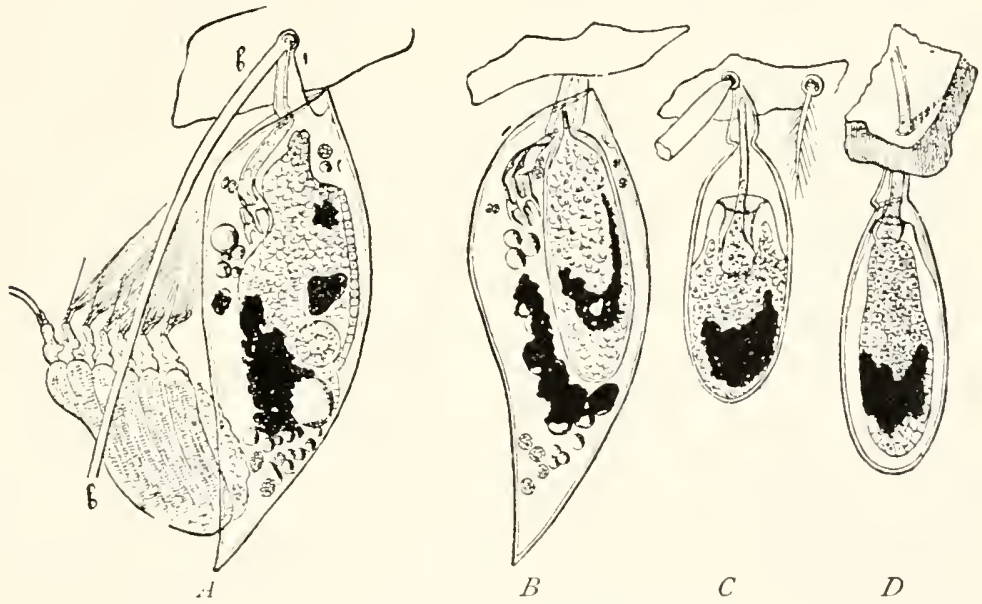

FIG. 46. - Development of Sacculina carcini.

A. Larva which has just become attached to the base of a hair $(b)$ on the surface of a crab. It is throwing off its legs and part of its body. $B, C, D$. Further stages in the degeneration of the Sacculina larva while attached to the outer surface of the crab.

digestive organs of its own, and consequently these disappear. Here, within the tissues of its host, relieved of all need of gathering or digesting its own food, and freed from the necessity of moving about from place to place by its own energy, it has an abundant amount of energy to devote to its growth and to the formation and maturing of its reproductive elements.

The Sacculina soon becomes little more than a bag of 
eggs and spermatozoa held together by a little soft tissue which surrounds these germ cells. In this condition, apparently to allow of its growth to still larger size, it begins to protrude from the body of the crab, becoming in the end a bag of considerable size held to the crab by root-like processes that penetrate through the shell and into the body of the crab, and take up nourishment from its blood (Plate Ior, E). Soon the Sacculina bursts and the eggs are set free, and each starts upon a new cycle of development similar to that described.

Life under the conditions of parasitism is very easy, and it is no wonder that many animals and plants have been adapted to such life. Since many organs essential to the welfare of self-dependent animals are useless to parasitic forms, we find that parasitism is usually associated with the loss of these useless organs; or, in other words, we can say that parasitism results in simplification. IVe have quoted an extreme instance of simplification. There are other cases of as great simplification of structure, but in most instances the degeneration is not so pronounced. Phenomena of degeneration, however, are not observed only in parasitic forms but are very general, and animals which as a whole are not degenerate, usually have some of their organs degenerate. In our own bodies are many such degenerate organs. (Skin muscles, except over the face; ear muscles, Plate 96; tail, coccyx, Plate 9I ; third eyelid, Plate 97; hair of body, Plate 93; vermiform appendix, Plate 96, $B$; and a hundred others.) Many phenomena of simplification are just as much the result of natural selection as are the phenomena of increasing complexity of structure. Natural selection brings about more perfect adaptation to the conditions of 
life, no matter whether this more perfect adaptation be secured through simplification or through elaboration.

Change in its conditions of life may render certain structures in an organism useless, so that natural selection will cease to keep the structures up to their former highly developed condition. Simplification may therefore be due either to cessation of the action of natural selection when an organ has become useless or to the direct action of natural selection in cases in which simplification is advantageous.

A second principle of great importance, and one we have already emphasized, is that natural selection secures the welfare of the species and not that of the individual, unless the welfare of the individual happens to be promoted by that which brings about the welfare of the species. Nature is socialistic, not individualistic, in the processes of evolution, and this statement applies to her relations to humankind as well as to her relations to plants and the lower animals. Those races whose ideals of life are such as to bring men into the most advantageous relations to their environment will in the end prevail. But, by the most advantageous relations to the environment, we mean such relations as will most effectively secure the perpetuation and increase in numbers of the race, and do not mean to imply any moral significance. It is interesting, however, to observe that nothing promotes the preservation and increase of mankind more than good morals, the foundation for which is, in great part, respect for the general welfare.

A third general consideration: There are two great factors in the processes of organic evolution, - first, the 
nature of the organism; and, second, the character of the environment and its relation to the organism. Of the latter, the character of the environment and its relation to the organism through the struggle for existence and in other ways, we know much. Of the intimate nature of the organism, however, we as yet know but little. We do not even know whether the life processes are conducted in accordance with the ordinary principles of chemistry and physics, or in conformity to some more subtle "vital" principles. There are many questions which we are unable to answer because we do not understand the intimate nature of living things. Are there inherent tendencies in the organism, leading it to evolve in certain directions rather than in others, as St. George Mivart contended, or is its evolution controlled by the needs created by the character of the environment? Such questions are as yet beyond our ken, and we have no present prospect of soon being able to answer them. It is possible that our knowledge of evolution may very materially advance when our knowledge of the life processes of living things becomes more intimate. 


\section{APPENDIX}

\section{A FEW BOOKS WHICH TREAT OF ORGANIC EVOLUTION}

AND PHENOMENA OF SPECIAL ADAPTATION

Darwix: The Origin of Species. Presents the theory of natural selection with a wealth of description of phenomena bearing upon it.

The Descent of Man. Treats especially sexual selection.

Wallace: Darwinism. Gives, on the whole, the best statement of natural selection; treats variation well ; is interesting in its criticism of sexual selection; suggests the use of colors for signals and recognition marks; does. not adequately treat segregation; claims that natural selection is insufficient to account for the evolution of the human mind.

Island Life. Gives a good statement of the phenomena of geographical distribution in their bearing upon evolution.

Romanes: Darwin and After Darain, three volumes. Vol. I, Natural and Sexual Selection and the natural phenomena which bear upon them ; very clearly stated, many good illustrations. Vol. II, Heredity and Utility : in part a discussion of the inheritance of parental modifications. Vol. III, Isolation and Physiological Selection : the best statement of the influence of segregation upon evolution.

Weismanx: Essays upon Heredity and Kindred Biological Problems. A very valuable and stimulating book in which is developed the theory of the continuity of the germ plasm and the non-inheritance of parental modifications.

The Germ Plasm. A fuller statement of Professor Weismann's theory of the continuity of the germ plasm: somewhat intricate.

Germinal Selection. Supplementary to The Germ Plasm.

Lectures on the Theory of Descent, translated by I. Arthur Thompson. ${ }^{1}$

1 This translation is expected to appear during the year 1904. The title of the translation has not been determined, but Professor Weismann writes it will probably be as stated. 
A summary of P'rofessor W'eismann's contributions to the theory of evolution, written for general readers as well as special students.

Huxiey: Man's Place in Nature. Giving comparisons between man and the apes.

Many of Huxley's essays deal with the theory of evolution, especially those collected in the two volumes Darriniand and Ezrolution and Ethics.

Lloví Morgan: Animal Life and Intelligenie and Animal Behaviour. Morgan is a very discriminating thinker in problems of heredity and evolution and his writings are very helpful as well as very reaclable.

Lubrock: The Origin of Cizilization, also a second volume, supplementary to this, entitled Prehistoric Times. Very interesting volumes, but by many regarded as unsound.

Westermarck: The History of Human Marriage. Largely a reply to Lubbock's Origin of Civilisation.

T. H. Morgan: Evolution and Adaptation. Contains an interesting criticism of the theory of sexual selection; gives a good statement of the theory of mutation; and attempts to minimize the importance of natural selection by advocating the belief that evolution may occur through mutation unaided by natural selection.

There are many books upon the theory of evolution, but those mentioned are perhaps as important as any for one who is not familiar with the subject. The author knows of no satisfactory presentation of evolution from the standpoint of those who believe in the inheritance of parental modifications. Cope's Origin of the Fittest is one of the most important books written from this standpoint, but it is very difficult reading, almost unintelligible in parts. Le CONTE's Eiolution and its Relution to Religious Thought is written from this point of view, but it is uncritical, assuming rather than discussing the inheritance of parental modifications.

There are also many books dealing with the phenomena of adaptation which have such an intimate relation to the theory of evolution. Coulter's Plant Life and JoRdan and Kellogg's Animal Life are written from the point of view of evolution, and are not only valuable for the information they convey, but are very readable and entertaining. KenNer's Natural Histor. of Plants, translated by Oliver, is a great storehouse of information as to special adaptations seen in plants. It is an expensive, four-volume work, but should be found in all libraries. Pountov's The Colors of Animals gives the best treatment of this interesting subject. Grant Allen's The Colours of Flowers suggests very interesting conceptions as to the evolution of the colors 
of blossoms. Its contentions are not fully admitted by botanists, but it is weil worth reading.

If any of the readers of this Ontline are interested to read further in regard to evolution, the author would suggest that Rosanes' Darain and After Damin, Vols. I and III, and Wallace's Daminism, followed by Weismany's Essat's upon Heredity, would probably be the best books to read first, and with these Coulter's Plant Life and Jordan and Kellogg's Animal Life. 



\section{NDEX}

(Italicized page numbers and plate numbers indicate illustrations of the subject mentioned.)

Abraxas glossularia, Pl. 70 .

Acquired characters, 67 .

Acree egina and gea, Pl. 77.

Acrecide, 132, 137, Pl. $76, P l .77$.

Acronycta alni and psi, Pl. 71 .

Actalia bipunctata, Pl. bo.

Adaptation, innate, 27; not explained by the theory of the inheritance of parental moditication, $7 \mathrm{~S}$.

Egialitis zocifera, Pl. \&2.

Agassiz's cave tish, 95 .

Aggressive coloration and resemblance, I25-

I27; mimicry, 145 .

Alaska, former mild climate of, 62, I1 2 .

Alchemy, Intro. ix.

Alste, 32, 36, 91, $\ell^{\prime} \% 21$.

Algiers, alluring color in lizard, I29.

Allen, Grant - colors of flowers, 162, I9o.

Allen, J. A. - variation in Florida birds, 9.

Alluring colors and resemblances, I27-1 29.

Altruism, 25, I76, ISo, ISz.

Anawris echeria and niavius, Pl. 76 .

Amazon Valley - buttertlies, $5 \mathrm{I}$; leaf-cutting ants and tree-hoppers, $137, \mathrm{Pl} .75$.

Amblystoma, tadpole, $g \&$.

"American Food and Game Fishes" (Jordan and Evermann), Pl. 48, Pl. 5 S.

Amaba, inheritance of parental modifications, 68 ; reproduction, 68 ; simple organization, $9 \mathbf{I}$.

Anatomy, comparative, $87,88-96$.

Ancon sheep - segregation, 65 .

"Animal Behaviour" (Lloyd Ilorgan), 190.

"Animal Life" (Jordan and Kellogg), 62, 95. 190, I9I.

"Animal Life and Intelligence" (Lloyd Morgan), 190.

Antarctic continent, former existence of, II $\mathbf{I}_{4}$.

Antelope, confusing coloration, I 4 S, Pl. $S_{I}$ : protective color, I20; signalling, I 46 , Pl. 81 .

Antlers - of deer, 106, $107, \mathrm{Pl} .43$; of elk - correlation with ligamentum nuche, 35.
Ants - antlike spiders, $137,138, \quad 145$; mimicked by tree-hoppers, I37, Pl. 75 ; unpalatable, 137.

Afatura iris. Pl. 56 .

Ape-related to Hominida, 163 ; ear of

Barbary ape, $P l$. 9f; nictitating mem-

brane, $P l .36$.

Apis mellifera, Pl. 7 .

Aplecta occulta, Pl. 55 .

Afocyrtus, $P .73$.

Appendis, vermiform, man and orang, I66. Pl. $q 6$.

Aptery, restigial wings, $94, \mathrm{Pl} 35$.

Arbutus, trailing. 7. 154 .

Archeopteryx lithographica, 109, Pl. 44.

Arctia caja, Pl. 7o, Pl. 71 .

Arctic fox, 126, 127.

Argus pheasant, $\mathrm{Pl} .27$.

Ariamnes attenuata, Pl. 6 .

Aristolochia sipho, $\mathbf{1 5} 8, \mathrm{Pl}$. go.

Artificial selection, 2S-3I.

Asexual reproduction and inheritance of parental modifications, $\boldsymbol{7} \mathbf{I}$.

Astia vittatu, var. nigra, Pl. 28.

"Astrolabe, Voyage de l'," I45.

Attacus atlus, $1+3$.

Attractiveness, criteria in choice in marriage, I $S_{1}$, I $S_{2}, I_{3}$.

Australasia - fauna, II 3 ; limits of fauna (nap), 115.

Avebury, Lord, color sense in insects, 159 et seq., I 90.

Bacterin, rate of increase, I4.

Bagworm, 21.

Baldwin, J. Nark, 27.

Bali - Lombok strait (map), 115 .

Barnacle gouse, $3,5:$ goose barnacle, $3,4,5$; sacculina, IS., 185. Pl. IOI.

Barriers to migration, I1 2 .

Basilarcha (Limenitis) disippus, $\mathbf{1}_{3} 8, \mathrm{Pl}$ 76.

Bastin, E. S., Pl. SS.

Bat - skeleton of wing, 92 . 
Bates, II. W. - butterflies of Amazon Valley, $5 \mathrm{I}$; convergelce in warning coloration, 134; terrifying attitude in caterpillar, 139.

Bear, polar, 126 .

liecldard, F. E., I25, I 27, Pl. 62.

Bee, carrying pollen, 57 ; color preference, 150, 162; evolution of instincts, 76 ; honey-bee, three types, 22; mimicked by flies, P.7t; mimicked by moths, $1 \% .70$; parasites, 146; protected by stings, 130 , 135; sacrifice of inclividuals for benefit of hive, 22; sterility of workers, 23; warning color, $130, \mathrm{Pl} .7 \%$.

Beetle, Colorado potato-beetle, 13I, Pl.69; color preference, 162: curculio, I34, P. 73; goldenrod-beetle, I3I; llercules beetle, 5I, Pl. 30 ; lady-beetle, I 3 I, 135, P. 69. P\%. 73; leaf beetle, 123; Pl. 62; mimiery, I 35, I 36, Pl. 73 ; sexual divergence, 51,52 ; staghorn beetle, 5I, Pl. 20: warning color, $13 \mathbf{I}$.

Behring Straits, migration across, 62, I 12.

lielt, moss insect, I 22, I'l. 6 I.

Biology, Intro. ix, $x$.

lird, confusing coloration, $\mathbf{I}_{4} 8$; females protectively colored, 50; gastrula, $\Gamma$. $f_{2}$; males serve as decoys, 50; mimicry, 144 , $P l$ So: noxious insects, I 30 ; protective color, i $8, I \%$. $79-5 I$ : recognition marks, $\mathbf{1 4 7 , P} 8.82$; segregation, 65 ; sexual coloration, 149, 150; sexual phenomena, 49-50; sexual selection, 53; skeleton, Q2, 110.

"Birds of Eastern North America, Handbook of" (Chapman), 49.

"Birds of New Guinea" (Gould), Pl. 25, P1. 26.

Birth-rate, I1, 12; relation to struggle for existence, 17 .

Blackbird, sexual coloration, I 50.

Blastomere, 7 o.

Blastopore, $\mathrm{HOH}, \mathrm{IO}_{2}, \mathrm{IO}_{3}, \mathrm{Pl} . \mathrm{f2}$.

Blind fish, 95 .

lilossoms, see Flowers.

Bluebird, sexual coloration, 150 .

Blue crab, $\mathrm{I} \%$ to

Bluefish, iा $8, M .+8$.

Boa constrictor, vestigial limbs, of.

lioar, correlation between tusks and bristles, 36.

liobolink, sexual coloration, I50, Pl. 22.

Boltun, Gambier, Pl. 68.

Bombus vancouzerensis, $\mathrm{Pl} .7$.
Bonasa umbellus, Pl. 23.

Borecole, I'. 6.

Bourru, friar-bird and oriole, I44, I 45.

Brassica oleracea, I\%. 5-S; rafus, M. O.

Breeting, in and in, 42; inethods used, 29; mice (Castle), 44; breeding-time and segregation, 43 .

lirehm, 4, 22, 31, I 33, Pl. 24, Pl. 30, Pl. 33, Pi. 62, Pl. 99.

Britcher, H. W., I37, Pl. 2, Pl. 64.

Britton, N. L., SS, 89, 90.

liroccoli, $\mathrm{Pl} .7, \mathrm{Pl}$. .

lironze, invention of, 176 .

Brown, Addison, 88, \$9, 90.

Brussels sprouts, $P l .7$.

Bufo lentiginosus, $1 \% 66$.

Bugs, noxious character and warning color, 1 $31,1 \% 69$.

Butomus umbellatus, Pl. 86.

Buttertly, color preference, 162 ; confusing coloration, I47, Pl. $\delta_{3}$ : courting, 55; leaf butterflies, I23, Pl. $\delta_{3}$ : mimicry, I37, Pl. 76, 1\%. 77; sexual coloration, $5 \mathrm{I}, \mathrm{Pl} .8_{7}$; warning color, $\mathbf{I}_{3} \mathbf{I}, \mathrm{Pl} .59, \mathrm{Pl}$. $76, \mathrm{Pl} .77, \mathrm{Pl} . \mathrm{s}_{4}$.

Cabbatre, varieties of, $29, P l .5-8$.

Calamesiu midama, 138, 150, Pl. 84.

Calanus arctifrons, $P \% .58$.

Calf embryo, $M .3 S$.

Callimortha dominula and hera, Pl. 70 .

Callinectes hastatus, Il. yo.

Callionymus ly'ra, I'. 32.

Calocalunus flumulosus and paz'o, 57 .

Calopteryx maculata, Pl. 33 .

Cambrian fossits, 106.

Cambridge, Pl. 64.

"Camera shots at Big Game" (Wallihan), PI. SI.

Cancer fagurus, 100.

Capital punishment, 25.

Carboniferous fossils, Io6.

Cardinal, scxual coloration, I 50.

Carrion flower, 154.

Castle, W. E., mendelian phenomena, 44.

Caterpillars, protective color, $P l .56$; terrifying at tit ude, $139,170,1 \%, 78$; warning color, $P l .7 \%$.

Catocala amatrix, I\%. 6o; concumbens, $\mathrm{M}$. $8_{3}$.

Cauliflower, $\mathrm{Pl} .7, \mathrm{Pl}$. S.

Cave-dwelling animals, eyes, 05 .

Cemophora cocinea, Pl. 79 . 
Ceram, friar bird and oriole, I4t.

Ceratophora stodilartii, Pl. 37 .

Cerebral hemispheres, man, I64, $P l .92$.

Cerura sinula, 140, Pl. 78 .

Cerr'us, antlers, $107, \mathrm{Pl}+73$.

Charocampa elpenor, 139. 170, Pl. $7^{8 .}$

Chameleo bifurcus and owenii, Pl.37.

Change, in environment makes evolution rapid, 26; of function in organs, 38 .

Chapman, Frank M., 49.

Chauliodes cornutus, Pl. 31 .

Chemistry, Intro. ix.

Chemistry, relation of life processes to, I 88.

Chickens, domestic, breeds of, 29, 30, Pl. 12-19; embryos, Pl. 38 ; reject noxious insects, I30; sexual coloration, 150, P\% $12-15$.

Chimpanzee, I64, I\%. 9I-97.

( hinese, segregation, I6S.

Choice in mating, 48 ; in marriage, ISo. See Sexual selection.

Chologaster, 95 .

Chordeiles a'irginianus, Pl. 82.

Christianity, effect on evolution, 179.

Cicadir septemdecim, 51, PI. 29.

Cidaria cucullata, Pl. 56; galiata and ocellata, $1 \% .55$.

Classification, SS.

Claus, C., Pl. +I.

Climate, cause of segregation, 61 ; of Alaska and siberia, 52 .

Cobra, imitated by moth, I42, 1.43 .

Coccinella, Pl. 73 .

Coccy.x, man and apes, . I64, I65, Il. 91 .

Cerostris mitralis. Pl. 6 f.

Colewort, varieties of, $P l .5-8$.

Colinus, airginianus, $\mathrm{Pl}+\mathrm{+q}$.

"College Botany" (Bastin), Pl. S8.

Colohorhombus fasciatipennis, Pl. 73 .

Color, adaptation in butterfly pupe, $121, P l$. 59; aggressive, 125-127; alluring, $127-$ I29; animals, II6-I5I; change, I2I, Pl. 58 ; clasification of color phenomena, II6; confusing, 147-I 49; convergence in warning color, 134 ; flowers, $15 \mathrm{I}-163$; insects and color of flowers, 159 et seq. : mimicry, I 35-I46; recognition nuarks, I 46-147; seasonal, I21, I26, $127, P \%$ 57; sexual, 52, I $49-15 \mathrm{I}$; signals, I $46-\mathbf{4} 47$; use and disuse and color of flowers, 75 ; warning, 1 29-1 34 .

Culorado potato-beetle, $13 \mathrm{I}, \mathrm{Pl} .69$.

"Colors of Animals, The" (Poulton), i 6 , I 39, I 90 .
"Colors of Flowers, The" (Grant Allen), I62, I63, I90.

Columba livia, 31, Pl. 20.

Community, length of life in communal animals, $2 \mathbf{1}$; unit in struggle for existence, 24.

Complexity, increases during growth of an organism, 96; in more recent fossils, I06; varying degrees of, 90, 97 .

Compositue, go.

Confu-ing coloration, I47-I $49, P \% \mathcal{S}_{3}$.

Convergence in warning coloration, 134 .

Cony, protective color, $1 \% 5 \%$

Cope, E. D., Pl. 46, 190.

Copepoda, 57 .

Coral polyp, gastrula, roz.

Correlation, of organs, $33,34,38$; between innate characters and attainments, $17 S$; between vigor and secondary sexual characters, $5 \mathrm{~s}$.

Corrus americunus, IIO.

Cotton-tail rabbit, confusing coloration, I $4 \mathrm{~S}$; protective culoration, Pl. 53: signals, I 46.

Coulter, J. MI., 190, I9I.

Courtship, bircls, 49, Pl. 23, Pl. 24, Pl. 27 : fish, 52, 150; Girco on relation of courtship to natural selection, 54; not observed in some forms which show divergence in secondary sexual characters, 56 ; observation difficult, 59 ; spiders, $50, \mathrm{Pl}$. 28.

Crab, 99, 100 ; blue crab, $P l$. fo ; protective color, I 20; sacculina parasitic upon crab. I $\$_{4}, P l .101$; which resembles a pebble, $124,126$.

Crawfish, nervous system, $\mathrm{Pl} . f_{0}$; protective color, 120.

Creation, Theory of Special, Intro. ix.

Cross-breeding swamps varieties, $4 \mathrm{I}$.

Cross-fertilization, 42, $153^{-1} 5^{8}, \mathrm{Pl}$. 88-9o.

Crustacea, development of higher, 98, Il. $39-71$ : pelagic crustacea transparent, II 7 ; protective color, 120.

Cryptolithodes sitchensis, 127 .

Ctenophores, transparency of, I I 7 .

Curculio, I35, Pl. 73 .

Curlew, protective color, II9.

Cycloptera, Pl. 62.

Cypris, I 4 .

Dahlia, varieties of, $29, \mathrm{Pl} . \mathrm{IO}, \mathrm{Pl} . \mathrm{II}$.

Daisy, marguerite - rate of increase, ${ }_{3} 3$.

Danaider, 132, 13S, Pl. 76, Pl. 84 . 
Danais architfus, $1_{3} 8, \mathrm{Pl} .76$; chrysifpus, P'. 76 .

Darwin, Charles, 47, 48, 52, I\$9, I'l. 32, Pl. 95.

"Darwin and after Darwin" (Romanes), I05, I 89 , I9I, I'l. I 7, Pl. 36, Pl. 37, Pl. 44, Pl. 75, Pl. 93-97, Pl. 99.

"Larwiniana" (Huxley), I 90.

"Darwinism” (Wallace), 35, 132, I44, I \$9, 19 I.

Dasychira pulibunda, Pl. 55 .

Datana ministra, $1 \% 75$.

Dean, Forest of, segregation of deer in, 65 .

Death, at close of reproductive period, 20 , 22, 23, 24; bagworm moth, 2I ; capital punishment, 25 : causes, 14 ; drone bees and young queen bees, 22, 23 ; of individual for general welfare, 20-25; rate, I 2.

Decapola, development of, $98, P l .39-7 I$.

Decoy, male birds serve as, 50 .

Deer, antlers, 106, 107, $\mathrm{Pl}+3$; protective color, I 20; secondary sexual characters, 53 ; segregation, 65 ; signals, 146.

Degeneration, $\mathbf{I} \delta_{3}-\mathbf{I} \$_{7}$.

Delage, Yves, Pl. IoI.

"Descent, Lectures on the Theory of" (Weismann), I 89.

"Descent of Man" (Darwin), 52, I $\$ 9$.

Deterioration due to escape from struggle for existence, I $7 \mathrm{O}$; due to parasitism, I 84 et seq.

Devonian fossils, Io6.

De Vries, Hugo - mutation, I8, 19, 39.

Dianthacia compta, I'l. 55 .

Diapheromera femorata, Pl. 61 .

Diatoms, skeletons of, 32, Pl. 21 .

Dimorphism, in flowers of Mitchella, 156, Pl. 8S; sexual, see Sexual selection.

Discontinuous variation, 19 .

Disease, I69, I 7 I.

Dismal Swamp fish, 95.

Dismorphia astynome, Pl. 77 .

Dissosteira carolina, $\mathrm{Pl} . \mathrm{S}_{3}$.

Distribution, gengraphical, $8_{7}$, I I I-I I 6 .

Divergence, degree of, in variation, 9 ; from species type, an advantage in struggle for existence, 26; in relation to Mendelian phenomena, 46 ; sexual, see Sexual selection; swamped by cross-breeding, 4 I.

Dog, mating, 48 ; skeleton of forc limb, 92.

Dolichonyx oryiziorus, Pl. 22.

Doliops sp. and D. curculionides, Fi. 73 .
Doryphora decemlineata, I'.60.

Uragon-fly, $\mathrm{I} \% 31, \mathrm{I} .33$.

Drone-fly, imitates bee, $136,1 \% .74$.

Drouth as cause of segregation, 43 .

Dugmore, A. K., Pl. 4 S, Pl. 5O, Pl. 58.

Dugong, nictitating membrane, $P l .36$.

Dynastes hercules, 5 I, Pl. 30 .

Eagle - nictitating membrane, $P .36$.

Ear, change of function, 39 ; man and apes. 165, Pl. 9.7-96; vestigial muscles of human, 94, 95 .

Education (plasticity), 27 ; susceptibility to, hinclers Evolution, 177 .

Egypt, I 75 .

Elaps, 142, Pl. 79 .

Elephant hawk moth, $139,170, P l .78$.

Elk - correlation between antlers and ligamentum nuthe, 35 .

Elymnias phegrea, Pl. 77 .

Embryology, comparative, $\mathrm{S}_{7}, 96-\mathrm{IO}_{3}$; of higher crustacea, $\mathrm{S9}, \mathrm{Pl} .39-41$; of man, I66, Pl. $9 S$; of vertebrates, 97, Pl. $3 S$, Pl. $Q S$.

Emylia jacobea, Pl. 70 .

Environment, and nature of organism. I 88 ; change in - makes evolution rapid, 26 ; inheritance of direct effects of, 72 ; nature of man's, I 72 .

Epeira prompta and stellata, Pl. 64.

Epilotizum hirsutum, I39.

Epipactys latifolia, Pl. So.

Equits, Pl. 77 .

Eriopus purpureofasciata, $\mathrm{Pl} .55$.

Eristalis tenax, $\mathrm{Pl} .77$.

Erythrolamprus esculapii and renustissimus, $1 \% 79$.

"Essays upon Heredity and Kindred Biological Problems" (Weismann), I89, I9I.

Euchistus serv'us, Pl. 60.

Euplaa midamus, I $_{3}$, I50, Pl. 84.

Evermann, Barton G., Pl. 48 , Pl. 58 .

"Evolution and Adaptation" (Morgan), 190.

“Evolution and Ethics” (Huxley), rgo.

"Evolution and its Relation to Religious Thought" (Le Conte), 190.

Extirpation of organs, effects of, 34 .

Eye, deterioration of human, 170 ; of cavedwelling animals, 95; of various vertebrates, $P l .97$.

Factors in evolution, Intro. xi, $82, \mathbf{I} 88$.

Family, 24, I82.

Faroe Islands, segregation of sheep, 65 . 
Faunas and floras, I I 2, II3.

Felis tigris and onca, Pl. 68 .

Fertilization, cause of variation, $8 \mathbf{I}$; cross and self, 42; of flowering plants, 152163 ; by wind, 153 ; by insects, 154 et seq.

Fescue-grass, $153, P l .87$.

Field sparrow, $P l .19$, I 26.

Fish, birth-rate, I 2: blind fish, 95 : bluefish,

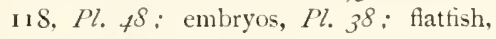
II $8, P l .4 S$; Protective coloration, II $S$, Pl. 48 ; sexual coloration, 52, 150 ; sexual divergence, $\mathrm{Pl} .32$.

Flatfish, II $8, P l . \neq S$.

Flies, drone-fly, mimics bee, 136, Pl. 7f; fertilization of Aristolochia, $\mathbf{I}_{5} 8$; fertilization of white flowers, I62; mimicry of bees and wasps, $135, \mathrm{Pl} .74$.

Flora, I I 2, I 13.

"Florida, On the Mammals and Birds of East" (Allen, J. A.), 9.

Flounder, protective color, $\mathrm{Pl} .48$.

Flower, W. H., 94, Pl. 44, Pl. 68, Pl. 72.

Flowers, diagrams of various, $P$ l. $\$ 6$ : insect visitors, I62; landing place for insects, 163, Pl. $89, \mathrm{Pl}$. 90 ; of .tristolochia, 158 , Pl. go; of Mitchella, 156, Pl. S8; of orchid, 156, Pl. 8o, Pl. go; of Salvia, $157, P l .89$; of wind-fertilized plants, 153 .

Forbes, H. O., I 27, I 44, I 45 .

Fossils, conditions for the formation and preservation of, $\mathrm{IO}_{4}$; table of fossiliferous rocks, I05; marsupials of America, $\mathbf{I}_{3}$.

Fowl, see Chickens.

Fox, aggressive coloration, I26; Arctic, I26, 127 ; segregation, 60.

Fox, Rev. W. D., mating of Chinese geese, 48.

Friar-bird, I44, Pl. 80 .

Frog, aggressive color, I 26; gastrula, $P l .72$; noxious insects, I 30 ; protective color, $\mathbf{I} 20$.

Gagea lutea, Pl. S6.

Galapagos Islands, segregation of locusts, $60,62$.

Galeus, nictitating membrane, $\mathrm{Pl} .36$.

Galileo, Intro. ix.

Game cock, evolution of, Pl. 16 .

Gastrula, coral polyp, 102 ; various animals, IO3; vertebrates, I02, Pl. 12.

Gazelle, white rump patch, 146.

General considerations, I $\$_{3}-\mathbf{I} \$ 8$.

General principles in operation of natural selection, 20 .

Geographical distribution, 87 , 1 1 1-1 I6.
Gerarde, 5.

Germ cells, 69; and variation, 79; nutrition of, So.

Germinal selection, 96 .

"Germinal Selection" (Weismann), I89.

"Germ Plasm, The" (Weismann), I\$9.

Giblon, 164, Pl. 91 .

Giesbrecht, 57 .

Gila monster (lizard), I33, Pl. 72.

Giraldus, Sylvester, 3.

Goat, protective color in wild, 120.

Goldfinch, American, sexual coloration, 150.

Goodale, William, Pl. SS.

Goose, barnacle, 3, 4, 5; mating of white and Chinese, 48 ; rariation slight, $S$.

Gorilla, I6.4, Pl. QI, Pl. q2.

Gould, Pl. 25, Pl. So.

Government, progress in, 176.

Grackle, sexual coloration, i 50.

Grapta, $\mathrm{Pl} . \delta_{3}$.

Grass, fertilization, 153 .

Grasshopper, confusing coloration, 147, Pl. $8_{3}$; leaf, I $23, \mathrm{Pl}$. 62; mimicking beetles, I 35, Pl. 73 .

Grass Porgy, I $21, \mathrm{Pl}_{5} 5^{8}$.

Gravitation, Intro. ix.

Gray's "Anatomy," 95, Pl. 96.

Greeks, 176 ; conception of origin of animals from plants, 3, 6 .

Greenland whale, skeleton, 9.7 .

Grip, strength of, of human infant, I66, Pl. 100 .

Groos, courtship, 54, 57.

Grouse, birth-rate, I2; ruffed grouse, II 8 , Pl. 23 ; snow grouse, 1 $21, P \% .57$.

Gulick, John T., segregation of land snails of Oahu, 63,64 .

Habrocestum howardii, Pl. 2S: splendens, Pl. 85.

Haeckel, Ernst, I02, Pl. 21, Pl. 3 S, Pl. 98.

Hair, change of function, $3 S$; of man and ape, $94,164, \mathrm{Pl} .37, \mathrm{Pl} .93$.

"Handbook of Birds of Eastern North America" (Chapman), 49.

Haswell, W. A., Pl. 44 .

Hawaiian Islands, segregation in land snails, 63.

Hawk moth, elephant, I39, $170, \mathrm{Pl} .78$.

II ayes, Pl. 4.

Heart, change of function, $3^{S}$.

Hebomoia glaucippe, Pl. $8_{3}$.

Helianthemum marifolium, 152 .

Helicunidix, $132, \mathrm{Pl} .77$. 
Heliconius eucrate, $P l .77$.

Heloderma horridum, I'l. 72.

Hemiptera, warning color and shape, I3I, P. 60 .

"I Herball, The" (Gerarde), 5.

I ercules beetle, $5 \mathrm{I}, \mathrm{Pl}$. 30 .

Heredity, 3, IO, IS; inheritance of parental modifications, $67,68,175$.

" Heredity and Kindred Hiological Problems, Essays upon" (Weismann), IS9, I 9 I.

"1leredity and Utility" (Komanes), I S9.

Herrick, F. H., I'l. 4 I.

Ilesperidie, I 28.

Ilesperornis regalis, 109, Pl. $\$ 5$.

Hestia, I 27.

Heterocampa biundata, Pl. 56 .

Heterocampa pulzerea, Pl. 55 .

Hifpiscus tuberculatus, P'. 83 .

IHphocampus mohnikei, I27.

Ihppodamia convergens, Pl. 60 .

I Iog, embryos, $P l .3 S$.

Homarus americanus, Pl. 39, Pl. ${ }^{I}$.

Homer, I 76 .

Hominidie, I64.

Homology, 92, 93, 10 .

Ilomoptern, - mimicking ants, 137, Pl. 75 ; elusa, $P \% .5$.

Iloney-bee, 22, 23.

Ifoneysucker, imitated by oriole, $144, \mathrm{Pl} .80$.

Hornet, I 30, I 35, P. 7 .

Horse, breeds of, $28, \mathrm{P} . \mathrm{f}$; correlation between hair and hoofs, 36 ; evolution of feet and teeth. I09, Pl.; $, \mathrm{Pl}, \mathrm{f}_{7}$ : gradwal change in horse family, 4o; nictitating membrane, $P$. 36 ; segregation in Paraguay, 65.

"IIorse, Points of the" (Hayes), Pl. 4.

Human evolution, I $6_{3}-18_{3}$; how controlled, I 79, I83; sexual selection, I68, I69, I72, I 73, I 75. I 78, I $79-$ I $_{3}$.

I Iumming-bird, - nest, $P l$. $5 I$; sexual coloration, I 50, $1 \% .26$.

I Iuxley, T. II., I00, I 90, Pl. 40, Pl. 9 I, Pl. 92.

Hydra, $r O r$.

Ilila r'ersicolor, Pl. 66.

Itymenoptera, mimicked by other insects and spiders, $135,136,137,138$ : peculiar form, I 3 I ; protected by stings, I 30, I 36 ; warning color, $130, P l .73, P l .74$.

IV'menopus bicornis, ras.

Ichthyornis wictor, I09, Pl. 75 .

Chthyura inclusa, var. intersa, Pl. 55.
Icius mitratus, Pl. 28 .

Immortality, I 79 .

Improvement of human race, I 73.

In-breeding, 42.

Indians, North American, measles, I 7 I.

Indigo-bird, sexual coloration, I 50.

Individual sacrificed for welfare of species, $20, \mathrm{IS}_{7}$.

Infant, human - foot position, I 66, P. 100 ; spinal curve, I66, $\%$. 99; strength of grip, I66, P. 100 .

Infertility, domestic races not infertile when crossed, 3I; of crosses between species, 3I; of hybrids, 3I; starting-point in evolution, 32 .

Inherent tendency, in variation, 40; in evolution, ISS.

Inheritance of parental modifications, Intro. xi, 67,175 .

Injury - effects of - inherited among unicellular organisms, 69.

Innate adaptation $z^{\prime}$. acquired adaptation, 27: character vs. training, 127 et seq.

Ino pruni and statices, Pl. 70 .

Insects, and color of flowers, I 5 I et seq.; and plant fertilization, I 54 et seq.; protective color, I 20.

Instinct, 39 .

Internal factors in evolution, I $S S$.

Invalidism, I 70, I 72, ISI.

Inventive genius, 176 .

"Ireland, Relations concerning" (Giral(lus), 3 .

Island faunas and floras, I I 2.

"Island Life" (Wallace), IS9.

Isolation, see Segregation.

"Isolation and Physiological Selection" (Komanes), I S9.

Jack-rabbit, confusing coloration, $\mathbf{I}_{4} \mathrm{~S}$.

Jaguar - aggressive coloration, I 27, Pl. 69. Jamaica-Neritina, 10.

Java-spider which resembles bird excrement, I 27.

Jellyfish, mouth, IOI ; transparency, I I 7 .

Jenner, I 7 I.

Jesus, influence upon evolution, I 79.

Job, 176 .

Jordan, D. S., 62, 95, I 24, I 90, I 9I, Pl. 4 S, Pl. 5 S.

Juncus bufonius, seedpods imitated by a spicler, $124, P \% 67$.

Jungle-fowl, 29, I 19, $P$. 16 .

Junonia, $P$. $S_{3}$. 
Kale, Pl. 6, Pl. S.

Kallima inachis, $\mathrm{I}_{23}, \mathbf{1} 47, \mathrm{Pl} .83$.

Kangaroo rat, confusing coloration, ${ }_{4} 8$.

Kappel and Kirby, Pl. 70, I'l. 7I, I'l. 76 , Pl. 7 S.

Kellogg, V. L., 62, 95, I90, I9I.

Kepler, Intro. ix.

Kerner, A., I 52, 158, 190, Pl. S6, Pl. S9.

Killdeer, recognition marks, ${ }_{477}, \mathrm{Pl}$.82.

Kirby, see Kappel.

Kohlrabi, $\mathrm{Il} .7, \mathrm{Pl} .8$.

Lady-beetle, noxious character and warning coloration, I3I, 135. Pl. 69, Pl. 73.

Lagopus leucurus, Pl. 57 .

Landing-place for insects in plant blossoms, I $63,1 \% .89, \mathrm{Pl} .90$.

Lang, Amold, PI. 4 I.

Larve, transparency of marine, is

Leaf-cutting ants, mimiched by tree-hoppers, $137,1 \% .75$.

Leaf-like insects, 122, $123, \mathrm{Pl} .56, \mathrm{Pl} .62$. $P l . s_{3}$.

Le Conte, Joseph, I9o.

"Lectures on the Theory of Descent" (Weismann), I 89 .

Lemur, I63.

Lepas a natifera, 7 .

Iereania l-album, Pl. 55.

Leucoma salacis, $P l .7 I$.

Lever, invention of, 176 .

Life, length of, 20, 23, 24; processes, chemistry and physics, 1 SS.

Limenitis (Basilurcha) disippus, I3 $_{3} \mathrm{Pl}$. 76; sibylla, Pl. 56, Pl. 76; populi, Pl. 78 .

Lion, aggressive color, I26; secondary sexual characters, 53 .

Lizard, aggressive coloration, I 26, Pl. 52: alluring coloration, I29; confusing coloration, I 49; gila, I33, Pl. 72: protective coloration, I 20, Pl. 52: rejects noxious insects, I 30 ; sexual coloration, I 50 ; sexual divergence, $P l .34$.

Lobster, 98, I 20, $\mathrm{Pl} .39-7 \mathrm{I}$.

Locust - Cialapagos Islands, 62; leaf, 122, Pl. 62.

logoa, $123, \mathrm{Pl} .63$.

Lophornis adorabilis, Pl. 26.

Love, foundation in marriage, $\mathbf{I} 80$.

I.ow, Professor, mating of domestic animals, 48.

Lubbock, Juhn, see Lord Avebury.

Lucanus dama, Pl. 29.
Lungs, change of function, 3 S.

Lycorea halii, 1 l. 77.

Lydekker, Richard, Pl. 6S, Pl. 72.

Lymnizus, development of, 97.

Lyre bird, Pl. 2t.

McCook, H. C., Pl. 75.

Macroglossa bombyliformis and stellatarum, Pl. 70 .

Mammalia, development, $97, P / .38$; fossils, 105, 106.

"Nammals and Winter Iirels of East Florida, On the" (Allen), 9.

Nammoth Cave, bind animals in, 95 .

Nan, embryos, $P \%$. $3 \&$ : evolution, $16_{3}-1 \delta_{3}$; nictitating membrane, $P \% 36$ : one species, 163; plasticity, 28, I77; sexual selection, 168, 169, 172, 173, 175, 178, I79-I $8_{3}$; skeleton of am, 92 ; slow evolution, I75; social progress $z^{\prime}$ s. evolution, 173.

"Nan's Place in Nature" (IIuxley), Igo.

Mantis, alluring color and form, 127, 128 ; leaf mantis, I23, I26, P7. 62 .

Marguerite daisy, rate of increase, I 3 .

Harptusa familiaris, M. $2 S$.

Marriage, human, I68; choice in, see Man, sexual selection; laws, ISI; responsibility in, I So.

"Narriage, The History of I Iuman" (Westermarck), I9o.

Narsh, O. C., Pl. 45, Pl. 47.

Marshall, A. M., I'l. 42.

Marsupialia, geographical distribution, I 13.

Nating, preferential, see Sexual selection.

Mean, species, I 9 .

Measles, among savage races, I7I.

Mechanitis lysimnia, Pl. 77.

Megilla maculatu, Pl. 60.

Melinita ethra, Pl. 77.

Melitara cinxia, $\mathrm{Pl}$. 7 I.

Mendel, 4o. 44 .

Menura superba. Pl. 24.

Mephitis mephitiar, Pl. 72.

Nerriam, C. Ilart, I47, 148 .

Mesohippus, $\mathrm{Pl} .77$.

Mice, Mendelian phenomena, 44 .

Migration, 64.

Mimicry, aggressive, I45, I46; conditions fulfilled in, I45; in insects. I35, I 37, Pl. $70 . \mathrm{Pl} .73, \mathrm{Pl} .7+, \mathrm{Pl} .76, \mathrm{Pl} .77$; in snakes, $142, I_{4}, P \%$. 97 ; protective, 135I 45 . 
Mind, 39; development of human, 167; training of human, I 7 S.

Miohifpus, $\mathrm{Pl}+7 \mathrm{7}$.

Misumena vatia, Pl. 75 .

Mitchella repens, $156,1 \% .88$.

Mivart, St. George, I $\$ S$.

Modification, inheritance of parental, $67-\$ 2$, $175 \mathrm{et}$ seq.

Monaxenia darwinii, ro2.

Monkey, ears, 165; reject noxious insects, I 30 ; relationship to man, I63.

Moral character, effect on evolution, I 87 ; growth in innate, 176; improvement through sexual selection, I $\$ \mathbf{2}$; training of, 177,178 .

Morgan, Lloyd, 27, 47, 48, 65, 130, 190.

Morgan, T. H., 57, 59, 190.

Mormolyce phylloides, Pl. 62.

Moss insect, 122, Pl. 6I.

Moths, confusing coloration, I47, $\mathrm{Pl} .83$; elephant hawk, I39, $140, P l .78$; leaf, 123, $\mathrm{Pl} . \delta_{3} ;$ mimicry, I $36, \mathbf{1}_{4} 2, I_{43}$, Pl. 7o, Pl. 79 ; protective color, $\mathrm{Pl}$. 5\%, $P l .55$; sexual coloration, $P l .87$; terrifying attitude, $17^{2}$; warning color, 132 , Pl. 70 ; waved-yellow, $\mathrm{I}_{23}, \mathrm{Pl} .63$.

Murray, Sir Robert, 5.

Muscles, of human ear, 94, I65, Pl. 96 ; of human skin, 94; vestigial - of tail in man, 165, Pl. 95 .

Mutation, IS-20, 39, 190.

Mydas claz'atus, $1 \%$. 74 .

Mygnimia aviculus, Pl. 73 .

Mysis stage in development of lobster, $P$. $f^{\prime}$; stenolefis, 99, Pl. fI. .

Nascent organs, IOI.

"Natural History of Plants, The" (Kerner), I 5 S, 190.

Natural selection, 3-47, Intro. xi; man, I6S, I 69; sacrifices individual for welfare of race, I 70 .

"Naturalist's Wanderings in the Eastern Archipelago, A" (Forbes), I 27.

"Natiirliche Schöpfungsgeschichte" (Haeckel), Pl. 2 I.

Nauplius, 184, Pl. ror.

Nectar, 154, 155, 163 .

Negro, segregation, I68.

Nerice bidentata, Pl. 56 .

Neritina virginea, var. minor, Frontispiece, 9.

Nesocentor milo, Pl. 25.

New Forest - segregation of sheep, 65 .
"New Guinea, Birds of" (Gould), Pl. 25, I'l. 26. I'l. So.

New Jersey scrub pine, $P l .87$.

Newton, Intro. ix.

Nictitating membrane, 94, 166, Pl. 36, Pl. 97.

Nighthawk, 147, Pl.5I, Pl. 82 .

Nutrition of germ cells, 68 .

Nymphalida, Pl. 77 .

Oahu - land shells, 63; map, 6.4.

Objections to natural selection, $3 \mathbf{I}-47$; to sexual selection, 56-60.

Odor of warning-colored butterflies, I32; of flowers, 154.

Enothera lamarckiana, IS.

Ophibolus doliatus, Pl. 79 .

Opossum - geographical distribution, I 13 .

Orang, 164, Pl. Q1, Pl. 9.7-Q6.

Orchid - cross-fertilization, $156, \mathrm{Pl} .89$.

Orchis militaris, Pl. go.

Orgya antiqun, Pl. $7 I$.

Origin of animals from plants, 3 .

"Origin of Civilization, The" (Lubbock), 190.

"Origin of Species, The" (Darwin), Intro. $\mathrm{x}, \mathrm{I} 89$.

"Origin of the Fittest, The" (Cope) 190.

Oriole, mimicry, 144, Pl. So; sexual coloration, 150.

Oriolus decipiens, Pl. So.

Ornithoptera (Pupilio) priamus, 150, Pl. 8 . Orohifpus, $1 \%+7$.

Ostracoda, I $S_{4}$.

Otaria, Pl. 36 .

Outdoor life and sexual selection, I $\$ \mathbf{I}$.

Owl, nictitating membrane, $P \% 36$; snowy, 126.

Oxyrrhopus trigeminus, $\mathrm{Pl} .79$.

Pachyrhynchus, Pl. 73 .

P'ackard, A. S., Pl. 55, Pl. 7 S.

Paleontology, $8_{7}$, IO3-1 $_{3}$ I.

Palms, fertilization, 153 .

Paludestrina frotea, Pl. 3 .

Paludina, fossil shells, Io7, 108 .

Panolis piniperda, Pl. 56 .

Panthia canobita, Pl. 55 .

Papilio machaon, Pl. $7^{I}$; merope, Pl. $7^{6}$; mimicry, ${ }_{3} \mathrm{~S}$; priamus, $\mathrm{Pl}$. 84; ridleyanus, $P$. 77 .

Papilionidae, 132, Pl. 76 .

Paradise, bird of, sexual coloration, 150.

Paraguay, segregation of wild horses, 65 .

Paralichthy's dentata, Pl. $7^{8}$. 
Parasitism, bee parasites, 146 ; effects of, IS6; sacalina, IS3.

Parental care and length of life, 20.

Parental modifications, inheritance of, $\sigma_{7}$, $68,175$.

Parker, T. J., Pl. 44.

Parnassius apollo, Pl. 7 I.

Parrot, protective color, 119.

I'artridge berry, 156, Pl. 88 .

Peacock, sexual coloration, 150.

Peckham, G. W. and E. G., spiders, sexual selection and sexual divergence, $55, \mathrm{Pl}$. 28, Pl. 67; wasps, breeding habits, 77; wasps, color sense, $\mathbf{1 6} \mathbf{I}$.

Pelagic animals, transparent, $\mathbf{1}_{\mathbf{7}} 7$.

Pelvis, man and apes, $164, \mathrm{Pl}$. $\mathrm{Qr}$.

Perluybris pyrrlac, Pl. 77 .

Permian fossils, го6.

Phanerogamia, 92.

Pheasant, Argus, 150, Pl. 27; protective color, IIs.

"Pheasants" (Tegetmeier), Pl. 24.

Phenacodus, 109, Pl. 76.

Phidipfus cardinalis, Pl. 85 .

Plailemon plumegenis, Pl. So.

Plhilohela minor, Pl. 50.

Mhloganas jobiensis, Pl. 25.

Ihrenicians, 175.

Phoraspis, Pl. 73 .

Phorodesmia smargdaria, Pl. 55 .

Phyllium Siccifolium, Pl. 62.

Phyllodes verhuellis, $\mathrm{Pl} . \mathrm{S}_{3}$.

Physics and life processes, 188.

Physiological selection and segregation, 66, 189.

Phytolacca decandra, Pl. 86 .

Pieriche, 132, Pl. 59 .

Pieris brassice, Pl. 56 ; rapa, color adaptation in pupe, 121, Pl. 59 .

Pigeon, Plaloganas, Pl. 25: rock, 31, Pl. 20: varieties of domestic, $30, P l .20$.

Pika, protective color, $\mathrm{Pl} .5 \%$.

Pine, $1_{53}, \mathrm{Pl} .8_{7}$.

Pinus inops, $\mathrm{Pl} .87$.

"Plant Life" (Coulter), I90, I9I.

Plasticity, 27, 28; of man, hinders evolution, 177 .

"Play of Animals, The" (Groos). 54.

Plica semilunaris, see Nictitating membrane.

Pliocercus elapsides and eury $\approx 0$ nus, Pl. 79.

Pliohippus, $\mathrm{Pl} .77$.

Plover, ring-necked, Pl. 82.

Polar-bear, aggressive color, 126 .

Polish fowl, skull, 30 .
Polistes, breeding habits, 77 .

Pollen, food of insects, 154; masses of orchid, $156, P l .89$; slow to sprout on stigma of same plant, 155; tube, 152, $153,156$.

Pomatomus saltatrix, $\mathrm{Pl} . \mathrm{f}^{\mathrm{S}}$.

Pompilus atrox, $\mathrm{Pl} .77$.

Pond snail, development, 97 .

Porgy, change of color in grass, 121, $\mathrm{Pl} . \mathrm{j}^{\mathrm{S}}$.

Potato beetle, I 3 I , $\% 69$.

Poulton, E. B., 116, 139, 190, P. 59.

"Poultry, New Book of" (Wright), 30, Pl. 16, PI. 18.

"Prehistoric Times" (Lubbock), 190.

Primates, I6 3 , I64.

F'rimulacé, 90.

Principle, general principles in operation of natural selection, 20.

Prionotus cristatus, Pl. bo.

Progress of human race, 173 .

P'rotective coloration and resemblance, II 6 , I $17-125$.

Protohifpus, Pl. 77 .

Providence, Intro. ix.

Psezudacréa boisduz'alii, Pl. 77 .

Psilura monacha, Pl. 56 .

Psyche, unicolor, Pl. 56.

Ptarmigan, seasonal color change, 121, Pl. 57.

Plerodactylus spectabilis, Pl. 75 .

Pterogon proserfina, Pl. 70.

Plerophryne histrio, 124, 126, Pl. 65.

I'ublic Opinion, a part of man's environment, 172, 179.

Pupa, color adaptation, I2 I, Pl. 59; Logoa, $123, P l .63$; protective color, $P$. 56 .

Putorius ermineus, $\mathrm{Pl} . \mathrm{b}_{7}$.

()uail, protective color, i IS, Pl. 79 .

Rabbit, confusing coloration, 148 ; embryos, Pl. 38 ; illustration of mutation, 19; illustration of natural selection, 15 ; protective coloration not explicable by the inheritance of effects of use and disuse, 75: signal, white rump patch, Iff.

Radiolaria, skeletons, Pl. $2 I$.

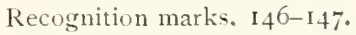

Regeneration and inheritance of parental modification, $7 \mathrm{I}$.

Relationship, key to classification, 9I.

"Relations concerning Ireland" (Giraldus), 3 .

Religion, a cause of segregation, 169. 
Reproduction, among unicellular organisms, 68,69 ; and length of life, 20, 22, 23, 24; asexual, and inheritance of parental modifications, 71; birth-rate, I1, I2 ; easily disturbed, 66 ; effects of destroying organs of, 34 ; evolution centres in, $\$ 2$; germ cells in higher organisms, 69; increase in, aids in struggrle for existence, 17; organs of, in flowering plants, 152 , I53, Pl. 86 ; regeneration of organs, $7 \mathrm{I}$.

king-necked plover, recognition marks, $P$. 83.

Robin, illustration of species, SS; rate of increase, $1 \mathrm{I}$; sexual coloration, $15 \mathrm{O}$.

Robinson, Louis, Pl. Ioo.

Rock-rose, 152.

Rocky Mountains, cause of segregation, 6I. Romanes, C. J., I 7, 94, I05, I89, I91, Pl. I 7 , Pl. 36-3S, Pl. 43, Pl. 44, Pl. 75, Pl. 93-99; sexual selection in birds, 53 ; physiological selection, 66 .

Rosacer, 90.

Rostellum of orchid, I $56, \mathrm{Pl} .89$.

Royal society of london, goose barnacle, 5 . Ruffed grouse, $\mathrm{Pl} .23$.

"Ruth," I 76.

Saculina, I $\delta_{4}, 18_{5}, \mathrm{Pl} .101$.

Sacrum, human, with tail muscles, Pl. 05; of man and apes, $16_{4}, P l . q 1$.

Saitis pulex, $P l .28$.

Salamander, embryos, $P l .3 s$; Tadpole, $q s$ : warning color, 133 .

Salamandra maculosa, 133 .

Salvia, I57; glutinosa, Pl. 88 .

sancl-flounder, $P l$. $f$ s.

sandpiper, protective color, I I9.

Sargassum fish. 124, 126, Pl. 65.

Savage, illustration of social progress, I73 et seq.

Savoy cabhage, Pl. 6, Pl. S.

Sceloporus undulatus, Pl. 52 .

Scepastus pachyrhynchoides, Pl. 73.

Schistocerca, b3.

Siclater, mimicry of leaf-cutting ants, I 37 , I $45, I l .75$.

Sea-horse, 127.

Sea-lion, nictitating membrane, $P l .36$.

Seasonal change of color, $121,126,129, \mathrm{Pl}$. $57, \mathrm{Pl} .67$.

Secondary sexual characters, see Sexual selection; more developed in female, 58 .

Seeds, spiny, not evolverl through inheritance of the effects of use, 76 .
Segregation, 60-67, I6S; see also $42-47,48$. Selection, artificial, 2S-3I; germinal, 96; natural, 3-47; physiological, 66; "selection value," I 7,37 .

Selenia tetralunaria, 122. Sesia culiciformis and tipuliformis, Pl. 70 . Seventeen-year cicada, $51, \mu l .29$.

Sexual coloration, I49-I5I.

Sexual selection, Intro xi, $47-60, \mathbf{1} 68$, I69, $172,173,175,178,179-1 S_{3}$; a cause of segregation, 44 ; objections to, 56-6o.

Sheep, Ancon, segregation, 65; laroe Islands, segregation, 65; merinos and heath sheep do not interbreed, $4 \mathrm{~S}$; protective color of wild, I 20.

Shore birds, protective color, I I9.

Siberia, former warm climate, 62 .

Signals and recognition marks, I 46-1 47 .

Silurian fossils, Io6.

Simiide, 164.

simplification ("degeneration"), I \&3-1 \$7.

Siphonophores, transparency, I 7 .

Sitana minor, I\%. 3.7.

Skeletons of unicellular organisms, $32, \mathrm{Pl}$. 21 ; of arm of vertebrates, 92.

Skin muscles in man, 94.

Skunk, I33, 134, I\%, I2.

Skunk-cabbage, I 54 .

Slavonia, fossil Paludina, I07.

small pox, $17 \mathrm{I}$.

smelting ore, 176 .

Smerinthus tilia, $P l .55$; ocellata, 142 .

Snail, development of pond, 97 .

Snails of Oahu, segregation, 63 .

Snakes, aggressive color, I 26 ; behavior of poisonous, 143; hind limbs, 93, 9.7; mimicry, 139, P. 79; protective color, I 20.

Snipe - protective color, I I 9 .

Snow grouse - seasonal color change, I 2 I, Pl. 57 .

Snowy-owl, I 26.

socialism, control of marriage, IS2; nature socialistic, ${ } S_{7}$.

Social progress, an end in itself, I 76 ; 2 's. evolution, $173^{-1} 77$.

Soil, relation to segregation, 63 .

Solea concolor, S9, 9o, 91.

Soma, distinguished from germ cells, 7o; relation to processes of reproduction, 74 .

Sparrow, aggressive color, I26; protective color, i is, $1 \%, 79$.

Spathura solstitialis, Pl. 26. 
Species, mean, I9; meaning of, SS; preservation of species, not of inclividual, secured by natural selection, IS7.

Spermophile, protective color, $\mathrm{Pl} .53$.

sphinx convoliuli, Pl. 55 .

Spiclers, agrgressive coloration, I26, Pl. 75 : aggressive mimicry of ants, $1+5$; enemies of, I2I; protective coloration, $120, P \%$ $75, \mathrm{Pl} .8_{5}$; protective resemblances, 124 , Yl. 67; resembling bird excrement, I 27 ; sexual coloration, $P l .85$; sexual selection, 50, Pl. 28.

Spilomyia hamifera, Pl. 7 .

spinal column, curvature in man an 1 apes, I 66, Pl. 99 .

Spizilla, pusulla. Pl. 19.

sports, 19, 39, +6 .

Sprouts, lirussels, $\mathrm{Pl} .7$.

Siquirrel, confusing coloration, I 4 S.

Stability of certain species, 9 .

staghorn beetle, 5I, Pl. 29.

starlish, birth-rate, I $3, I_{7}$.

stearns, Pl. 3 .

Sterility, domestic races not mutually sterile, $3 \mathrm{I}$; of crosses between certain inclividuals, 66; of crosses between species, $3 \mathrm{I}$; of hybrils, 3I, 4I; of soma cells, 7I; of worker bees, recently acquired, 77 ; starting-point in formation of species, 32.

Stick-like insects, I22, Pl. $6_{1}$; spider, $\mathrm{Pl}$. 6.4 .

Striclulating organs, 51, Pl. 29.

Struggle for existence, IO-IS; between near relatives, 25; man, 169.

Summary, of Part I, \$2; of color in animals, I5I.

Supernaturalism, Intro. ix, $\mathrm{x}$.

superstition, Intro. ix.

Survival of the fittest, I 5 , IS.

swamping of varieties by cross breeding, $40-47$.

Swedish turnip, $P l .7$.

Synageles picata, Pl. 28.

Tarlpole, of salamander, $q S$.

Tail, vestigial muscles in man, $165, \mathrm{Pl} .95$.

Taxonomy, SS.

Teeth, deterioration of human, I $0^{\circ}$; man and gorilla, I64, Pl. 92 .

Tegetmeier, Pl. I 2-I 5 , Pl. IS, Pl. I9, Pl. 24.

Tendency, inherent, in evolution, ISS; in variation, fo.

Terrifying attitude, $139,170,172, P l .78$.
Tetragnatha srallator, 120; laboriosa, $\mathrm{Pl}$. 85.

"Theury of Descent, Lectures on the" (Weismann), rSg.

"Thierleben" (Brehm), 4, 22, 3I, I 33, Pl.

24, 1'l. 30, Pl. 33, Pl. 62, Pl. 99.

Thomisicke, I 29.

Thompson, J. A., I \$9.

Thyroillopteryx epheneriformis, 21 .

Tiger, aggressive culoration, I29, Pl. 68 .

Timor, friar-bird and oriole, I 4 .

limor Laut, friar-lird and oriole, I4t.

Toad, aggressive coloration, I26, I33, $\mathrm{Pl}$.

66: rejects noxious insects, I 30 .

Tody, green, protective coloration, I 9.

Tortoise, embryos, Pl. $3^{8}$.

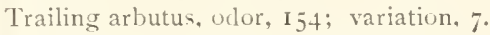

Transparency of pelagic animals, I I 7 .

Tree-frogs, protective coloration, $125, \mathrm{P}$. 66.

Tree-hopper, mimicry of leaf-cutting ants, I $37, \mathrm{Pl} .75$.

Trillium srandiftorum, Pl. 2.

Triton cristatus, 52, I'. 33; punctatus, 52 .

Trochilium apiforme, Pl. 70 .

Tropiclorhynchus, It+t.

Tunicates, transparency of pelagic, II 7 .

Turkey cock, 49, Pl. 27.

Turnip, 29, Pl. 9; Siwedish, Pl. 7 .

Turtle, embryos, $\mathrm{Pl} .3^{8}$; nictitating membrane, $\mathrm{Pl} .36$.

Twig-like caterpillars, $122, \mathrm{Pl} .60$.

Typhlichthys, 95.

\section{Tloborus plumipes, $\mathrm{Pl}$. 67 .}

Unicellular organisms and inheritance of parental modifications, $6 S$.

Unselfishness in marriage, I So.

Crsus maritimus, I26.

Lse and disuse, Intro. xi; effects of, 68: inheritance of effects of, 72,73 .

"Utility" (Romanes), I $\$$ 9.

Utility, and segregation, 67 ; uselessness of certain specific characters, 32: uselessness of organs in their beginnings, 37 .

Vaccination, I 7 I.

Ianessa, c-alhum, Pl. 56 ; io, 121 ; urtica, Pl. $56, P \%, 59$.

Variation. 7-IO, I8, 39; advantageous when environment changing, 27; causes of, 79, So, SI : (legree of divergence, 9, 39; fluctuating, IS ; in Veritina, 9, frontisfiece; in Paludestrina, Pl. 3 ; in trailing 
arbutus, 7 ; in Trillium, $P l .2$; mutation, IS; unequal in different species, 9.

Varieties, of domestic animals and plants, 29; of horses, 25, Pl. f: swamped by intercrossing, $4 \mathrm{I}$.

Vermiform appendix, man and orang, I66, I\%. 96 .

"Tertebrate Embryology" (Narshall), Pl. 42. Vertebrates, development of, $97,0 S, \mathrm{Pl} .38$, Pl. $q S$; varying degrees of complexity, 97.

lespa, breeding habits, 77 ; occidentalis, Pl. 7 t.

Vestigial structures, $93-96$; in man, 164 , I\%. 93-97.

Vigor, correlated with secondary sexual characters, 58 .

Vilmorin, Pl. 87 .

Vinson, Pl. 64.

liola cucullata, 88 ; rostrata, 89 .

I'iolacere, 90.

Voice, in birds, 49.

Volucella facialis, Pl. $7 \neq$.

Vries, de, IIugo, I8, 19, 39.

Walking stick, I22, Pl. 61 .

Wallace, A. R., 35, 47, 50, 58, I 32, 144, I 89 , I9I, Pl. 73 .

Wallihan, A. G., Pl. SI.

Warning coloration, 129-134; convergence, I34.

W'arren, E. R., I46, Pl. 53, Pl. 54, Pl. 57.
Wasps, color sense, $\mathbf{I} 6 \mathbf{I}$; enemies of spiders, I2I ; fertilizing orchid, 15\%, I $\%$. SQ; mimicked by other insects, I36, Pl. 70 , Pl. 73 ; protected by stings, 130, 135; warning color, $130, P .73, P \% .74$.

Waved-yellow moth, I23, Pl.63.

Weasel, Pl. 67 .

Weismann, August, acquired characters, 67 ; germinal selection, 96: also, I22, I 42 , IS9, I9I, Pl. 70, Pl. IoI.

Westermarck, I 90.

Whale, hind limbs, 93, 97.

Wheel, invention of, 176 .

White Mountains, flora, II 2.

"Vild Flowers of America" (Goodale), Pl. SS.

Wing, of bird and of butterfly, 92; fore limbs of vertebrates, $Q_{2}$.

Wolf, aggressive coloration, I 26.

Woodcock, protective coloration, 49, II9, Pl. 50 .

Wright, Lewis, 3o, Pl. I6, Pl. IS.

Xiphophorus hellerii, $P l .32$

Yellow-jacket, warning color, I30, I35 Pl. 74 .

Zenzera asculi, $\mathrm{Pl} .70$.

Zittel, K., Pl. 44, Pl. 45.

Zygana, Pl. 56, Pl. 70 . 


\title{
COLUMBIA UNIVERSITY BIOLOGICAL SERIES.
}

\author{
DESIGNED FOR INDEPENDENT READING AND AS TEXT-BOOKS \\ FOR LECTURE AND LABORATORY COURSES \\ OF INSTRUCTION.
}

EDITED BY

\author{
HENRY FAIRFIELD OSBORN, Sc.D., LL.D., \\ De Costa Professor of Zö̈logy, Columbia Cniversity,
}

EDMUND B. WILSON, Ph.D., LL.D.,

Profissor of Zö̈logry, Columbia L niviersity.

\section{VOL. I. FROIM THE GREEKS TO DARWIN.}

\author{
THE DEIELOPHENT OF THE ETOLCTTON IDEA.
}

By HENRY FAIRFIELD OSBORN, Sc.D., LL.D.

Cloth. 8vo. 259 pages. Hustrated. Price, \$2.00 net.

\section{OPINIONS OF THE PRESS.}

\begin{abstract}
"Professor Henry Fairfield Osborn has rendered an important service by the preparation of a concise history of the growth of the idea of Erolution. The chief contributions of the different thinkers from Thales to Darwin are brought into clear perspective, and a just estimate of the methods and results of each one is reached. The work is extremely well done, and it has an added value of great importance in the fact that the author is a trained biologist. Dr. Osborn is himself one of the authorities in the science of Evolution, to which he has made important contributions. He is therefore in a position to estimate the value of scientific theories more justly than would be possible to one who approached the subject from the standpoint of metaphysics or that of literature."
\end{abstract} - President Dalid Starr Jordan, in The Dial, Chicago.

"A somewhat new and very interesting field of inquiry is opened in this work, which is devoted to demonstrating that the doctrine of Evolution, far from being a child of the middle of the nineteenth century, of sudden birth and phenomenally rapid growth, as it is by many supposed to be, has really been in men's minds for ages. It appears in the germ in the earliest Greek philosophy; in vigorous childhood in the works of Aristotle; in adolescence at the closing period of the last century; and reaches full-grown manhood in our own age of scientific thought and indefatigable research."

$$
\text { - New Science Reaiew. }
$$

"This is a timely book. For it is time that both the special student and general public should know that the doctrine of Evolution has cropped out of the surface of human thought from the period of the Greek philosophers, and that it did not originate with Darwin, and that natural selection is not a synonym of Evolution. ... The book should be widely read, not only by science teachers, by biological students, but we hope that historians, students of social science, and theologians will acquaint themselves with this clear, candid, and catholic statement of the origin and early history of a theory, which not only explains the origin of life-forms, but has transformed the methods of the historian, placed philosophy on a higher plane, and immeasurably widened our views of nature and of the Infinite Power working in and through the universe."

$$
\begin{array}{r}
\text { - Professor A. S. PAckard, } \\
\text { in Science, New York. }
\end{array}
$$

"This is an attempt to determine the history of Evolution, its development and that of its elements, and the indebtedness of modern to earlier investigators. The book is a valuable contribution; it will do a great deal of good in disseminating more accurate ideas of the accomplishments of the present as compared with the past, and in broadening the views of such as have confined themselves too closely to the recent or to specialties. ... As a whole the book is admirable The author has been more im. partial than any of those who have in part anticipated him in the same line of work." - The tation.

" But whether the thread be broken or continuous, the history of thought upon this all-important subject is of the deepest interest, and Professor Osborn's work will be welcomed by all who take an intelligent interest in Evolution. $\mathrm{U}_{\mathrm{p}}$ to the present, the preDarwinian evolutionists have been for the most part considered singly, the claims of particular naturalists being urged often with too warm an enthusiasm. Professor Osborn has undertaken a more comprehensive work, and with well-balanced judgment assigns a place to each writer."

- Professor Edward P. Pollton, in Wature', London. 


\title{
VOL. II. AMPHIOXUS AND THE ANCESTRY OF THE VERTEBRATES.
}

\author{
By ARTHUR WILLEY, Sc.D., Bulfour Student of the University of Cambridge.
}

\section{6 pages. 135 Illustrations. Price, $\$ 2.50$ net.}

"This important monograph will be welcomed by all students of zoölogy as a valuable accession to the literature of the theory of descent. More than this, the volume bears internal evidence throughout of painstaking care in bringing together, in exceedingly readable form, all the essential details of the structure and metamorphosis of Amphioxus as worked out by anatomists and embryologists since the time of Pallas, its discoverer. The interesting history of the changes it undergoes during metamorphosis, especially its singular symmetry, is clearly described and ingenious explanations of the phenomena are suggested. Most important, perhaps, are the carefully suggested homologies of the organs of $A$ mphionus with those of the embryos of the Vertebrates above it in rank, especially those of the Marsipobranchs and Selachians. Though the comparisons with the organisms next below $\mathrm{Am}$ phioxus, such as Ascidians, Balanoglossus, Cephalociscus, Rhabdoplewra, and the Echinoderms, will be found no less interesting. In short, the book may be commended to students already somewhat familiar with zoulogical facts and principles, as an important one to read. They may thus be brought to appreciate to what an extent the theory of descent is indebted to the patient labors of the zoologists of the last forty years for a secure foundation in observed facts, seen in their correlations, according to the comparative method. ... The present work contains everything that should be known about Amphioxus, besides a great deal that is advantageous to know about the Tunicata, Balanoglossus, and some other types which come into structural relations with Amphioxus."

- Professor John A. RYder,

in The American Naturalist, Philadelphia.

" The observations on Amphioxus made before the second half of the present century, amongst which those of Johannes Miiller take a foremost place, showed that this remarkable animal bears certain resemblances to Vertebrates: and since then its interest in this respect has gradually become more apparent. . . . A consecutive history of the more recent observations was, therefore, greatly needed by those whose opportunities did not pernit them to follow out the matter for themselves, and who will welcome a book written in an extremely lucid style by a naturalist who can speak with authority on the subject.

- Professor W. Newton Parker, in Nature, London.

\section{VOL. III. FISHES, LIVING AND FOSSIL.}

\author{
AN IVTRODUCTORY STUDY.
}

\section{By BASHFORD DEAN, Ph.D., Adjunct Professor of Zö̈logy, Columbia University.}

\section{0 pages. 344 Illustrations. Price, $\$ 2.50$ net.}

This work has been prepared to meet the need of the general student for a concise knowledge of the living and extinct Fishes. It covers the recent advances in the comparative anatomy, embryology, and palæontology of the five larger groups of Lampreys, Sharks, Chimæroids, Teleostomes, and Dipnoans - the aim being to furnish a well-marked ground plan of Ichthyology. The figures are mainly original and designed to aid in practical work as well as to illustrate the contrasts in the development of the principal organs through the five groups.

"The intense specialization which prevails in zoölogy at the present day can lead to no other result than this, that a well-educated zoölogist who becomes a student of one group is in a few years quite left behind by the student of other groups. Books, therefore, like those of Mr. Dean are necessary for zoïlogists at large."

$$
\text { - The Athenawm, London. }
$$

"Dr. Bashford Dean is known to zoölogists, first, as the author of exhaustive and critical articles in the publications of the United States Fish Commission, on the systems of oyster culture pursued in Europe, and, secondly, as an embryologist who has lately been doing good work on the development of various Ganoid fishes and the comparison that may be instituted with Teleostei. His recent addition to the well-known 'Columbia University Piological Series,' now being hrought out by The Macmillan Company, under the editorship of Professor H. F. Osborn, is an interesting volume upon fishes, in which considerable prominence is given to the fossil forms, and the whole subject is presented to us from the point of view of the evolutionist. This is the characteristic feature of the book. From the very first page of the introduction to the last page in the volume, preceding the index, which is a table of the supposed descent of the groups of fishes, the book is full of the spirit and the language of evolution." - Professor W. A. HerdmaN, in Nature, London.

"The length to which this review has extended must be evidence of the importance of Dr. Dean's work. The suggestions here offered may be of use for another edition. That another may be called for, we may hope. For the work as it is, and for the care and thought bestowed on it, our thanks are due." - Theodore Gill,

in Science, New York.

“ L'ouvrage de M. Bashford Dean nous paraît fait avec soin; les illustrations sont excellentes et très nombreuses, et il merite le meilleur accueil de la part des zoologistes."

$$
\text { - Ch. Brongniart, }
$$

in Le Revue Scientifique, Paris.

"For the first time in the history of Ichthyology students are now provided with an elementary handbook affording a general view of the whole subject... The last sixty pages of the volume are devoted to a list of derivations of proper names, a copious bibliography, and a series of illustrated tabular statements of the anatomical characters of the great groups of fishes. These sections bear signs of having been prepared most carefully and laboriously, and form an admirable appendix for purposes of reference. There will be much difference of opinion among specialists as to the value of some of the tables and the judgment pronounced-by the author; but we have detected a very small proportion of errors for so bold an enterprise, and students of the lower Vertebrata are much indebted to Dr Dean for an invaluable compendium." - ARthur Smith Woodward, in Natural Science, Londan. 


\author{
By EDMUND B. WILSON, Ph.D., LL.D.,
}

Professor of Zoölogy, Columbia Lniverersity.

371 pages. 142 Illustrations. Price, $\$ 3.50$ net.

\begin{abstract}
"In the highest degree fascinating. . . It is a matter for congratulation that Professor WiIson has given us in our own speech a book which is second to none in the clear and comprehensive manner in which the facts of cell-structure and division are set forth, and the masterly way in which the principal theories are stated and criticised." - Nature.

"It certainly takes rank at once among the most important biological works of the period."
\end{abstract}

\section{- Science.}

"We heartily recommend this book. There are many practitioners who have neither time nor disposi- tion to read the larger treatises on botany or histology in which the modern views on the structure and func. tions of the cell are to be found in detail.... In the present volume they will find an admirable exposition of the knowledge that has been acquired during the lasi, twenty years." - London Lancet.

"One of the very best scientific manuals published in America. ... A noteworthy characteristic of the book is its thoroughness. . . Students and investigators of biology, in whatever department they may be working, ought to be familiar with this important work:" -New York Viation.

\title{
VOL. V. THE FOUNDATIONS OF ZOÖLOGY. \\ By WILLIAM KEITH BROOKS, I'rofessor of Zoülogr', Johns Hopkins Lniversity.
}

8vo. Cloth. viii +339 pages. Price, $\$ 2.50$ net.

"A book that will live as a permanent addition to the common sense of science. It belongs to literature as well as to science. It belongs to philosophy as much as to either, for it is full of that fundamental wisdom about realities which alone is worthy of the name of philosophy." - Science.

\section{VOL. VI. THE PROTOZOA. \\ By GARY N. CALKINS, Ph.D., Instructor in Zö̈logy, Columbiar Cnizersity}

8vo. Cloth. 365 pages. Price, $\$ 3.00$ net.

The object of this volume is to set forth the main characteristics of the Protozoa without undertaking an exhaustive description. It is intended for students and for general readers who wish to know what the Protozoa are, and what their relations are to current biological problems. In the first few chapters of the book the Protozoa are treated as a phylum of the animal kingdom. A short historical sketch leading up to the present systems of classification is followed by a general description of the group, touching upon some of the more special subjects, such as mode of life, motion, excretion, respiration, reproduction, colony-formation, encystment, etc., and this is followed by more general subjects dealing with the Protozoa in relation to man and other animals; e.g. their sanitary aspects, parasitism, symbiosis, etc.

In the final chapter the Protozoa are dealt with from the standpoint of phylogeny. Theories as to the origin of life, spontaneous generation, and the relations of the classes of Protozoa to one another are considered, and the volume ends with a discussion of the various views regarding the origin of the Metazoa from the Protozoa.

\author{
VOL. VII. REGENERATION. \\ By THOMAS HUNT MORGAN, \\ Professor of Biology, Bryn Ihawr College, \\ Author of "THE DEVELOPMENT OF THE FROG'S EGG."
}

\section{VOL. VIII. AN INTRODUCTION TO COMPARA- TIVE NEUROLOGY.}

By OLIVER S. STRONG, Ph.D.

THE MACMILLAN COMPANY, 66 Fifth Avenue, New York. 




